Federal Building and Fire Safety Investigation of the World Trade Center Disaster

\title{
Global Structural Analysis of the Response of World Trade Center Building 7 to Fires and Debris Impact Damage
}


January 2009 Text Changes to the NIST Reports of the

Federal Building and Fire Investigation of the World Trade Center Disaster, NCSTAR 1A, NIST NCSTAR 1-9, and NIST NCSTAR 1-9A

Based on comments received, NIST has made the following changes to the reports on the collapse of World Trade Center Building 7:

1. In reports NIST NCSTAR 1A, NIST NCSTAR 1-9, and NIST NCSTAR 1-9A, appended the following two rows to the end of Table P-2. Public meetings and briefings of the WTC Investigation, with accompanying footnote:

\begin{tabular}{|l|l|l|}
\hline August 21, 2008* & $\begin{array}{l}\text { Gaithersburg, MD; } \\
\text { Teleconference }\end{array}$ & $\begin{array}{l}\text { Media and public briefing on release of all draft reports } \\
\text { for WTC 7 and draft recommendations for public } \\
\text { comment. }\end{array}$ \\
\hline August 26, 2008* & Teleconference & $\begin{array}{l}\text { Technical briefing on the probable collapse sequence } \\
\text { for WTC 7, draft reports for WTC 7, and draft } \\
\text { recommendations for public comment. }\end{array}$ \\
\hline
\end{tabular}

2. In report NIST NCSTAR 1-9, Volume 2, Chapter 11, page 533, corrected the text, with accompanying footnote, as follows:

Comparing Figure $11-51^{\star}$ to Figure 4-7, it can be seen that the temperature rise in the lower flange and web is similar. Figure 4-7 shows the temperature of a W24x55 floor beam with 0.5 in. of SFRM in a composite floor assembly for a constant $1100^{\circ} \mathrm{C}$ gas temperature below the concrete slab. Figure 11-51* shows the temperature of a W24x55 beam (no concrete slab) with 0.53 in. of SFRM for a constant $1100{ }^{\circ} \mathrm{C}$ gas temperature. The beam without a slab analysis was conducted to evaluate the effect of SFRM thickness on steel temperature for a floor beam. The lower flange and web in Figure 4-7 and the beam in Figure $11-51^{*}$ both reached $600{ }^{\circ} \mathrm{C}$ in 25 to $30 \mathrm{~min}$.

Thus, an increase in the SFRM thickness on the floor beams would have delayed heating of the floor beams by $10 \mathrm{~min}$ to $20 \mathrm{~min}$, but would not* have altered the outcome.

* Corrected text January 2009. Changes were made to this page only. Similar statements are correct in the original text for Chapter 11 Summary and in the findings and recommendations in NIST NCSTAR 1A.

3. In report NIST NCSTAR 1-9, Volume 2, Appendix D, pages 699 and 709, deleted text and added footnotes as follows:

Section D.3.3, Page 699, first sentence

A Shard Fly-out Model (SFOM) [Meyer 2002*, Marchand 2002] was used to predict window breakage, based on the pressure profiles from the SHAMRC analysis.

* All pertinent material is contained in Meyers 2002.

Section D.6, Page 709

Marchand, Kirk A., 2002. "Analysis of Insulated Glass Units Subjected to Blast Loadings: Model and

DataComparisons," AMSAA Contract DAADM01-97-D-0013, ARA Project Number 0093, Applied

Research Associates, San Antonio, Texas, July 19.

** Deleted reference January 2009. All pertinent material is contained in Meyers 2002.** 

Federal Building and Fire Safety Investigation of the World Trade Center Disaster

\section{Global Structural Analysis of the Response of World Trade Center Building 7 to Fires and Debris Impact Damage}

Robert MacNeill

Steven Kirkpatrick, Ph.D.

Brian Peterson

Robert Bocchieri, Ph.D.

Silicon Valley Office

Applied Research Associates

November 2008

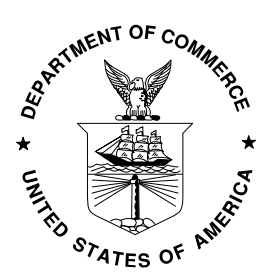

U.S. Department of Commerce Carlos M. Gutierrez, Secretary 
Disclaimer No. 1

Certain commercial entities, equipment, products, or materials are identified in this document in order to describe a procedure or concept adequately or to trace the history of the procedures and practices used. Such identification is not intended to imply recommendation, endorsement, or implication that the entities, products, materials, or equipment are necessarily the best available for the purpose. Nor does such identification imply a finding of fault or negligence by the National Institute of Standards and Technology.

\title{
Disclaimer No. 2
}

The policy of NIST is to use the International System of Units (metric units) in all publications. In this document, however, units are presented in metric units or the inch-pound system, whichever is prevalent in the discipline.

\section{Disclaimer No. 3}

Pursuant to section 7 of the National Construction Safety Team Act, the NIST Director has determined that certain evidence received by NIST in the course of this Investigation is "voluntarily provided safety-related information" that is "not directly related to the building failure being investigated" and that "disclosure of that information would inhibit the voluntary provision of that type of information" (15 USC 7306c).

In addition, a substantial portion of the evidence collected by NIST in the course of the Investigation has been provided to NIST under nondisclosure agreements.

\section{Disclaimer No. 4}

NIST takes no position as to whether the design or construction of a WTC building was compliant with any code since, due to the destruction of the WTC buildings, NIST could not verify the actual (or as-built) construction, the properties and condition of the materials used, or changes to the original construction made over the life of the buildings. In addition, NIST could not verify the interpretations of codes used by applicable authorities in determining compliance when implementing building codes. Where an Investigation report states whether a system was designed or installed as required by a code provision, NIST has documentary or anecdotal evidence indicating whether the requirement was met, or NIST has independently conducted tests or analyses indicating whether the requirement was met.

\section{$\underline{\text { Use in Legal Proceedings }}$}

No part of any report resulting from a NIST investigation into a structural failure or from an investigation under the National Construction Safety Team Act may be used in any suit or action for damages arising out of any matter mentioned in such report (15 USC 281a; as amended by P.L. 107-231).

\author{
National Institute of Standards and Technology National Construction Safety Team Act Report 1-9A \\ Natl. Inst. Stand. Technol. Natl. Constr. Sfty. Tm. Act Rpt. 1-9A, 172 pages (November 2008) \\ CODEN: NSPUE2
}

\section{U.S. GOVERNMENT PRINTING OFFICE WASHINGTON: 2005}

For sale by the Superintendent of Documents, U.S. Government Printing Office Internet: bookstore.gpo.gov — Phone: (202) 512-1800 - Fax: (202) 512-2250

Mail: Stop SSOP, Washington, DC 20402-0001 


\section{ABSTRACT}

The objective of the work described in this report was to analyze the global response of WTC 7 to initial failure events due to fire and to analyze the resulting sequence of component and subsystem failures to determine the events that led to the global collapse.

The modeling approach began with collapse analyses of a multi-floor subassembly, leading to a global collapse analysis of WTC 7 using a model of the entire building. The floor model was used to test modeling methods and to test initiating event hypotheses.

Experience from the previous WTC tower modeling effort was utilized to aid in modeling WTC 7. In particular, steel material models formulated for the tower models formed the basis for those used in WTC 7. Also, meshing and model construction techniques were adapted from the tower models, where appropriate. A new material model was developed for the composite slab in WTC 7. Also, the existing steel models from the WTC $1 \& 2$ analyses were modified with thermally dependant properties to predict damage due to fire induced heating. Connection models were developed for the column-to-column connections as well as beam framing shear, moment, and seated connections that were used throughout the WTC 7 building construction.

The WTC 7 finite element model used in the analyses was developed based on the original structural drawings as well as construction fabrication shop drawings for connections. The models included the primary structural components throughout the building, including exterior and core columns, floor framing beams and girders, floor slabs, column transfer truss structures, wind bracing truss members, and penthouse structures. A uniform finite element mesh was used throughout to provide the same level of fidelity in the entire structure. The global model contained approximately 3 million nodes and required approximately 8 weeks to process 25 seconds of simulated time, while using 12 processors in parallel.

A model initialization sequence was developed to sequentially apply (1) gravity loads, (2) WTC 1 impact debris damage, and (3) fire induced temperatures on the structure prior to model analyses.

Several load cases were considered with the multi-floor subassembly including damage effects from heating alone and with additional imposed connection failures. Most subassembly analyses were performed with a two floor model, however, a larger 14 story subassembly was used to test the effect of debris damage application and load redistribution within the structure.

Global analyses were conducted to study the progression from initial localized failures leading to global collapse. The sequence of events within the model were documented and compared to observable behavior from photographic evidence.

Keywords: WTC 7, progressive collapse, finite element analysis. 
This page intentionally left blank. 


\section{TABLE OF CONTENTS}

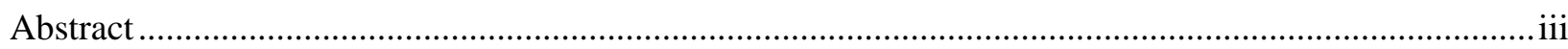

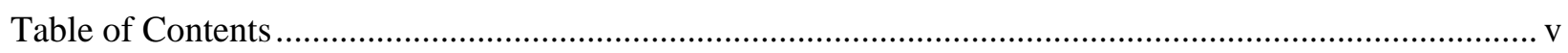

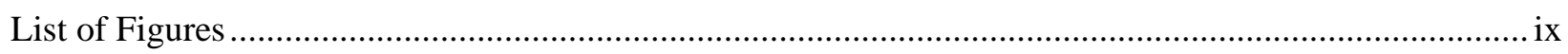

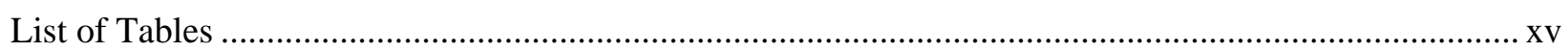

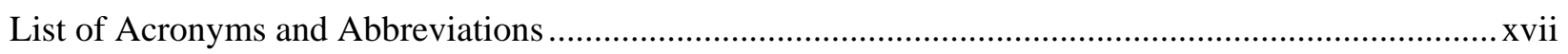

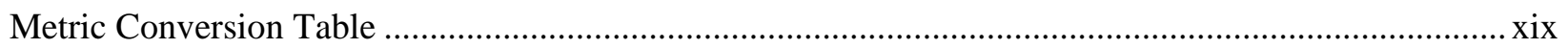

Preface

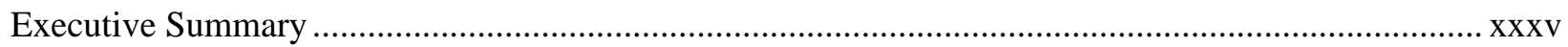

\section{Chapter 1}

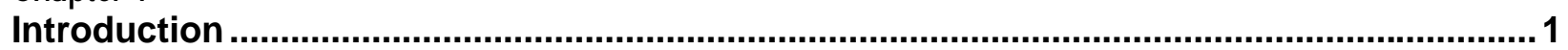

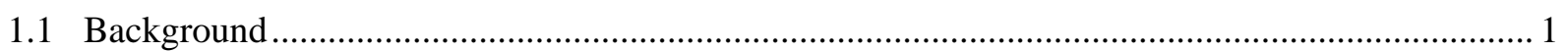

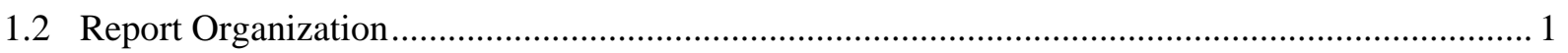

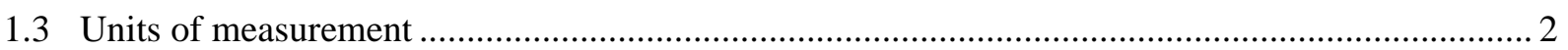

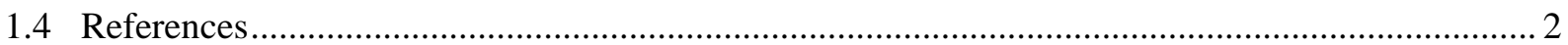

\section{Chapter 2}

Material Constitutive Modeling .................................................................................. 3

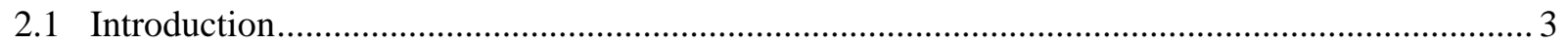

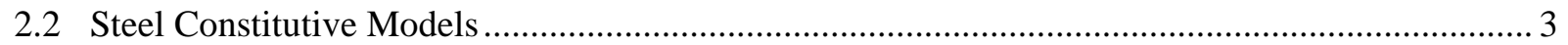

2.2.1 36, 42, and 50 ksi (248, 290, and 345 MPa) Steel Models............................................... 4

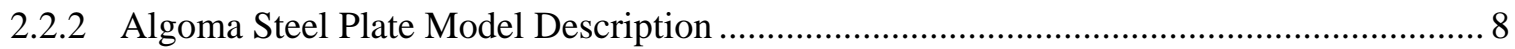

2.2.3 Temperature-Dependent Material Models....................................................................... 8

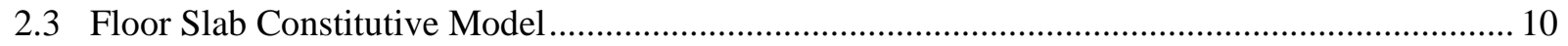

2.3.1 Composite Concrete \& Metal Decking ......................................................................... 11

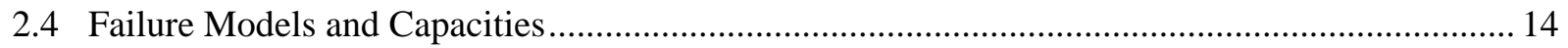

2.4.1 Mesh Refinement Effects (Lessons Learned from WTC Tower Model

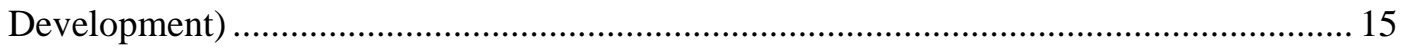

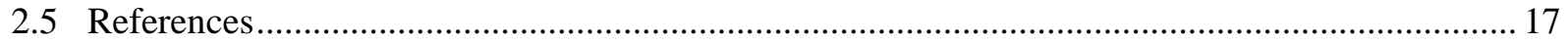

\section{Chapter 3}

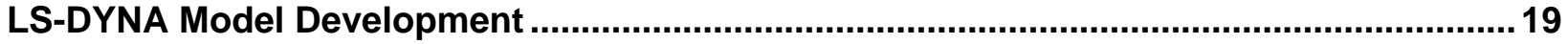

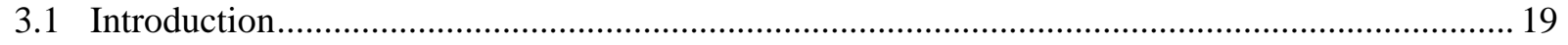

3.2 Methodology of Model Construction.................................................................................... 19

NIST NCSTAR 1-9A, WTC Investigation $\quad \mathrm{v}$ 


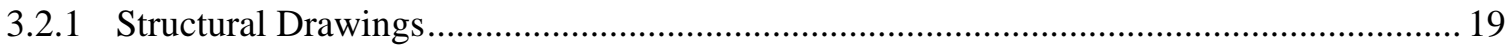

3.2.2 Preprocessing and Model Organization............................................................................. 19

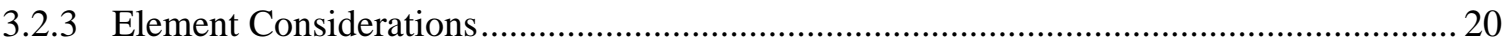

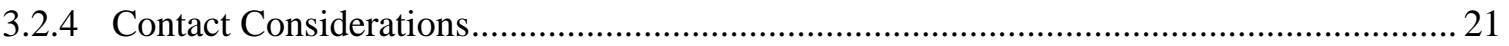

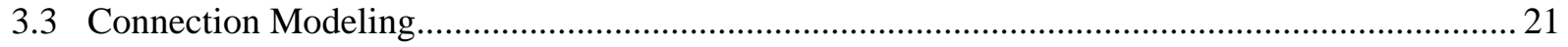

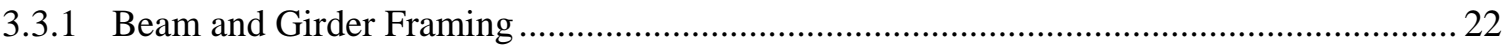

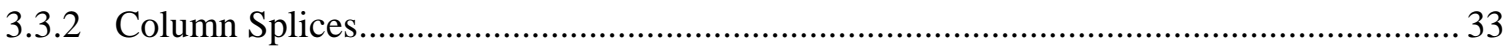

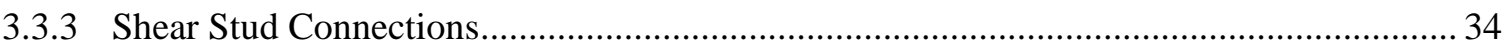

3.4 Development of the Global Model …....................................................................................... 34

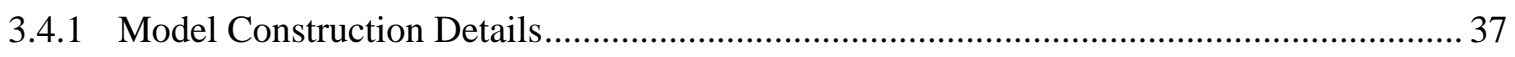

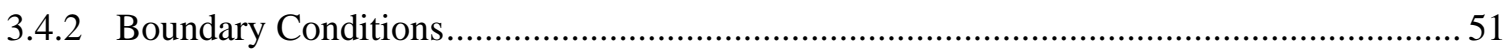

3.4.3 Model Initialization and Loading Sequence ................................................................ 51

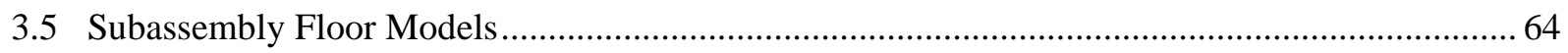

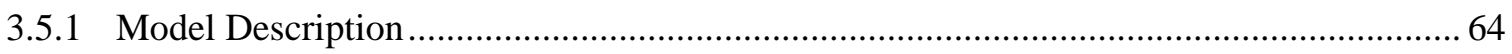

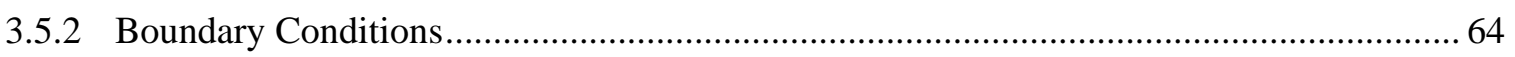

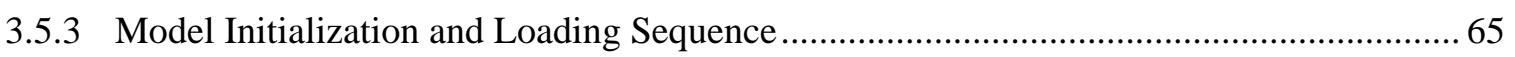

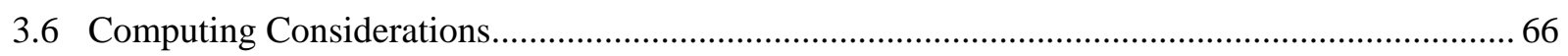

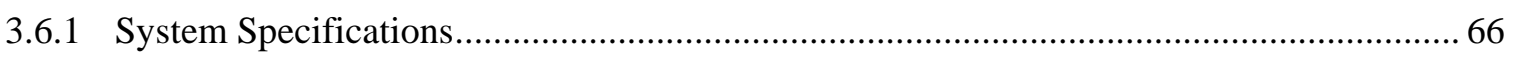

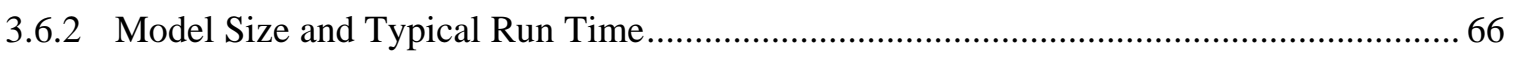

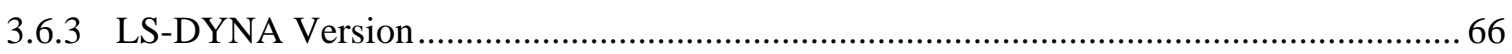

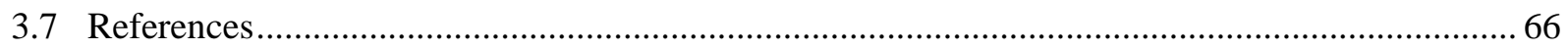

\section{Chapter 4}

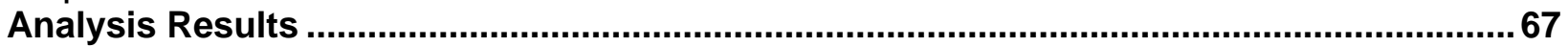

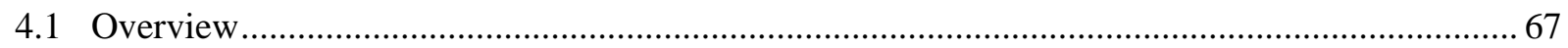

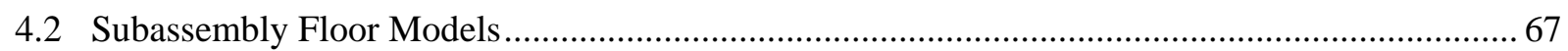

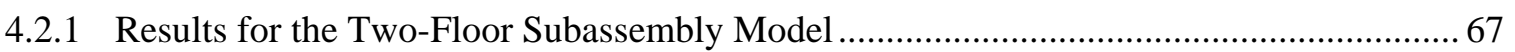

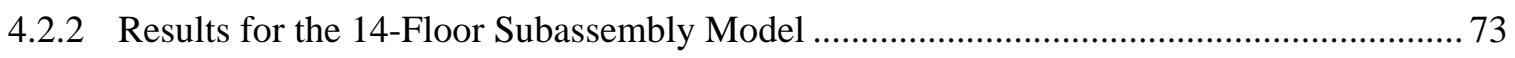

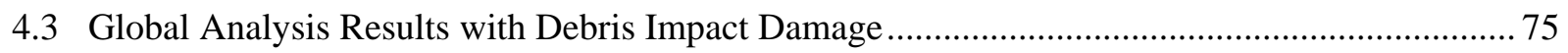

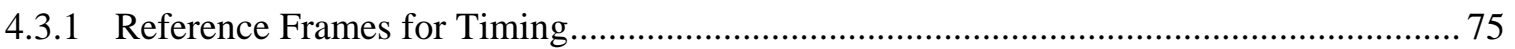

4.3.2 Overview of Global Collapse Results from the LS-DYNA 47 story Analysis .................. 75

4.3.3 Initial Failure Event and Vertical Progression of Collapse ............................................... 79

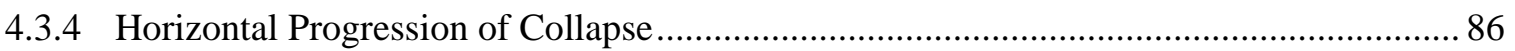

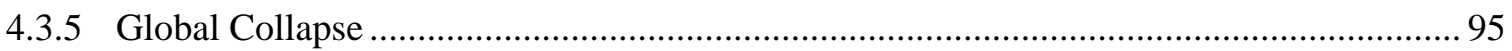

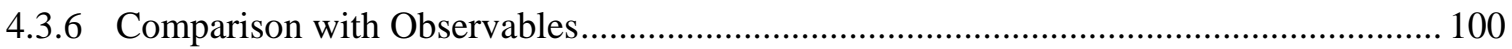


4.4 Global Analysis Results with Fire Induced Damage AT 3.5 H ............................................. 105

4.5 Global Analysis Results without Debris Impact Damage...................................................... 106

4.6 Classic Global Progressive collapse ANALYSIS results without Fire or debris impact

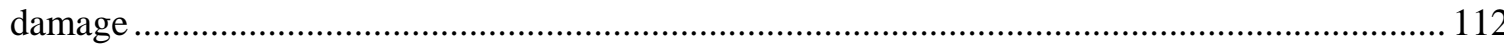

\section{Chapter 5}

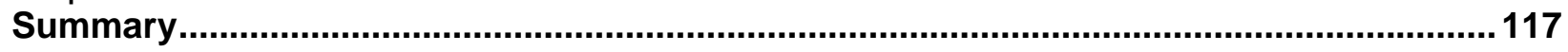

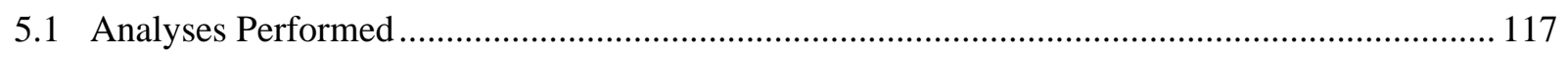

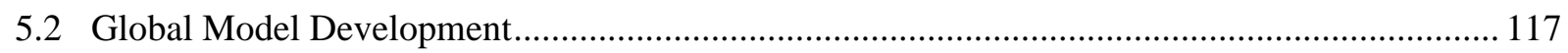

5.3 Model Initialization and Loading Sequence ......................................................................... 118

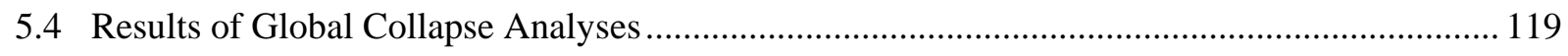

5.4.1 Global Collapse Results with Debris Impact and Fire Induced Damage ........................ 119

5.4.2 Global Results with Earlier Fire Induced Damage ...................................................... 120

5.4.3 Global Results without Debris Impact Damage ........................................................... 121

5.4.4 Global Results for a Classic Progressive Collapse Analysis ......................................... 121 
This page intentionally left blank. 


\section{LIST OF FIGURES}

Figure P-1. Technical components of the federal building and fire safety investigation of the WTC disaster. XXV

Figure E-1. Global tower model for WTC 7. View from southwest. xxxvi

Figure E-2. Seated connection model overview. xxxvii

Figure E-3. Initialization sequence for global model. xxxviii

Figure E-4. Global response: vertical displacement contours (-2 to $0 \mathrm{~m}$ ). View from NW. xlii

Figure E-5. Column 79 to 81 stress and displacements. ......................................................................

Figure E-6. Column 79-81 lateral supports at buckle initiation..........................................................xliv

Figure E-7. Core lateral displacement. Time: 2.5 (18.5) s, Columns 77 and 78 buckle when Truss 2 fails from debris loads.............................................................................................

Figure E-8. Lower floor exterior column buckling (slabs removed from view)....................................xlv

Figure 2-1. Example finite element models of the ASTM 370 tensile specimen. .................................... 4

Figure 2-2. Test data and true stress-strain conversion for the $50 \mathrm{ksi}(345 \mathrm{MPa})$ steel............................. 5

Figure 2-3. Tabular true stress-strain constitutive model curve for the $50 \mathrm{ksi}$ (345 MPa) steel. ................ 6

Figure 2-4. Calculated tensile test response with necking for the $50 \mathrm{ksi}$ (345 MPa) steel........................ 6

Figure 2-5. Comparison of measured and calculated engineering stress-strain curves for the $50 \mathrm{ksi}$ (345 MPa) steel. .7

Figure 2-6. Tabular true stress-strain constitutive model curves. …..................................................... 7

Figure 2-7. Stress-strain curves of the $36 \mathrm{ksi}$ (248 MPa) structural steel as a function of temperature

Figure 2-8. Stress-strain curves of the $50 \mathrm{ksi}(345 \mathrm{MPa})$ structural steel as a function of temperature 9

Figure 2-9. Typical composite floor construction detail (along strong direction). ................................. 10

Figure 2-10. Typical composite floor construction detail (along weak direction)................................... 10

Figure 2-11. Concrete stress-strain behaviors in tension and compression. ............................................ 11

Figure 2-12. Stress-strain behaviors for the metal decking and wire mesh. ........................................... 12

Figure 2-13. Composite floor slab curves in compression and tension. ................................................. 13

Figure 2-14. Calculated composite slab behaviors in tension and compression...................................... 14

Figure 2-15. Calculated necking response in the $75 \mathrm{ksi}$ (517 MPa) tensile specimen............................. 15

Figure 2-16. Coarse shell element mesh for the tensile specimen. ........................................................ 16

Figure 2-17. Mesh refinement effects in the calculated tensile test...................................................... 16 
Figure 3-1. TrueGrid WTC 7 model generation hierarchy. ................................................................. 20

Figure 3-2. Fin, header, and knife shear connection schematics. ........................................................ 23

Figure 3-3. Component model used to develop the LS-DYNA fin connection model.............................. 24

Figure 3-4. Spring and shear model force-deflection behaviors for fin connections with various

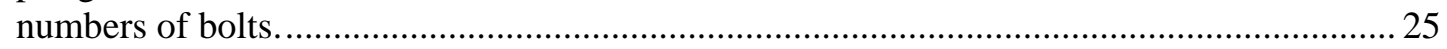

Figure 3-5. Comparison of the fin connection spring and shear model energy capacity........................... 25

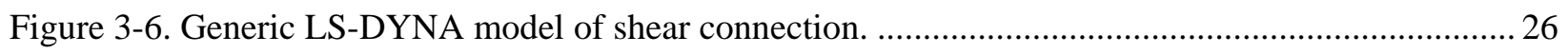

Figure 3-7. Schematic of north/south STP connection at exterior columns............................................ 27

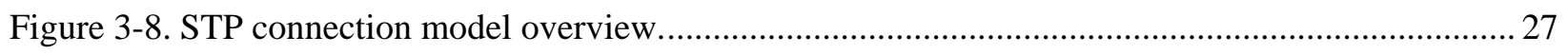

Figure 3-9. STP connection model; horizontal connection force and energy characteristics. .................... 28

Figure 3-10. STP connection in global model, view of southwest corner above Floor 9......................... 28

Figure 3-11. STP connection in global model, bottom view at Floor 8 on south face............................... 29

Figure 3-12. Schematic of unstiffened seat connection at Column 79................................................... 30

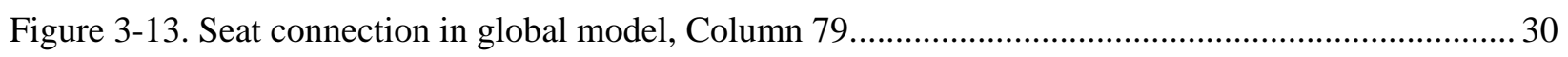

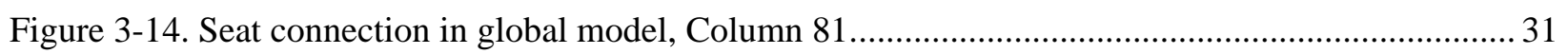

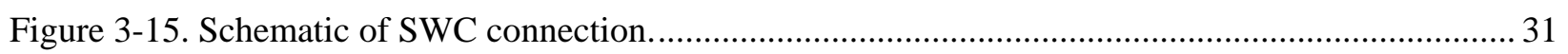

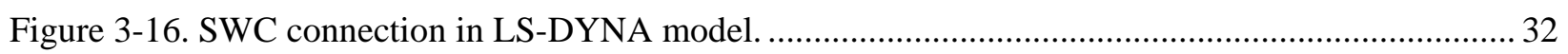

Figure 3-17. Wind girder moment connection model.......................................................................... 33

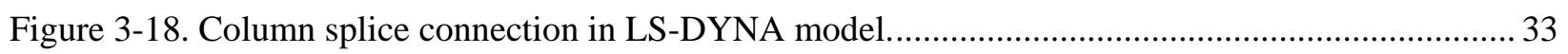

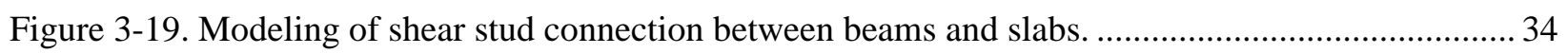

Figure 3-20 Global model of WTC 7, viewed from the southwest....................................................... 35

Figure 3-21 Global model of WTC 7, viewed from the northeast. ........................................................ 36

Figure 3-22. Model and drawing comparison of typical tenant floor structural framing, drawing and model of Floors 8 through 20 and 24 through 45) ........................................................... 37

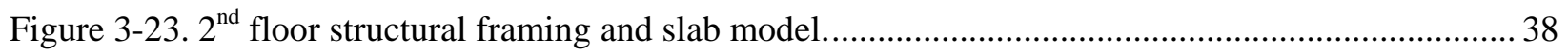

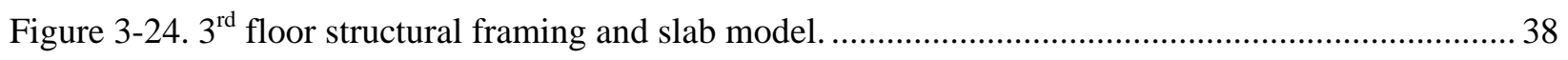

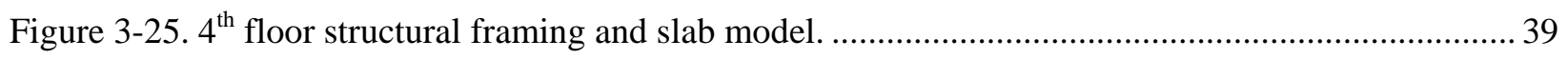

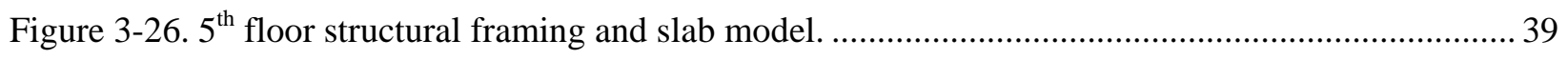

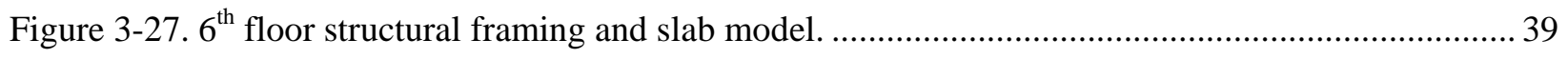

Figure $3-28.7^{\text {th }}$ floor structural framing and slab model. ..................................................................... 40

Figure 3-29. Standard tenant floor structural framing and slab model (Floors 8 through 20 and 24

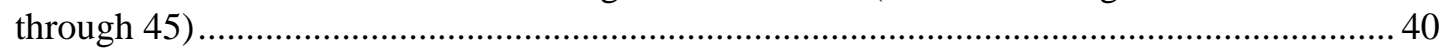

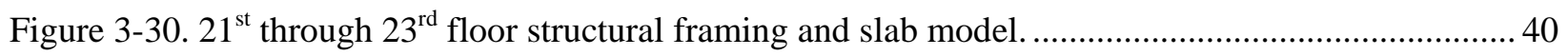

Figure $3-31.46^{\text {th }}$ floor structural framing and slab model. .................................................................... 41

Figure $3-32.47^{\text {th }}$ floor structural framing and slab model. .................................................................. 41

Figure 3-33. Roof structural framing and slab model. ......................................................................... 41 


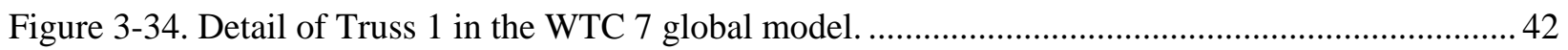

Figure 3-35. Framing connections for the beam elements used in Truss 1 .............................................. 43

Figure 3-36. Detail of Truss 2 in the WTC 7 global model. .............................................................. 43

Figure 3-37. Framing connections for the beam elements used in Truss 2............................................ 44

Figure 3-38. Detail of Truss 3 in the WTC 7 global model. .............................................................. 44

Figure 3-39. Framing connections for the beam elements used in Truss 3............................................. 45

Figure 3-40. Detail of Columns 58 and 59 load transfer connections in the WTC 7 global model............ 45

Figure 3-41. Typical north face transfer girder MG-27 ......................................................................... 46

Figure 3-42. Exterior wind bracing in lower floors of the LS-DYNA model......................................... 47

Figure 3-43. Core wind bracing in lower floors of the LS-DYNA model. View from southwest.............. 47

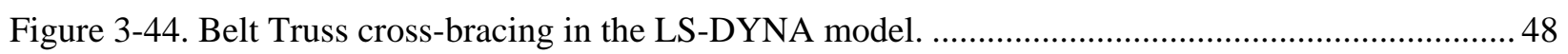

Figure 3-45. Model and drawing comparison of the $5^{\text {th }}$ floor diaphragm framing plan. (Upper view

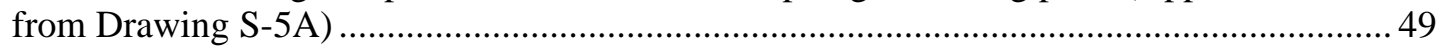

Figure 3-46. Simplified beam element model of the penthouse structure. …........................................... 50

Figure 3-47. Separation of east penthouse from central screening wall structure. .................................... 50

Figure 3-48. Initialization sequence for the global model. ..................................................................... 52

Figure 3-49. Rigid body models for additional loads at Floor 7 .......................................................... 53

Figure 3-50. Rigid body models for additional loads at Floor 46........................................................ 53

Figure 3-51. Load history (in lbf) above Floor 8 during gravity initialization (25\% live load case).......... 54

Figure 3-52. WTC 1 debris impact damage application to the global LS-DYNA model.......................... 55

Figure 3-53. Detail view of Zone 1 impact debris damage in the LS-DYNA model. ............................... 55

Figure 3-54. Detail view of Zone 2 impact debris damage in the LS-DYNA model. ...............................56

Figure 3-55 Temperature profile (Case B) imposed on the global WTC 7 model.................................... 57

Figure 3-56. Detail view of the temperature profile in Floors 7 through 14...........................................5

Figure 3-57. Application of ANSYS computed buckled beams in LS-DYNA model............................... 58

Figure 3-58. ANSYS shear connection damage application in LS-DYNA model. ...................................59

Figure 3-59. Calculated global vertical displacements after gravity initialization..................................... 60

Figure 3-60. Calculated global vertical displacements after initial impact damage. ................................. 60

Figure 3-61. Calculated global vertical displacements after temperature initialization............................. 61

Figure 3-62. Detailed comparison of vertical displacements after damage and temperature

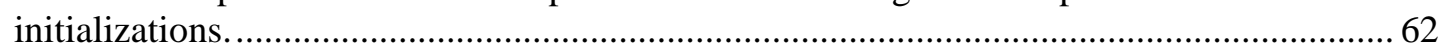

Figure 3-63. Detailed comparison of effective stress after damage and temperature initializations. .......... 63

Figure 3-64. Two-floor subassembly model (slabs shown as transparent). .............................................. 64

Figure 3-65. Vertical displacement in the two floor model after gravity initialization.............................. 65

Figure 3-66. Vertical displacement in the two floor model after Case A $5 \mathrm{~h}$ temperature initialization. 
Figure 4-1. Calculated collapse behavior from Column 79 support removal (two floor model)................ 68

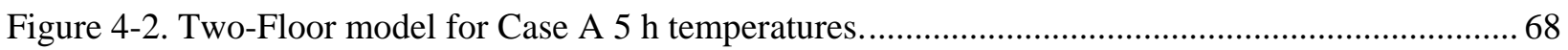

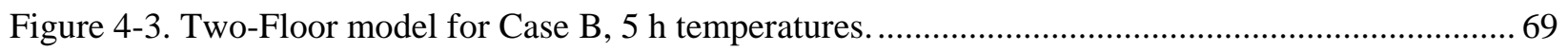

Figure 4-4. Connection damage in the two floor model for Case A, 5 h temperatures............................... 69

Figure 4-5. Connection damage in the two floor model for Case B, $5 \mathrm{~h}$ temperatures.............................. 70

Figure 4-6. Load Case 1 results, $9 \mathrm{~s}$ after applying $5 \mathrm{~h}$ temperatures...................................................... 71

Figure 4-7. Load Case 2 results, $9 \mathrm{~s}$ after applying $5 \mathrm{~h}$ temperatures..................................................... 71

Figure 4-8. Detail of Load 2, with Case A, 5 h temperatures illustrating collapse of floor sections

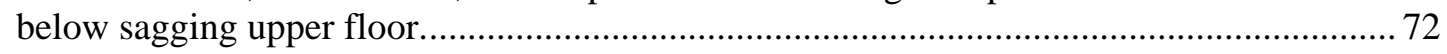

Figure 4-9. Load Case 3 results, $9 \mathrm{~s}$ after applying 5 h temperatures................................................... 72

Figure 4-10. Assessment of impact damage on the 14-floor subassembly model. ................................... 73

Figure 4-11. Calculated impact damage displacements on the 14-floor model. Vertical displacement

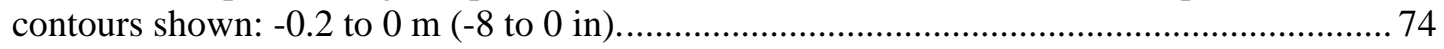

Figure 4-12. Calculated collapse behavior for Column 79 support removal (14-floor Model). Vertical displacement contours shown: -0.1 to $0 \mathrm{~m}$ (-4 to 0 in).............................................. 74

Figure 4-13. Global response: vertical displacement contours ( $-2 \mathrm{~m}$ to $0 \mathrm{~m}$ ), view from the northwest.

Figure 4-14. Global response: vertical displacement contours (-2 $\mathrm{m}$ to $0 \mathrm{~m}$ ), view from the northwest.

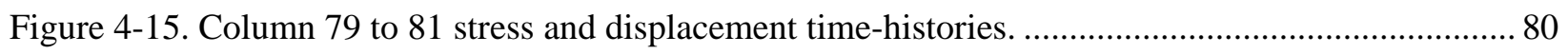

Figure 4-16. Column 79 to 81 vertical displacement with contours from $-0.5 \mathrm{~m}$ to $0 \mathrm{~m}$.......................... 80

Figure 4-17. Column 79 to 81 lateral supports at initiation of buckling................................................. 81

Figure 4-18. Core lateral displacement at $-7.5(8.5) \mathrm{s}$; end of temperature application.............................. 82

Figure 4-19. Core lateral displacement at -6.5 (9.5) s; start of failure of Floors 13 and 14 start around Column 79......

Figure 4-20. Columns 59, 62 and 65 connection damage at the $13^{\text {th }}$ floor.

Figure 4-21. East-west displacement history including exterior framing at -7.5 (8.5) s; completion of temperature application.

Figure 4-22. Core lateral displacement at -5.5 (10.5) s; collapse of floors onto the floor below around Columns 79, 80, and 81.

Figure 4-23. Core lateral displacement at $-4.5(11.5)$ s; continuation of floors collapsing onto the floor below around Columns 79, 80, and 81 and debris continuing to fall around Columns 65 and 66.

Figure 4-24. Core lateral displacement at -1.5 (14.5) s; buckling of Column 79 followed by the buckling of Column 80, then Column 81.

Figure 4-25. Core lateral displacement at 0.5 (16.5) s; descent of the column sections above the buckled columns and progression of the failure vertically upward to the roof of WTC 7. 86 
Figure 4-26. Core lateral displacement at 1.5 (17.5) s; falling of debris from the collapsing floors onto the lower floors, including Trusses 1 and 2, impacting Columns 76, 77, and 78.

Figure 4-27. Failure of Truss 2 east diagonal, viewed from the southeast and above. ….......................... 87

Figure 4-28. Truss 2 collapse, viewed from the south with most of debris removed from view............... 88

Figure 4-29. Core lateral displacement at 2.5 (18.5) s; buckling of Columns 77 and 78 buckled when Truss 2 failed from debris loads.

Figure 4-30. Core lateral displacement at 3.5 (19.5) s; buckling Column 76 buckled and start of horizontal progression of the failure.

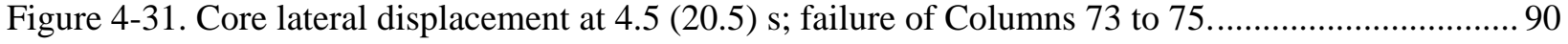

Figure 4-32. Core lateral displacement at 5.5 (21.5) s; all interior columns buckled............................... 90

Figure 4-33. Core lateral displacement at 6.5 (22.5) s; global collapse underway.................................. 91

Figure 4-34. Core north-south displacement history, viewed from the south.......................................... 91

Figure 4-35. Core north-south displacement history, viewed from the south.......................................... 92

Figure 4-36. Horizontal progression of column buckling ....................................................................... 92

Figure 4-37. Interior column loads, illustrating east to west collapse progression................................... 93

Figure 4-38. West interior column loads, illustrating progression of failure............................................ 93

Figure 4-39. Close-up of cantilevered floor sections, vertical displacement contours, $-0.2 \mathrm{~m}$ to $0 \mathrm{~m}$ (-8 in. to 0 in), viewed from the southwest. ......................................................................... 94

Figure 4-40. Western core column vertical displacements (contours: $-0.5 \mathrm{~m}$ to $0 \mathrm{~m}$ ).............................. 95

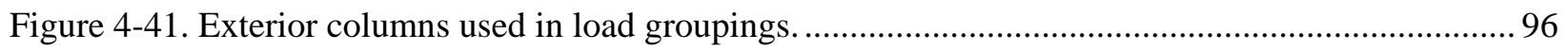

Figure 4-42. Sampling of average perimeter column load by group. ..................................................97

Figure 4-43. Global model with lateral displacement contours (-1 m to $1 \mathrm{~m})$ at 1.1 (17.1) s................... 97

Figure 4-44. Global model with lateral displacement contours (-1 m to $1 \mathrm{~m}$ ) at 3.5 (19.5) s................... 98

Figure 4-45. Global model with lateral displacement contours (-1 m to $1 \mathrm{~m}$ ) at 6.5 (22.5) s................... 98

Figure 4-46. Global model with lateral displacement contours (-1 m to $1 \mathrm{~m}$ ) at 8.6 (24.6) s.................... 99

Figure 4-47. Global model with lateral displacement contours (-1 m to $1 \mathrm{~m}$ ) at 8.6 (24.6) s.................... 99

Figure 4-48. Lower floor exterior column buckling, with floor slabs removed from view. .................... 100

Figure 4-49. Kink on east penthouse: 0.2 (16.2) s. View from north. .................................................... 101

Figure 4-50. Collapse sequence at roofline: $2.7(18.7) \mathrm{s}$, viewed from the north................................... 102

Figure 4-51. Collapse sequence at roofline: 4.7 (20.7) s, viewed from the north................................... 102

Figure 4-52. Collapse sequence at roofline: 5.7 (21.7) s, viewed from the north................................... 103

Figure 4-53. Collapse sequence at roofline: 6.2 (22.2) s, viewed from the north................................... 103

Figure 4-54. Collapse sequence at roofline: 7.7 (23.7) s, viewed from the north................................... 104

Figure 4-55. Collapse sequence at roofline: 7.7 (23.7) s, viewed from the north................................... 104

Figure 4-56. Floor framing damage around Columns 76 to 81 after stability has been reached. ............. 105

Figure 4-57. Lower floor damage in stable structure at -3.8 s (12.2 s), viewed from the southwest........ 106 


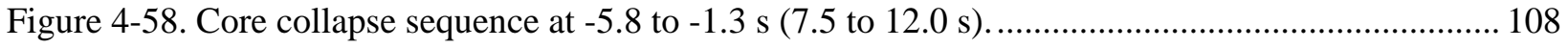

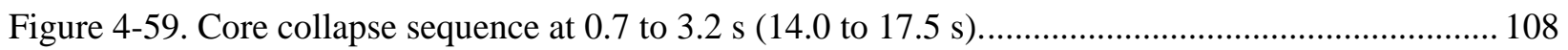

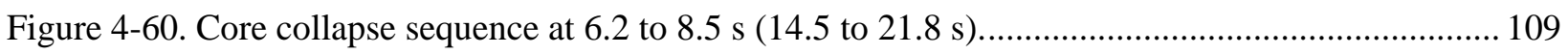

Figure 4-61. Core collapse sequence at 10.8 to 15.5 s (24.1 to 28.8 s) .................................................. 109

Figure 4-62. Global model with lateral displacement contours (-1 m to $1 \mathrm{~m})$ at 15.8 (29.1) s................ 110

Figure 4-63. Exterior buckling after global collapse initiation............................................................. 111

Figure 4-64. Collapse of the north interior columns from $12.2 \mathrm{~s}$ to $18.0 \mathrm{~s}$. Contours of resultant lateral displacement 0 in. to 16 in. $(0 \mathrm{~m}$ to $0.4 \mathrm{~m})$........................................................... 113

Figure 4-65. Collapse of the north interior columns from 19.5 s to 24.7 s. Contours of resultant

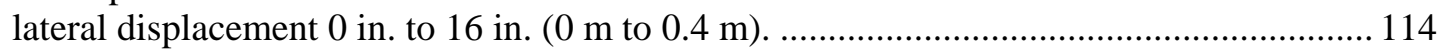

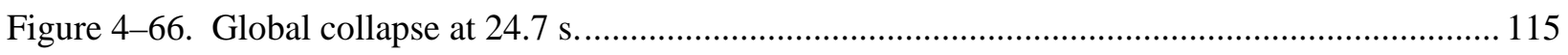

Figure 4-67. Global kinetic energy during the analysis without fire or debris impact damage. ............. 115 


\section{LIST OF TABLES}

Table P-1. Federal building and fire safety investigation of the WTC disaster. ...................................xxiv

Table P-2. Public meetings and briefings of the WTC Investigation..................................................xxviii

Table E-1. Summary of the global collapse model for the WTC 7 tower.........................................xxxvi

Table E-2. Comparison of collapse analyses with observable events. ................................................xlvi

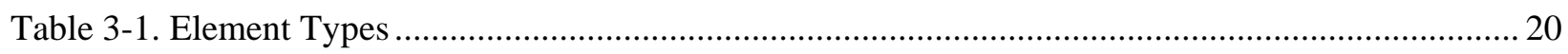

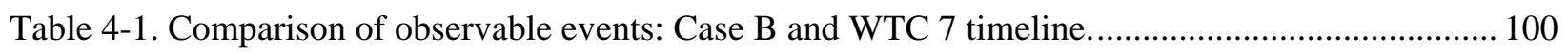

Table 4-2. Comparison of observable events: Case B with and without initial damage and WTC 7

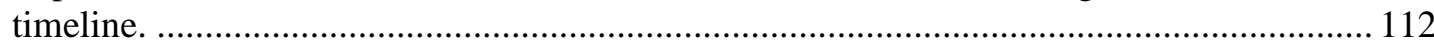


This page intentionally left blank. 


\section{LIST OF ACRONYMS AND ABBREVIATIONS}

\section{Acronyms}

ASCE American Society of Civil Engineers

ASTM ASTM International

BPS Building Performance Study

FCD Fire Command Desk

FDNY The Fire Department of the City of New York

FDS Fire Dynamics Simulator

FEMA Federal Emergency Management Agency

FSI Fire Structure Interface

IBC International Building Code

NFPA National Fire Protection Association

NIST National Institute of Standards and Technology

NYC New York City

NYCBC New York City Building Code

NYPD New York City Police Department

NYS New York State

OEM New York Mayor's Office of Emergency Management

PANYNJ The Port Authority of New York and New Jersey

PAPD Port Authority Police Department

SEC Securities and Exchange Commission

SFRM Sprayed fire-resistive material

USC United States Code

WTC World Trade Center

WTC 1 World Trade Center 1 (North Tower)

WTC 2 World Trade Center 2 (South Tower)

WTC $7 \quad$ World Trade Center 7 


\section{Abbreviations and Conversion Factors}

$\begin{array}{llr}{ }^{\circ} \mathrm{C} & \text { degrees Celsius } & \mathrm{T}\left({ }^{\circ} \mathrm{C}\right)=5 / 9\left[\mathrm{~T}\left({ }^{\circ} \mathrm{F}\right)-32\right] \\ { }^{\circ} \mathrm{F} & \text { degrees Fahrenheit } & \\ \mathrm{ft} & \text { feet } & 1 \mathrm{gal}=3.78 \times 10^{-3} \mathrm{~m}^{3} \\ \text { gal } & \text { gallon } & \\ \text { in. } & \text { inch } & \\ \mathrm{kg} & \text { kilogram } & \\ \mathrm{kip} & 1,000 \mathrm{lb} & 1 \mathrm{lb}=0.453 \mathrm{~kg} \\ \mathrm{ksi} & 1,000 \mathrm{lb} / \mathrm{in} .{ }^{2} & 1 \mathrm{~m}=3.28 \mathrm{ft} \\ \mathrm{lb} & \text { pound } \\ \mathrm{m} & \text { meter } \\ \mu \mathrm{m} & \text { micrometer } \\ \text { min } & \text { minute } \\ \mathrm{MJ} & \text { megajoule } \\ \mathrm{MW} & \text { megawatt } \\ \mathrm{psi} & \text { pounds per square inch } \\ \mathrm{s} & \text { second } \\ \mathrm{T} & \text { temperature }\end{array}$




\section{Metric Conversion TABle}

To convert from

to

Multiply by

\section{AREA AND SECOND MOMENT OF AREA}

$$
\begin{aligned}
& \text { square foot }\left(\mathrm{ft}^{2}\right) \\
& \text { square inch }\left(\mathrm{in}^{2}\right) \\
& \text { square inch }\left(\mathrm{in}^{2}\right) \\
& \text { square yard }\left(\mathrm{yd}^{2}\right)
\end{aligned}
$$

\section{ENERGY (includes WORK)}

kilowatt hour $(\mathrm{kW}$ * $\mathrm{h})$

quad (1015 BtuIT)

therm (U.S.)

ton of TNT (energy equivalent)

watt hour $(\mathrm{W}$ * $\mathrm{h})$

watt second $\left(\mathrm{W}^{*} \mathrm{~s}\right)$

\section{FORCE}

dyne (dyn)

kilogram-force (kgf)

kilopond (kilogram-force) (kp)

kip (1 kip=1000lbf)

kip (1 kip=1000lbf)

pound-force (lbf)

\section{FORCE DIVIDED BY LENGTH}

pound-force per foot (lbf/ft)

pound-force per inch (lbf/in)

\section{HEAT FLOW RATE}

calorieth per minute (calth/min)

calorieth per second (calth/s)

kilocalorieth per minute (kcalth/min)

kilocalorieth per second (kcalth/s)

\author{
square meter $\left(\mathrm{m}^{2}\right)$ \\ square meter $\left(\mathrm{m}^{2}\right)$ \\ square centimeter $\left(\mathrm{cm}^{2}\right)$ \\ square meter $\left(\mathrm{m}^{2}\right)$
}

\author{
9.290304 E-02 \\ 6.4516 E-04 \\ $6.4516 \mathrm{E}+00$ \\ 8.361274 E-01
}

$\begin{array}{ll}\text { newton }(\mathrm{N}) & 1.0 \mathrm{E}-05 \\ \text { newton }(\mathrm{N}) & 9.80665 \mathrm{E}+00 \\ \text { newton }(\mathrm{N}) & 9.80665 \mathrm{E}+00 \\ \text { newton }(\mathrm{N}) & 4.448222 \mathrm{E}+03 \\ \text { kilonewton }(\mathrm{kN}) & 4.448222 \mathrm{E}+00 \\ \text { newton }(\mathrm{N}) & 4.448222 \mathrm{E}+00\end{array}$

newton per meter $(\mathrm{N} / \mathrm{m})$

$1.459390 \mathrm{E}+01$

newton per meter $(\mathrm{N} / \mathrm{m})$
$3.6 \mathrm{E}+06$

$1.055056 \mathrm{E}+18$

$1.054804 \mathrm{E}+08$

$4.184 \mathrm{E}+09$

$3.6 \mathrm{E}+03$

$1.0 \mathrm{E}+00$ 
To convert from

\section{LENGTH}

foot (ft)

inch (in)

inch (in)

micron (m)

yard (yd)

\section{MASS and MOMENT OF INERTIA}

kilogram-force second squared per meter $\left(\mathrm{kgf} * \mathrm{~s}^{2} / \mathrm{m}\right)$

pound foot squared $\left(\mathrm{lb}^{*} \mathrm{ft}^{2}\right)$

pound inch squared $\left(\mathrm{lb}^{*} \mathrm{in}^{2}\right)$

ton, metric (t)

ton, short (2000 lb)

\section{MASS DIVIDED BY AREA}

pound per square foot $\left(\mathrm{lb} / \mathrm{ft}^{2}\right)$

pound per square inch

(not pound force) (lb/in ${ }^{2}$ )

\section{MASS DIVIDED BY LENGTH}

pound per foot $(\mathrm{lb} / \mathrm{ft})$

pound per inch (lb/in)

pound per yard (lb/yd) to

Multiply by

$\begin{array}{ll}\text { meter }(\mathrm{m}) & 3.048 \mathrm{E}-01 \\ \text { meter }(\mathrm{m}) & 2.54 \mathrm{E}-02 \\ \text { centimeter }(\mathrm{cm}) & 2.54 \mathrm{E}+00 \\ \text { meter }(\mathrm{m}) & 1.0 \mathrm{E}-06 \\ \text { meter }(\mathrm{m}) & 9.144 \mathrm{E}-01\end{array}$

kilogram (kg) $\quad 9.80665 \mathrm{E}+00$

kilogram meter squared $\left(\mathrm{kg}^{*} \mathrm{~m}^{2}\right) \quad 4.214011 \mathrm{E}-02$

kilogram meter squared $\left(\mathrm{kg}^{*} \mathrm{~m}^{2}\right) \quad 2.926397 \mathrm{E}-04$

kilogram (kg)

$1.0 \mathrm{E}+03$

$9.071847 \mathrm{E}+02$

$4.882428 \mathrm{E}+00$

$7.030696 \mathrm{E}+02$

$1.488164 \mathrm{E}+00$

$1.785797 \mathrm{E}+01$

4.960546 E-01

\section{PRESSURE or STRESS (FORCE DIVIDED BY AREA)}

$\begin{array}{lll}\text { kilogram-force per square centimeter }\left(\mathrm{kgf} / \mathrm{cm}^{2}\right) & \text { pascal (Pa) } & 9.80665 \mathrm{E}+04 \\ \text { kilogram-force per square meter }\left(\mathrm{kgf} / \mathrm{m}^{2}\right) & \text { pascal (Pa) } & 9.80665 \mathrm{E}+00 \\ \text { kilogram-force per square millimeter }\left(\mathrm{kgf} / \mathrm{mm}^{2}\right) & \text { pascal (Pa) } & 9.80665 \mathrm{E}+06 \\ \text { kip per square inch }(\mathrm{ksi})\left(\mathrm{kip} / \mathrm{in}^{2}\right) & \text { pascal (Pa) } & 6.894757 \mathrm{E}+06 \\ \text { kip per square inch }(\mathrm{ksi})\left(\mathrm{kip} / \mathrm{in}^{2}\right) & \text { kilopascal }(\mathrm{kPa}) & 6.894757 \mathrm{E}+03 \\ \text { pound-force per square foot }\left(\mathrm{lbf} / \mathrm{ft}^{2}\right) & \text { pascal }(\mathrm{Pa}) & 4.788026 \mathrm{E}+01 \\ \text { pound-force per square inch }(\mathrm{psi})\left(\mathrm{lbf} / \mathrm{in}^{2}\right) & \text { pascal }(\mathrm{Pa}) & 6.894757 \mathrm{E}+03 \\ \text { pound-force per square inch }(\mathrm{psi})\left(\mathrm{lbf} / \mathrm{in}^{2}\right) & \text { kilopascal }(\mathrm{kPa}) & 6.894757 \mathrm{E}+00 \\ \text { psi (pound-force per square inch) }\left(\mathrm{lbf} / \mathrm{in}^{2}\right) & \text { pascal }(\mathrm{Pa}) & 6.894757 \mathrm{E}+03 \\ \text { psi (pound-force per square inch) }\left(\mathrm{lbf} / \mathrm{in}^{2}\right) & \text { kilopascal }(\mathrm{kPa}) & 6.894757 \mathrm{E}+00\end{array}$




\section{To convert from}

\section{TEMPERATURE}

degree Celsius $\left({ }^{\circ} \mathrm{C}\right)$

degree centigrade

degree Fahrenheit $\left({ }^{\circ} \mathrm{F}\right)$

degree Fahrenheit $\left({ }^{\circ} \mathrm{F}\right)$

kelvin (K)

\section{TEMPERATURE INTERVAL}

degree Celsius $\left({ }^{\circ} \mathrm{C}\right)$

degree centigrade

degree Fahrenheit $\left({ }^{\circ} \mathrm{F}\right)$

degree Fahrenheit $\left({ }^{\circ} \mathrm{F}\right)$

degree Rankine $\left({ }^{\circ} \mathrm{R}\right)$

\section{VELOCITY (includes SPEED)}

foot per second (ft/s)

inch per second (in/s)

kilometer per hour $(\mathrm{km} / \mathrm{h})$

mile per hour (mi/h)

mile per minute (mi/min)

\section{VOLUME (includes CAPACITY)}

cubic foot $\left(\mathrm{ft}^{3}\right)$

cubic inch (in $\left.{ }^{3}\right)$

cubic yard $\left(\mathrm{yd}^{3}\right)$

gallon (U.S.) (gal)

gallon (U.S.) (gal)

liter (L)

ounce (U.S. fluid) (fl oz)

ounce (U.S. fluid) (fl oz) to

kelvin (K)

degree Celsius $\left({ }^{\circ} \mathrm{C}\right)$

degree Celsius $\left({ }^{\circ} \mathrm{C}\right)$

kelvin (K)

degree Celsius $\left({ }^{\circ} \mathrm{C}\right)$

\section{Multiply by}
$\mathrm{T} / \mathrm{K}=\mathrm{t} /{ }^{\circ} \mathrm{C}+273.15$
$\mathrm{t} /{ }^{\circ} \mathrm{C} \approx \mathrm{t} /$ deg. cent.
$\mathrm{t} /{ }^{\circ} \mathrm{C}=\left(\mathrm{t} /{ }^{\circ} \mathrm{F} 232\right) / 1.8$
$\mathrm{T} / \mathrm{K}=\left(\mathrm{t} /{ }^{\circ} \mathrm{F}+459.67\right) / 1.8$
$\mathrm{t} /{ }^{\circ} \mathrm{C}=\mathrm{T} / \mathrm{K} 2273.15$

$\begin{array}{ll}\text { meter per second }(\mathrm{m} / \mathrm{s}) & 3.048 \mathrm{E}-01 \\ \text { meter per second }(\mathrm{m} / \mathrm{s}) & 2.54 \mathrm{E}-02 \\ \text { meter per second }(\mathrm{m} / \mathrm{s}) & 2.777778 \mathrm{E}-01 \\ \text { kilometer per hour }(\mathrm{km} / \mathrm{h}) & 1.609344 \mathrm{E}+00 \\ \text { meter per second }(\mathrm{m} / \mathrm{s}) & 2.68224 \mathrm{E}+01\end{array}$

cubic meter $\left(\mathrm{m}^{3}\right)$

2.831685 E-02

cubic meter $\left(\mathrm{m}^{3}\right)$

1.638706 E-05

cubic meter $\left(\mathrm{m}^{3}\right)$

7.645549 E-01

cubic meter $\left(\mathrm{m}^{3}\right)$

3.785412 E-03

liter (L)

cubic meter $\left(\mathrm{m}^{3}\right)$

$3.785412 \mathrm{E}+00$

1.0 E-03

cubic meter $\left(\mathrm{m}^{3}\right)$

2.957353 E-05

milliliter (mL)

$2.957353 \mathrm{E}+01$ 
This page intentionally left blank. 


\section{Preface}

\section{Genesis of This Investigation}

Immediately following the terrorist attack on the World Trade Center (WTC) on September 11, 2001, the Federal Emergency Management Agency (FEMA) and the American Society of Civil Engineers began planning a building performance study of the disaster. The week of October 7 , as soon as the rescue and search efforts ceased, the Building Performance Study Team went to the site and began its assessment. This was to be a brief effort, as the study team consisted of experts who largely volunteered their time away from their other professional commitments. The Building Performance Study Team issued its report in May 2002, fulfilling its goal "to determine probable failure mechanisms and to identify areas of future investigation that could lead to practical measures for improving the damage resistance of buildings against such unforeseen events.”

On August 21, 2002, with funding from the U.S. Congress through FEMA, the National Institute of Standards and Technology (NIST) announced its building and fire safety investigation of the WTC disaster. On October 1, 2002, the National Construction Safety Team Act (Public Law 107-231), was signed into law. (A copy of the Public Law is included in Appendix A). The NIST WTC Investigation was conducted under the authority of the National Construction Safety Team Act.

The goals of the investigation of the WTC disaster were:

- To investigate the building construction, the materials used, and the technical conditions that contributed to the outcome of the WTC disaster.

- To serve as the basis for:

- Improvements in the way buildings are designed, constructed, maintained, and used;

- Improved tools and guidance for industry and safety officials;

- Recommended revisions to current codes, standards, and practices; and

- Improved public safety.

The specific objectives were:

1. Determine why and how WTC 1 and WTC 2 collapsed following the initial impacts of the aircraft and why and how WTC 7 collapsed;

2. Determine why the injuries and fatalities were so high or low depending on location, including all technical aspects of fire protection, occupant behavior, evacuation, and emergency response;

3. Determine what procedures and practices were used in the design, construction, operation, and maintenance of WTC 1, 2, and 7; and

4. Identify, as specifically as possible, areas in current building and fire codes, standards, and practices that warrant revision. 
NIST is a nonregulatory agency of the U.S. Department of Commerce. The purpose of NIST investigations is to improve the safety and structural integrity of buildings in the United States, and the focus is on fact finding. NIST investigative teams are authorized to assess building performance and emergency response and evacuation procedures in the wake of any building failure that has resulted in substantial loss of life or that posed significant potential of substantial loss of life. NIST does not have the statutory authority to make findings of fault nor negligence by individuals or organizations. Further, no part of any report resulting from a NIST investigation into a building failure or from an investigation under the National Construction Safety Team Act may be used in any suit or action for damages arising out of any matter mentioned in such report (15 USC 281a, as amended by Public Law 107-231).

\section{Organization of the Investigation}

The National Construction Safety Team for this Investigation, appointed by the then NIST Director, Dr. Arden L. Bement, Jr., was led by Dr. S. Shyam Sunder. Dr. William L. Grosshandler served as Associate Lead Investigator, Mr. Stephen A. Cauffman served as Program Manager for Administration, and Mr. Harold E. Nelson served on the team as a private sector expert. The Investigation included eight interdependent projects whose leaders comprised the remainder of the team. A detailed description of each of these eight projects is available at http://wtc.nist.gov. The purpose of each project is summarized in Table $\mathrm{P}-1$, and the key technical components are illustrated in Fig. $\mathrm{P}-1$.

Table P-1. Federal building and fire safety investigation of the WTC disaster.

\begin{tabular}{|c|c|}
\hline Technical Area and Project Leader & Project Purpose \\
\hline $\begin{array}{l}\text { Analysis of Building and Fire Codes and } \\
\text { Practices; Project Leaders: Dr. H. S. Lew } \\
\text { and Mr. Richard W. Bukowski }\end{array}$ & $\begin{array}{l}\text { Document and analyze the code provisions, procedures, and practices } \\
\text { used in the design, construction, operation, and maintenance of the } \\
\text { structural, passive fire protection, and emergency access and } \\
\text { evacuation systems of WTC } 1,2 \text {, and } 7 \text {. }\end{array}$ \\
\hline $\begin{array}{l}\text { Baseline Structural Performance and } \\
\text { Aircraft Impact Damage Analysis; Project } \\
\text { Leader: Dr. Fahim H. Sadek }\end{array}$ & $\begin{array}{l}\text { Analyze the baseline performance of WTC } 1 \text { and WTC } 2 \text { under } \\
\text { design, service, and abnormal loads, and aircraft impact damage on } \\
\text { the structural, fire protection, and egress systems. }\end{array}$ \\
\hline $\begin{array}{l}\text { Mechanical and Metallurgical Analysis of } \\
\text { Structural Steel; Project Leader: Dr. Frank } \\
\text { W. Gayle }\end{array}$ & $\begin{array}{l}\text { Determine and analyze the mechanical and metallurgical properties } \\
\text { and quality of steel, weldments, and connections from steel } \\
\text { recovered from WTC } 1,2 \text {, and } 7 \text {. }\end{array}$ \\
\hline $\begin{array}{l}\text { Investigation of Active Fire Protection } \\
\text { Systems; Project Leader: Dr. David } \\
\text { D. Evans; Dr. William Grosshandler }\end{array}$ & $\begin{array}{l}\text { Investigate the performance of the active fire protection systems in } \\
\text { WTC } 1,2 \text {, and } 7 \text { and their role in fire control, emergency response, } \\
\text { and fate of occupants and responders. }\end{array}$ \\
\hline $\begin{array}{l}\text { Reconstruction of Thermal and Tenability } \\
\text { Environment; Project Leader: Dr. Richard } \\
\text { G. Gann }\end{array}$ & $\begin{array}{l}\text { Reconstruct the time-evolving temperature, thermal environment, } \\
\text { and smoke movement in WTC 1, 2, and } 7 \text { for use in evaluating the } \\
\text { structural performance of the buildings and behavior and fate of } \\
\text { occupants and responders. }\end{array}$ \\
\hline $\begin{array}{l}\text { Structural Fire Response and Collapse } \\
\text { Analysis; Project Leaders: Dr. John } \\
\text { L. Gross and Dr. Therese P. McAllister }\end{array}$ & $\begin{array}{l}\text { Analyze the response of the WTC towers to fires with and without } \\
\text { aircraft damage, the response of WTC } 7 \text { in fires, the performance of } \\
\text { composite steel-trussed floor systems, and determine the most } \\
\text { probable structural collapse sequence for WTC } 1,2 \text {, and } 7 \text {. }\end{array}$ \\
\hline $\begin{array}{l}\text { Occupant Behavior, Egress, and } \\
\text { Emergency Communications; Project } \\
\text { Leader: Mr. Jason D. Averill }\end{array}$ & $\begin{array}{l}\text { Analyze the behavior and fate of occupants and responders, both } \\
\text { those who survived and those who did not, and the performance of } \\
\text { the evacuation system. }\end{array}$ \\
\hline $\begin{array}{l}\text { Emergency Response Technologies and } \\
\text { Guidelines; Project Leader: Mr. J. Randall } \\
\text { Lawson }\end{array}$ & $\begin{array}{l}\text { Document the activities of the emergency responders from the time } \\
\text { of the terrorist attacks on WTC } 1 \text { and WTC } 2 \text { until the collapse of } \\
\text { WTC } 7 \text {, including practices followed and technologies used. }\end{array}$ \\
\hline
\end{tabular}




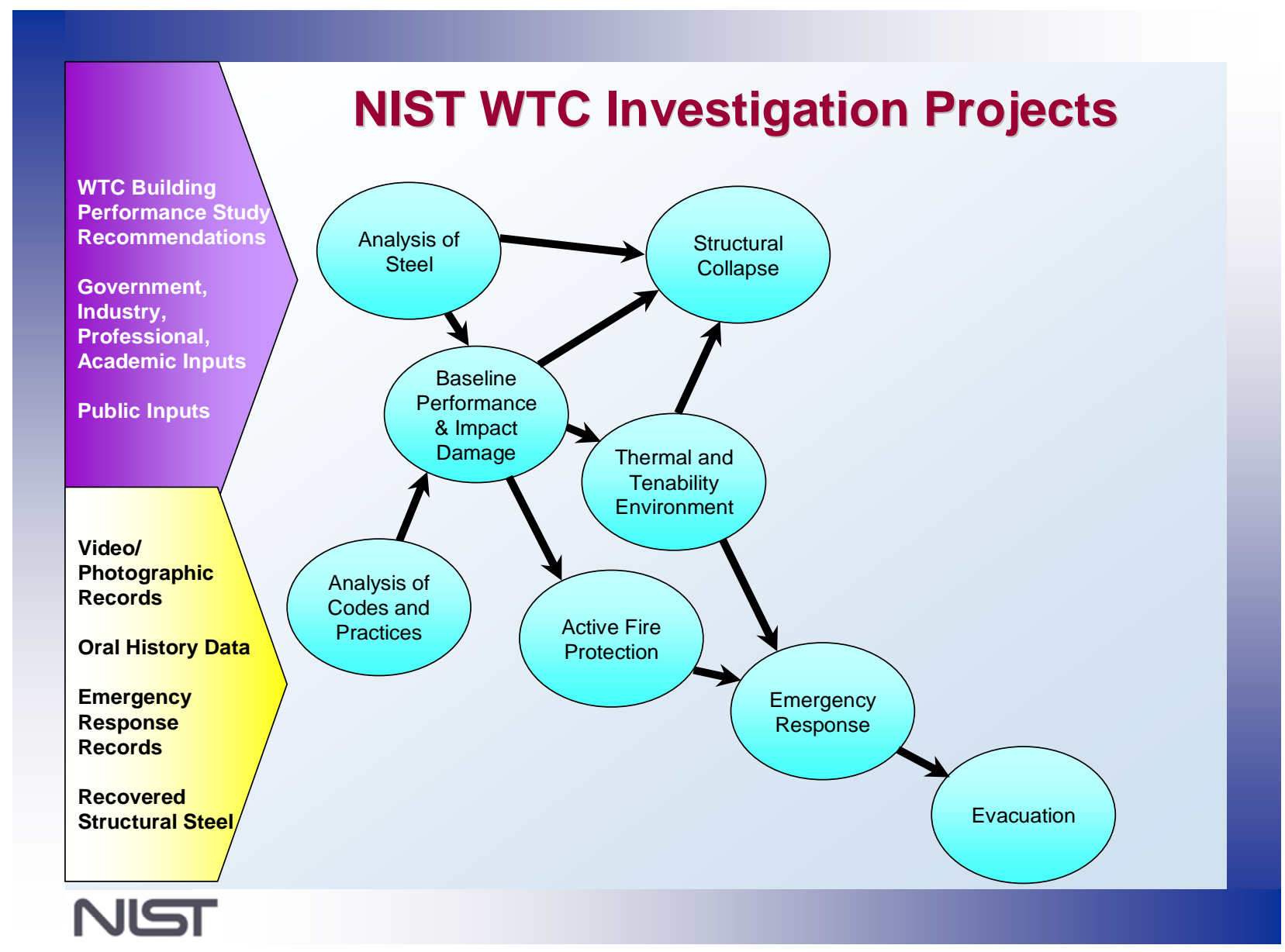

Figure P-1. Technical components of the federal building and fire safety investigation of the WTC disaster.

\section{National Construction Safety Team Advisory Committee}

The NIST Director also established an advisory committee as mandated under the National Construction Safety Team Act. The initial members of the committee were appointed following a public solicitation. These were, with their terms in parentheses:

- $\quad$ Paul Fitzgerald, Executive Vice President (retired) FM Global, National Construction Safety Team Advisory Committee Chair (2003-2009)

- John Barsom, President, Barsom Consulting, Ltd. (2003-2011).

- John Bryan, Professor Emeritus, University of Maryland (2003-2004)

- David Collins, President, The Preview Group, Inc. (2003-2010)

- Glenn Corbett, Professor, John Jay College of Criminal Justice (2003-2006)

- $\quad$ Philip DiNenno, President, Hughes Associates, Inc.(2003-2006) 
- Robert Hanson, Professor Emeritus, University of Michigan (2003-2009)

- Charles Thornton, Co-Chairman and Managing Principal, The Thornton-Tomasetti Group, Inc. (2003-2011)

- Kathleen Tierney, Director, Natural Hazards Research and Applications Information Center, University of Colorado at Boulder (2003-2007)

- Forman Williams, Director, Center for Energy Research, University of California at San Diego (2003-2011)

This National Construction Safety Team Advisory Committee provided technical advice during the Investigation and commentary on drafts of the Investigation reports prior to their public release. NIST has benefited from the work of many people in the preparation of these reports, including the National Construction Safety Team Advisory Committee. The content of the reports and recommendations, however, are solely the responsibility of NIST.

\section{Public Outreach}

During the course of this Investigation, NIST held public briefings and meetings (listed in Table P-2) to solicit input from the public, present preliminary findings, and obtain comments on the direction and progress of the Investigation from the public and the Advisory Committee.

NIST maintained a publicly accessible Web site during this Investigation at http://wtc.nist.gov. The site contained extensive information on the background and progress of the Investigation.

Prior to publishing the final reports, NIST released a draft of the reports for public comment. NIST received many comments from individuals, designers, professional organizations within the building and fire communities, and building owners. The comments were reviewed by the authors and addressed to the extent appropriate. The reports were modified with clarifications and supplemental text where needed, and the changes resulted in an improved final product. Comments on topics outside the scope of the investigation were not addressed.

\section{Information Quality Standards}

NIST conducted its World Trade Center (WTC) Investigation in accordance with Office of Management and Budget (OMB) directives and the Department of Commerce's and NIST's Information Quality Standards. This ensured that NIST's findings were objective, had utility to the industry, to emergency response professionals and to the general public, and insured the integrity of the information collected and presented in NIST's reports.

As defined in NIST's Information Quality Standards, “Objectivity consists of two distinct elements: presentation and substance. The presentation element includes whether disseminated information is presented in an accurate, clear, complete, and unbiased manner and in a proper context. The substance element involves a focus on ensuring accurate, reliable, and unbiased information." NIST obtained original source materials whenever possible, including design and renovation drawings, reports, correspondence, photographs and videos, and interviews of eye witnesses. Source materials were 
obtained from multiple sources, so as to minimize the influence of individual roles or accounts in understanding the design, construction, and operations of the WTC buildings and the events that occurred that day.

NIST conducted detailed analyses to simulate the impact damage caused by aircraft and/or debris and the fires, the building response to fires, and the subsequent collapse. These were extensive, state-of-the-art reconstructions of the events, and were validated using observations obtained from photographs and videos as well as observations made by emergency responders and building occupants.

All relevant data and analyses were presented in detailed reports (NIST NCSTAR 1-9 and 1-9A for WTC 7). The National Construction Safety Team (NCST) Advisory Committee reviewed NIST's technical approach in open session. The individual Advisory Committee members also conducted detailed reviews of NIST's draft reports, findings, and recommendations in their capacities as individual subject matter experts and provided substantive comments that were addressed in preparing the final reports. In addition, the draft NIST reports on WTC 7 were peer reviewed by five individual subjects matter experts, contracted by NIST, whose comments were also addressed in preparing the final reports. Thus, NIST made every effort to ensure that the investigation was conducted objectively, that the findings were reasonable and consistent with observations, and that the recommendations had a rational, scientific basis.

NIST's Information Quality Standards define Utility as "the usefulness of information to its intended users, including the public.” NIST identified four specific objectives for the WTC Investigation, which are stated at the beginning of the Preface. These goals and objectives were addressed and are reflected in the Principal Findings and Recommendations listed in the NIST NCSTAR 1 report for the WTC towers and the NIST NCSTAR 1A report for WTC 7. Individuals and organizations have responded to NIST's recommendations by developing proposals for changes to codes and standards. At the time of this publication, this effort has resulted in twenty-three changes being adopted into the International Building Code and fifteen introduced into the NFPA 5000 Building Code, NFPA 1 Fire Code, and NFPA 101 Life Safety Code. Some local jurisdictions have incorporated NIST's recommendations in their local codes and some building designers have incorporated the recommendations into their practice. All of these steps will lead to improved safety and security of buildings, building occupants, and emergency responders. The findings and recommendations of the NIST investigation of the World Trade Center disaster have clearly proven to be useful to those charged with ensuring the safety of buildings, building occupants, and emergency responders.

As defined in NIST's Information Quality Standards, “Integrity refers to security - the protection of information from unauthorized access or revision, to ensure that the information is not compromised through corruption or falsification.” NIST has been vigilant in protecting all of the information gathered for use in the investigation from outside sources or produced as a part of the investigation (e.g., computer models) from unauthorized access or revision. Access to information has been limited only to those individuals working directly on the investigation. The WTC reports are available electronically as Adobe .pdf files at http://wtc.nist.gov and have been "locked” to prevent revision or other alterations. These measures have ensured the integrity of materials collected or produced during the course of the WTC Investigation. 


\section{NIST's WTC Public-Private Response Plan}

The collapse of the WTC buildings has led to broad reexamination of how tall buildings are designed, constructed, maintained, and used, especially with regard to major events such as fires, natural disasters, and terrorist attacks. Reflecting the enhanced interest in effecting necessary change, NIST, with support from Congress and the Administration, has put in place a program, the goal of which is to develop and implement the standards, technology, and practices needed for cost-effective improvements to the safety and security of buildings and building occupants, including evacuation, emergency response procedures, and threat mitigation.

Table P-2. Public meetings and briefings of the WTC Investigation.

\begin{tabular}{|c|c|c|}
\hline Date & Location & Principal Agenda \\
\hline June 24, 2002 & New York City, NY & $\begin{array}{l}\text { Public meeting: Public comments on the Draft Plan for the } \\
\text { pending WTC Investigation. }\end{array}$ \\
\hline August 21, 2002 & Gaithersburg, MD & Media briefing announcing the formal start of the Investigation. \\
\hline December 9, 2002 & Washington, DC & $\begin{array}{l}\text { Media briefing on release of the Public Update and NIST request } \\
\text { for photographs and videos. }\end{array}$ \\
\hline April 8, 2003 & New York City, NY & $\begin{array}{l}\text { Joint public forum with Columbia University on first-person } \\
\text { interviews. }\end{array}$ \\
\hline April 29-30, 2003 & Gaithersburg, MD & $\begin{array}{l}\text { NCST Advisory Committee meeting on plan for and progress on } \\
\text { WTC Investigation with a public comment session. }\end{array}$ \\
\hline May 7, 2003 & New York City, NY & Media briefing on release of May 2003 Progress Report. \\
\hline August 26-27, 2003 & Gaithersburg, MD & $\begin{array}{l}\text { NCST Advisory Committee meeting on status of the WTC } \\
\text { investigation with a public comment session. }\end{array}$ \\
\hline September 17, 2003 & New York City, NY & $\begin{array}{l}\text { Media and public briefing on initiation of first-person data } \\
\text { collection projects. }\end{array}$ \\
\hline December 2-3, 2003 & Gaithersburg, MD & $\begin{array}{l}\text { NCST Advisory Committee meeting on status and initial results } \\
\text { and release of the Public Update with a public comment session. }\end{array}$ \\
\hline February 12, 2004 & New York City, NY & $\begin{array}{l}\text { Public meeting on progress and preliminary findings with public } \\
\text { comments on issues to be considered in formulating final } \\
\text { recommendations. }\end{array}$ \\
\hline June 18, 2004 & New York City, NY & Media/public briefing on release of June 2004 Progress Report. \\
\hline June 22-23, 2004 & Gaithersburg, MD & $\begin{array}{l}\text { NCST Advisory Committee meeting on the status of and } \\
\text { preliminary findings from the WTC Investigation with a public } \\
\text { comment session. }\end{array}$ \\
\hline August 24, 2004 & Northbrook, IL & $\begin{array}{l}\text { Public viewing of standard fire resistance test of WTC floor } \\
\text { system at Underwriters Laboratories, Inc. }\end{array}$ \\
\hline October 19-20, 2004 & Gaithersburg, MD & $\begin{array}{l}\text { NCST Advisory Committee meeting on status and near complete } \\
\text { set of preliminary findings with a public comment session. }\end{array}$ \\
\hline November 22, 2004 & Gaithersburg, MD & $\begin{array}{l}\text { NCST Advisory Committee discussion on draft annual report to } \\
\text { Congress, a public comment session, and a closed session to } \\
\text { discuss pre-draft recommendations for WTC Investigation. }\end{array}$ \\
\hline April 5, 2005 & New York City, NY & $\begin{array}{l}\text { Media and public briefing on release of the probable collapse } \\
\text { sequence for the WTC towers and draft reports for the projects on } \\
\text { codes and practices, evacuation, and emergency response. }\end{array}$ \\
\hline June 23, 2005 & New York City, NY & $\begin{array}{l}\text { Media and public briefing on release of all draft reports for the } \\
\text { WTC towers and draft recommendations for public comment. }\end{array}$ \\
\hline $\begin{array}{l}\text { September 12-13, } \\
2005\end{array}$ & Gaithersburg, MD & $\begin{array}{l}\text { NCST Advisory Committee meeting on disposition of public } \\
\text { comments and update to draft reports for the WTC towers. }\end{array}$ \\
\hline
\end{tabular}




\begin{tabular}{|l|l|l|}
\hline \multicolumn{1}{|c|}{ Date } & \multicolumn{1}{|c|}{ Location } & \multicolumn{1}{c|}{ Principal Agenda } \\
\hline $\begin{array}{l}\text { September 13-15, } \\
\text { 2005 }\end{array}$ & Gaithersburg, MD & $\begin{array}{l}\text { WTC Technical Conference for stakeholders and technical } \\
\text { community for dissemination of findings and recommendations } \\
\text { and opportunity for the public to make technical comments. }\end{array}$ \\
\hline December 14, 2006 & Teleconference & $\begin{array}{l}\text { NCST Advisory Committee meeting on status of WTC 7 } \\
\text { investigation and draft annual report to Congress, with a public } \\
\text { comment session. }\end{array}$ \\
\hline December 16, 2007 & Teleconference & $\begin{array}{l}\text { NCST Advisory Committee meeting on status of WTC 7 } \\
\text { investigation and draft annual report to Congress, with a public } \\
\text { comment session. }\end{array}$ \\
\hline August 26, 2008* & Teleconference & $\begin{array}{l}\text { Tedia and public briefing on release of all draft reports for WTC } \\
\text { 7 and draft recommendations for public comment. }\end{array}$ \\
\hline & & $\begin{array}{l}\text { Traft reports for WTC7, and draft recommendations for public } \\
\text { comment. }\end{array}$ \\
\hline
\end{tabular}

* Appended to table January 2009.

The strategy to meet this goal is a three-part, NIST-led, public-private response program that includes:

- A federal building and fire safety investigation to study the most probable factors that contributed to post-aircraft impact collapse of the WTC towers and the 47 story WTC 7 building, and the associated evacuation and emergency response experience.

- A research and development (R\&D) program to (a) facilitate the implementation of recommendations resulting from the WTC Investigation, and (b) provide the technical basis for cost-effective improvements to national building and fire codes, standards, and practices that enhance the safety of buildings, their occupants, and emergency responders.

- A dissemination and technical assistance program (DTAP) to (a) engage leaders of the construction and building community in ensuring timely adoption and widespread use of proposed changes to practices, standards, and codes resulting from the WTC Investigation and the R\&D program, and (b) provide practical guidance and tools to better prepare facility owners, contractors, architects, engineers, emergency responders, and regulatory authorities to respond to future disasters.

The desired outcomes are to make buildings, occupants, and first responders safer in future disaster events.

\section{National Construction Safety Team Reports on the WTC Investigation}

This report documents the global collapse analysis for WTC 7. A summary report of the investigation into WTC 7 appears as NIST NCSTAR 1A, presenting the reconstruction of the collapse of WTC 7, the principal technical findings, and the NIST recommendations. A support document, NIST NCSTAR 1-9, presents the techniques and technologies by which these technical results were achieved. The titles of the full set of Investigation publications are:

NIST (National Institute of Standards and Technology). 2005. Federal Building and Fire Safety Investigation of the World Trade Center Disaster: Final Report on the Collapse of the World Trade Center Towers. NIST NCSTAR 1. Gaithersburg, MD, September. 
NIST (National Institute of Standards and Technology). 2008. Federal Building and Fire Safety Investigation of the World Trade Center Disaster: Final Report on the Collapse of World Trade Center Building 7. NIST NCSTAR 1A. Gaithersburg, MD, November.

Lew, H. S., R. W. Bukowski, and N. J. Carino. 2005. Federal Building and Fire Safety Investigation of the World Trade Center Disaster: Design, Construction, and Maintenance of Structural and Life Safety Systems. NIST NCSTAR 1-1. National Institute of Standards and Technology. Gaithersburg, MD, September.

Fanella, D. A., A. T. Derecho, and S. K. Ghosh. 2005. Federal Building and Fire Safety Investigation of the World Trade Center Disaster: Design and Construction of Structural Systems. NIST NCSTAR 1-1A. National Institute of Standards and Technology. Gaithersburg, MD, September.

Ghosh, S. K., and X. Liang. 2005. Federal Building and Fire Safety Investigation of the World Trade Center Disaster: Comparison of Building Code Structural Requirements. NIST

NCSTAR 1-1B. National Institute of Standards and Technology. Gaithersburg, MD, September.

Fanella, D. A., A. T. Derecho, and S. K. Ghosh. 2005. Federal Building and Fire Safety Investigation of the World Trade Center Disaster: Maintenance and Modifications to Structural Systems. NIST NCSTAR 1-1C. National Institute of Standards and Technology. Gaithersburg, $\mathrm{MD}$, September.

Grill, R. A., and D. A. Johnson. 2005. Federal Building and Fire Safety Investigation of the World Trade Center Disaster: Fire Protection and Life Safety Provisions Applied to the Design and Construction of World Trade Center 1, 2, and 7 and Post-Construction Provisions Applied after Occupancy. NIST NCSTAR 1-1D. National Institute of Standards and Technology. Gaithersburg, MD, September.

Razza, J. C., and R. A. Grill. 2005. Federal Building and Fire Safety Investigation of the World Trade Center Disaster: Comparison of Codes, Standards, and Practices in Use at the Time of the Design and Construction of World Trade Center 1, 2, and 7. NIST NCSTAR 1-1E. National Institute of Standards and Technology. Gaithersburg, MD, September.

Grill, R. A., D. A. Johnson, and D. A. Fanella. 2005. Federal Building and Fire Safety Investigation of the World Trade Center Disaster: Comparison of the 1968 and Current (2003) New York City Building Code Provisions. NIST NCSTAR 1-1F. National Institute of Standards and Technology. Gaithersburg, MD, September.

Grill, R. A., and D. A. Johnson. 2005. Federal Building and Fire Safety Investigation of the World Trade Center Disaster: Amendments to the Fire Protection and Life Safety Provisions of the New York City Building Code by Local Laws Adopted While World Trade Center 1, 2, and 7 Were in Use. NIST NCSTAR 1-1G. National Institute of Standards and Technology. Gaithersburg, MD, September. 
Grill, R. A., and D. A. Johnson. 2005. Federal Building and Fire Safety Investigation of the World Trade Center Disaster: Post-Construction Modifications to Fire Protection and Life Safety Systems of World Trade Center 1 and 2. NIST NCSTAR 1-1H. National Institute of Standards and Technology. Gaithersburg, MD, September.

Grill, R. A., D. A. Johnson, and D. A. Fanella. 2005. Federal Building and Fire Safety Investigation of the World Trade Center Disaster: Post-Construction Modifications to Fire Protection, Life Safety, and Structural Systems of World Trade Center 7. NIST NCSTAR 1-1I. National Institute of Standards and Technology. Gaithersburg, MD, September.

Grill, R. A., and D. A. Johnson. 2005. Federal Building and Fire Safety Investigation of the World Trade Center Disaster: Design, Installation, and Operation of Fuel System for Emergency Power in World Trade Center 7. NIST NCSTAR 1-1J. National Institute of Standards and Technology. Gaithersburg, MD, September.

Sadek, F. 2005. Federal Building and Fire Safety Investigation of the World Trade Center Disaster: Baseline Structural Performance and Aircraft Impact Damage Analysis of the World Trade Center Towers. NIST NCSTAR 1-2. National Institute of Standards and Technology. Gaithersburg, MD, September.

Faschan, W. J., and R. B. Garlock. 2005. Federal Building and Fire Safety Investigation of the World Trade Center Disaster: Reference Structural Models and Baseline Performance Analysis of the World Trade Center Towers. NIST NCSTAR 1-2A. National Institute of Standards and Technology. Gaithersburg, MD, September.

Kirkpatrick, S. W., R. T. Bocchieri, F. Sadek, R. A. MacNeill, S. Holmes, B. D. Peterson, R. W. Cilke, C. Navarro. 2005. Federal Building and Fire Safety Investigation of the World Trade Center Disaster: Analysis of Aircraft Impacts into the World Trade Center Towers, NIST NCSTAR 1-2B. National Institute of Standards and Technology. Gaithersburg, MD, September.

Gayle, F. W., R. J. Fields, W. E. Luecke, S. W. Banovic, T. Foecke, C. N. McCowan, T. A. Siewert, and J. D. McColskey. 2005. Federal Building and Fire Safety Investigation of the World Trade Center Disaster: Mechanical and Metallurgical Analysis of Structural Steel. NIST NCSTAR 1-3. National Institute of Standards and Technology. Gaithersburg, MD, September.

Luecke, W. E., T. A. Siewert, and F. W. Gayle. 2005. Federal Building and Fire Safety Investigation of the World Trade Center Disaster: Contemporaneous Structural Steel Specifications. NIST Special Publication 1-3A. National Institute of Standards and Technology. Gaithersburg, MD, September.

Banovic, S. W. 2005. Federal Building and Fire Safety Investigation of the World Trade Center Disaster: Steel Inventory and Identification. NIST NCSTAR 1-3B. National Institute of Standards and Technology. Gaithersburg, MD, September.

Banovic, S. W., and T. Foecke. 2005. Federal Building and Fire Safety Investigation of the World Trade Center Disaster: Damage and Failure Modes of Structural Steel Components. NIST NCSTAR 1-3C. National Institute of Standards and Technology. Gaithersburg, MD, September. 
Luecke, W. E., J. D. McColskey, C. N. McCowan, S. W. Banovic, R. J. Fields, T. Foecke, T. A. Siewert, and F. W. Gayle. 2005. Federal Building and Fire Safety Investigation of the World Trade Center Disaster: Mechanical Properties of Structural Steels. NIST NCSTAR 1-3D. National Institute of Standards and Technology. Gaithersburg, MD, September.

Banovic, S. W., C. N. McCowan, and W. E. Luecke. 2005. Federal Building and Fire Safety Investigation of the World Trade Center Disaster: Physical Properties of Structural Steels. NIST NCSTAR 1-3E. National Institute of Standards and Technology. Gaithersburg, MD, September.

Evans, D. D., R. D. Peacock, E. D. Kuligowski, W. S. Dols, and W. L. Grosshandler. 2005. Federal Building and Fire Safety Investigation of the World Trade Center Disaster: Active Fire Protection Systems. NIST NCSTAR 1-4. National Institute of Standards and Technology. Gaithersburg, MD, September.

Kuligowski, E. D., D. D. Evans, and R. D. Peacock. 2005. Federal Building and Fire Safety Investigation of the World Trade Center Disaster: Post-Construction Fires Prior to September 11, 2001. NIST NCSTAR 1-4A. National Institute of Standards and Technology. Gaithersburg, MD, September.

Hopkins, M., J. Schoenrock, and E. Budnick. 2005. Federal Building and Fire Safety Investigation of the World Trade Center Disaster: Fire Suppression Systems. NIST NCSTAR 1-4B. National Institute of Standards and Technology. Gaithersburg, MD, September.

Keough, R. J., and R. A. Grill. 2005. Federal Building and Fire Safety Investigation of the World Trade Center Disaster: Fire Alarm Systems. NIST NCSTAR 1-4C. National Institute of Standards and Technology. Gaithersburg, MD, September.

Ferreira, M. J., and S. M. Strege. 2005. Federal Building and Fire Safety Investigation of the World Trade Center Disaster: Smoke Management Systems. NIST NCSTAR 1-4D. National Institute of Standards and Technology. Gaithersburg, MD, September.

Gann, R. G., A. Hamins, K. B. McGrattan, G. W. Mulholland, H. E. Nelson, T. J. Ohlemiller, W. M. Pitts, and K. R. Prasad. 2005. Federal Building and Fire Safety Investigation of the World Trade Center Disaster: Reconstruction of the Fires in the World Trade Center Towers. NIST NCSTAR 1-5. National Institute of Standards and Technology. Gaithersburg, MD, September.

Pitts, W. M., K. M. Butler, and V. Junker. 2005. Federal Building and Fire Safety Investigation of the World Trade Center Disaster: Visual Evidence, Damage Estimates, and Timeline Analysis. NIST NCSTAR 1-5A. National Institute of Standards and Technology. Gaithersburg, MD, September.

Hamins, A., A. Maranghides, K. B. McGrattan, E. Johnsson, T. J. Ohlemiller, M. Donnelly, J. Yang, G. Mulholland, K. R. Prasad, S. Kukuck, R. Anleitner and T. McAllister. 2005. Federal Building and Fire Safety Investigation of the World Trade Center Disaster: Experiments and Modeling of Structural Steel Elements Exposed to Fire. NIST NCSTAR 1-5B. National Institute of Standards and Technology. Gaithersburg, MD, September. 
Ohlemiller, T. J., G. W. Mulholland, A. Maranghides, J. J. Filliben, and R. G. Gann. 2005. Federal Building and Fire Safety Investigation of the World Trade Center Disaster: Fire Tests of Single Office Workstations. NIST NCSTAR 1-5C. National Institute of Standards and Technology. Gaithersburg, MD, September.

Gann, R. G., M. A. Riley, J. M. Repp, A. S. Whittaker, A. M. Reinhorn, and P. A. Hough. 2005. Federal Building and Fire Safety Investigation of the World Trade Center Disaster: Reaction of Ceiling Tile Systems to Shocks. NIST NCSTAR 1-5D. National Institute of Standards and Technology. Gaithersburg, MD, September.

Hamins, A., A. Maranghides, K. B. McGrattan, T. J. Ohlemiller, and R. Anleitner. 2005. Federal Building and Fire Safety Investigation of the World Trade Center Disaster: Experiments and Modeling of Multiple Workstations Burning in a Compartment. NIST NCSTAR 1-5E. National Institute of Standards and Technology. Gaithersburg, MD, September.

McGrattan, K. B., C. Bouldin, and G. Forney. 2005. Federal Building and Fire Safety Investigation of the World Trade Center Disaster: Computer Simulation of the Fires in the World Trade Center Towers. NIST NCSTAR 1-5F. National Institute of Standards and Technology. Gaithersburg, MD, September.

Prasad, K. R., and H. R. Baum. 2005. Federal Building and Fire Safety Investigation of the World Trade Center Disaster: Fire Structure Interface and Thermal Response of the World Trade Center Towers. NIST NCSTAR 1-5G. National Institute of Standards and Technology. Gaithersburg, MD, September.

Gross, J. L., and T. McAllister. 2005. Federal Building and Fire Safety Investigation of the World Trade Center Disaster: Structural Fire Response and Probable Collapse Sequence of the World Trade Center Towers. NIST NCSTAR 1-6. National Institute of Standards and Technology. Gaithersburg, MD, September.

Carino, N. J., M. A. Starnes, J. L. Gross, J. C. Yang, S. Kukuck, K. R. Prasad, and R. W. Bukowski. 2005. Federal Building and Fire Safety Investigation of the World Trade Center Disaster: Passive Fire Protection. NIST NCSTAR 1-6A. National Institute of Standards and Technology. Gaithersburg, MD, September.

Gross, J., F. Hervey, M. Izydorek, J. Mammoser, and J. Treadway. 2005. Federal Building and Fire Safety Investigation of the World Trade Center Disaster: Fire Resistance Tests of Floor Truss Systems. NIST NCSTAR 1-6B. National Institute of Standards and Technology. Gaithersburg, MD, September.

Zarghamee, M. S., S. Bolourchi, D. W. Eggers, Ö. O. Erbay, F. W. Kan, Y. Kitane, A. A. Liepins, M. Mudlock, W. I. Naguib, R. P. Ojdrovic, A. T. Sarawit, P. R Barrett, J. L. Gross, and T. P. McAllister. 2005. Federal Building and Fire Safety Investigation of the World Trade Center Disaster: Component, Connection, and Subsystem Structural Analysis. NIST NCSTAR 1-6C. National Institute of Standards and Technology. Gaithersburg, MD, September. 
Zarghamee, M. S., Y. Kitane, Ö. O. Erbay, T. P. McAllister, and J. L. Gross. 2005. Federal Building and Fire Safety Investigation of the World Trade Center Disaster: Global Structural Analysis of the Response of the World Trade Center Towers to Impact Damage and Fire. NIST NCSTAR 1-6D. National Institute of Standards and Technology. Gaithersburg, MD, September.

Averill, J. D., D. S. Mileti, R. D. Peacock, E. D. Kuligowski, N. Groner, G. Proulx, P. A. Reneke, and H. E. Nelson. 2005. Federal Building and Fire Safety Investigation of the World Trade Center Disaster: Occupant Behavior, Egress, and Emergency Communication. NIST NCSTAR 1-7. National Institute of Standards and Technology. Gaithersburg, MD, September.

Fahy, R., and G. Proulx. 2005. Federal Building and Fire Safety Investigation of the World Trade Center Disaster: Analysis of Published Accounts of the World Trade Center Evacuation. NIST NCSTAR 1-7A. National Institute of Standards and Technology. Gaithersburg, MD, September.

Zmud, J. 2005. Federal Building and Fire Safety Investigation of the World Trade Center Disaster: Technical Documentation for Survey Administration. NIST NCSTAR 1-7B. National Institute of Standards and Technology. Gaithersburg, MD, September.

Lawson, J. R., and R. L. Vettori. 2005. Federal Building and Fire Safety Investigation of the World Trade Center Disaster: The Emergency Response Operations. NIST NCSTAR 1-8. National Institute of Standards and Technology. Gaithersburg, MD, September.

McAllister, T., R. G. Gann, J. D. Averill, J. L. Gross, W. L. Grosshandler, J. R. Lawson, K. B. McGrattan, H. E. Nelson, W. M. Pitts, K. R. Prasad, F. H. Sadek. 2008. Federal Building and Fire Safety Investigation of the World Trade Center Disaster: Structural Fire Response and Probable Collapse Sequence of World Trade Center Building 7. NIST NCSTAR 1-9. National Institute of Standards and Technology. Gaithersburg, MD, November.

MacNeill, R., S. Kirkpatrick, B. Peterson, and R. Bocchieri, 2008. Federal Building and Fire Safety Investigation of the World Trade Center Disaster: Global Structural Analysis of the Response of World Trade Center Building 7 to Fires and Debris Impact Damage. NIST NCSTAR 1-9A. National Institute of Standards and Technology, Gaithersburg, MD, November. 


\section{EXECUTIVE SUMMARY}

\section{E.1 INTRODUCTION}

As part of the National Institute of Standards and Technology (NIST) investigation into the collapse of World Trade Center (WTC) 7, NIST worked with Applied Research Associates, Inc. (ARA) under contract to conduct global collapse analyses of the WTC 7 building. The purpose of this work was to analyze the global response of WTC 7 to initial failure events due to fire and to analyze the resulting component and subsystem failures to determine the events that led to the global collapse.

The nonlinear dynamic collapse analyses were performed using LS-DYNA, which is capable of explicitly modeling sequential failures, falling debris, and debris impact on other structural components. LS-DYNA is well suited for this type of analysis since it can model the dynamic sequential failure processes, including nonlinear material properties, nonlinear geometric deformations, material failures, and contact between the collapsing structural components. In addition, LS-DYNA has capabilities to include thermal softening of materials and thermal expansion.

Analyses of the LS-DYNA model of the 47 story WTC 7 were used to evaluate the global response of the building to initial failure events due to fire, including component and subsystem failures, to determine the events that led to the global collapse. Four global analyses were performed:

- Analysis of the building response to debris impact damage, temperature effects (Case B, $4.0 \mathrm{~h}$ temperatures), and fire induced damage based on the 16 story ANSYS analysis (Case B, $4.0 \mathrm{~h}$ damage).

- Analysis with earlier fire induced damage (Case B, $3.5 \mathrm{~h}$ ) to determine if a lesser degree of induced damage state was sufficient to initiate a global collapse of WTC 7.

- Analysis with temperature effects (Case B, $4.0 \mathrm{~h}$ temperatures), and fire induced damage based on the 16 story ANSYS analysis (Case B, 4.0 h damage) but without the debris impact damage. The purpose of this analysis was to determine the contribution of debris impact to the global collapse sequence and whether WTC 7 would have collapsed solely due to the effects of the fires.

- Analysis for a classic progressive collapse, i.e., disproportionate structural damage from a single failure, without debris impact or fire-induced damage, to determine if a progressive collapse would occur following the removal of a section of Column 79 between Floors 11 and 13.

The key aspects of the model and the results of the three global analyses are summarized.

\section{E.3 GLOBAL MODEL DEVELOPMENT}

The model of WTC 7 for the global collapse analyses is shown in Figure E-1. The building was modeled primarily with shell elements. Beam elements were used to model the diagonal framing elements in the structural frame as well as for the frame of the penthouse structures. The nonlinear discrete elements were used for details of the connection components. Brick elements were used for some rigid masses 
representing large equipment. A summary of the size of the global collapse model of WTC 7 is presented in Table E-1.

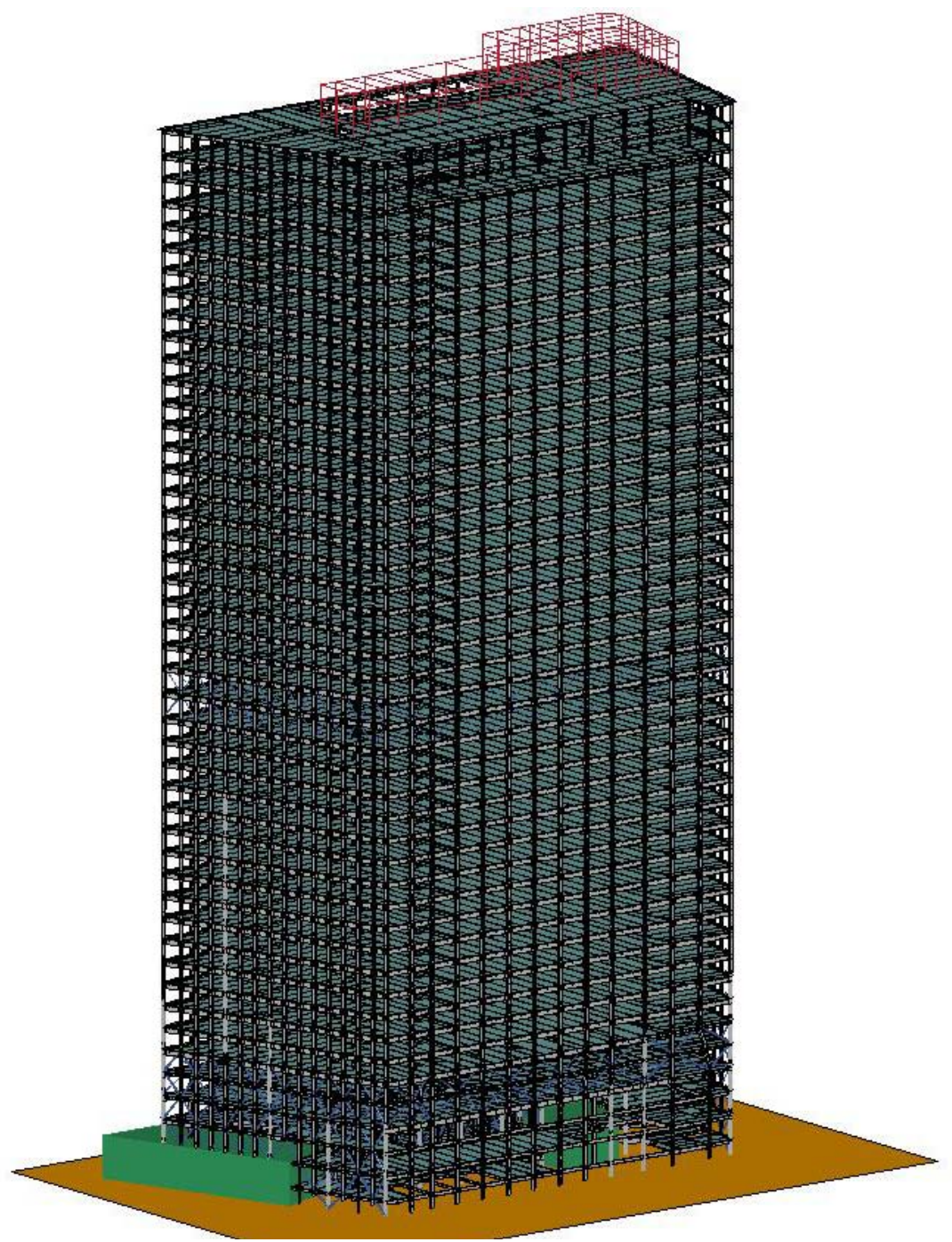

Figure E-1. Global tower model for WTC 7. View from southwest.

Table E-1. Summary of the global collapse model for the WTC 7 tower.

\begin{tabular}{|l|l|}
\hline & \multicolumn{1}{|c|}{ WTC 7 Tower Model } \\
\hline Number of Nodes & $3,593,049$ \\
\hline Hughes-Liu Beam Elements & 3,190 \\
\hline Belytschko-Tsay Shell Elements & $3,006,910$ \\
\hline Constant Stress Solid Elements & 2,461 \\
\hline Nonlinear Discrete Elements & 33,364 \\
\hline
\end{tabular}

A key aspect of modeling the structural integrity of WTC 7 for global collapse was the strength characteristics of the various structural connections in the building. The structural frame for WTC 7 contained a variety of structural connection types. These connection modeling efforts were a significant 
part of the WTC 7 model generation effort. The strengths and damage tolerance of the connections varied based on details such as whether the connection had welds or bolts. Similarly, the relative strength of different connections would vary based on the directionality of the load (e.g. the ability of connections to resist vertical and lateral loads).

Models of the various connections were developed based on the fabrication shop drawings and incorporated into the subassembly and global models. One example was the seated connection between exterior columns and interior framing beams. The connections included plates welded between the column flanges above and below the framing member, and the beam was bolted to the plates. The seated connection model developed for LS-DYNA is shown in Figure E-2. Bolts in the LS-DYNA model were represented with discrete elements. The properties of the discrete elements were tailored to match the bolt specifications in the actual construction. By including these details the relative strength in both vertical and lateral loading could be reproduced.

Wind bracing trusses were added to the lower core and exterior. Belt truss bracing at mid-height of the building was also included. The belt truss at Floors 22 to 24, which was part of the exterior framing, was also included as beam elements merged directly into the columns.

A simplified model of the penthouse structures was also generated using beam elements. The penthouse structures are shown in red in Figure E-1. Attachment of the penthouse structure to the global WTC 7 model was achieved by merging the beam ends into supporting columns or other framing in the roof structure. In addition, the global model accounted for the various load transfer mechanisms at the lower floors of WTC 7.

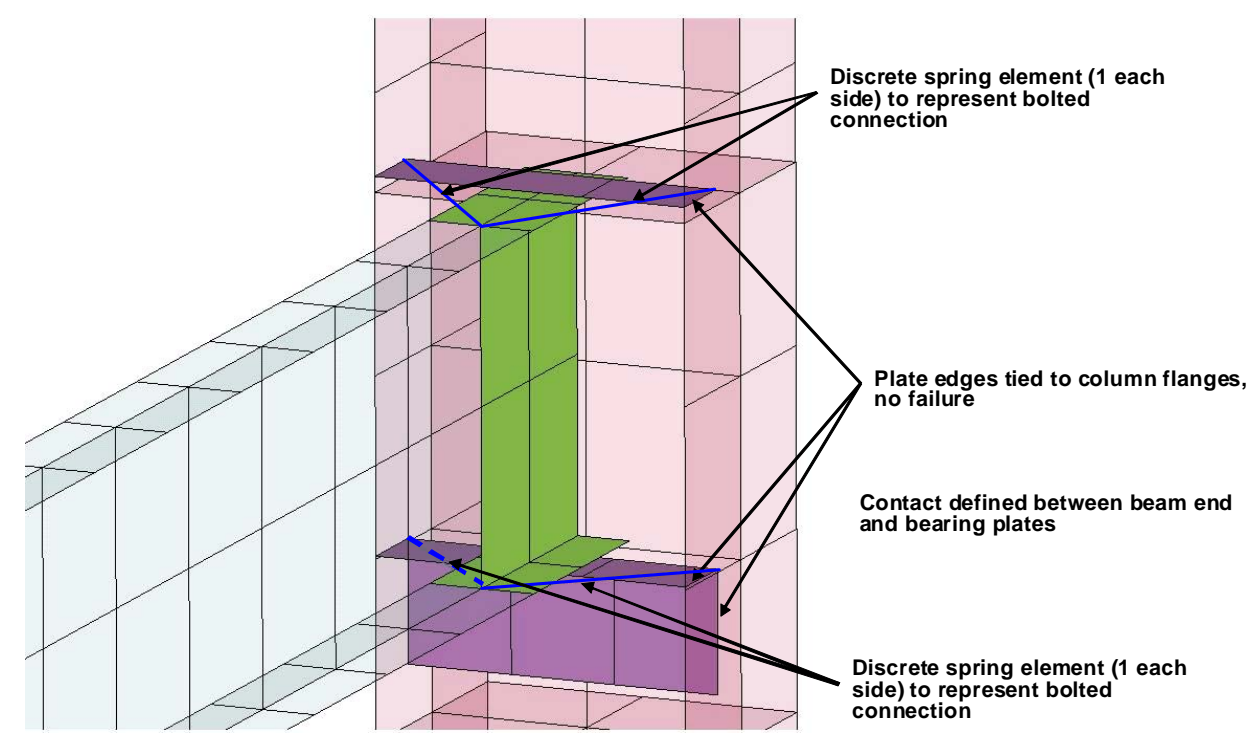

Figure E-2. Seated connection model overview.

\section{E.5 MODEL INITIALIZATION AND LOADING SEQUENCE}

The LS-DYNA model was initiated as follows to minimize any undue dynamic effects associated with loading sequence. First, gravity was applied slowly to the 47 floor structure over $4.5 \mathrm{~s}$ of elapsed simulation time to damp residual vibrations and eliminate dynamic response. Then the debris impact damage from the collapse of WTC 1 was applied to the structure instantaneously by removing damaged 
elements from the model that were no longer capable of bearing their loads. The structure was then allowed to damp residual vibrations for $2 \mathrm{~s}$. Next, the structural temperatures were applied at the same time as the damage data from the ANSYS simulation and allowed to damp residual vibrations for $2 \mathrm{~s}$. Last, the fire-induced damage obtained from the 16 story ANSYS analysis, including damage to floor beams, girders, and connections, was applied instantaneously. The heated, damaged structure was then free to react. The time at which the east penthouse began to descend was defined as $0.0 \mathrm{~s}$, i.e., the beginning of the collapse of WTC 7. A chart showing the initialization sequence with the load curve profiles used is shown in Figure E-3.

Live load (LL) was distributed evenly in the concrete slabs and steel structure. This was accomplished by multiplying the modeled material densities with a common scale factor to achieve the desired total load. A 25 percent live load was used, based on estimates from the design live loads in the building at the time of collapse.

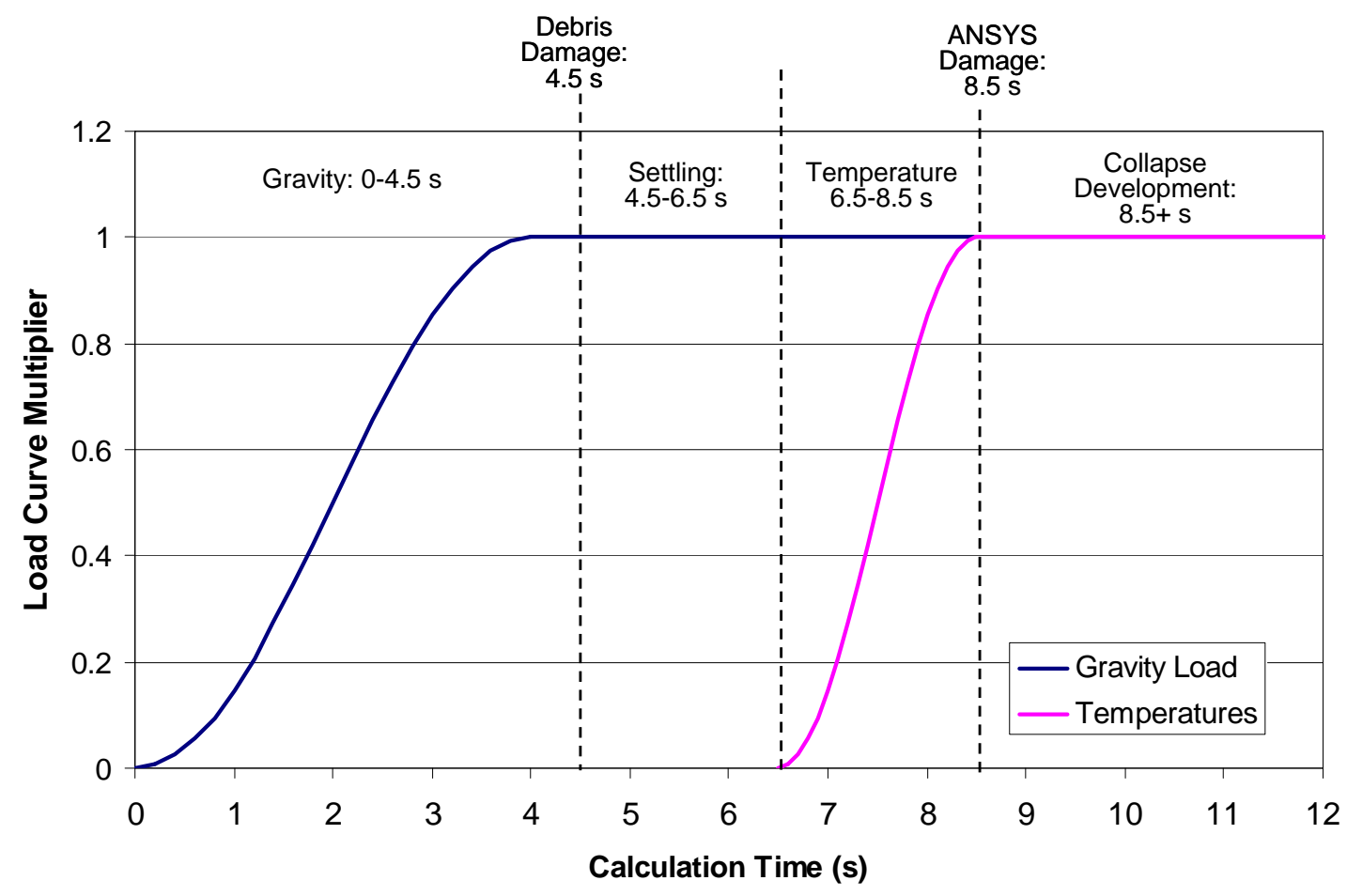

Figure E-3. Initialization sequence for global model.

After gravity initialization, debris impact damage from the collapse of WTC 1 was applied to the global model instantaneously to approximate the dynamic event. The damage applied was isolated to two zones on the southern side of the building. The first zone is on the south face of the tower and southwest corner extending over Floors 5 to 16 of WTC 7. The other zone had much less damage and was on the south face near the top of the tower on Floors 44 to the roof. The analysis demonstrated that the remaining structure was able to redistribute the loads from the damaged zone and that the tower developed a new equilibrium state.

Temperatures applied in the global model analysis were Case B temperatures at either 3.5 or 4.0 hours (NCSTAR NIST 1-9, Chapter 10). Elevated temperatures occurred between Floors 7 and 14. Temperature 
profiles were mapped onto the LS-DYNA model as nodal properties and followed the sinusoidal load curve shown in Figure E-3.

The final step in the initialization process was to apply fire-induced damage from the 16 story ANSYS analysis. The ANSYS analysis estimated the damage that occurred as the fires grew and spread on Floors 7, 8, and 9 and Floors 11, 12, and 13. The LS-DYNA analysis, by comparison, considered only a temperature profile at the time when thermally-induced damage was transferred from the ANSYS analysis. The damage was added to the LS-DYNA model as the final step before simulating the structural response to the temperatures and damage.

\section{E.6 GLOBAL COLLAPSE ANALYSES}

\section{Global Collapse Results with Debris Impact Damage}

The 47 story model calculation showed that the combination of debris-impact damage, fire-induced damage, and thermal loads resulted in the global collapse of WTC 7. The key events that occurred in the global analysis are summarized below.

\section{- $\quad-16.0$ to -7.5 (0 to 8.5) s: Model was initialized. ${ }^{1}$}

o Gravity, WTC 1 debris impact damage, and temperatures were applied to the LS-DYNA model.

0 The structure sustained damage developed from the load redistribution due to debris impact damage and Case B, $4.0 \mathrm{~h}$ temperatures.

0 The structure was stable at end of initialization.

\section{- $\quad-7.5$ (8.5) s: Fire-induced floor damage from the ANSYS analysis was added.}

o Sections of Floors 13 and 14 collapsed in the northeast region around Columns 79, 80, and 81.

o Floor areas below, also weakened by fires, collapsed from the falling debris until Columns 79 and 80 were unsupported between Floors 5 and 15. Column 81 was unsupported between Floors 7 and 15 .

- $\quad$-1.3 (14.7) s: The Initial Failure Event occurred and started the Vertical Progression.

o Column 79 buckled between Floors 5 and 14 .

o Columns 80 and 81 buckled quickly in succession, both within 1 second of Column 79 buckling.

o Following buckling of Columns 79 , 80 , and 81 , the remaining column section above the buckled lengths began to move downward, and the floors sections above were pulled downward, first by Column 79, then by Columns 80 and 81 .

o A global southward sway developed and grew in the upper floors, emanating from the collapsed east floor area.

- $\quad 0.0-1.5+(16.0-17.5+)$ s: Kink in east penthouse roofline appeared.

\footnotetext{
${ }^{1}$ The times are presented as follows: $t_{1}\left(t_{2}\right)$, where $t_{1}$ is the time following the first observation of the descent of the east penthouse (NIST NCSTAR 1-9, Section 5.7) and $t_{2}$ is the elapsed time from the start of the simulation.
} 
o 0 (16.0) s: The floor collapse progressed upward, and a kink appeared near the middle of the east penthouse roofline on the north side.

o $\quad 0.7+(16.7+)$ s: The east face near the top of the building deflected westward as floors surrounding Columns 79 to 81 pulled the exterior wall inward .

- 2.0 (18.0) s: The east penthouse fell below the WTC 7 roofline.

0 The east penthouse fell completely below the WTC 7 roofline.

- 2.7-5.3+ (18.7-21.3+) s: The Horizontal Progression started.

o 2.7 (18.7) s: The Truss 2 eastern diagonal member buckled due to the impact of falling debris, compromising the support of Columns 77, 78, and 78A.

o $\quad 3.3$ to 3.7 (19.3 to 19.7) s: Columns 77 and 78 buckled as a result of the Truss 2 failure. Column 76 buckled due to the load redistribution and impact of falling debris.

o 3.9 to 6.1 (19.9 to 22.1) s: The remaining interior columns buckled sequentially, as loads transferred from adjacent buckled columns and as they were impacted by falling debris.

o $\quad 4.3+(20.3+)$ s: West core columns buckled between Floors 9 and 13.

- $\quad$ 5.5-7.4 (21.5-23.4) s: Exterior Collapse occurred.

o 5.5 (21.5) s: Exterior column buckling began at the southwest corner Column 14, adjacent to the debris impact zone, between Floors 10 and 12.

o 5.5-7.4 (21.5-23.4) s: Exterior columns buckled along the south and west faces between Floors 7 and 14 . The buckling of exterior columns rapidly spread to the north, and then east, faces.

o 7.4 (23.4) s: All interior and exterior columns were buckled in the lower floors.

- 5.7 to 7.7 (21.7 to 23.7) s: West Penthouse and Screening Wall fell below the WTC 7 roofline.

o Collapse in the western core caused the west penthouse and screening wall to fall below the building roofline.

- 6.2 to 8.5 (22.2 to 24.5) s: Global Vertical Motion began.

o 6.2 to 6.3 (22.2 to 22.3 ) s: The east side of the north face roofline began moving downward.

o 6.5 to 7.5 (22.5 to 23.5 ) s: Global vertical motion spread across to the west side of the north face roofline.

o $7.5+(23.5+)$ s: The entire building was falling and the upper floors continued accelerating downward.

o At 8.5 (24.5) s: The roof was falling with velocity of approximately $10 \mathrm{~m} / \mathrm{s}$ to $15 \mathrm{~m} / \mathrm{s}$.

- 8.59 (24.59) s: The calculation was terminated.

Figure E-4 shows the progression of collapse as viewed from the northwest. The figures present contours of vertical displacement of the structure with a range between $-2.0 \mathrm{~m}$ and $0 \mathrm{~m}$ (-80 in. to 0 in.).

At -1.1 (14.9) s, floor segments had started collapsing around Columns 79, 80, and 81 between Floor 5 and Floor 14. The floor collapses were due to fire-induced structural damage obtained from the ANSYS analysis. 
At 2.3 (18.3) s, Columns 79 to 81 had buckled and the floor sections above were pulled downward by the unsupported columns, resulting in a vertical progression of collapse up to the east penthouse on the roof.

At 7.3 (23.3) s, column buckling had spread horizontally across the entire core. As the core columns fell downward, buckling of the exterior columns developed as the floors attached to the west face pulled inward at the lower floors. There were no fires on Floors 9 to 14 on the west floor area, so the floors were not thermally weakened in this area. Note that the north exterior wall appears generally intact, while most of the structure behind the north face is collapsing. Much of the interior structure and the south wall was falling downward at that point. By 8.6 (24.6) s, buckling had occurred in all the exterior columns, and global downward vertical movement had started. The calculation was stopped after the building had fallen downward approximately 10 floors, as global collapse occurred.

\section{Initial Failure Event and Vertical Progression of Collapse}

The initial failure event was the buckling of Column 79. This event was quickly followed by the buckling of adjacent Columns 80 and 81.

The floor framing structure was thermally weakened at Floors 8 to 14, with the most substantial damage occurring in the east region of Floors 12, 13, and 14. During the LS-DYNA temperature application cycle, combined thermal expansion and thermally degraded material properties resulted in beam and girder connection damage throughout the heated floor structures. The connection damage and buckled beam data transferred from the 16 story ANSYS analysis were then applied. The LS-DYNA analysis calculated the dynamic response of the floor failures and resulting impact on the surrounding structure. After the fire-induced ANSYS damage was applied, floor sections surrounding Columns 79 to 81 on Floors 13 and 14 collapsed to the floors below.

The thermally weakened floors below could not withstand the impact from the collapsing floors, and resulted in progressive floor collapses, which removed lateral support to Columns 79 to 81 over several floors. Eventually, critical conditions developed for column buckling due to a large unsupported length. Once Columns 79, 80, and 81 buckled, the column sections above Floor 14 began to descend downward and pulled the floor structures downward with them, thereby creating a vertical progression of floor collapses. The floors pulled on adjacent Columns 76, 77, and 79 until their connections failed. The east penthouse, which was supported by Columns 79, 80, and 81, fell downward. 


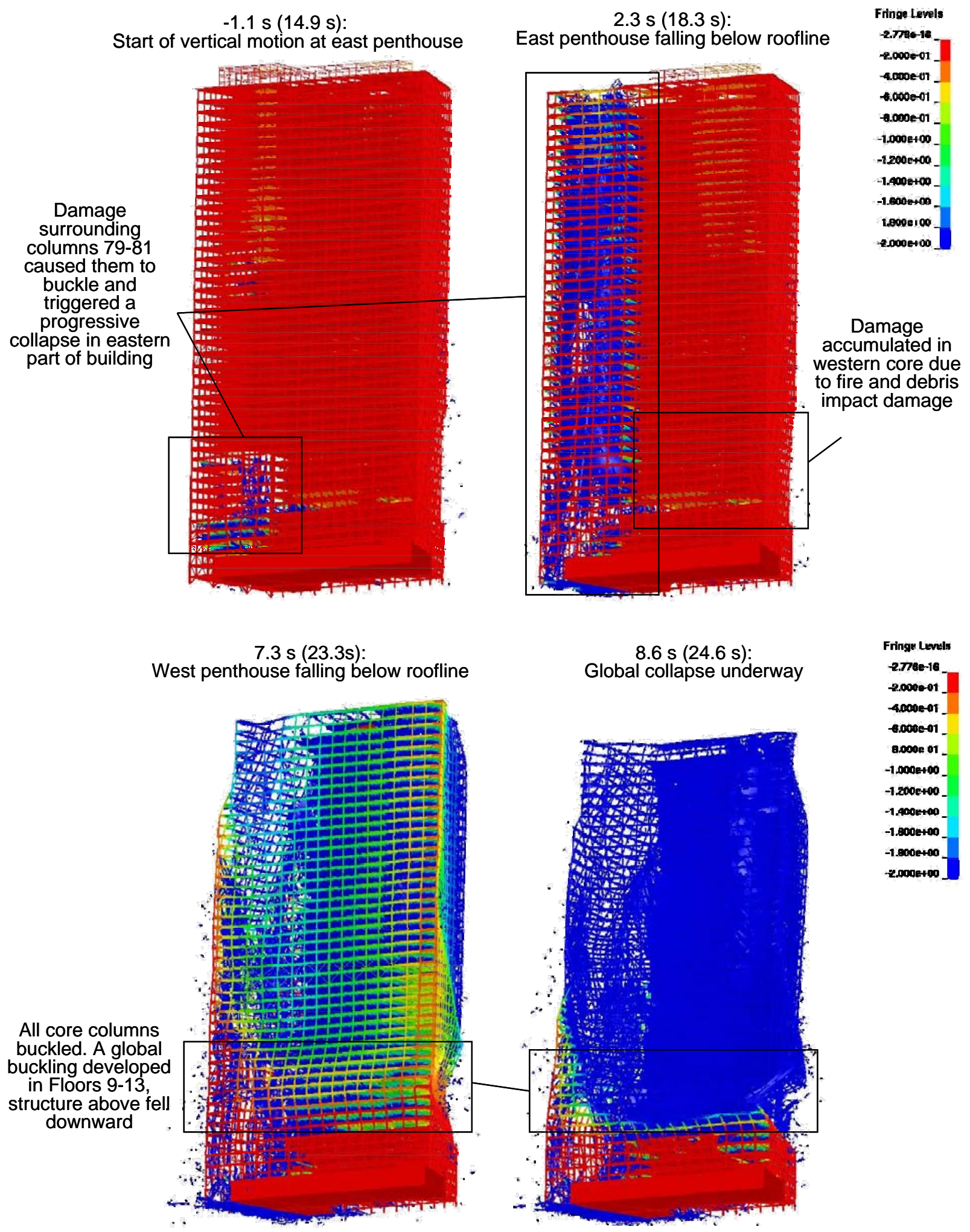

Figure E-4. Global response: vertical displacement contours (-2 to $0 \mathrm{~m}$ ). View from NW. 
Figure E-5 is a cutaway view that illustrates the structural condition surrounding Columns 79, 80, and 81 when they buckled. Included in the figure are resultant lateral displacements and column axial stress histories for the three columns. Note that a rapid lateral displacement developed, indicating buckling. Likewise, the column stresses indicated a rapid loss of stress at the time, signifying column buckling. The buckling of Column 80 and 81 was preceded by a slight increase in compressive stress due to load redistribution and tensile forces from floor systems being pulled downward by Column 79, and then by Column 80.

Figure E-6 illustrates the girder-to-column connection status at the time of buckling for Columns 79 through 81. The figure indicates large unsupported or partially supported (in one direction) lengths for each column at the time of buckling for each column. In addition to axial compressive loads that could have caused buckling, the columns were in a dynamic environment where lateral loads from falling debris and failure of girder connections occurred frequently. These lateral perturbations aided the onset of column buckling.

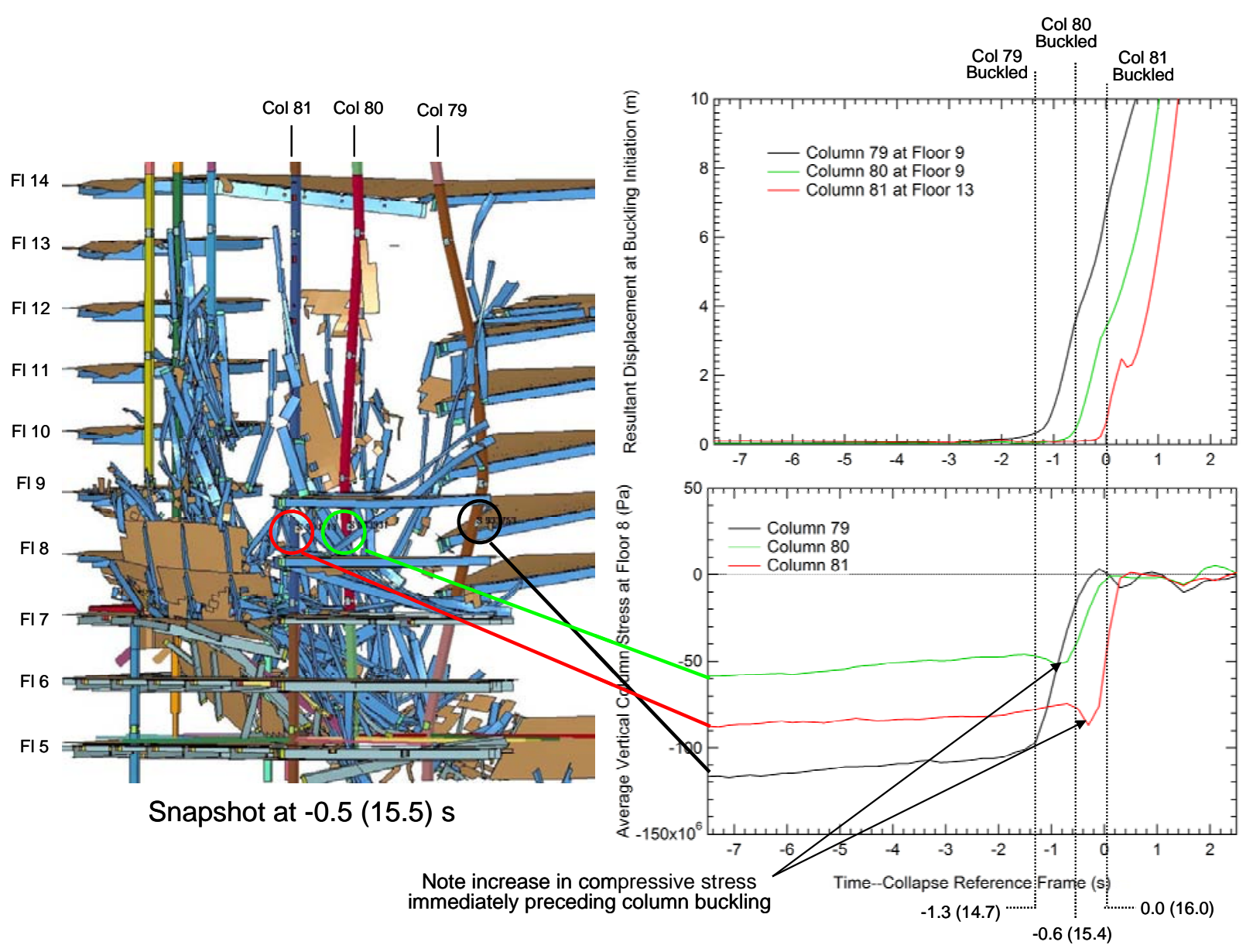

Figure E-5. Column 79 to 81 stress and displacements. 

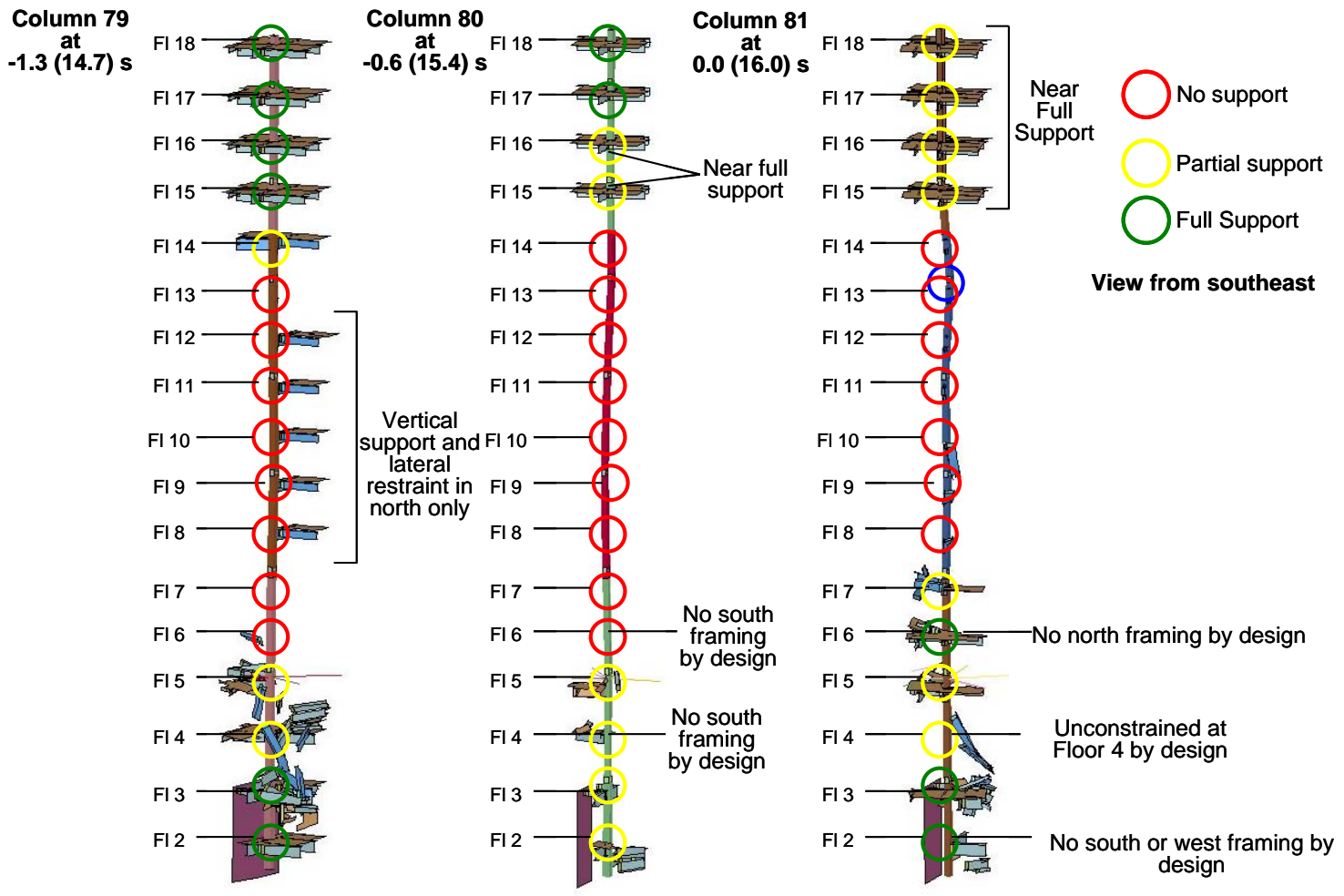

Figure E-6. Column 79-81 lateral supports at buckle initiation.

\section{Horizontal Progression of Collapse}

After the vertical progression of failure around Columns 79, 80, and 81, the failures continued to propagate across the interior columns in the lower floors. As the vertical progression of failures progressed, floor system and column debris fell from the upper floors, impacting adjacent intact columns and floors, including Truss 1 and Truss 2. The lateral support for Columns 76 to 78 was lost on the east side, when the floor connections failed. The accumulation of debris and debris impacts eventually caused Truss 2 to fail, as noted in Figure E-7.

The failure of Truss 2 precipitated the buckling of Columns 77 and 78, which along with Column 76 had already lost lateral support. Column 76 buckled due to the load redistribution from Columns 77 and 79 and from the impact of falling debris.

Column buckling progressed westward and the weakened interior columns continued to deflect due to load redistribution and global motion of the floors above. Eventually all core columns buckled between Floors 9 and 14. The occurrence of this westward progression indicates that the failure of Truss 2 was not essential to the failure of Columns 77 and 78, as they would have buckled like the other columns.

\section{Global Collapse}

The buckling of the interior columns in the LS-DYNA analysis was followed by the buckling of the exterior columns. 


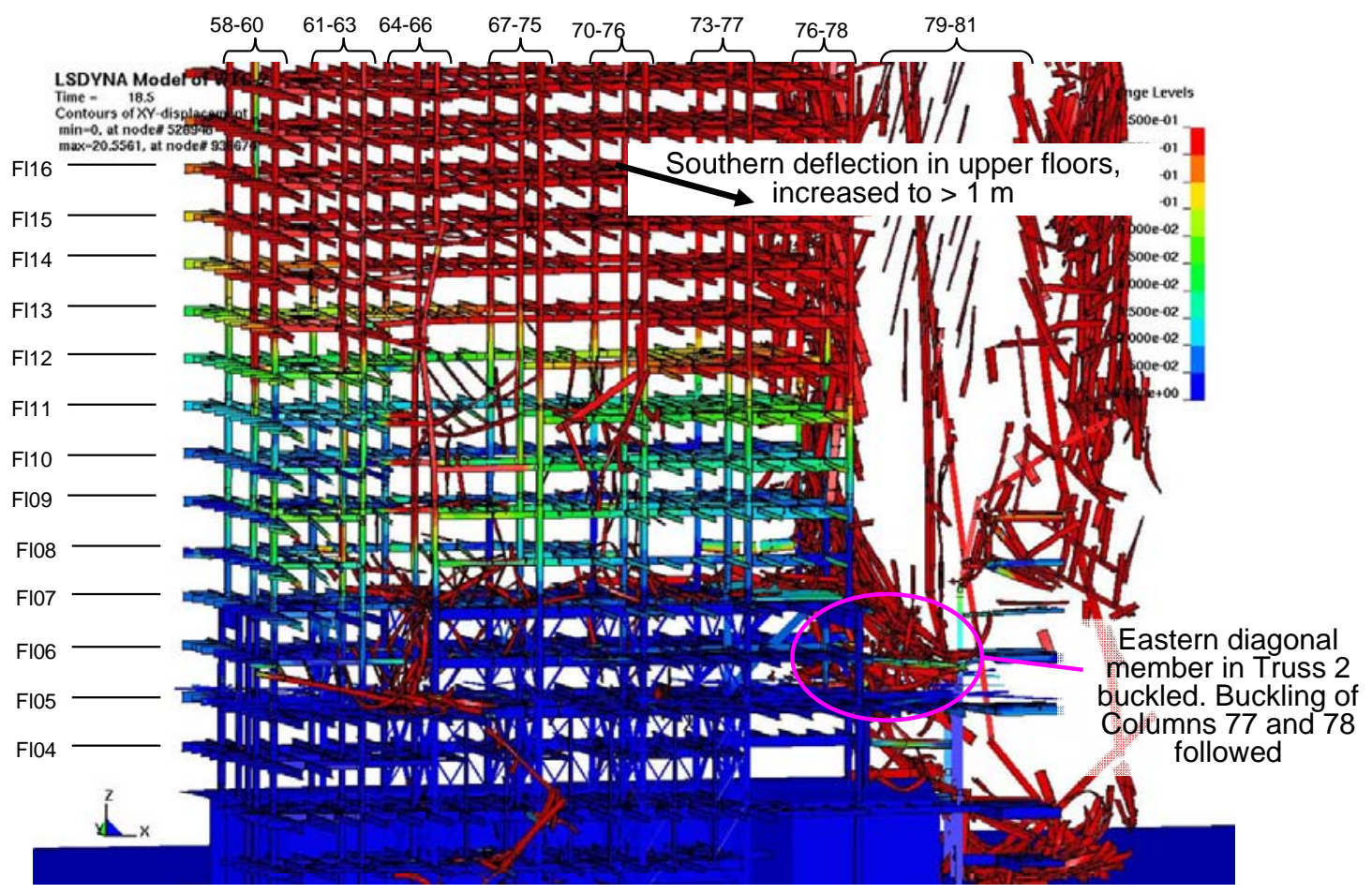

Figure E-7. Core lateral displacement. Time: $2.5(18.5) \mathrm{s}$, Columns 77 and 78 buckle when Truss 2 fails from debris loads.

As the core columns buckled across the building, the exterior columns were impacted by falling debris and load redistribution from the interior columns. All exterior columns buckled between approximately Floors 7 and 14. The south and west columns buckled first around 6 (22) s, followed by the north and east face columns. Once column support was lost in the lower floors, the remaining structure above began to fall vertically as a single unit. Views of the lower floor exterior column buckle modes are shown in Figure E-8.

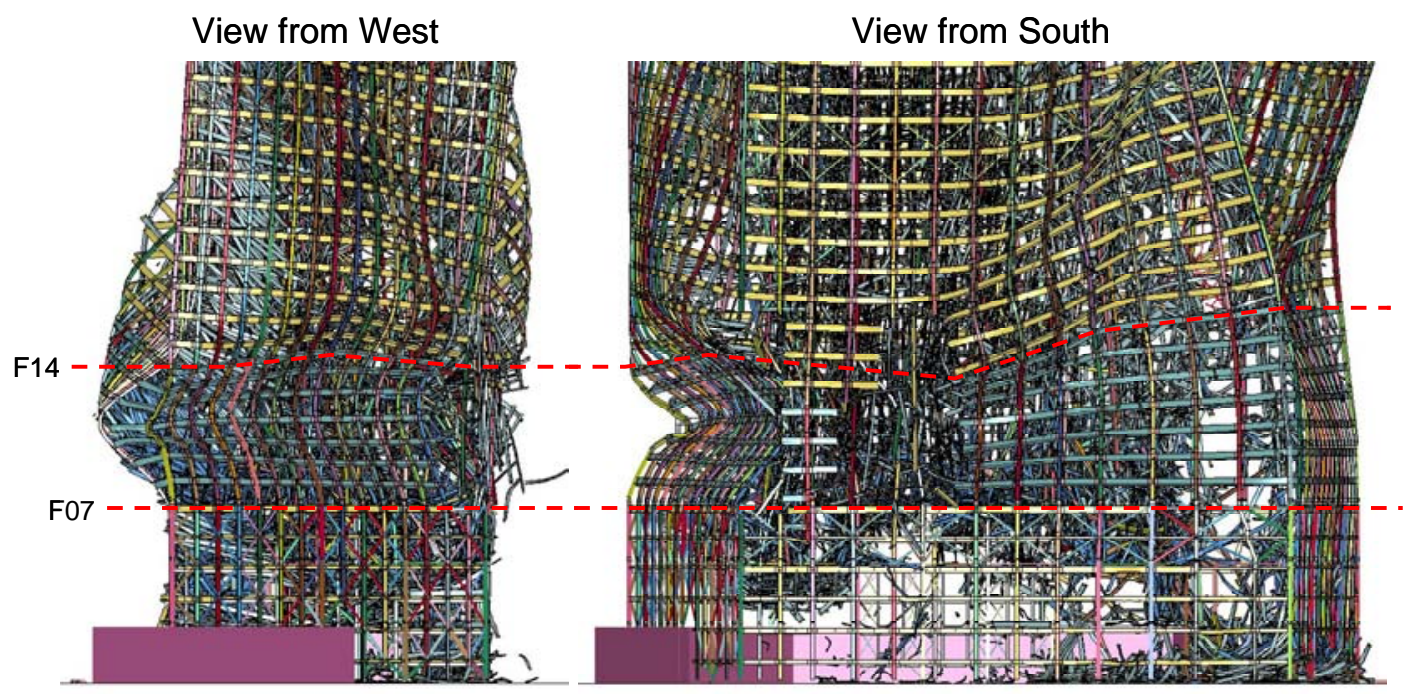

Figure E-8. Lower floor exterior column buckling (slabs removed from view). 


\section{Comparison with Observables}

Observed collapse events (NIST NCSTAR 1-9, Chapter 5) are compared to the results of the LS-DYNA analysis. Table 4-1 lists events with corresponding times from observed events and from the analysis.

Table E-2. Comparison of collapse analyses with observable events.

\begin{tabular}{|c|c|l|}
\hline Observation Time (s) & Collapse Analysis Time (s) & \multicolumn{1}{|c|}{ Event } \\
\hline N/A & -1.3 & $\begin{array}{l}\text { Column 79 buckles, quickly followed by Columns } \\
80 \text { and } 81\end{array}$ \\
\hline 0 & 0 & East penthouse begins to move downward \\
\hline 2.0 & $2.4-2.7$ & East penthouse falls below roofline \\
\hline N/A & $4.7-6.1$ & Buckling of core columns across core taking place \\
\hline 6.9 & $6.2-6.3$ & $\begin{array}{l}\text { Global collapse initiated, (initial downward motion } \\
\text { of eastern section of building) }\end{array}$ \\
\hline 8.5 & $7.3-7.7$ & East end of screening wall falls below roofline \\
\hline 9.3 & $6.9-7.3$ & West penthouse falls below roofline \\
\hline
\end{tabular}

a Not available

Given the complexity of the modeled behavior, the simulation closely matched the observed behavior.

\section{Global Results with Fire-induced Damage at $3.5 \mathrm{~h}$}

The global analysis with fire-induced damage obtained from the 16 story ANSYS analysis at $3.5 \mathrm{~h}$ instead of $4.0 \mathrm{~h}$ (as before) indicated that the level of damage was not sufficient to initiate global collapse of the building. The structure remained stable due to the lack of an initiating event (i.e., buckling of an interior column).

\section{Global Results without Debris Impact Damage}

The global analysis without debris impact damage showed that WTC 7 would have collapsed solely due to the effects of the fires. The initiation of collapse was virtually the same as for the global analysis with debris impact damage.

The initial failure event, vertical progression of failure, and early stages of the horizontal progression of failure occurred in the same order and at essentially the same times. The progression of horizontal failure in both analyses (with and without impact damage) was due to loss of lateral support as floors failed and to debris impact from adjacent failing floors and columns.

As the horizontal progression moved from east to west, some differences began to occur relative to the analysis with impact damage. Some floors failed at mid-height of the building around Columns 73 to 75 , leading to the buckling of some interior columns at this location, rather than at lower floors. The buckling at lower floor elevations in the analysis with impact damage was influenced by the damage around the west core columns when the debris impact damage was applied.

Additionally, the screenwall fell downward prior to the west penthouse, which was consistent with the observed sequence of events. In the analysis without impact damage, the horizontal progression 
continued to move westward after Columns 70 through 72 buckled. In the analysis with impact damage, the horizontal progression moved westward until Columns 70 to 72 buckled, after which the damaged west core columns also buckled.

For the analysis without debris impact damage, the timing of the exterior column buckling and onset of global collapse occurred at a slightly later time than was calculated for the analysis with impact damage.

\section{Global Results for a Classic Progressive Collapse Analysis}

The classic progressive collapse analysis showed that WTC 7 collapsed when a section of Column 79 between Floors 11 and 13 was removed. The global collapse occurred in the absence of debris impact damage and fire-induced damage. The collapse sequence demonstrated a vertical and horizontal progression of failure upon the removal of the Column 79 section, followed by buckling of exterior columns, which led to the collapse of the entire building. 
This page intentionally left blank. 


\section{Chapter 1 \\ INTRODUCTION}

\subsection{BACKGROUND}

As part of the National Institute of Standards and Technology (NIST) investigation into the collapse of World Trade Center (WTC) 7, Applied Research Associates, Inc. (ARA) conducted global collapse analyses of the WTC 7 building under contract to and in close collaboration with NIST. The purpose of this work was to analyze the global response of WTC 7 to an initial failure event due to fire and to analyze the resulting component and subsystem failures to determine the events that led to the global collapse.

The nonlinear dynamic collapse analyses were performed using LS-DYNA (Livermore 2007), which is capable of explicitly modeling sequential failures, falling debris, and debris impact on other structural components. LS-DYNA is well suited for this type of analysis since it can model the dynamic failure processes, including nonlinear material properties, nonlinear geometric deformations, material failures, and contact between the collapsing structural components. In addition, LS-DYNA has capabilities to include thermal softening of materials and thermal expansion.

The WTC 7 model was developed with sufficient fidelity to accurately capture the progressive failure modes, while maintaining computational efficiency. A similar approach was used previously in the analysis of the aircraft impacts into the WTC towers (NIST NCSTAR 1-2B). The approach used in that study, which was focused on assessing the effects of aircraft impact prior to collapse initiation, was to refine the model only in the regions where damage occurred, and to use reduced models elsewhere with damage and failure modes that captured the behavior of the refined models. The WTC 7 model, which was focused on capturing the entire collapse initiation and collapse propagation process of the building, required a more uniform mesh with sufficient fidelity to capture failure modes throughout the structure as it collapsed, while maintaining computational efficiency.

The modeling approach began with collapse analyses of a multi-floor subassembly, and was followed by a global collapse analysis of WTC 7 using a model of the entire building. The multi-floor model was used to test modeling methods and to test initiating event hypotheses. Lessons learned from the floor modeling effort were incorporated into the global analysis. Experience from the previous WTC tower modeling effort was utilized to aid in modeling WTC 7. In particular, steel material models formulated for the WTC tower models formed the basis for those used in WTC 7. Also, meshing and model construction techniques were carried over from the WTC tower models, where appropriate.

\subsection{REPORT ORGANIZATION}

Chapter 2 describes the material models and methods used in the WTC 7 global analyses. Models developed specifically for the WTC 7 analyses are described in more detail, including modeling of thermal effects and composite slabs. 
Chapter 3 describes the WTC 7 LS-DYNA model construction and development process. Model organization and preprocessing are detailed in the chapter. Connection models developed for the LSDYNA analyses are described. Features within the floor subassembly and global response models are discussed. The model initialization process that was developed and the resulting states prior to conducting the collapse analyses are presented.

Chapter 4 describes the modeling results from the floor subassembly and global collapse analyses. The floor modeling section shows the primary results and describes the process leading up to the global model analysis. The global collapse modeling results describe the collapse events and the associated details. A summary of the report is included in Chapter 5.

\subsection{UNITS OF MEASUREMENT}

All models were developed using the SI system of units. The SI system measures length in meters (m), mass in kilograms (kg), and time in seconds (s). Under this system, stresses are measured in Pascals (Pa), loads in Newtons $(\mathrm{N})$, and temperatures in Kelvin $\left({ }^{\circ} \mathrm{K}\right)$ or Celsius $\left({ }^{\circ} \mathrm{C}\right)$. All building dimensions from the structural drawings were converted to the SI system during model generation. The simulation results presented are in these units. Material models are discussed primarily in English units (lb-f-in-s), since material testing data that was used to generate the models was in English units, but material properties were converted to SI units for compatibility within the LS-DYNA model. Some model construction details are discussed in English units as well since the drawings and specifications are in English units. All units were converted to SI for the LS-DYNA analyses.

\section{$1.4 \quad$ REFERENCES}

Livermore. 2007. LS-DYNA Keyword User’s Manual, Livermore Software Technology Corporation, Version 971, May. 


\section{Chapter 2 \\ MATERIAL Constitutive Modeling}

\section{$2.1 \quad$ INTRODUCTION}

Constitutive models available in LS-DYNA were capable of reproducing a wide range of response, damage, and failure of structural materials under various loading conditions. The primary materials modeled were the structural steel used in the framing of WTC 7 and the composite floor slabs, including the reinforced concrete slab and metal deck. The constitutive models for the steel framing and floor slab are described in Sections 2.1 and 2.3, respectively.

Much of the material modeling techniques used in this investigation was originally developed for the aircraft impact damage assessment of the WTC towers (NIST NCSTAR 1-2B and 1-3D). However, in addition to the mechanical response of the structural materials at room temperatures, the effects of thermal loading were also important for the global collapse initiation. As a result, additional constitutive models were used that included the relevant thermal effects (e.g., thermal expansion and thermal softening). These constitutive models are described in Section 2.1.3

\subsection{STEEL CONSTITUTIVE MODELS}

Various constitutive models were available in LS-DYNA that captured the nonlinear behavior and failure of the steel. The primary constitutive model applied was the Piecewise Linear Plasticity model (material type 24 in LS-DYNA). This model was sufficient to model the nonlinear deformation and failure of the steel structures. A tabular effective stress versus effective strain curve was used with a pre-defined strain at failure.

The constitutive model parameters for the steel frame were developed previously as part of the NIST Federal Building and Fire Safety Investigation of the World Trade Center Disaster (NIST NCSTAR 12B). The material parameters were developed for each grade of steel used in the construction of the WTC towers based on engineering stress-strain data provided by Project 3 of the NIST Investigation, Mechanical and Metallurgical Analysis of Structural Steel (NIST NCSTAR 1-3). A summary of the constitutive model development and material properties is provided here for completeness.

The approach to developing the constitutive model parameters for each grade of steel was:

- Convert the engineering stress-strain curve to a true stress versus true strain curve. The conversion process is valid up to the onset of necking in the specimen.

- Extrapolate the true stress-strain curve beyond the point of necking onset.

- Perform iterative finite element analyses of the tensile test and adjust the true stress-strain curve extrapolation and failure strain until the necking behavior and failure point were accurately captured. The primary criterion was the quantitative agreement of the measured and calculated engineering stress-strain behavior in the softening region beyond maximum 
stress. These analyses required a fine mesh resolution in the specimen to accurately model the large strain deformation response during necking.

- Perform a final finite element analysis of the material test using a coarser mesh resolution (referred to here as a 'Medium Mesh'). Adjust the failure criterion (strain at failure) to obtain failure at the same engineering strain level.

The advantage of this approach was that the measured nonlinear material behavior up to failure was accurately captured in the constitutive model. In addition, the simulation of the material testing provided a validation that the constitutive model parameters were defined accurately and that the model could reproduce the measured response for the test conditions.

The tensile tests performed by NIST applied the ASTM 370 test standard (ASTM 2003). Example finite element models of the specimen models used for testing of the WTC core column steels are shown in Figure 2-1. The typical element length used in the gage section for the fine meshes was approximately 0.015 in $(0.381 \mathrm{~mm})$ and for the medium meshes was approximately 0.10 in $(0.254 \mathrm{~mm})$.

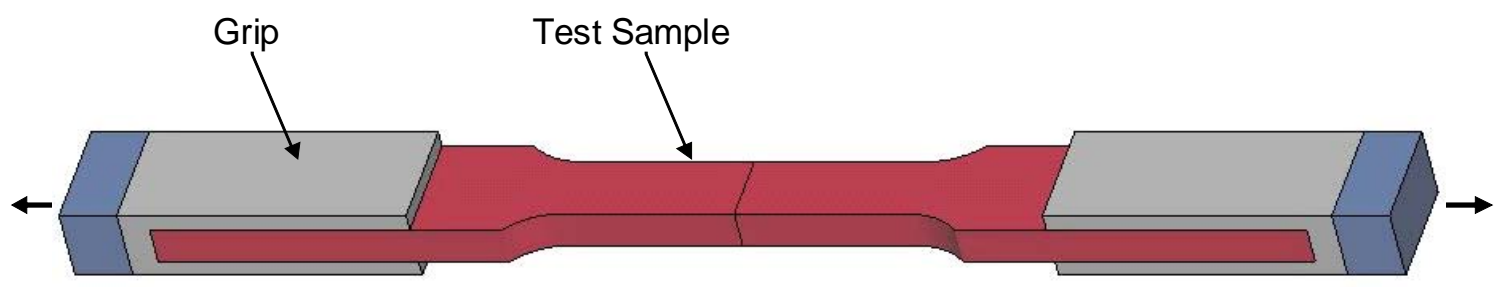

Fine Mesh

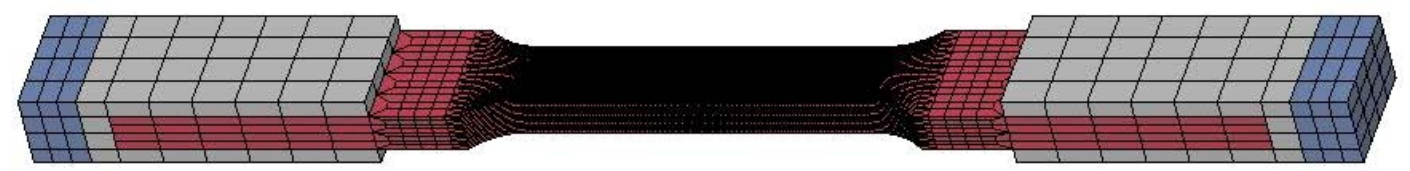

Medium Mesh

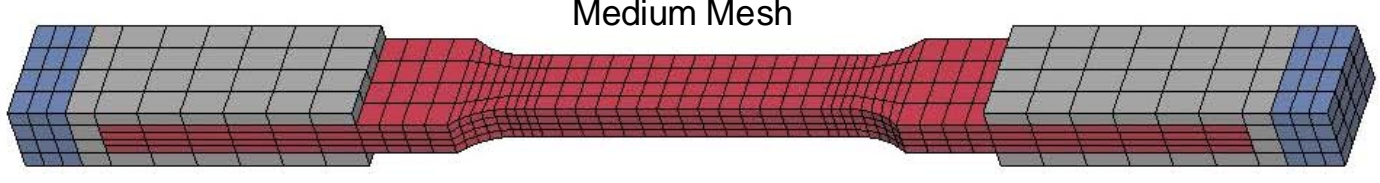

Figure 2-1. Example finite element models of the ASTM 370 tensile specimen.

\subsubsection{6, 42, and $50 \mathrm{ksi}(248,290$, and $345 \mathrm{MPa})$ Steel Models}

The steels used to construct WTC 7 were ASTM Grade A36 (nominal yield strength of $36 \mathrm{ksi}$ ), ASTM A572 Grade 50 (nominal yield strength of $50 \mathrm{ksi}$ ), and steel plates for connections produced by Algoma Steel (nominal yield strength of $42 \mathrm{ksi}$ ).

In this section, examples are provided to illustrate the methodology for developing constitutive models of the WTC 7 steels, as well as typical results. Figure 2-2 shows an example of the measured engineering stress-strain behavior for the $50 \mathrm{ksi}(345 \mathrm{MPa}$ ) steel. Four tests were performed by NIST (NIST NCSTAR 1-3) on this grade of steel, and the data indicated that there was little anisotropy in the behavior 
introduced by the roll forming process (longitudinal tests L1 and L2 versus transverse tests T1 and T2 in the figure). The primary effect of the anisotropy was the greater ductility for specimens aligned with the rolling direction.

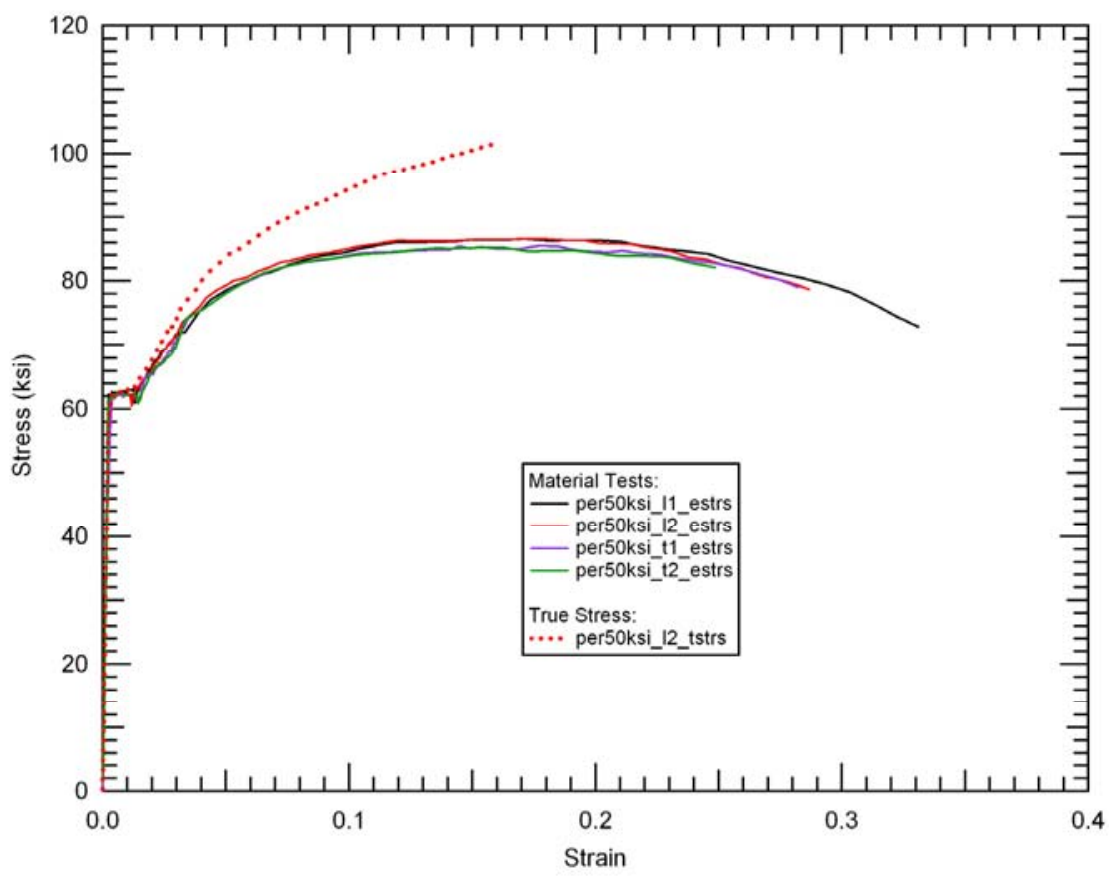

Figure 2-2. Test data and true stress-strain conversion for the $50 \mathrm{ksi}$ (345 MPa) steel.

The first step in the constitutive model development process was to obtain a true stress-true strain curve. The typical approach was to select a representative test and perform the data conversion process. In this example, the data from test L1 was used to create the true stress-strain curve shown in Figure 2-2. This true stress-strain curve was then approximated by a piecewise linear curve in tabular form as shown in Figure 2-3. This tabular curve was the input used to specify the mechanical behavior in the constitutive model.

The final step was to apply the tabular true stress-strain behavior in the constitutive model to simulate the tensile test as shown in Figure 2-4. If necessary, the extrapolation of the true stress-strain behavior was adjusted until the simulation matched the measured engineering stress-strain response, including necking and failure (the portion of the stress-strain curve beyond the maximum engineering stress). A comparison of the calculated and measured engineering stress-strain behavior for the $50 \mathrm{ksi}$ (345 MPa) steel is shown in Figure 2-5. The agreement in the calculated and measured tensile test behavior was good. The ductility of the material was selected to be an average between the longitudinal and transverse properties.

The procedure used to develop the $36 \mathrm{ksi}$ and $42 \mathrm{ksi}$ (248 MPa and $290 \mathrm{MPa}$ ) material parameters was identical to that for the $50 \mathrm{ksi}$ (345 MPa) material described above, and the correlation with test data was similar. The true stress-strain curves used in the constitutive models for the (36, 42, and 50) ksi (248, 290, and $345 \mathrm{MPa}$ ) WTC 7 steels are summarized in Figure 2-6. 


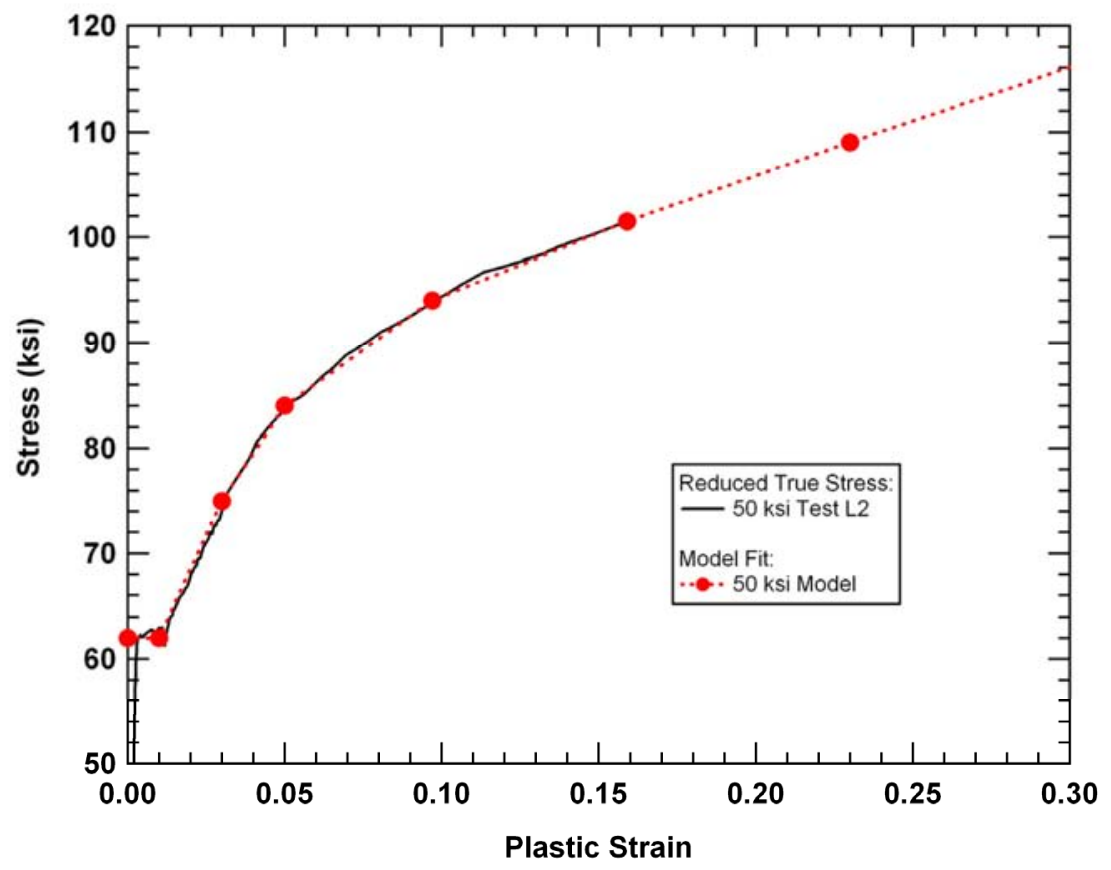

Figure 2-3. Tabular true stress-strain constitutive model curve for the $50 \mathrm{ksi}$ (345 MPa) steel.

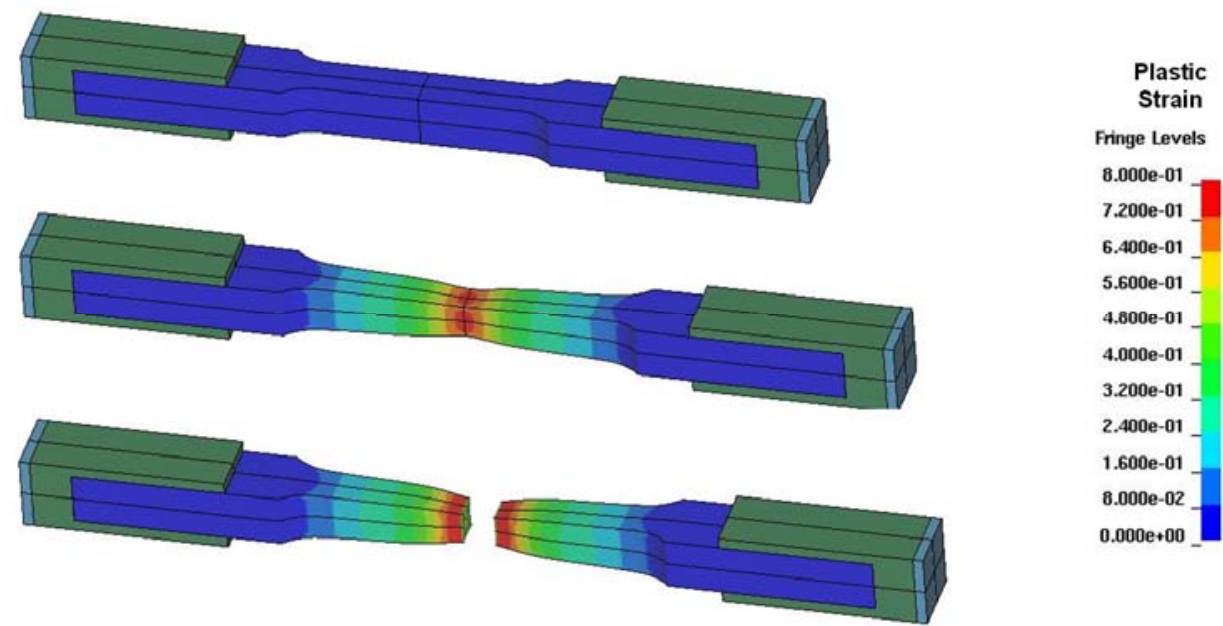

Figure 2-4. Calculated tensile test response with necking for the $50 \mathrm{ksi}$ (345 MPa) steel. 


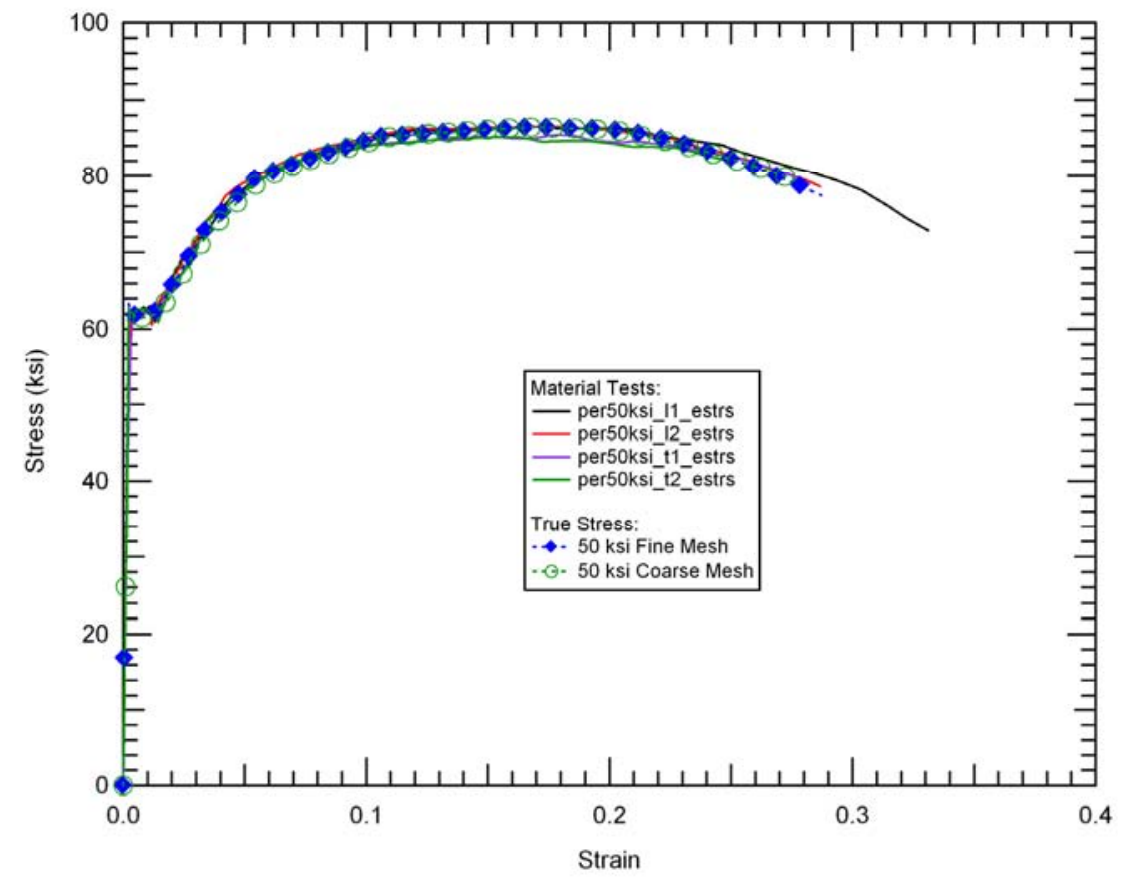

Figure 2-5. Comparison of measured and calculated engineering stress-strain curves for the $50 \mathrm{ksi}(345 \mathrm{MPa})$ steel.

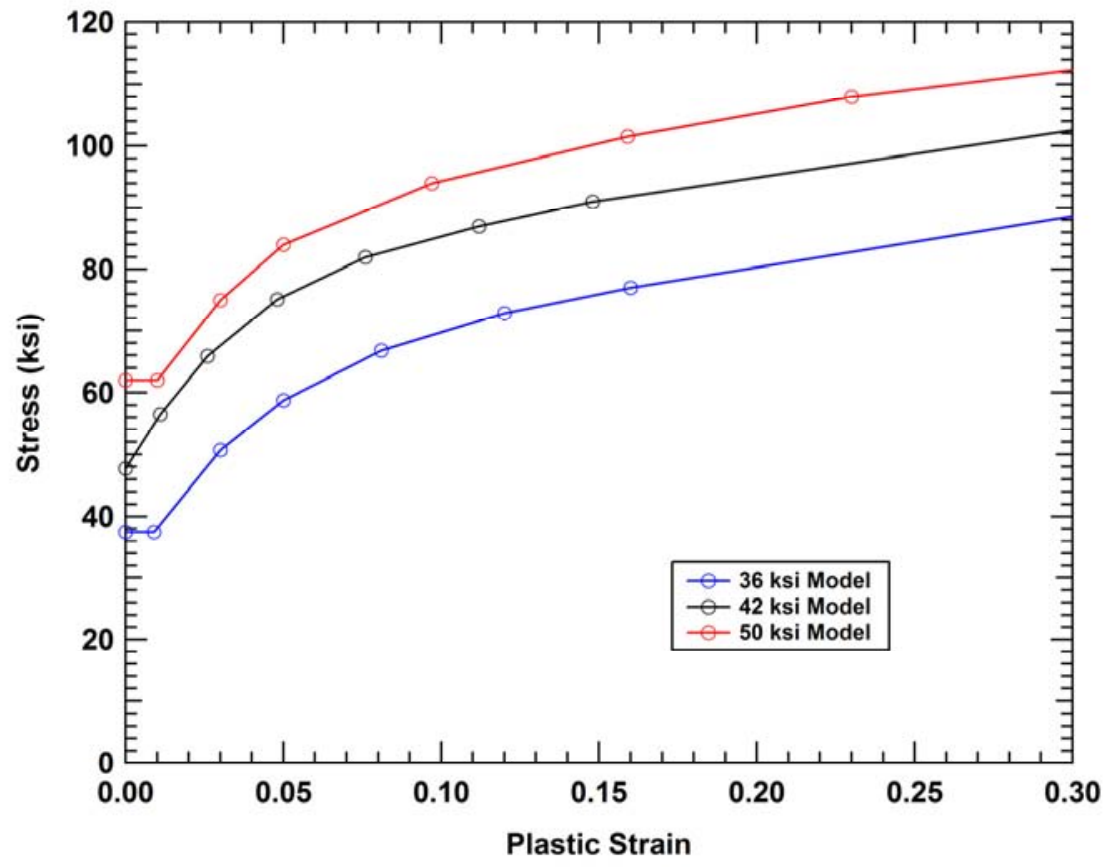

Figure 2-6. Tabular true stress-strain constitutive model curves. 


\subsubsection{Algoma Steel Plate Model Description}

An additional material used in WTC 7 that was not previously modeled for the WTC Towers was steel plates produced by Algoma (CSA G40.21-44W) for floor framing connections (NIST NCSTAR 1-9, Chapter 2). The properties obtained for the Algoma steel were a yield strength of $44 \mathrm{ksi}$ (303 MPa) and an ultimate tensile strength of $75 \mathrm{ksi}^{1}$ (517 MPa) occurring at a true strain of 16 percent. With this limited information, a bilinear constitutive model was generated that had a yield strength of $44 \mathrm{ksi}$ (303 MPa) and a plastic hardening modulus of $194 \mathrm{ksi}$ (1.34 GPa).

\subsubsection{Temperature-Dependent Material Models}

For the regions of WTC 7 subjected to elevated temperatures due to fires, temperature-dependent material models were needed that included the effects of thermal softening in the structural steel and the deformations and stresses produced by the thermal expansion of the structural components. The material model selected to define the thermal response of the structural steels is the Elastic-Viscoplastic Thermal (Type 106) model in LS-DYNA. This model used the same parameters to define nonlinear material behavior as in the Type 24 models, but included additional parameters to define temperature dependence.

The temperature-dependent material properties and constitutive model parameters were developed by NIST (NIST NCSTAR 1-3D and NIST NCSTAR 1-9, Appendix E). Examples of the stress-strain curves for the $36 \mathrm{ksi}$ and $50 \mathrm{ksi}$ (248 MPa and $345 \mathrm{MPa}$ ) steels at various temperatures are shown in Figure 2-7 and Figure 2-8, respectively. In these models, the yield strength, the elastic modulus, Poisson's ratio, and thermal expansion coefficient were defined as a function of temperature. The same strain failure criterion was applied at room temperature and at elevated temperatures.

For the temperature-dependent version of Algoma steel, the thermal data was interpolated between the $36 \mathrm{ksi}$ and $50 \mathrm{ksi}$ (248 MPa and $345 \mathrm{MPa}$ ) Type 106 models to get a $44 \mathrm{ksi}$ (303 MPa) version. The same procedure was used to develop a temperature-dependent model for the few components in WTC 7 made of $42 \mathrm{ksi}(290 \mathrm{MPa})$ steel.

Addition of the thermal behavior added significant computational complexity to the material model and increased the run time requirements. As a result, these thermal constitutive models were only applied in the regions where elevated temperatures were significant as a result of the fire effects preceding the initial failure event.

\footnotetext{
${ }^{1}$ The ultimate tensile strength for the Algoma steel was estimated to be 70.6 ksi (see Appendix E), but 75 ksi was used in the LSDYNA analyses. However, the Algoma steel model was only applied to the seats of the seated connections. The other connection components used custom material models that were developed to capture the appropriate connection strengths.
} 


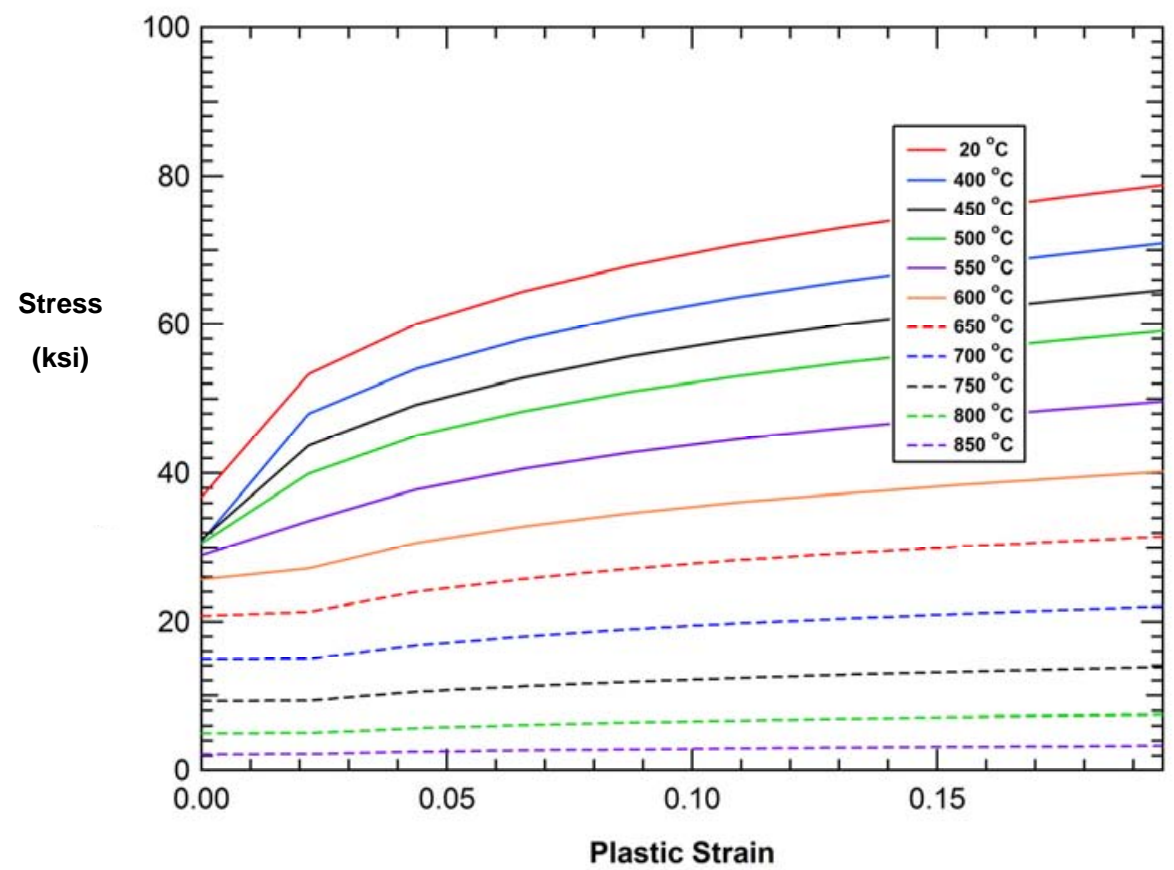

Figure 2-7. Stress-strain curves of the $36 \mathrm{ksi}(248 \mathrm{MPa})$ structural steel as a function of temperature.

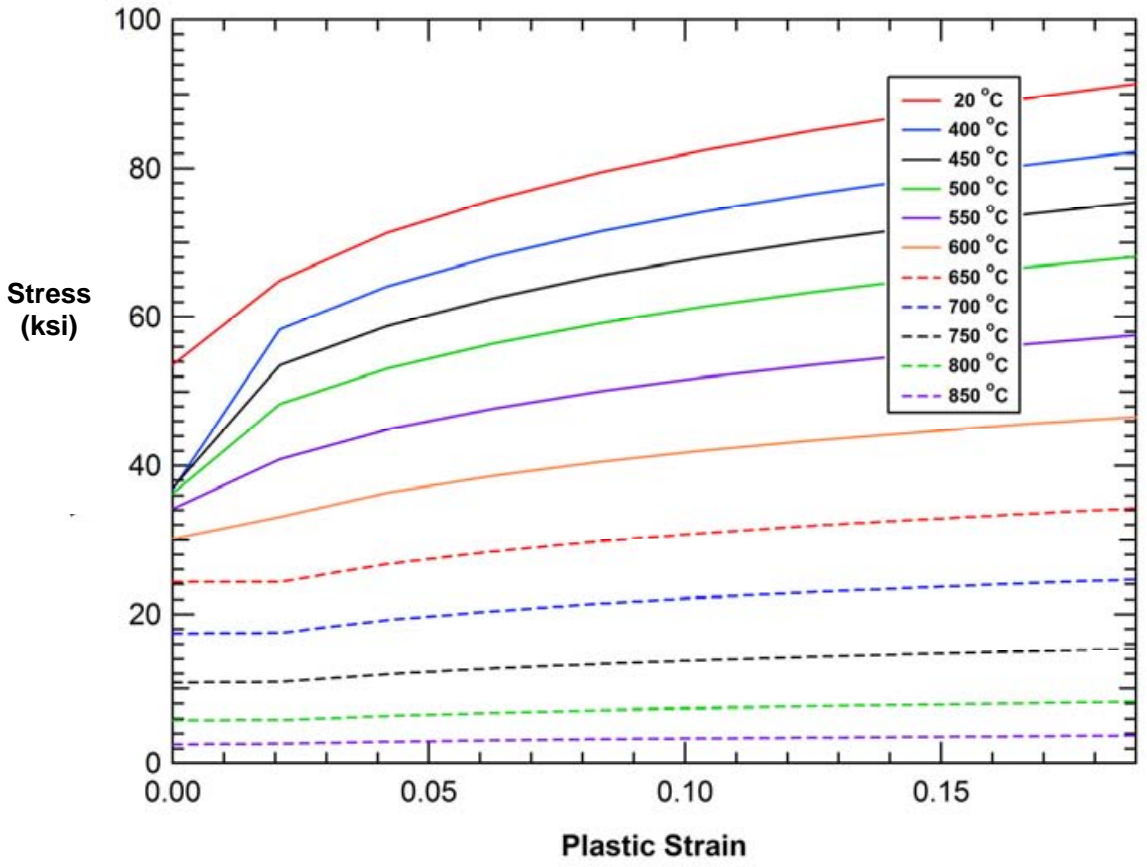

Figure 2-8. Stress-strain curves of the $50 \mathrm{ksi}(345 \mathrm{MPa})$ structural steel as a function of temperature. 


\subsection{FLOOR SLAB CONSTITUTIVE MODEL}

The floor slabs in WTC 7 consisted of a corrugated metal deck with a normal weight concrete slab that had an average thickness of approximately 4 in $(0.1 \mathrm{~m})$. The corrugated metal deck resulted in orthotropic stiffness contributions to the floor stiffness. Welded wire fabric was placed with a 3/4 in. cover to reinforce the slab. Cross sections of the typical floor slab construction details are shown in Figure 2-9 and Figure 2-10. The development of the composite floor slab model is described in the following section.

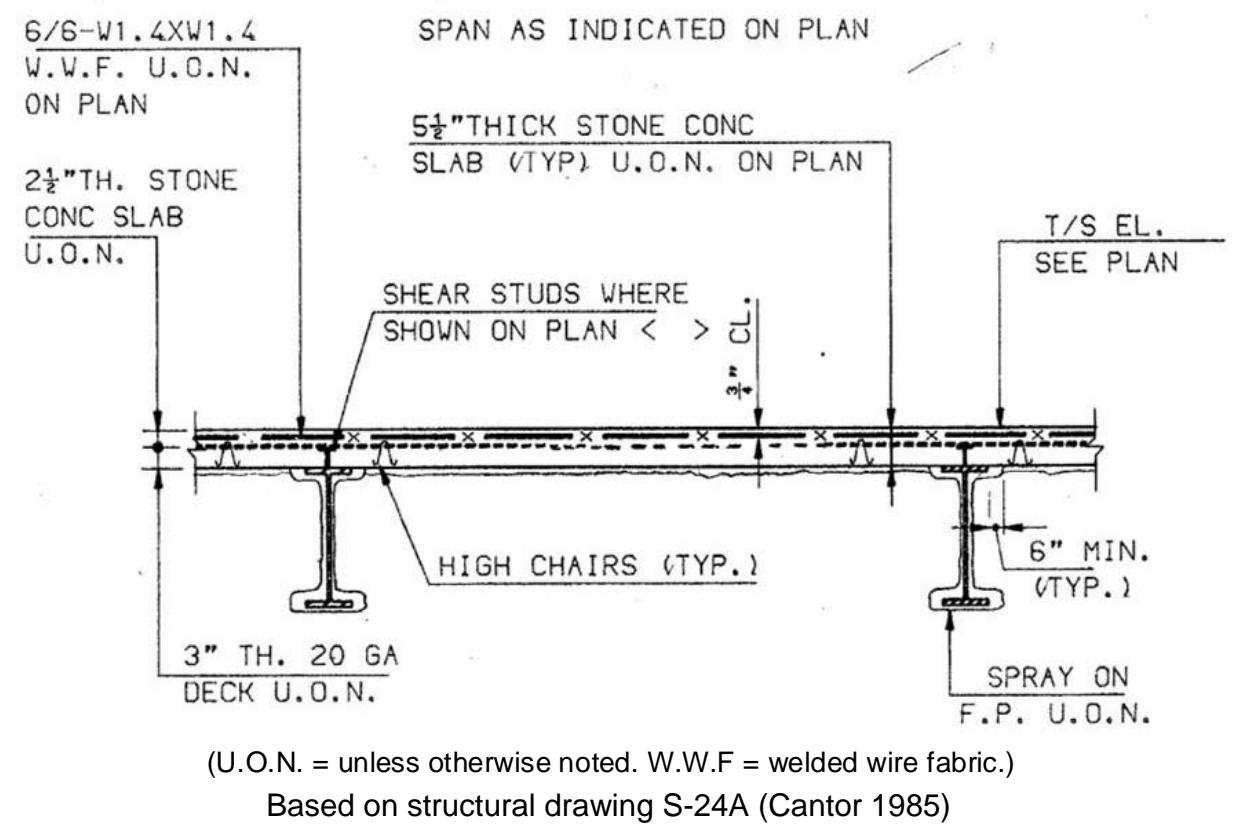

Figure 2-9. Typical composite floor construction detail (along strong direction).

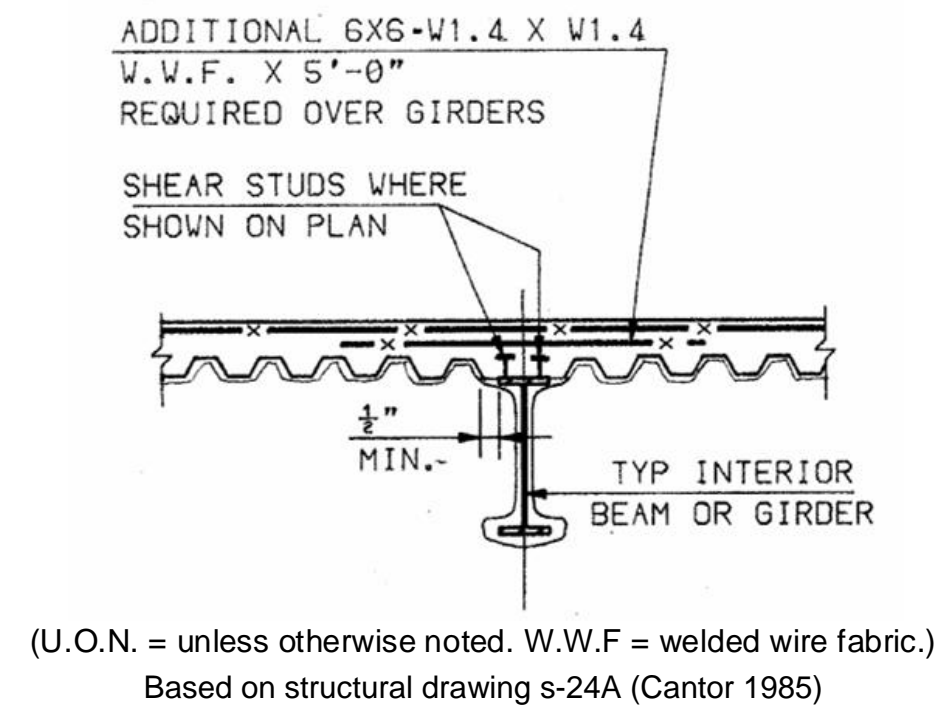

Figure 2-10. Typical composite floor construction detail (along weak direction). 


\subsubsection{Composite Concrete \& Metal Decking}

The primary feature required in modeling the composite slab was the different behaviors in tension and compression. This difference was primarily a result of the concrete behavior. Typical stress-strain behaviors for concrete in compression and tension are shown in Figure 2-11. The specified unconfined compressive strength for the concrete was $3.5 \mathrm{ksi}$ (24 MPa). However, concrete compressive strength has been found to increase significantly with age. Lange (1994) showed that the strength of concrete aged four years is approximately 40 percent higher than the strength at 28 days. As a result, the unconfined compressive strength for the WTC 7 concrete was estimated at approximately $4.9 \mathrm{ksi}$ (34 MPa). This compressive stress was reached at a strain of approximately 0.2 percent.

By comparison, the behavior in tension was initially elastic. However, at very small strains, a tensile stress of about 500 psi (3.4 MPa) was reached, at which time a tensile crack formed and the concrete could no longer support tension.

To offset the tensile deficiencies of concrete, reinforcement is added in structural applications to improve the tensile strength and damage tolerance. In this application, the concrete slab reinforcement was provided by the metal deck and wire mesh. The stress-strain behaviors of the metal deck and wire mesh are provided in Figure 2-12. By comparison, the strengths of the metal reinforcement were an order of magnitude higher than the concrete compressive strength and two orders of magnitude higher than the concrete tensile strength.

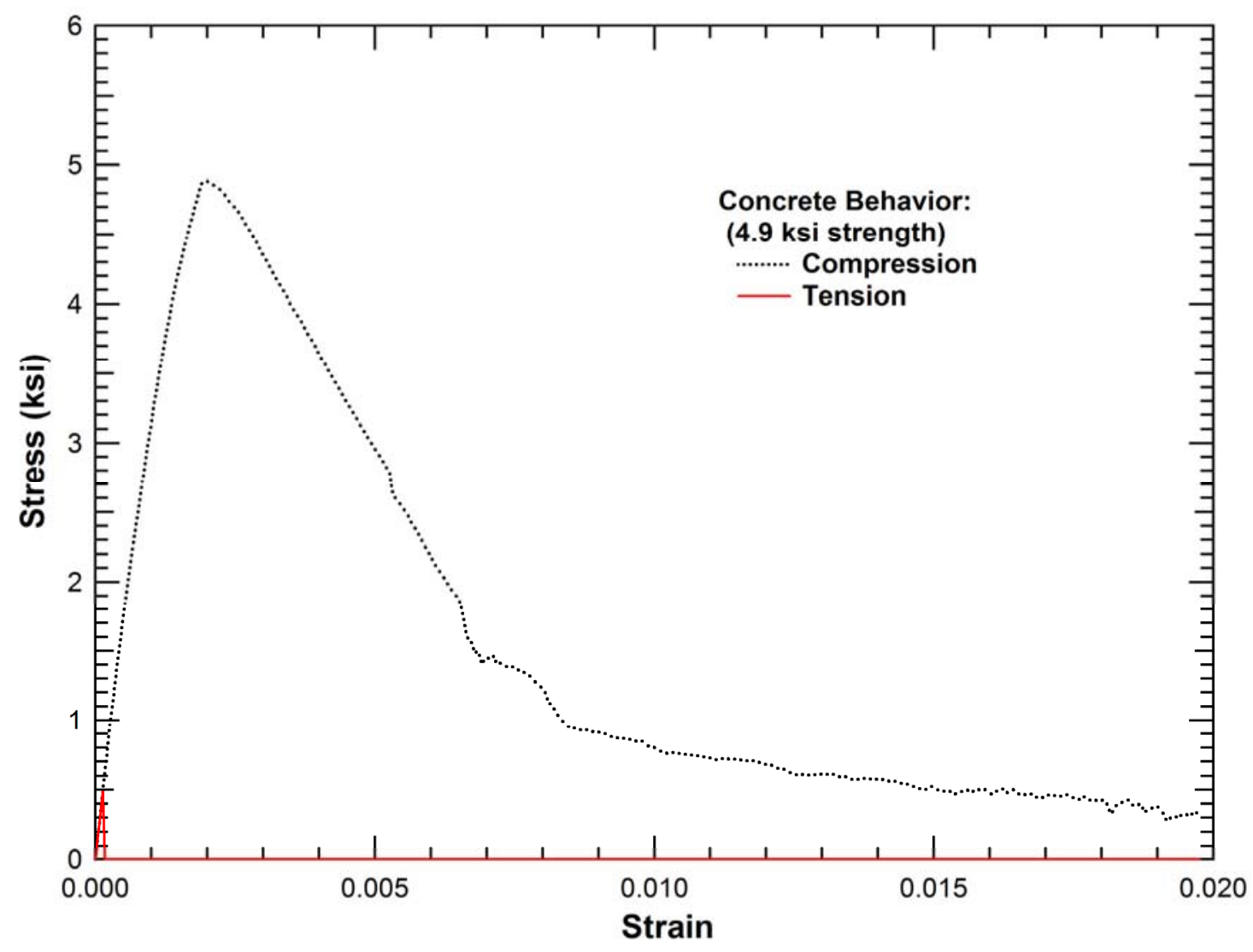

Figure 2-11. Concrete stress-strain behaviors in tension and compression. 


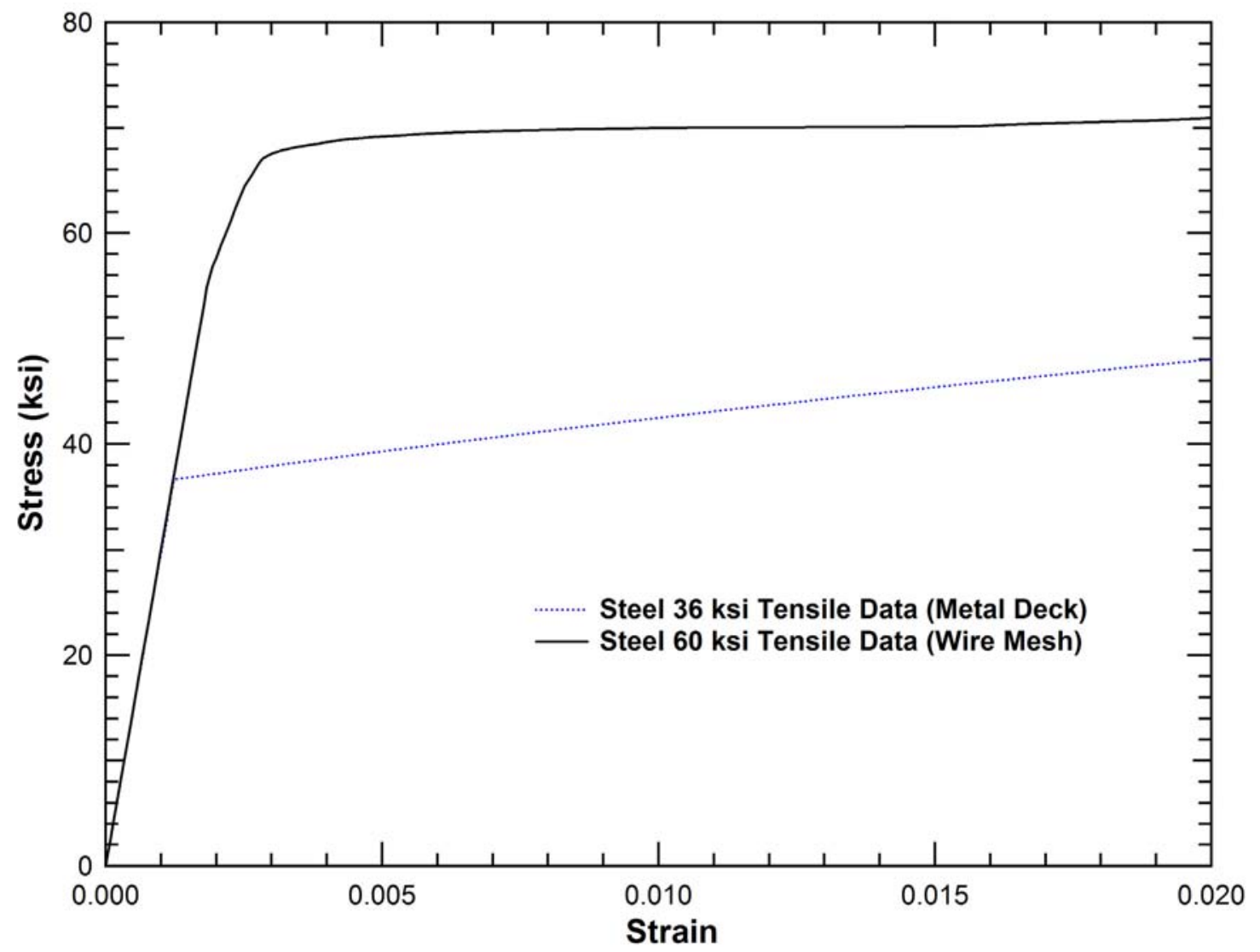

Figure 2-12. Stress-strain behaviors for the metal decking and wire mesh.

The constitutive model used in LS-DYNA for the composite floor slab was material type 124 (Mat_Plasticity_Compression_Tension). This model allowed the specification of unique tabular plastic stress-strain curves in compression and tension. The separate tension and compression curves for the composite slab were obtained by using the rule of mixtures, which provides average properties based on the volume fraction of the concrete and reinforcement.

The ratios of area of concrete, metal deck, and wire mesh in the strong direction (along the deck corrugation) of the composite slab were

- $A_{\text {conc }}=4.0$ in. $^{2} \quad$ This is the average concrete thickness per inch width

- $A_{d e c k}=0.062$ in. $^{2} \quad$ Equivalent decking area per inch width - strong direction only

- $A_{\text {wire }}=0.00467$ in. $^{2}$ Equivalent wire mesh area per inch width

The composite slab stress-strain curve in the strong direction is then developed according to the equation:

$$
\begin{aligned}
& \sigma_{\text {slab }}^{\text {Tension }}(\varepsilon)=\left\{\left[A_{\text {conc }} \sigma_{\text {conc }}^{\text {Tension }}(\varepsilon)+A_{\text {deck }} \sigma_{\text {deck }}(\varepsilon)+A_{\text {wire }} \sigma_{\text {wire }}(\varepsilon)\right] / A_{\text {total }}\right\} \\
& \sigma_{\text {slab }}^{\text {Comp }}(\varepsilon)=\left\{\left[A_{\text {conc }} \sigma_{\text {conc }}^{\text {Comp }}(\varepsilon)+A_{\text {deck }} \sigma_{\text {deck }}(\varepsilon)+A_{\text {wire }} \sigma_{\text {wire }}(\varepsilon)\right] / A_{\text {total }}\right\}
\end{aligned}
$$


The composite slab stress-strain curve in the weak direction would be developed by similar equations except that the contribution from the metal deck is not included since the stiffness of the deck in the direction transverse to the corrugation would be much less than that in the strong direction.

The plots of the composite curves developed for the strong and weak directions in both tension and compression are shown in Figure 2-13. LS-DYNA did not have a constitutive model that allowed both the different behaviors in tension and compression and the orthotropy in the strong and weak directions. Since the differences in tension and compression were significantly larger than the differences in the strong and weak direction, the average of the strong and weak directions for both tension and compression were used in the model. These average tension and compression stress-strain curves for the composite slab are indicated by the black curves in Figure 2-13.

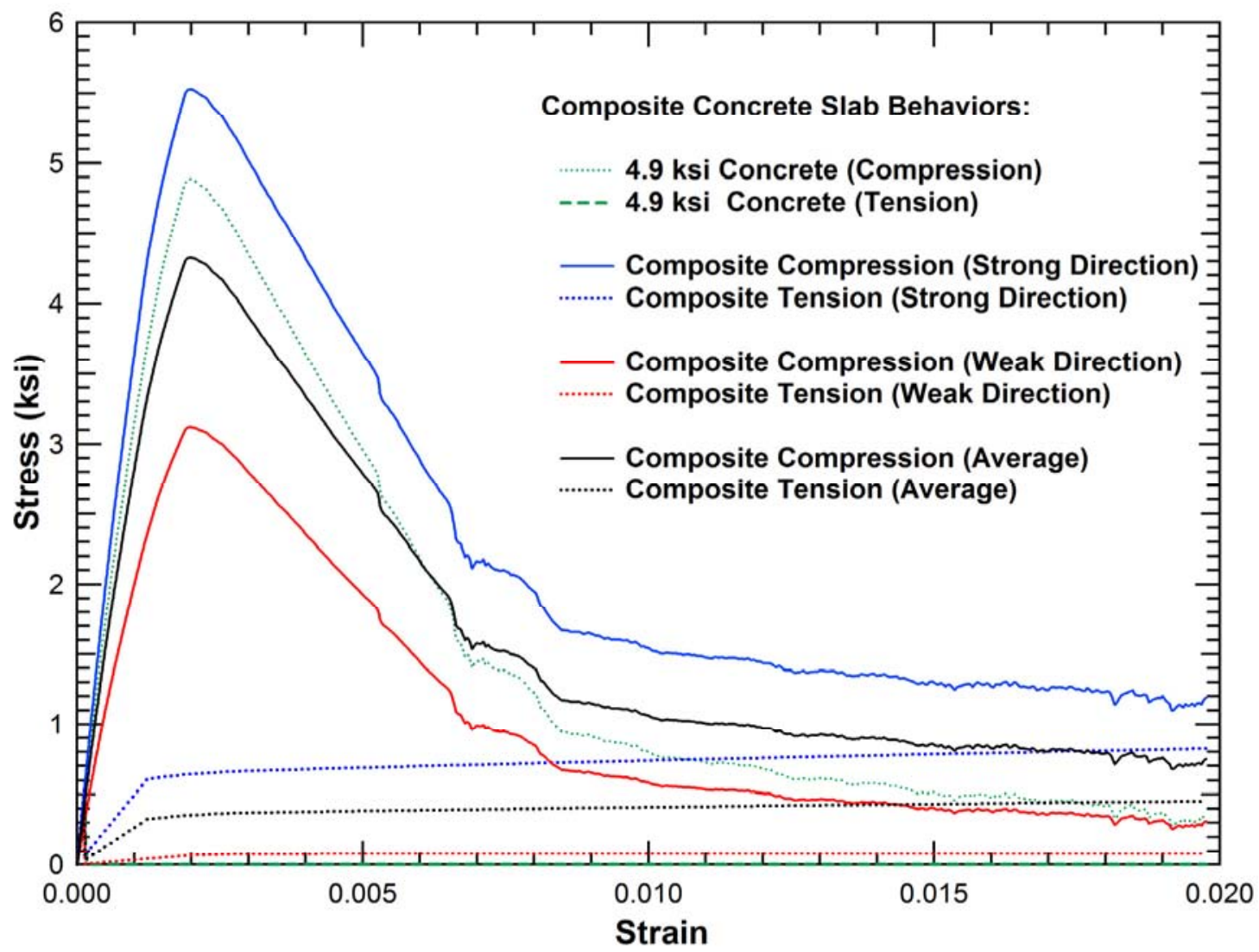

Figure 2-13. Composite floor slab curves in compression and tension.

The final stage of the slab constitutive behavior development was to generate a model for a material test specimen and simulate the behavior in uniaxial tension and compression. The calculated tensile and compressive behaviors for the composite slab are shown in Figure 2-14. The calculated stress-strain curves in Figure 2-14 reproduced the desired material behaviors shown by the average curves in Figure 2-13. 


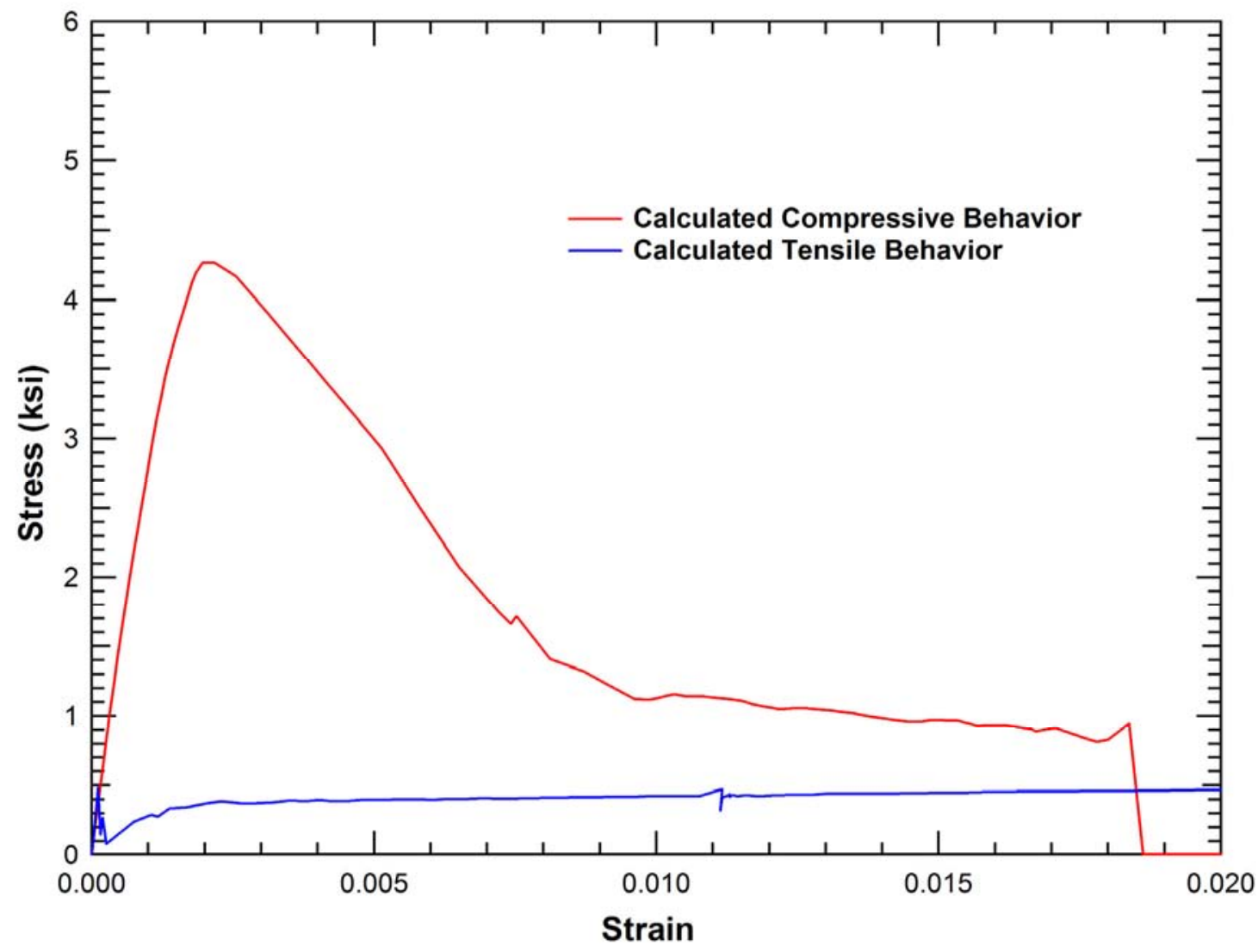

Figure 2-14. Calculated composite slab behaviors in tension and compression.

\section{$2.4 \quad$ FAILURE MODELS AND CAPACITIES}

To model the damage and sequence of failures in WTC 7 following the initial failure event, engineering failure models were used within the framework of the LS-DYNA finite element analyses. The approach to modeling failure was identical to that used in the aircraft impact damage assessment (NIST NCSTAR 1-2B) where material failure was calculated for each element based on the local state, including plastic strain and stress state. When the specified failure criterion in an element was exceeded, the element was eroded (deleted) from the calculation. The erosion of elements allowed for the propagation of failure through a structure.

Calculation of the failure of structural components was further complicated by the scale of the model. For the global collapse analyses of WTC 7, element sizes had to be a few inches on average to maintain a model size of approximately 3 million elements or on the order of 10 million degrees of freedom. At this resolution, the gradients around a fracture could not be accurately resolved, and the damage criteria required adjustment to obtain the appropriate strength and ductility of the structures. In the following section, the failure modeling techniques applied to WTC 7 are described. 


\subsubsection{Mesh Refinement Effects (Lessons Learned from WTC Tower Model Development)}

One of the significant modeling issues for the analysis of aircraft impact damage for the WTC towers was the effect of mesh refinement on the failure criterion for the steel components. The global impact analyses of the aircraft impacts into the WTC towers were very large analyses of complex structures and required the refinement of the model to be reduced significantly from the detailed component analyses. As the mesh refinement was reduced, it was important to ensure that the damage mechanisms and extent of impact damage were properly captured.

A preliminary example of the effects of mesh refinement on the response was introduced earlier in the analysis of the material tests on the WTC tower steels. Figure 2-1 showed both fine mesh and a coarser mesh (referred to as medium mesh) versions of the ASTM 370 rectangular tensile specimen for plate material. A comparison of the calculated necking behavior for the two specimen meshes immediately preceding failure is shown in Figure 2-15. The fine mesh was able to better resolve the strain gradients in the necking region, and as a result, had higher peak strain values at the same level of specimen displacement.

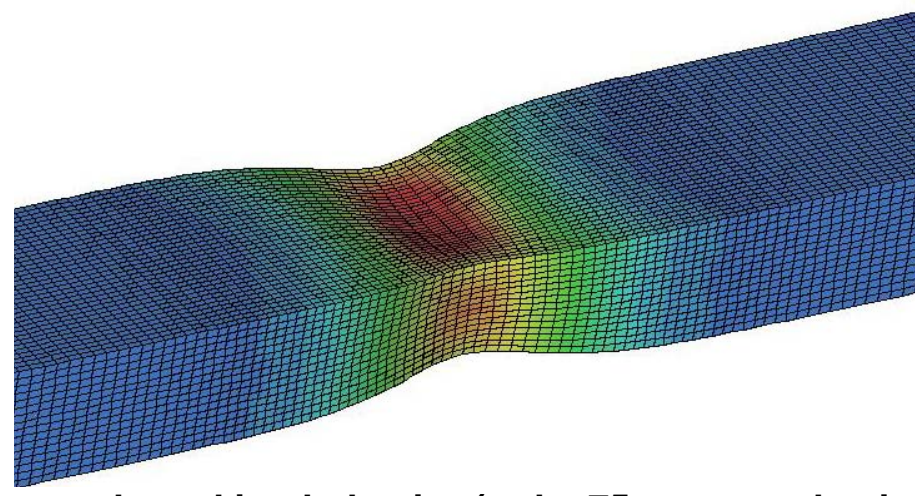

(a) Fine mesh necking behavior (red = 75 percent plastic strain)

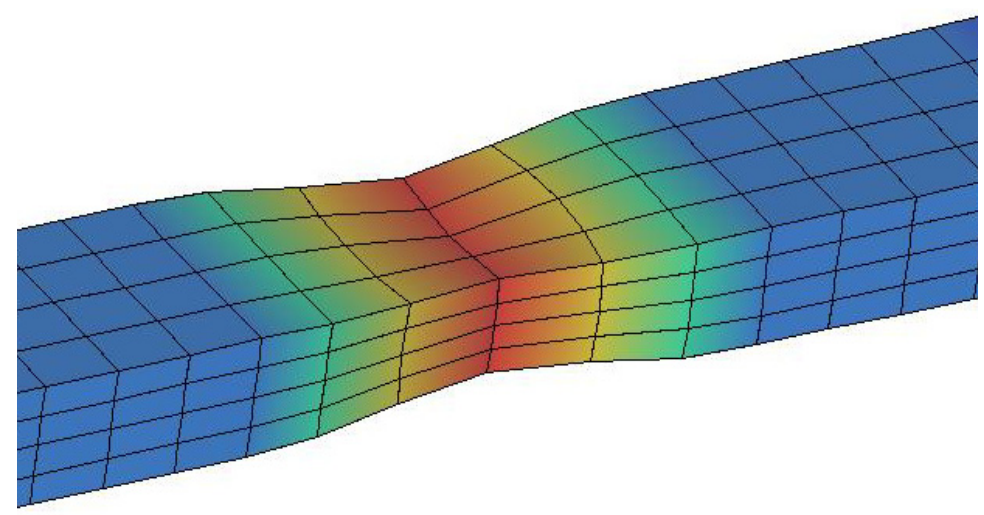

(b) Medium mesh necking behavior (red = 50 percent plastic strain)

Figure 2-15. Calculated necking response in the $75 \mathrm{ksi}(517 \mathrm{MPa})$ tensile specimen.

The effects of further reductions in mesh refinement required for global analyses was demonstrated with the ASTM 370 tensile test example used in this section. To most closely resemble the mesh and element types used in the global analyses, three full width shell elements were used to model the entire specimen 
gage section, as shown in Figure 2-16. This coarse tensile specimen model had a single stress and a single strain value across the specimen gage section and did not have sufficiently independent degrees of freedom to capture the localization that occurred during necking. To most closely match the behavior of the fine-mesh model, a failure strain of 0.18 was needed to model failure for this single shell element. Note that this closely matches the engineering failure strain of 0.20 for this material.

The calculated engineering stress-strain behavior obtained with the three different mesh resolutions (fine, medium, and coarse) is shown in Figure 2-17. In these calculations, a maximum plastic strain criterion was used, and the critical failure strain was shifted until each calculation failed at a value matching the average measured engineering failure strain. The corresponding critical plastic strains were 1.00 for the fine mesh resolution, 0.56 for the medium mesh resolution, and 0.18 for the coarse mesh resolution (shell element model).

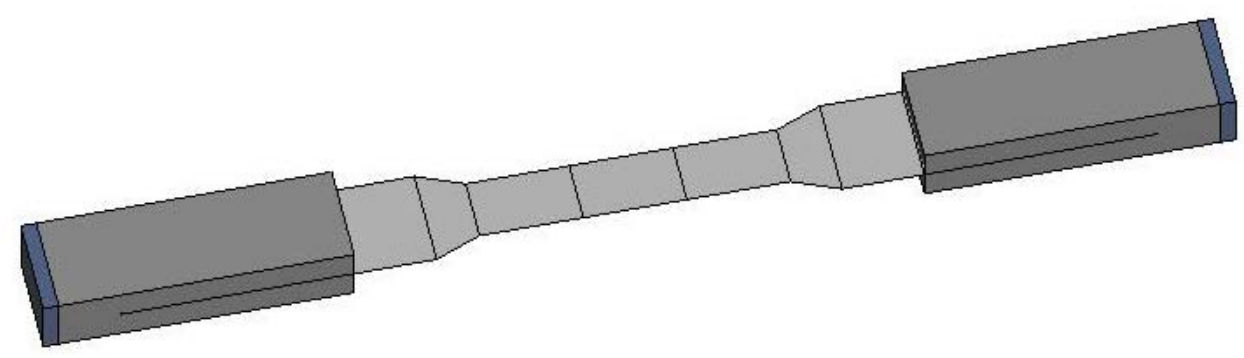

Figure 2-16. Coarse shell element mesh for the tensile specimen.

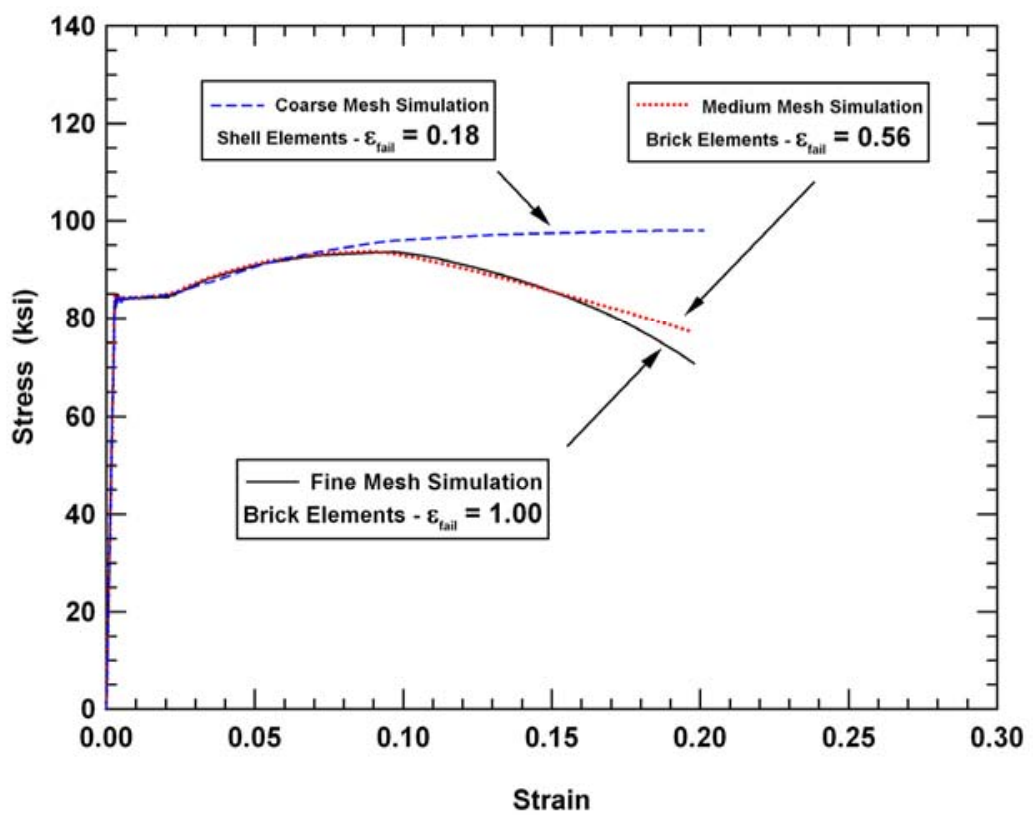

Figure 2-17. Mesh refinement effects in the calculated tensile test.

The WTC 7 global collapse model was developed with shell elements and a resolution corresponding to the coarse model shown in Figure 2-17. Therefore, the measured engineering elongation of the specimens was used for the critical strain. 


\section{$2.5 \quad$ REFERENCES}

ASTM. 2003. A 370 - 03a, Standard Test Methods and Definitions for Mechanical Testing of Steel Products, June 10, 2003.

Lange, D.A. 1994. Long-term Strength Development of Concrete, Journal of Materials in Civil Engineering, (ASCE), Vol. 6., No. 1, pp. 78-87. 
This page intentionally left blank. 


\section{Chapter 3 \\ LS-DYNA MODEL DEVELOPMENT}

\section{$3.1 \quad$ INTRODUCTION}

In this chapter, the LS-DYNA model developed for the WTC 7 collapse analyses is described. The model construction methodologies and details are included. Two analysis types were conducted in the investigation, one with a subassembly model and the other with a full model of the WTC 7 structure. Both models are discussed. In addition, an initialization procedure and its effect on both models are described. Computing requirements for the analyses are also included.

\subsection{METHODOLOGY OF MODEL CONSTRUCTION}

\subsubsection{Structural Drawings}

The building frame and composite floor models were developed based on the WTC 7 structural drawings by Irwin G. Cantor, P.C., Structural Engineers (Cantor 1985) Drawing numbers S-1 through S-28 and SBR-1 through SBR-8 were used. These drawing sets included floor framing plans, girder and column schedules, elevations, superstructure details, and slab and wall details. In addition, connection details were based on the fabrication shop drawings (see Chapter 2 of NIST NCSTAR 1-9).

\subsubsection{Preprocessing and Model Organization}

\section{TrueGrid Preprocessor}

The TrueGrid parametric mesh generation program (XYZ 2006) was used for the WTC 7 model development. The input data for TrueGrid includes a set of commands that define the geometries, materials, boundary conditions, and mesh properties. The output from TrueGrid is a complete LS-DYNA input data file for the desired analysis.

\section{Model Organization}

The WTC 7 model was built parametrically with TrueGrid in a semi-automated fashion. TrueGrid uses a command driven hierarchy that can be saved and organized into files. The model was organized much like a set of drawings with components feeding into subassemblies that were controlled by higher level subassemblies and finally by a top assembly. The same files could be used to generate the entire global model or a subset of the model, as in the two floor subassembly. Model generation was performed floorby-floor in single floor segments. The user specified which floors to generate in the top level assembly file. For the global model, all floors were specified. Figure 3-1 illustrates the file hierarchy used in the TrueGrid model of WTC 7. 


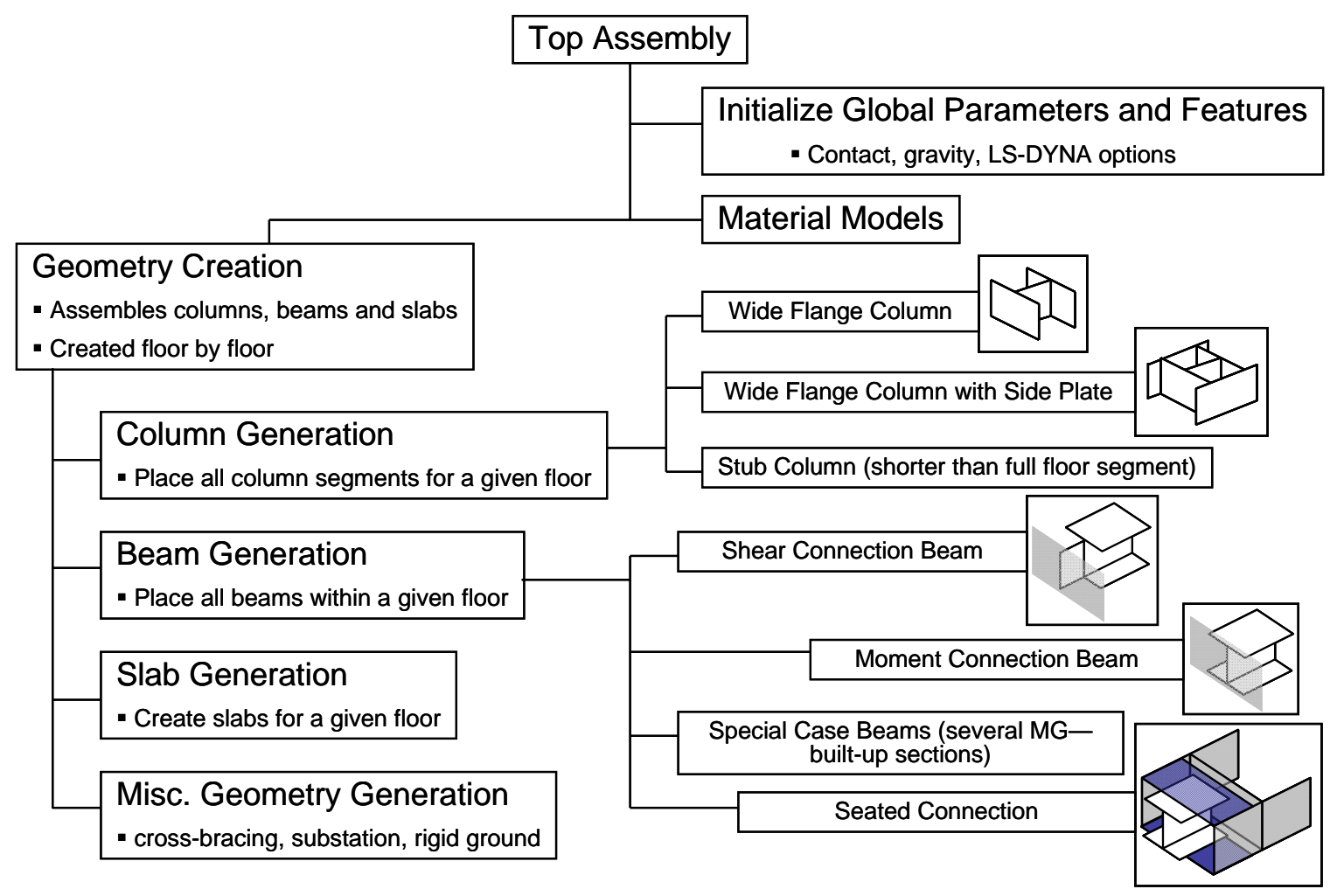

Figure 3-1. TrueGrid WTC 7 model generation hierarchy.

\subsubsection{Element Considerations}

The LS-DYNA element types used in the WTC 7 model are outlined in Table 3-1. The element formulations were selected based on efficiency and accuracy and were appropriate for this application. Furthermore, the same element formulations were used as in the WTC 1 and 2 aircraft impact analyses (NIST NCSTAR 1-2B).

Table 3-1. Element Types

\begin{tabular}{|l|l|l|l|}
\hline $\begin{array}{c}\text { Basic Element } \\
\text { Type }\end{array}$ & \multicolumn{1}{|c|}{$\begin{array}{c}\text { LS-DYNA Element } \\
\text { Formulation }\end{array}$} & \multicolumn{1}{|c|}{ Structure Modeled } & \multicolumn{1}{c|}{ Note } \\
\hline Solid & Constant Stress Brick & Discrete masses & $\begin{array}{l}\text { LS-DYNA solid type 1, single } \\
\text { integration point, 8-nodes, used only } \\
\text { as rigid in this model (i.e. no } \\
\text { deformation or stresses developed) }\end{array}$ \\
\hline Shell & Belytschko-Tsay & $\begin{array}{l}\text { Beams, columns, slabs, } \\
\text { connections }\end{array}$ & $\begin{array}{l}\text { LS-DYNA shell type 2, 4 } \\
\text { integration points by default, 4- } \\
\text { nodes }\end{array}$ \\
\hline Beam & $\begin{array}{l}\text { Hughes-Liu with cross } \\
\text { section integration }\end{array}$ & $\begin{array}{l}\text { Cross bracing, truss } \\
\text { diagonals, penthouse } \\
\text { structure }\end{array}$ & $\begin{array}{l}\text { LS-DYNA beam type 1, 2 nodes per } \\
\text { beam element, extensive cross- } \\
\text { section database available }\end{array}$ \\
\hline
\end{tabular}


One of the significant requirements in developing the global model was to minimize the model size while keeping sufficient fidelity to capture deformations and damage. The limitation was a model size that could be run in a reasonable amount of time with the available computer system.

The WTC 7 models were constructed mainly with shell elements. Shells were used to model beams, girders, columns and the slabs. The basic modeling methodology and characteristic element lengths were based on the models developed during the WTC 1 and 2 impact analysis. Typical shell element dimensions were between 0.15 and $0.30 \mathrm{~m}$ (6 and $12 \mathrm{in}$ ). Unlike the WTC 1 and 2 models, where higher refinement could be localized, simulating the global response of WTC 7 required the same level of refinement throughout the model.

\subsubsection{Contact Considerations}

In the WTC 7 model, contact between interacting elements was controlled with the LS-DYNA automatic contact algorithm, *CONTACT_AUTOMATIC_SINGLE_SURFACE. The soft constraint option (SOFT $=1$ ) was used in the contact model and was well suited to deal with the range of materials in the model. Contact within LS-DYNA was treated much like a spring between contacting segments. A restoring force, whose formulation depends on the SOFT option employed, was imposed on the contacting nodes to counteract penetrations between materials. For SOFT $=1$, the restoring force was based on nodal mass and time step. Other optional specifications included friction and initial penetration tracking (IGNORE=1). A coefficient of static and dynamic friction of 0.3 was specified in the model.

Several tied interfaces were used to connect components in the model. An edge-to-surface contact (*CONTACT_TIED_SHELL_EDGE_TO_SURFACE) was used to connect beam ends to other beams and columns. Tied surface-to-surface contact definitions

(*CONTACT_TIED_SURFACE_TO_SURFACE) were used to connect column ends to splice plates and other structures, as well as to connect clips and seats to structural members. Examples of the tied contact connections are included in the following section, Connection Modeling.

Offset (_OFFSET) and initial penetration tracking (IGNORE=1) options were used for all tied contacts. The offset option allowed contact between parts that were close but not necessarily in intimate contact, which is common in shell element models where parts are typically spaced by half a shell thickness to avoid penetrations in automatic contact definitions.

Special care had to be taken in grouping the components specified in the contact definitions to avoid specifying conflicting or doubly defined contacts. If such conflicting cases occur, numerical instability usually results.

\subsection{CONNECTION MODELING}

Connection modeling was an important facet of the WTC 7 model development. There were many types and sizes of connections in the model. Much effort was spent to accurately capture the mechanical properties and failure characteristics of the various connection types. The following sections describe the connection types considered and how they were represented in the LS-DYNA model. 


\subsubsection{Beam and Girder Framing}

Most connection types in the model were floor framing connections (i.e., beams to girders and girders to columns). Shear connections were used at all interior floor framing connections. There were six shear connection types: fin (F), header (H), knife (K), seated web clip (SWC), seated top clip (STC), and seated top plate (STP) (see NIST NCSTAR 1-9, Section 2.4.3). Fin, header, and knife connections connected the interior floor beams to the girders, and girders to interior columns except for the seated connections at Columns 79 and 81. Seated connections were used to connect the floor beams and girders to the exterior columns and the north side of Column 79 and the south side of Column 81. Moment connections were used in the exterior framing and portions of the core framing at Floors 5 and 7 as part of the lateral load resisting system.

Given a target element size of $0.15 \mathrm{~m}$ to $0.30 \mathrm{~m}$ (6 in. to $12 \mathrm{in}$.) within the LS-DYNA model, it was not possible to explicitly model the connections in fine detail. The connections were modeled with a simplified geometry, and connection material models were developed for the expected load capacity and ductility. Different connection models were developed for the actual construction geometry. Beam and girder connection models and their placement in the LS-DYNA model were based on information that NIST obtained from WTC 7 fabrication shop drawings and structural drawings. The framing connections included in the model are described in the following subsections.

\section{Fin, Knife, and Header Connections}

This section explains the modeling methodology for three distinct types of shear connections: fin (F), header $(\mathrm{H})$ and knife (K). A schematic of each type is shown in Figure 3-2.

In the LS-DYNA model, fin connections were developed first. Fin connections were grouped by the depth of the beam web, which generally determined the number of bolts in the fin connection.

A series of component calculations were performed to develop fin connection models for the depth-based groupings. The idealized strength and ductility of fin connections (also known as shear tab connections) were obtained from a connection spring model developed by Sadek et al. (2008). The spring model output by Sadek et al. (2008) included force-deflection results for the fin connection, based on the number of bolts. A simple LS-DYNA beam-column connection model was developed, as shown in Figure 3-3.

The LS-DYNA fin models were calibrated to match the connection behaviors obtained from the spring model provided by Sadek et al. (2008). The appropriate connection strength and ductility were obtained by adjusting the material behavior and failure strain for the connection tab. A comparison of forcedeflection curves from the resulting shear model along with the spring model for the set of connections considered is shown in Figure 3-4. A similar comparison of connection energy capacity is provided in Figure 3-5. Good agreement of the spring and LS-DYNA fin models was obtained. 
The knife and header connections were developed in a similar manner to that described for the fin connection. Based on the shop drawing specifications, a spreadsheet was developed to assist in the grouping task, which detailed the locations and connection types along with horizontal and vertical load capacities for each connection. Critical geometry properties such as weld size and plate thickness were specified as well.

A grouping strategy was devised to map the information within the existing framework of the LS-DYNA model based on section depth. First, the spreadsheet connection information was sorted into groupings by section depth (W12 through W36) then divided into subgroups by connection type (F, H, or K). The groupings revealed that horizontal and vertical failure strengths were dependent on the geometric features of the connections. All horizontal and vertical load capacities within a group were normalized by geometric features (weld or plate thickness, as appropriate) and averaged to formulate a standard,
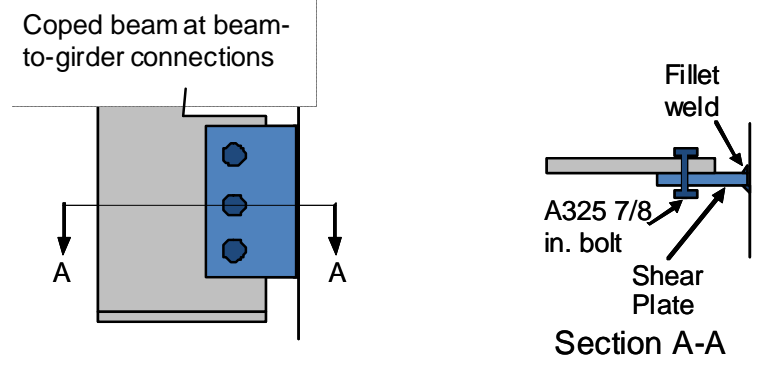

a) Fin (F) connection
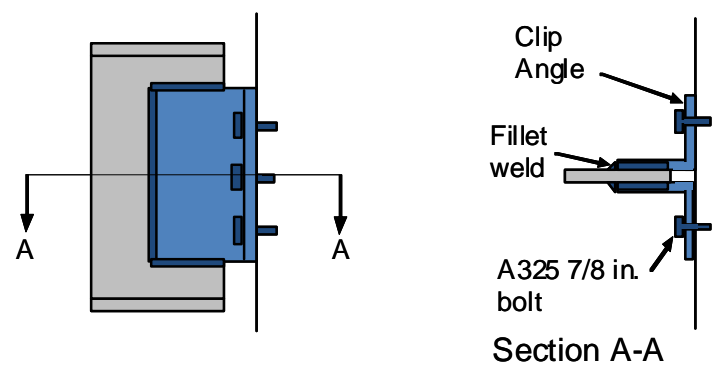

b) Header $(\mathrm{H})$ connection
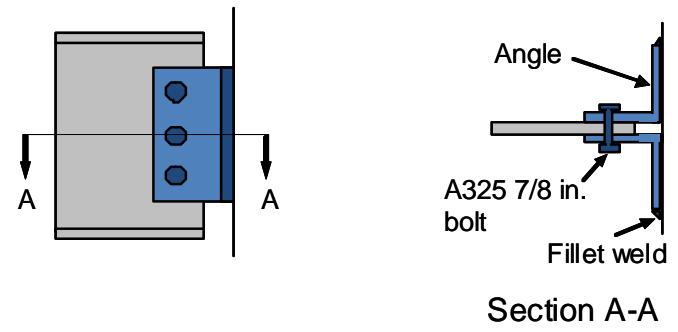

c) Knife (K) connection

Based on fabrication shop drawings (Frankel 1985)

Figure 3-2. Fin, header, and knife shear connection schematics. 
normalized strength for each group. A coefficient of variation of 0.3 was used as a guideline to indicate an appropriately tight grouping of connection strengths. Outliers not conforming to the grouping strategy were handled separately to obtain the correct strength. Shear connection models were generated using the same methodology for approximately 20 unique groups. To obtain the original, non-normalized strength of a given connection in the WTC 7 model, the geometric parameter specific to each connection was input at each location and used as a multiplier for that connection.

The model shown in Figure 3-3 was applied for all fin, knife, and header connections and was used to develop the specific connection properties for the connection groupings. During the component analyses, horizontal capacity was calibrated first by pulling on the beam and loading the shell element-based connection in tension. A discrete element was added to achieve a vertical load capacity equivalent to the shear capacity of each connection. The discrete element was located across the web of the shear tab to provide vertical support while contributing minimally to horizontal capacity, as shown in Figure 3-6. The discrete element, which appears as a spring in the model visualization, has an elastic-perfectly-plastic behavior with an ultimate load calculated as the difference between the actual shear capacity of the connection and the shear capacity based on analyzing the shear model alone.

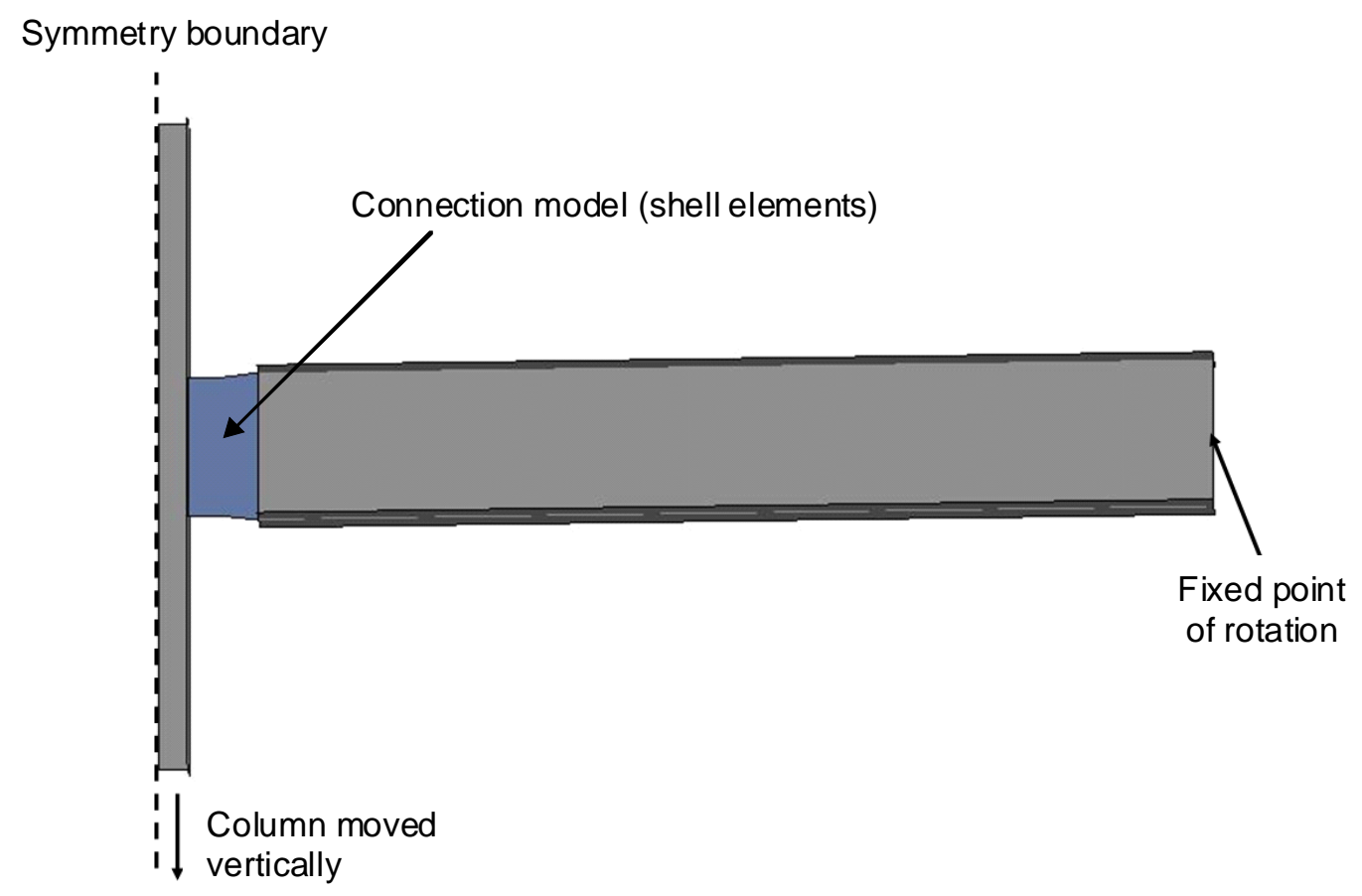

Figure 3-3. Component model used to develop the LS-DYNA fin connection model. 


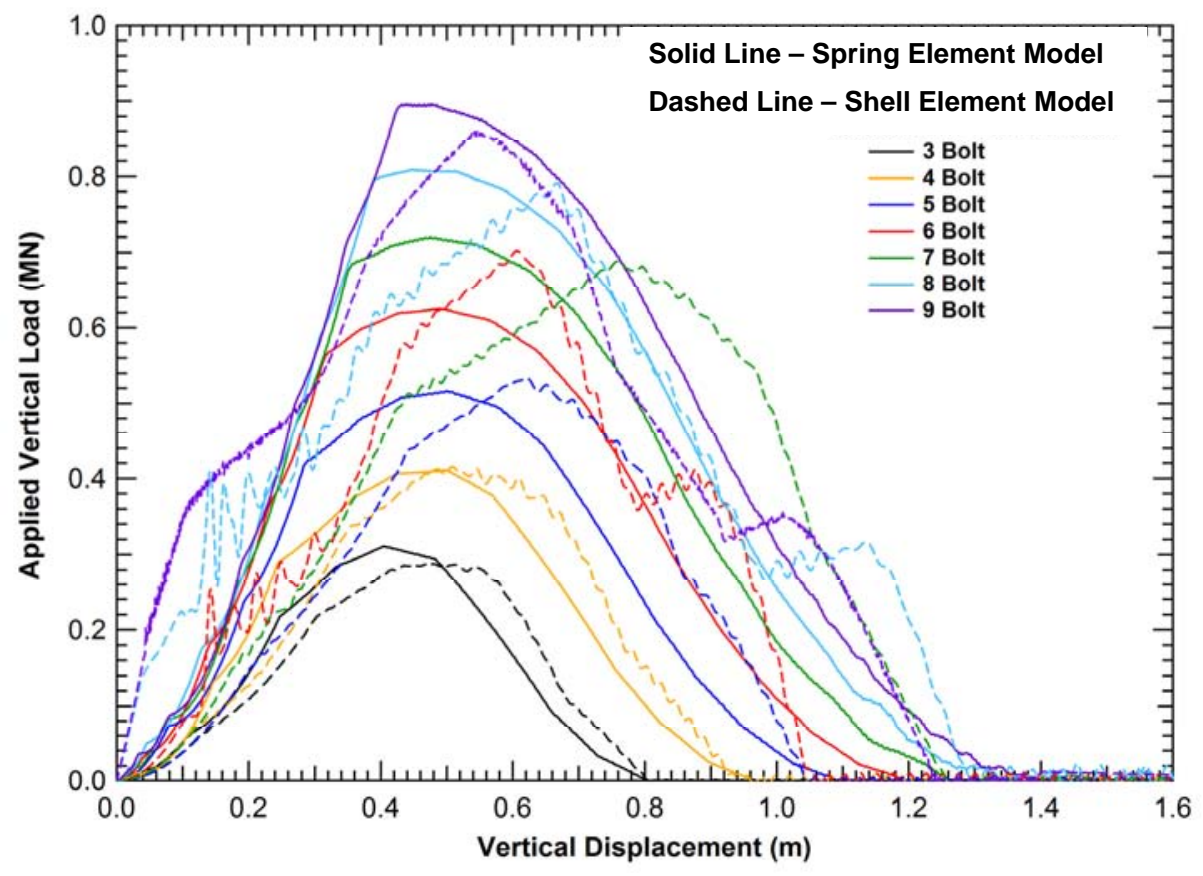

Figure 3-4. Spring and shear model force-deflection behaviors for fin connections with various numbers of bolts.

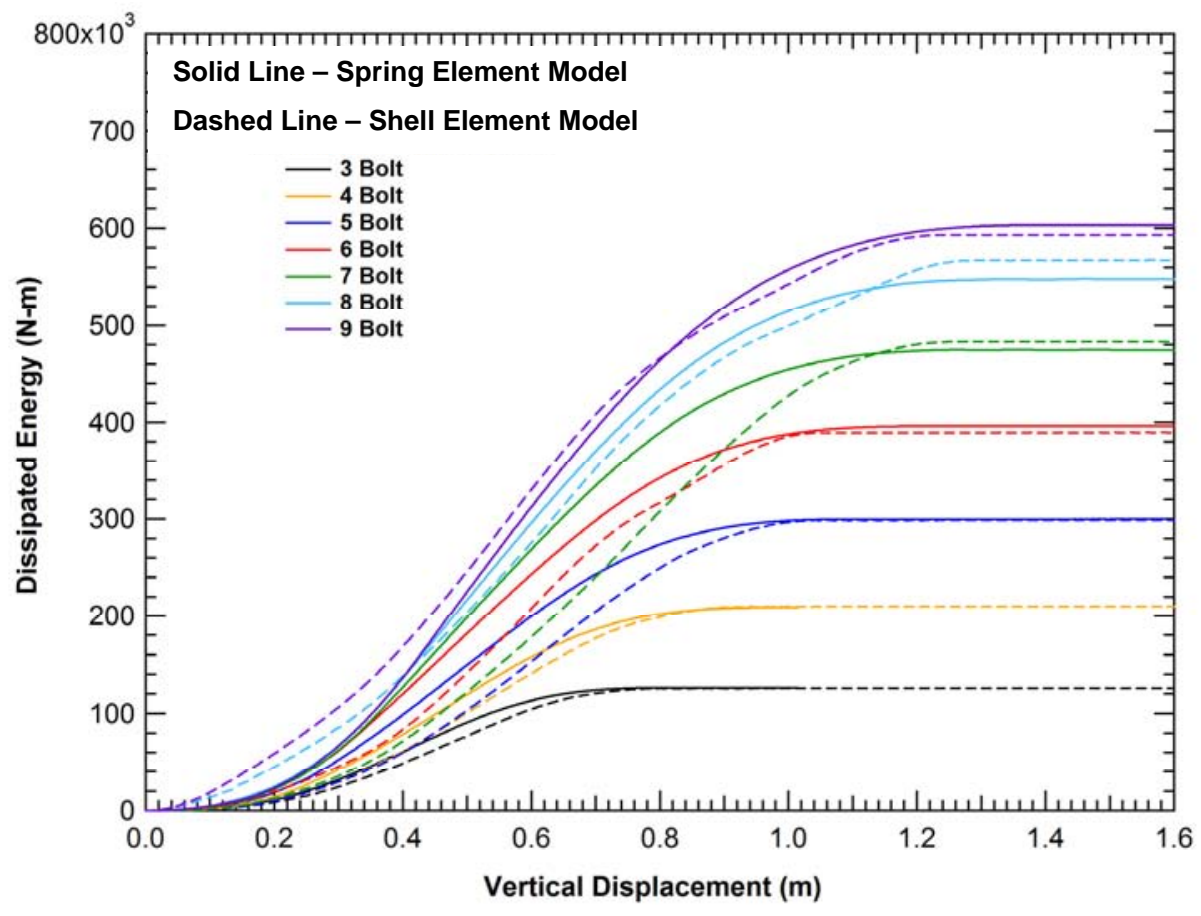

Figure 3-5. Comparison of the fin connection spring and shear model energy capacity. 


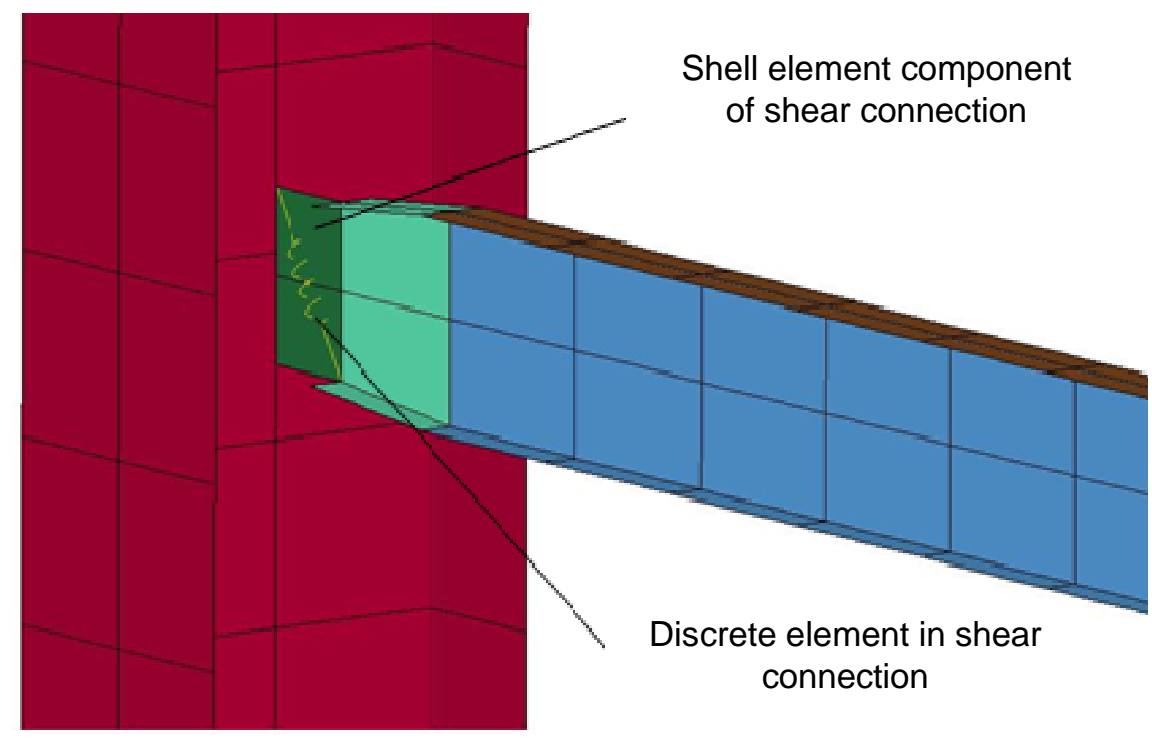

Figure 3-6. Generic LS-DYNA model of shear connection.

After developing models for all of the shear connection groupings in LS-DYNA, a comparison was performed between the LS-DYNA and ANSYS models. The ANSYS model used a different approach to modeling the connection failure mechanisms with the use of beam and break elements (NIST NCSTAR 1-9, Chapter 11). The comparison showed good agreement for selected connections, which increased confidence in both of the separately developed modeling approaches.

\section{Seated Top Plate (STP) Connections}

The STP connections connected the interior girders and beams to exterior columns. A schematic of a STP connection is shown in Figure 3-7. The connections included plates welded between the column flanges above and below the framing member. During construction, the beam was bolted to the plates with two $7 / 8$ in. A325 bolts per plate. The shear force-deflection behavior of an individual bolt is shown in the figure as well. The geometry varied slightly in the actual details for north/south and east/west bearing connections. In the model, the same basic geometry was used to approximate both.

The STP connection model developed for LS-DYNA is shown in Figure 3-8. It included the plates above and below the beam, which provided vertical constraint. The plates were attached to the columns with an edge-to-surface tied interface. Separate sliding contact definitions were used for bearing connections to avoid conflicts with the main sliding contact definition and the required tied contact between the plates and columns. Sliding contact was specified between the beams and plates.

Bolts in the LS-DYNA model were represented with discrete elements. The properties of the discrete elements were tailored to match the bolt specifications in the actual construction. Each bolt had a 35 kip $(156 \mathrm{kN})$ yield and $45 \mathrm{kip}(200 \mathrm{kN})$ failure load in shear. Maximum displacement at failure was $0.45 \mathrm{in}$. $(0.011 \mathrm{~m})$ in shear. A component model was developed and tested with respect to the predicted behavior. Figure 3-9 shows the resulting horizontal load and connection energy capacity.

Examples showing STP connections and shear connections along the building perimeter are shown in Figure 3-10 and Figure 3-11. 


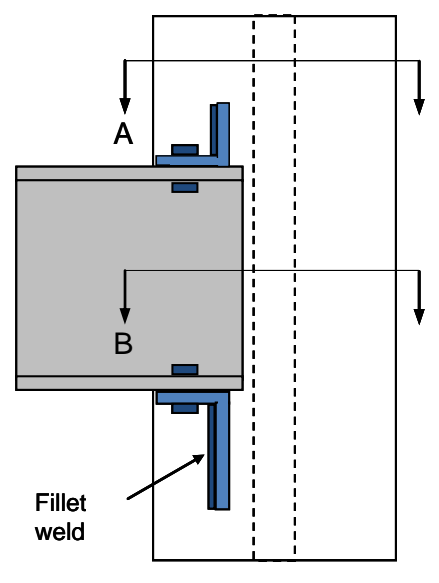

Elevation View

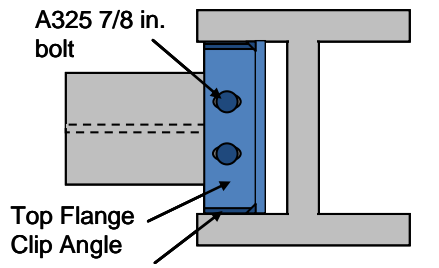

Fillet weld

Section A-A

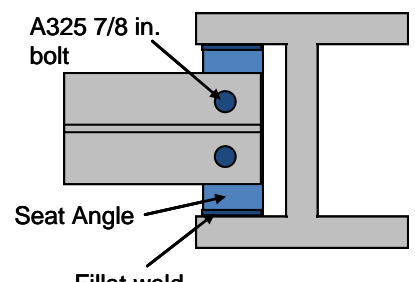

Fillet weld
Bolt Strength

- $45 \mathrm{~K}$ Shear capacity / bolt

-Relatively ductile

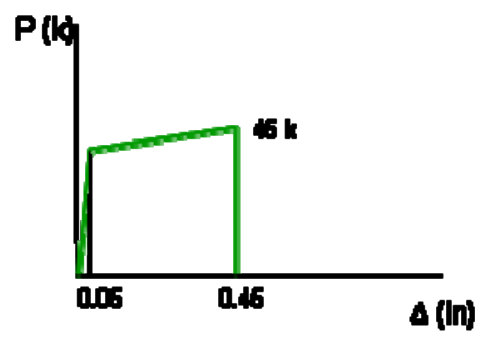

$79 \mathrm{~h} . \mathrm{A305}$ bolk h where

Section B-B

Based on structural drawings (Frankel 1985)

Figure 3-7. Schematic of north/south STP connection at exterior columns.

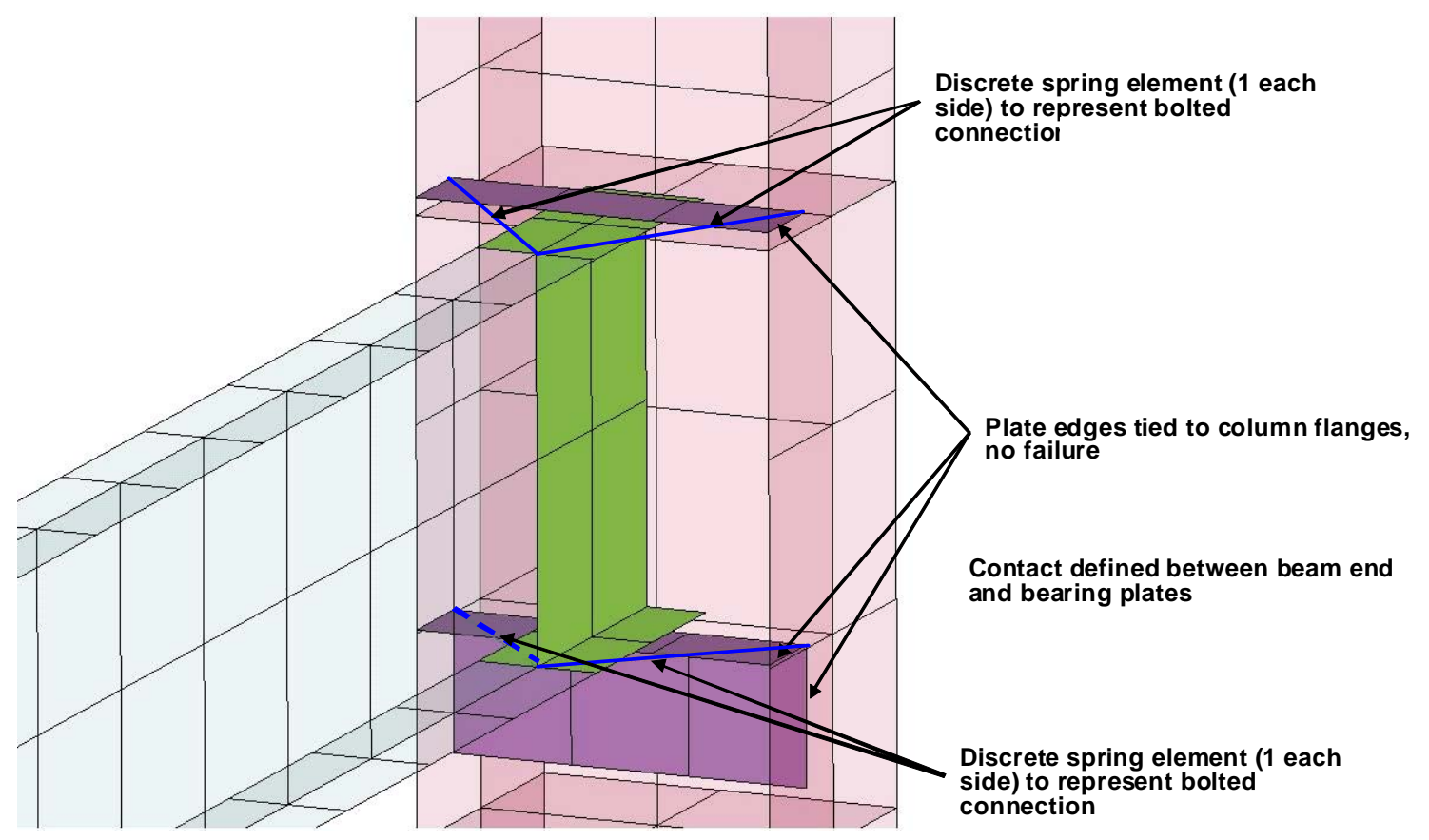

Figure 3-8. STP connection model overview. 


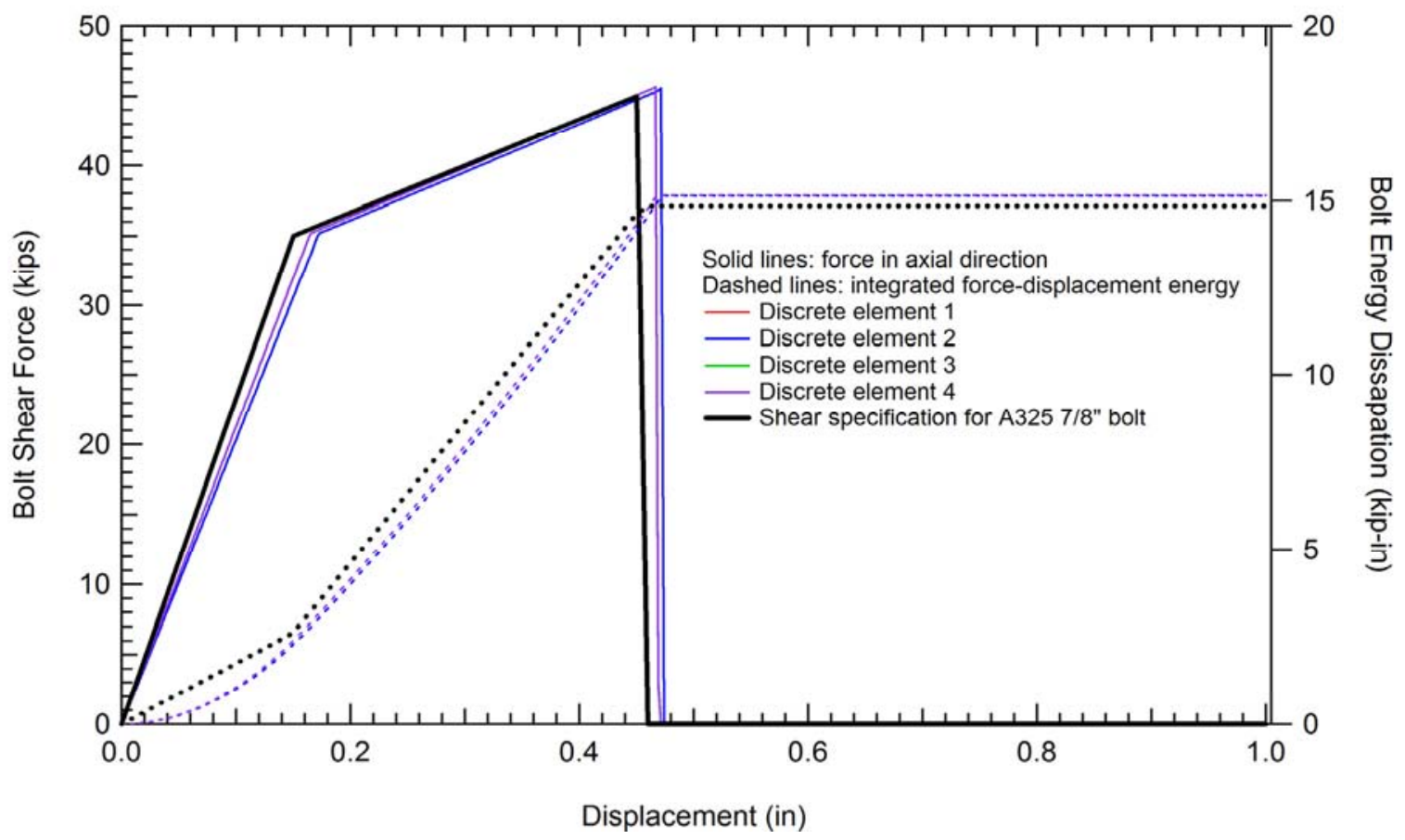

Figure 3-9. STP connection model; horizontal connection force and energy characteristics.

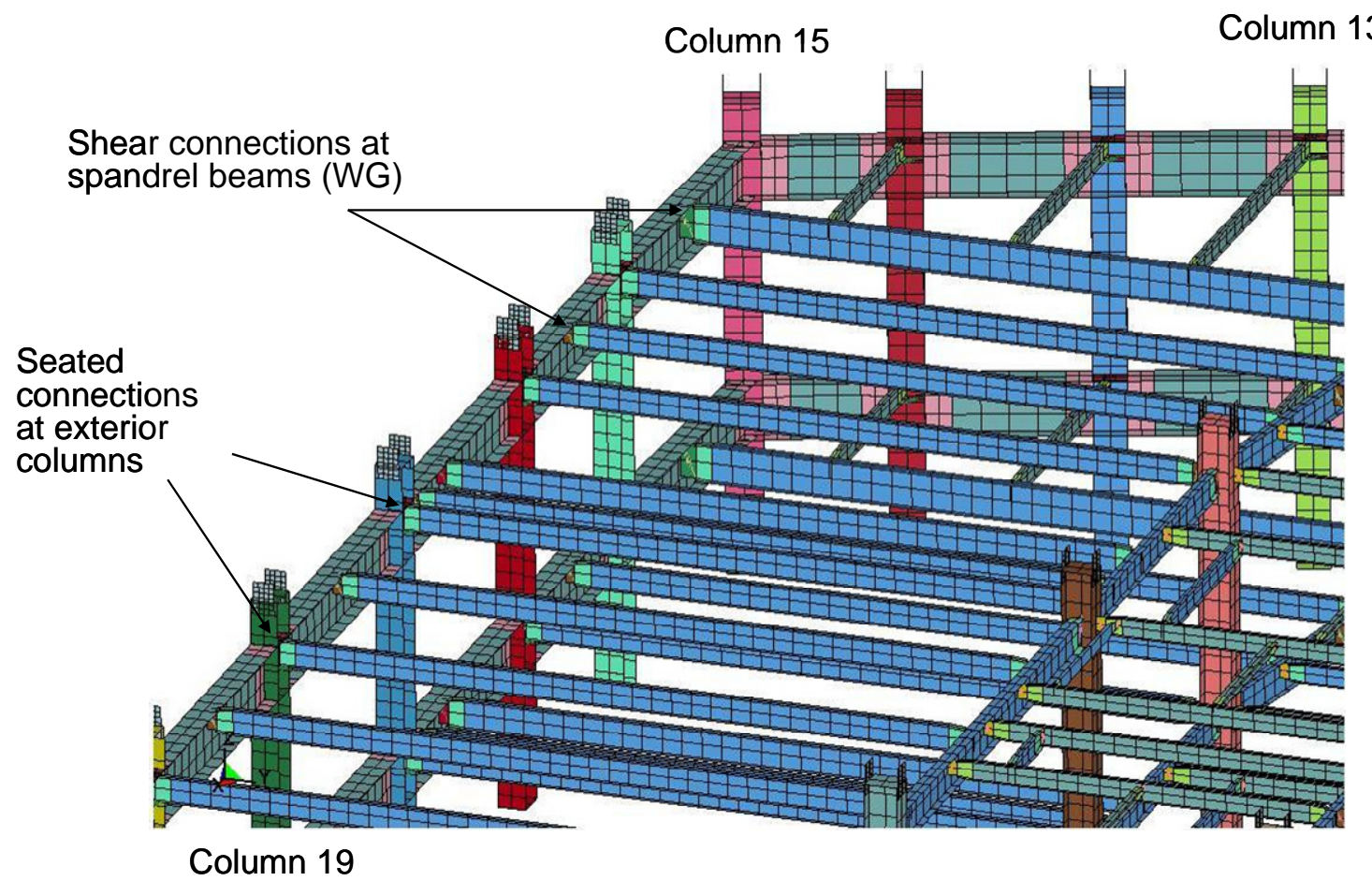

Figure 3-10. STP connection in global model, view of southwest corner above Floor 9. 


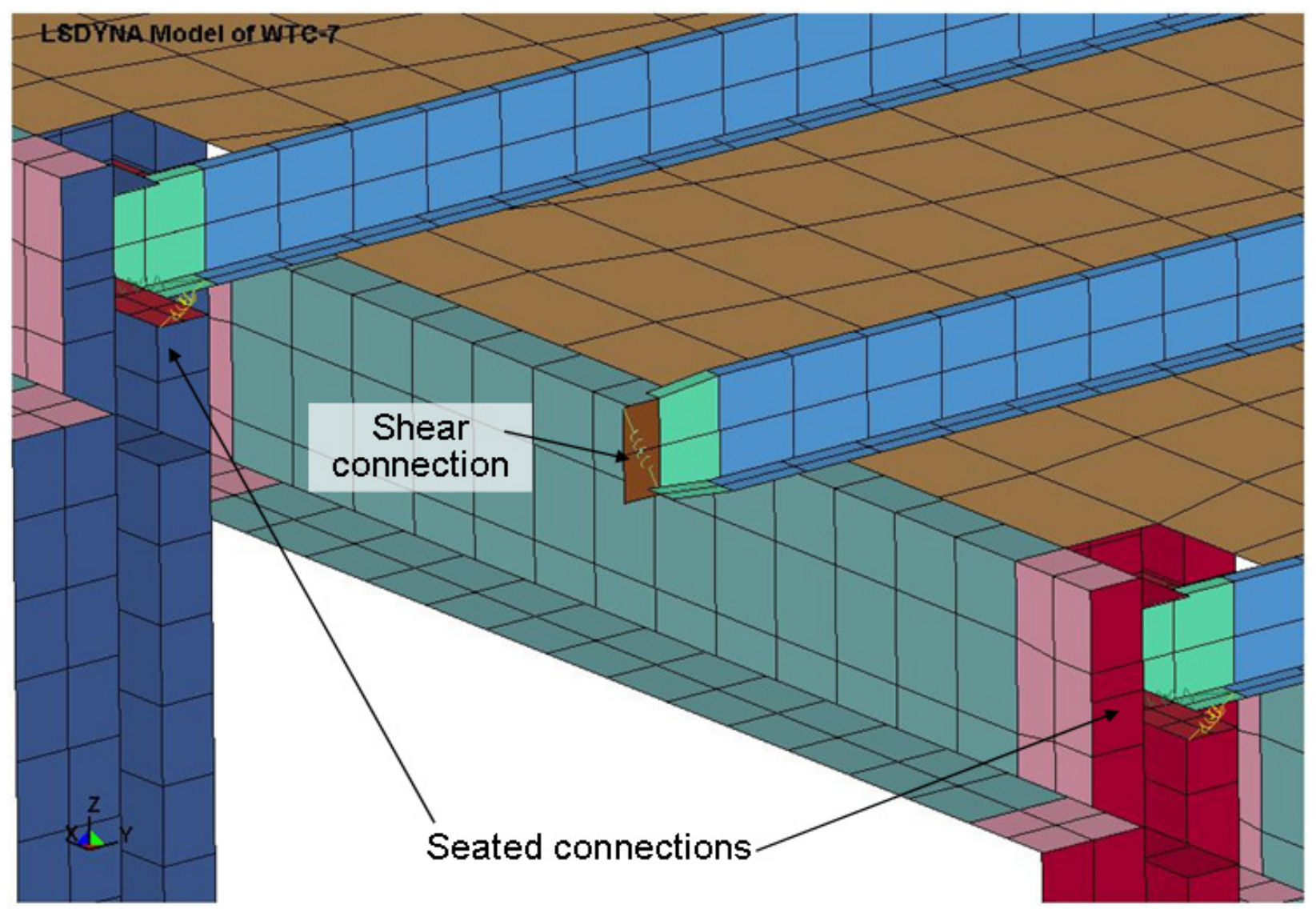

Figure 3-11. STP connection in global model, bottom view at Floor 8 on south face.

\section{Seated Top Clip (STC) Connections}

According to the shop drawings and photographic evidence of the building construction, the girders that framed into the north side of Column 79 and into the south side of Column 81 were connected with an STC connection. A schematic of the Column 79 connection is shown in Figure 3-12. The connection had a seat with a stiffener plate under the girder, which constrained vertical motion of the girder, and an angle clip above the girder. The four bolts provided lateral restraint during construction until the floor beams were connected to the girder. The seated connection at Column 81 was the same as that for Column 79, except for the angle of the girder axis relative to the column.

In the model, seat and clip plates, constructed with shell elements, were tied to the column elements and discrete bolt elements. The same A325 force-deflection properties for the bolts and the same contact strategy as with the STP connections were used. Models of the Column 79 and Column 81 seated connections, which had slightly different geometry, are shown in Figure 3-13 and Figure 3-14. 

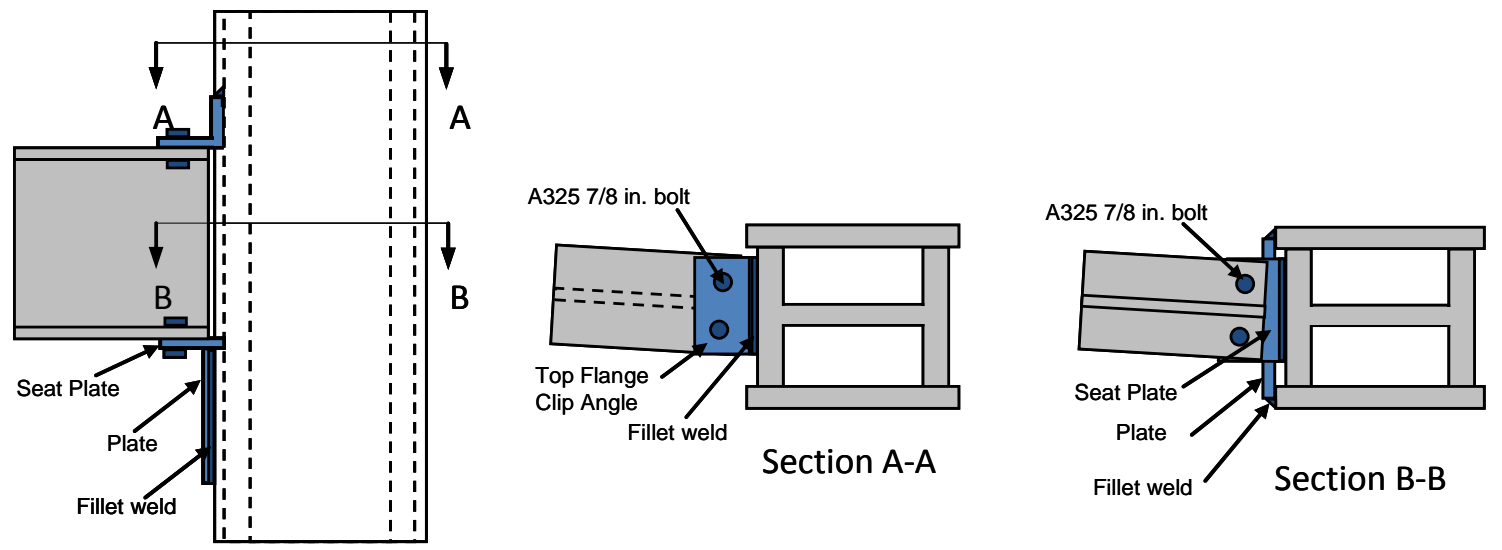

Elevation View

Based on structural drawings (Frankel 1985)

Figure 3-12. Schematic of unstiffened seat connection at Column 79.

\section{Column 79 seated connection}

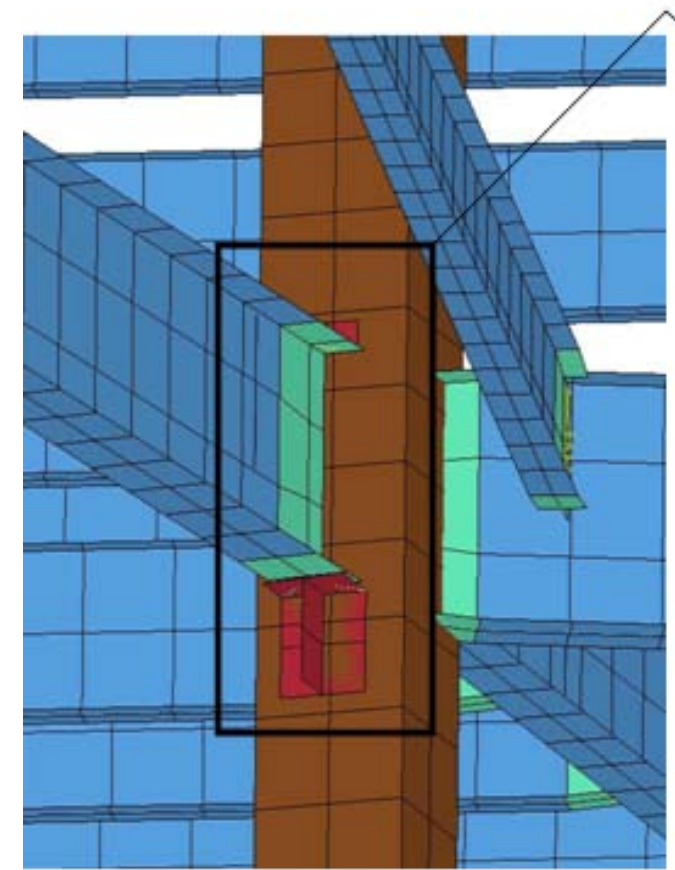

From below

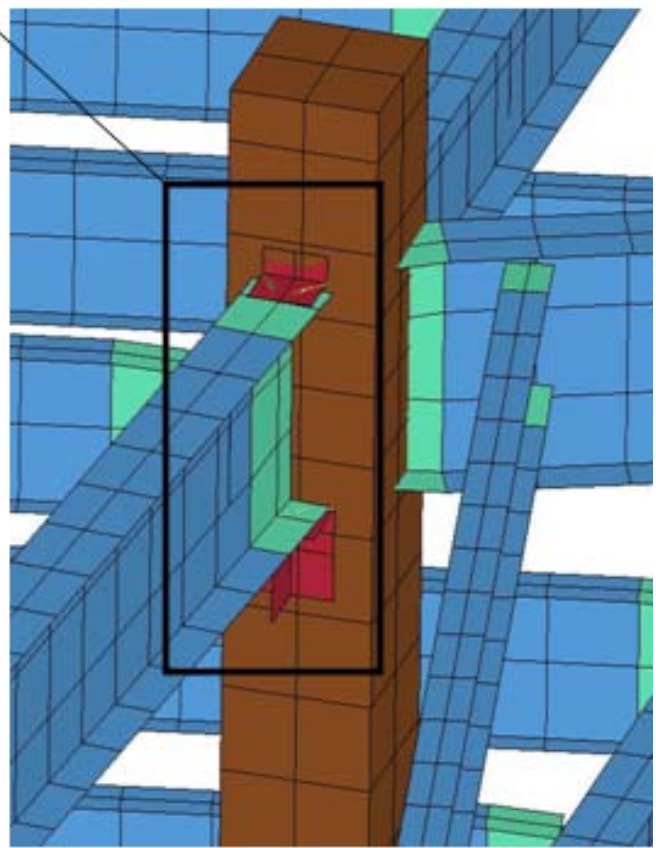

From above

Figure 3-13. Seat connection in global model, Column 79. 


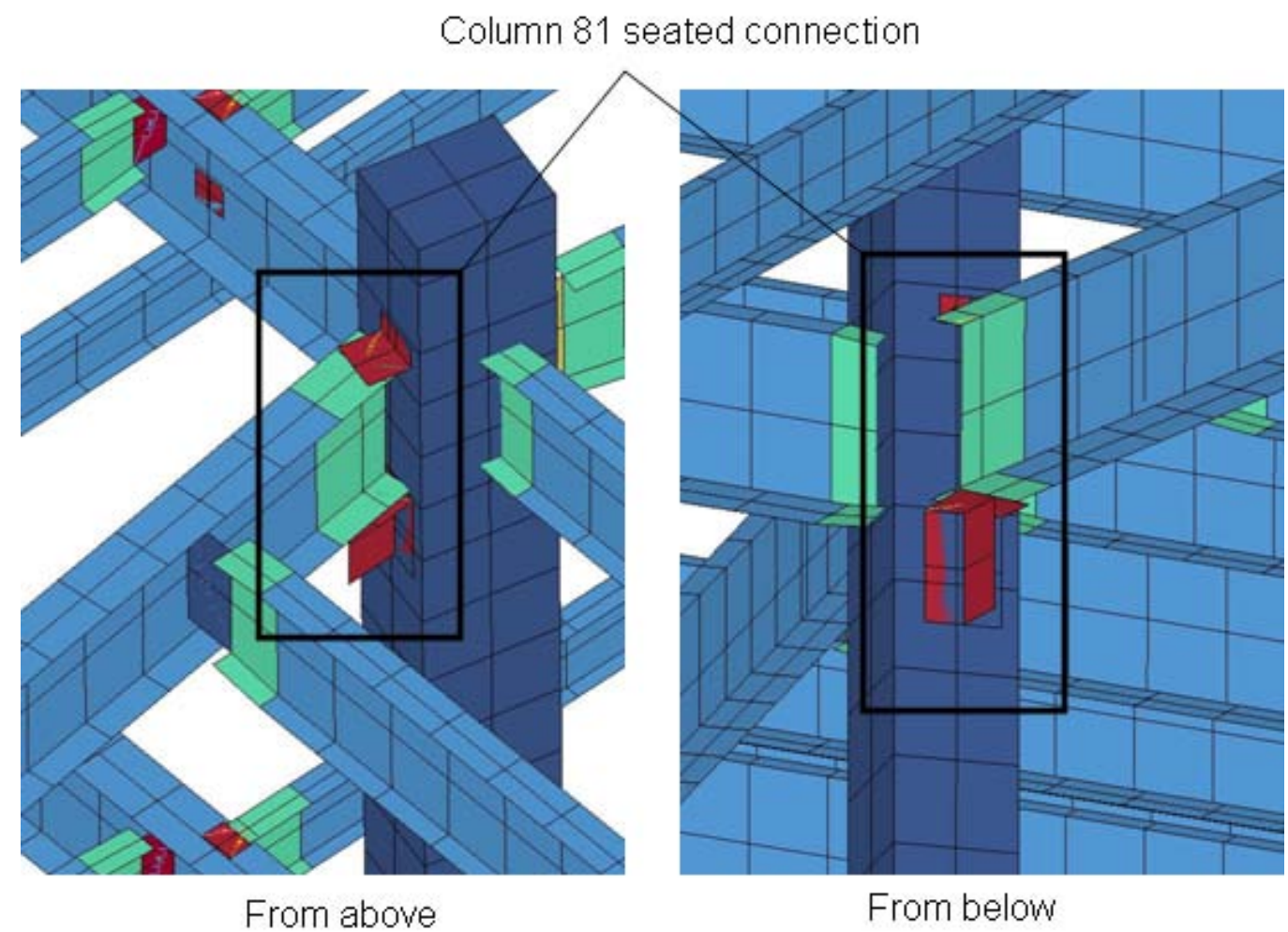

Figure 3-14. Seat connection in global model, Column 81.

\section{Seated Web Clip (SWC) Connections}

The SWC connection had a web clip (angle) instead of a top flange clip, along with an angle seat supporting the beam. As with other seated connections in the building, two 7/8 inch A325 bolts were used at the seat plate and web clip. A schematic of the connection is shown in Figure 3-15.

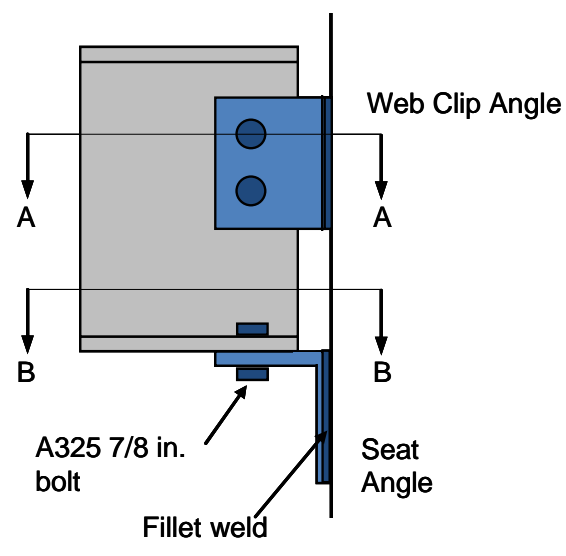

Elevation View

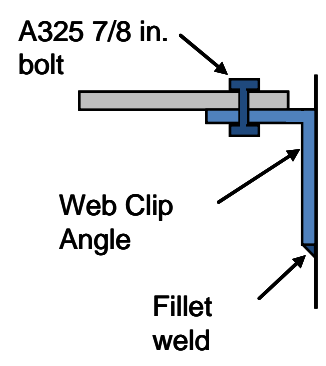

Section A-A

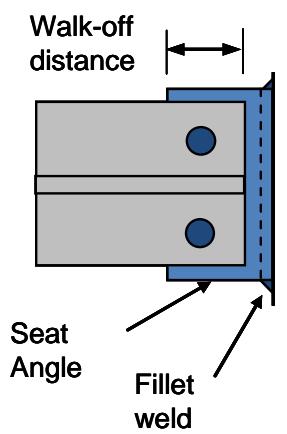

Section B-B

Based on structural drawings (Frankel 1985)

Figure 3-15. Schematic of SWC connection. 
A modified version of the Column 79 and 81 seated connection models was used to approximate the SWC connection. In the global model, the web clip was approximated as a flange clip. This approximation did not affect the horizontal or vertical capacity of the connection. The same discrete element properties were used to approximate the bolts strength. An example of the SWC implementation in the LS-DYNA model is shown in Figure 3-16.

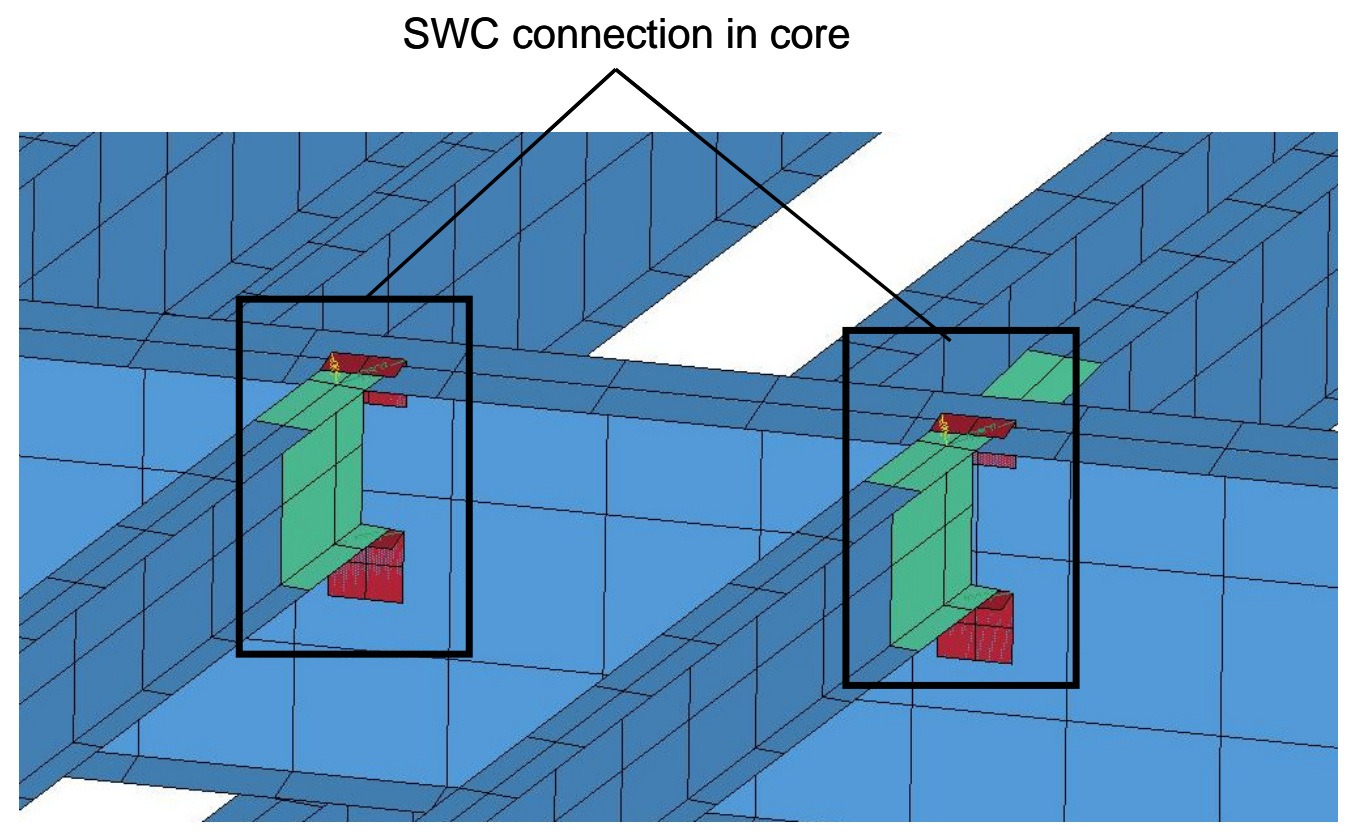

Figure 3-16. SWC connection in LS-DYNA model.

\section{Moment Connections}

In the construction of WTC 7, moment connections were used for exterior wind girders (WG) between exterior columns. Moment connections were also used at several core girder locations on Floors 5 and 7.

Figure 3-17 illustrates a moment connection model in the LS-DYNA model. The connection between the girder and column flanges was assumed to have the same material properties as the WG, except the failure strain was lowered by 30 percent to approximate the weld zone at the connection to the column. For all moment connections, a stiffener plate was added between the exterior column flanges, at the beam flange locations, to resist local crippling of the column, as was done in the construction of WTC 7. 


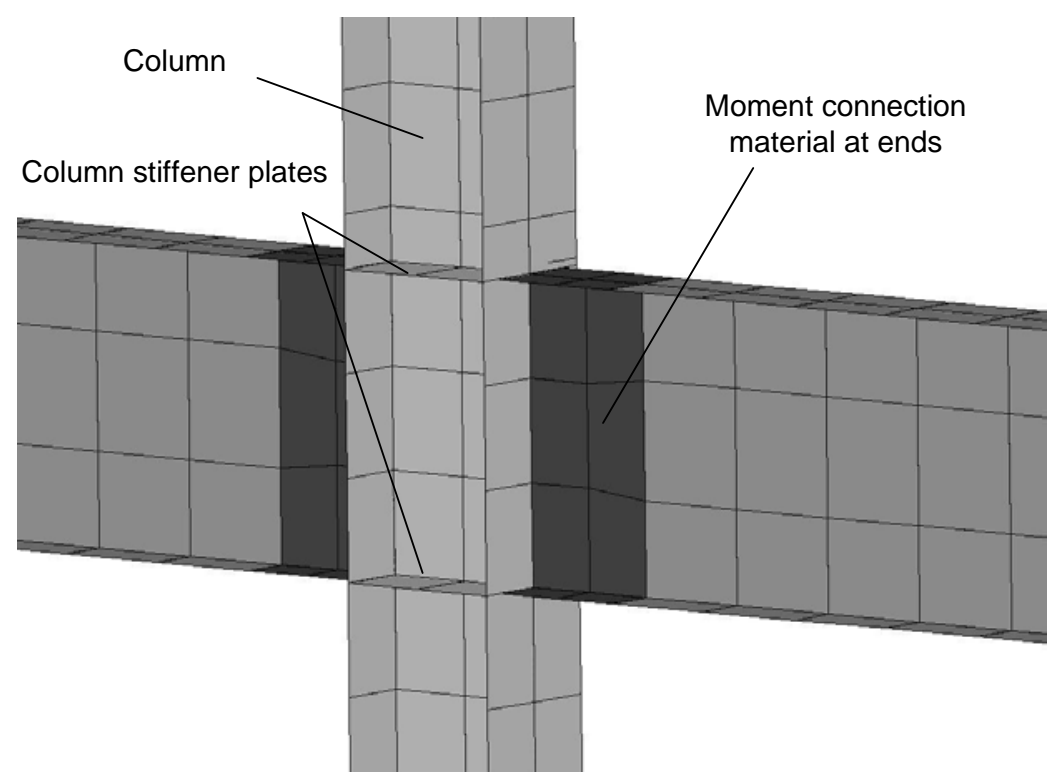

Figure 3-17. Wind girder moment connection model.

\subsubsection{Column Splices}

In the WTC 7 building construction, columns were spliced at every other floor. Column splices used bolted and/or welded flange plates; typical column splices were described in structural drawing S-17. In the LS-DYNA model, all column splices were explicitly represented with shell element models of the splice plates. An example of a column splice in the model is shown in Figure 3-18.

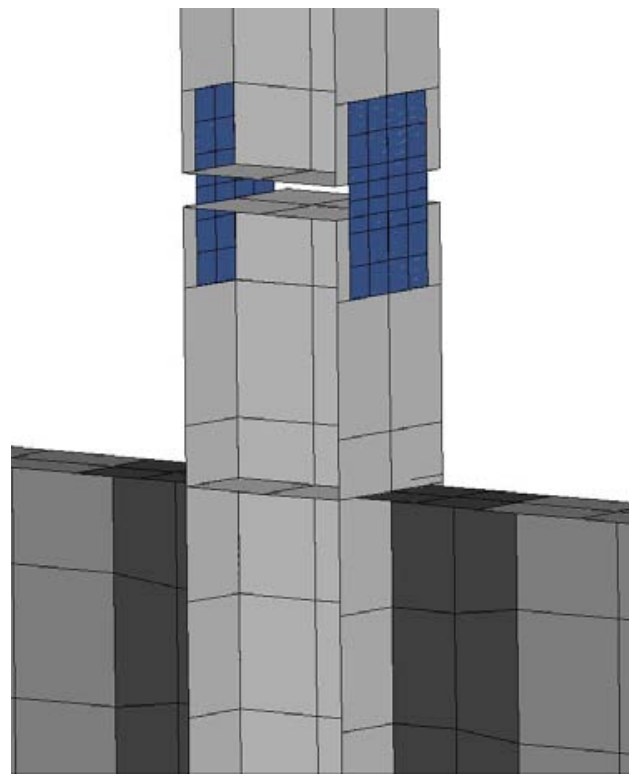

\section{Figure 3-18. Column splice connection in LS-DYNA model.}

The plates were connected to the column flanges with a tied contact interface. Change in column section dimensions (column size reduced with elevation in the building) were compensated for by using an offset tied interface between the columns and splice plates. This allowed for gaps between the splice plate and columns when a larger section column below was attached to a smaller section column above. 
Smaller splice plate elements, roughly 0.05- 0.08 m (2-3 in.) per side, were used to more accurately model splice failure for column buckling.

To avoid contact instability common with shell edge-to-edge contacts, a plate was added to column section ends to produce a more numerically stable surface-to-surface contact condition between column ends. Thickness of the end plate was assigned the flange thickness for a given column section. In Figure 3-18, a gap can be seen between the column end plates, which was created by a half shell thickness offset to improve contact stability. The end plates were not expected to alter the structural response, and they were necessary to ensure contact stability in the model.

\subsubsection{Shear Stud Connections}

The shear stud connections were modeled with a tied contact interface, where the center nodes along the top flange of beams were tied to surface slab shell element segments. The contact interface approach is illustrated in Figure 3-19. No failure was allowed in the tied contact. Individual connections were severed when a node or shell element in the contact list exceeded its material failure criteria. This usually occurred when the composite slab material failed. Once a node or element was freed from the tied contact, it could interact with other contacting materials.

The slab-to-beam tied contact was applied only to the interior floor beams and spandrel beams (WG) where shear studs were located. Interior girders and $\mathrm{MG}^{1}$ sections did not have shear studs.

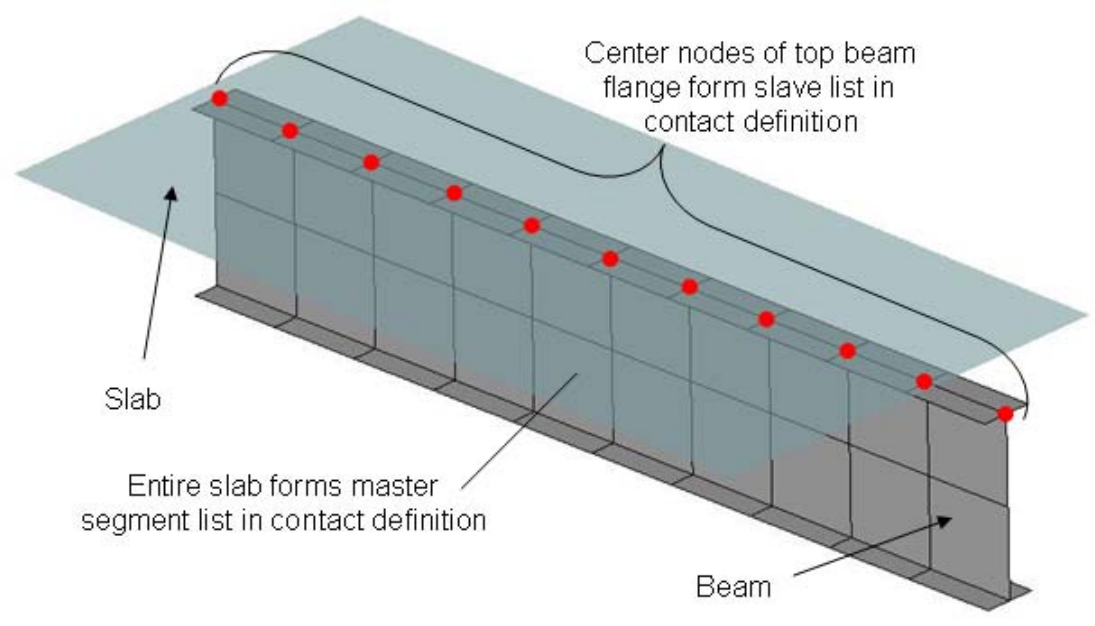

Figure 3-19. Modeling of shear stud connection between beams and slabs.

\subsection{DEVELOPMENT OF THE GLOBAL MODEL}

Details of the model construction, as well as a discussion of boundary conditions and model initialization, are included in the following subsections. The resulting model is shown in Figure 3-20 and Figure 3-21.

\footnotetext{
${ }^{1}$ Built-up girders were referred to in the design drawings as MG.
} 


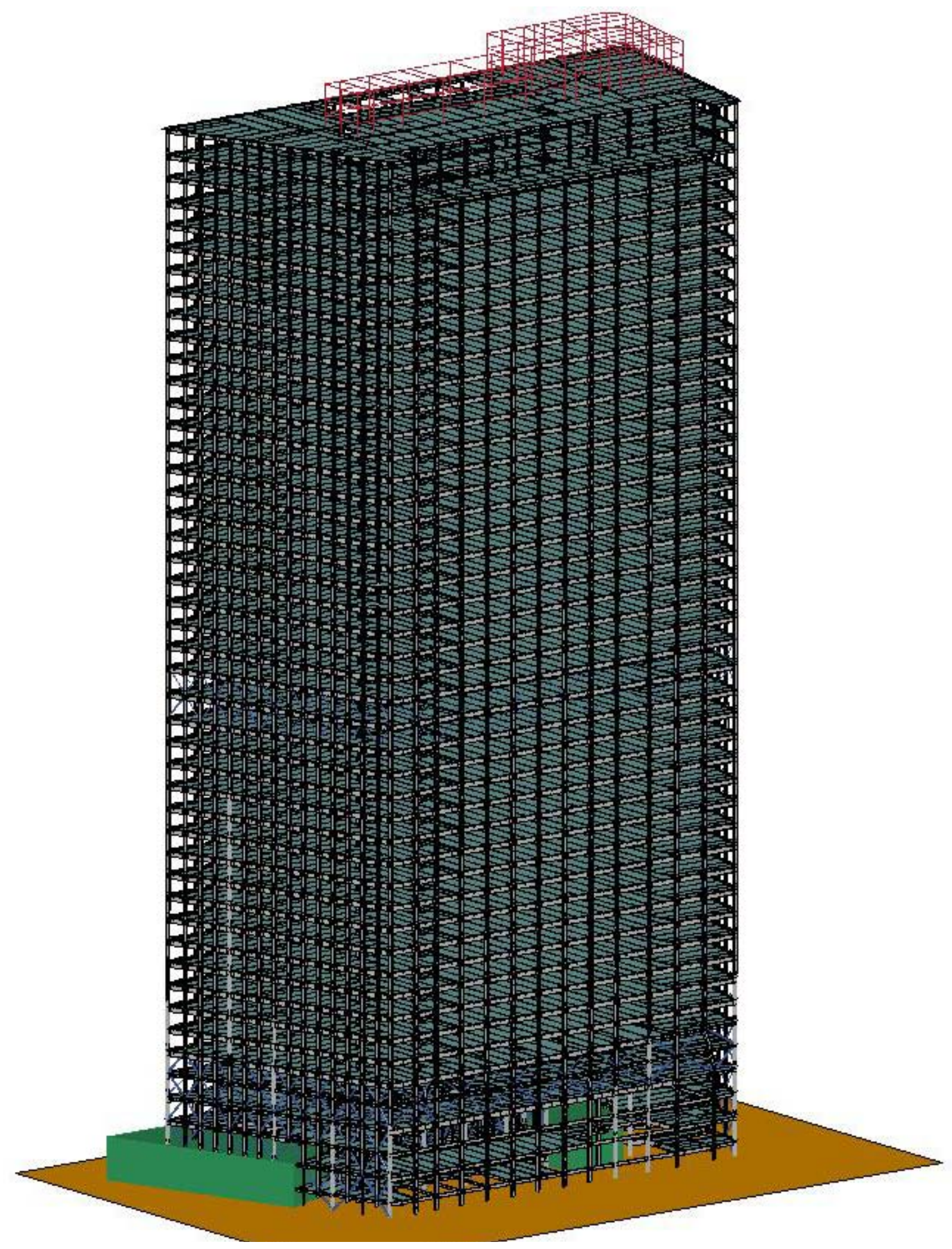

Figure 3-20 Global model of WTC 7, viewed from the southwest. 


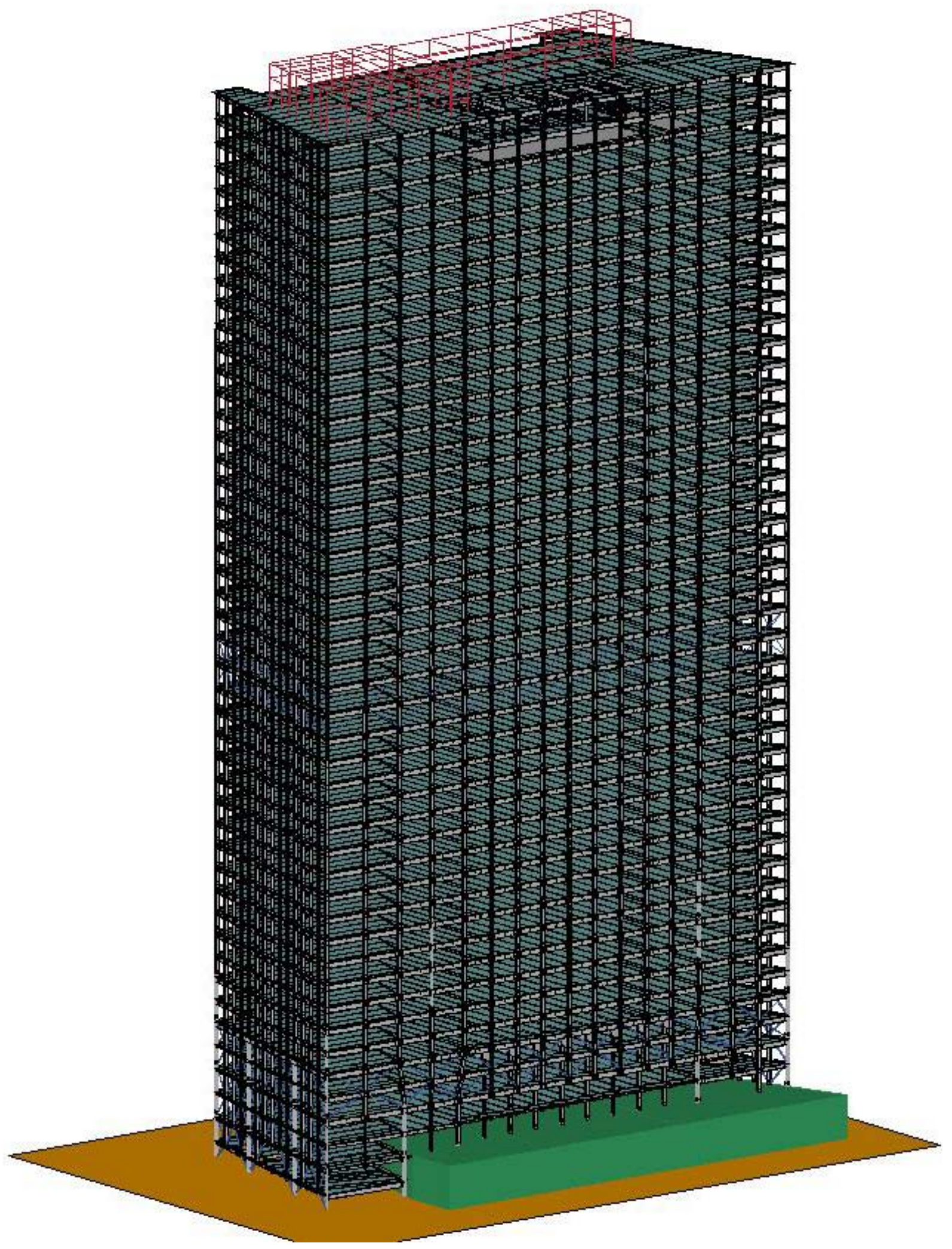

Figure 3-21 Global model of WTC 7, viewed from the northeast. 


\subsubsection{Model Construction Details}

The global model was constructed in accordance with the structural drawings. Structural drawings corresponding to the floor layouts shown were S-2 through S-14.

\section{Floor Framing Layouts}

Figure 3-22 shows drawing S-8, the framing plan for a typical floor found on Floors 8 to 20 and 24 to 45, and the corresponding LS-DYNA model layout. All beams, girders, and columns were included in the model except for a few non-critical, small section beams in the core.
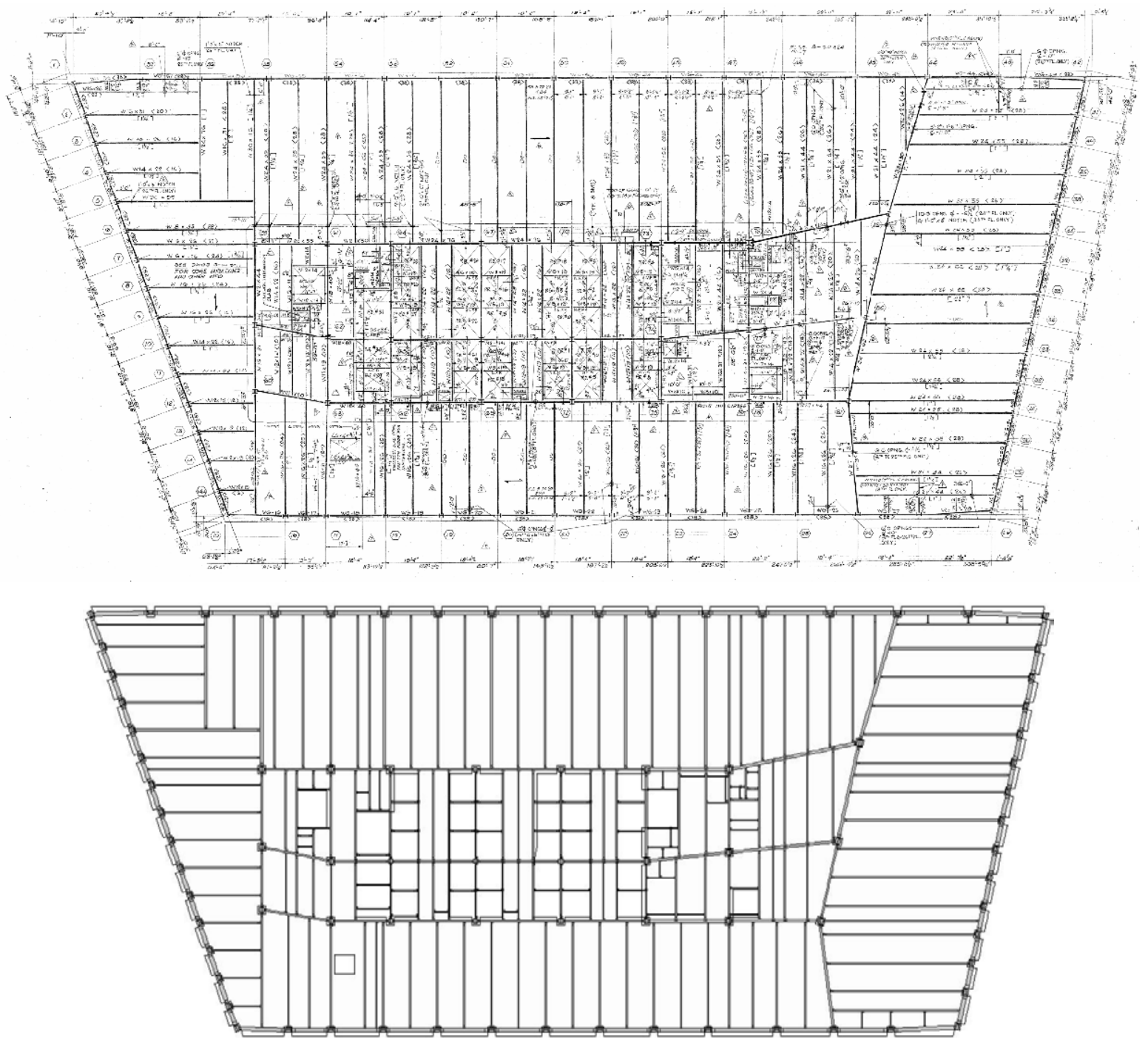

Based on structural drawings (Cantor 1985)

Figure 3-22. Model and drawing comparison of typical tenant floor structural framing, drawing and model of Floors 8 through 20 and 24 through 45)

(Top figure from Drawing S-8) 
Floors 2 through 7 are shown in Figure 3-23 through Figure 3-28. The Con Edison substation shown in the $2^{\text {nd }}$ and $3^{\text {rd }}$ floor models (in green) was modeled as a rigid body and supported the deformable framing.

The typical tenant floor, shown again in Figure 3-29, used the same framing layout for Floors 8 to 20, and 24 to 45. Floors 21 to 23 are shown in Figure 3-30, and had the same framing as the typical floor layout, except for slightly larger beam sizes in some locations. Floors 46 and 47, along with the roof structure, are shown in Figure 3-31 through Figure 3-33.

Slight changes to beam and girder lengths were automatically made in the TrueGrid model generation process to account for the changing column dimensions. Generally, the column sections decreased in size with increasing building height. In the TrueGrid model, columns were placed and given section properties based on a database of column properties of the building. The columns had two-story lengths, and were connected with models of splice plates. Also, a few slight variations in girder specifications, depending on the floor, were called out in drawing S-8. For example, the girder between Column 66 and 69 varied from the standard W21X68 at Floors 14 and 17. These variations were accounted for in the model.

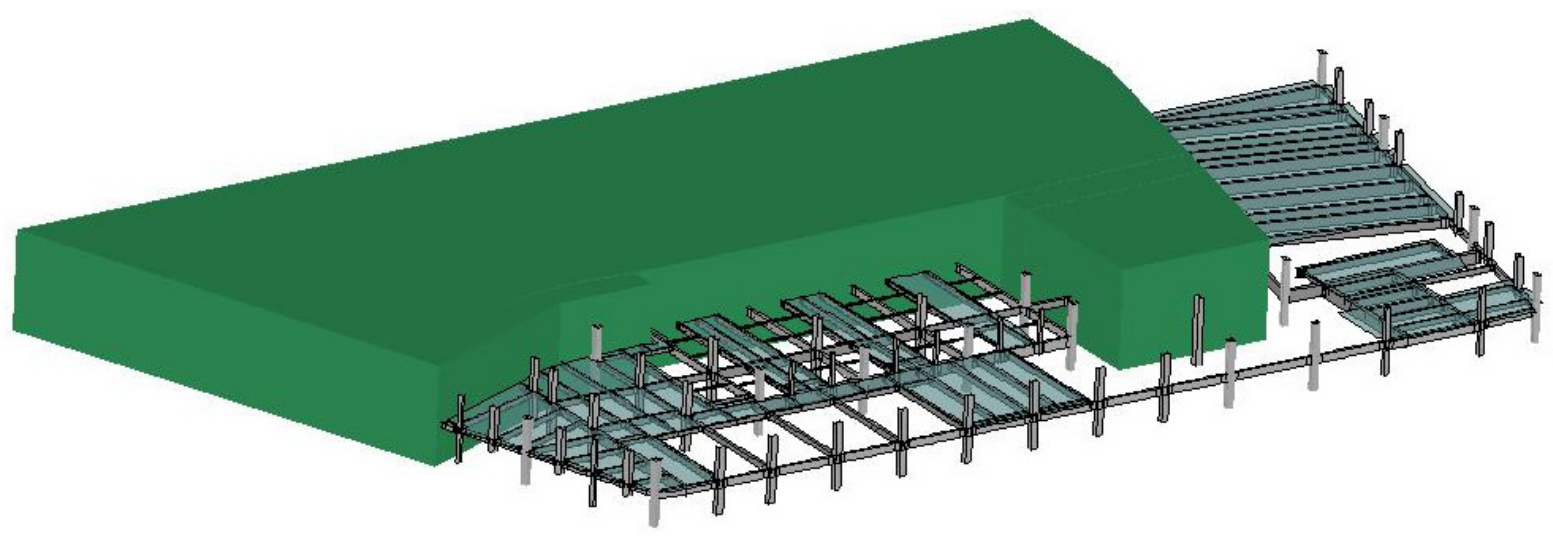

Figure 3-23. $2^{\text {nd }}$ floor structural framing and slab model.

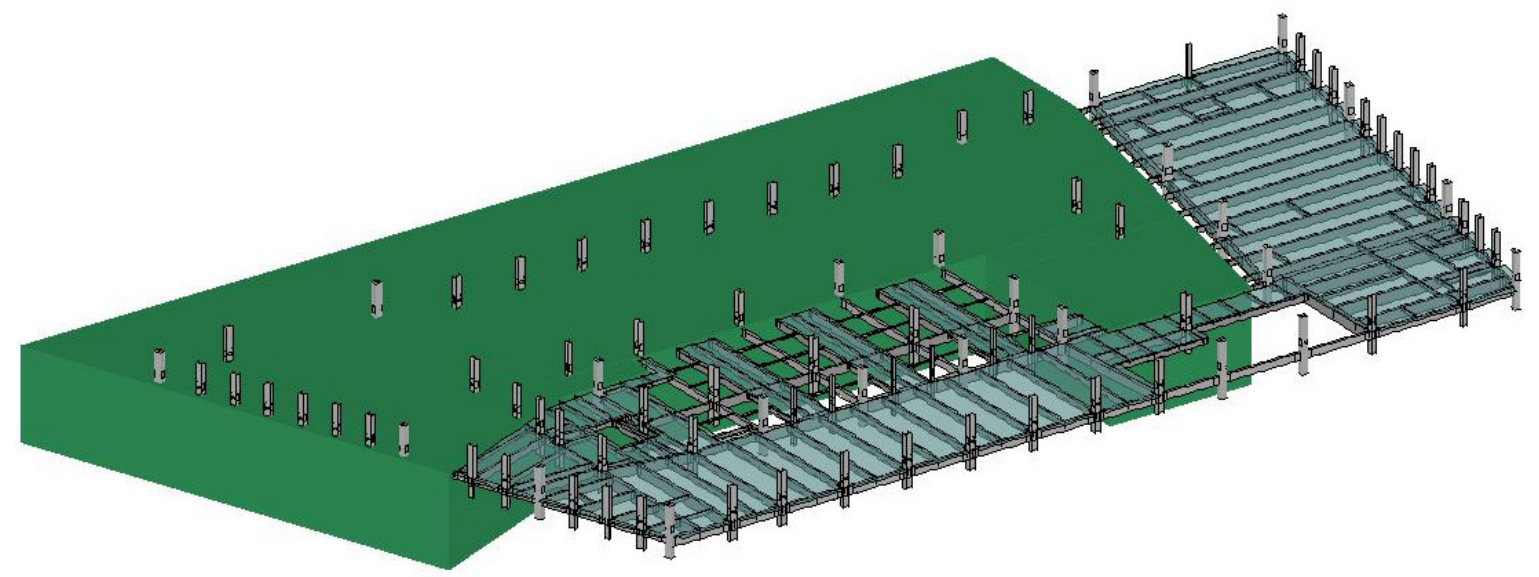

Figure 3-24. $3^{\text {rd }}$ floor structural framing and slab model. 


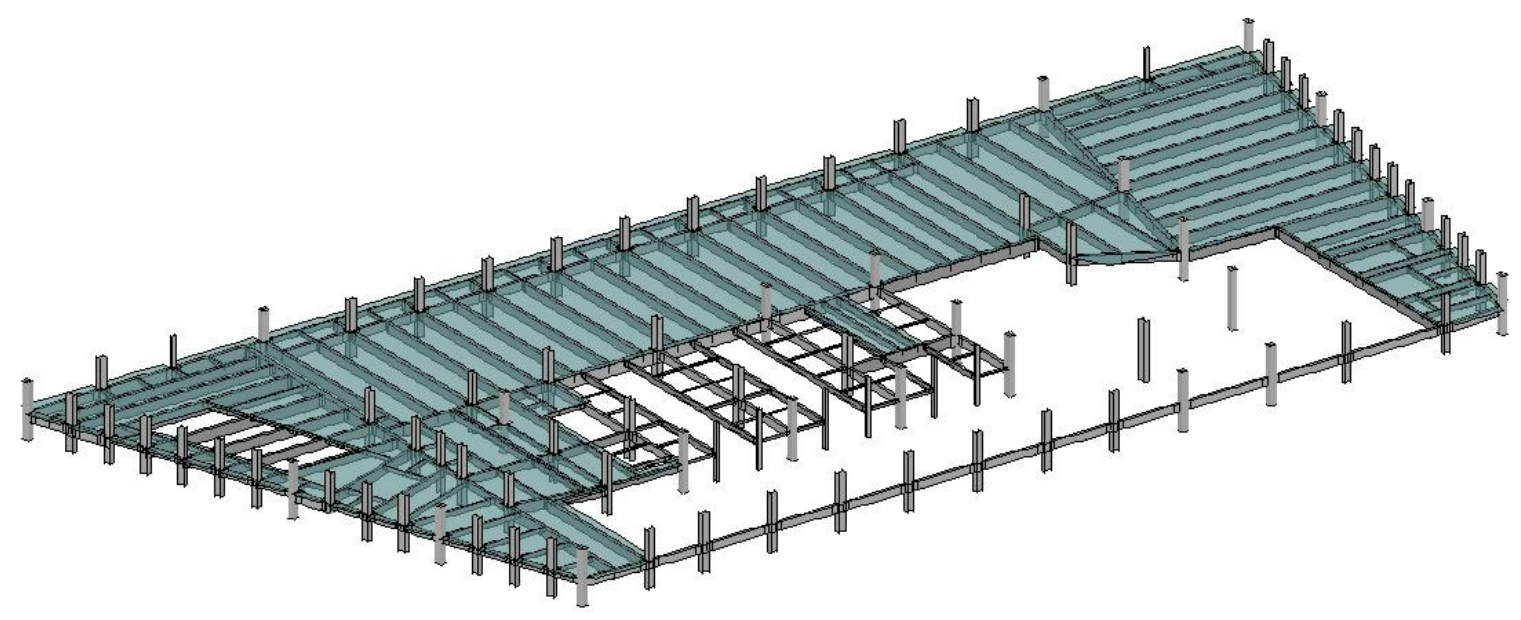

Figure $3-25.4^{\text {th }}$ floor structural framing and slab model.

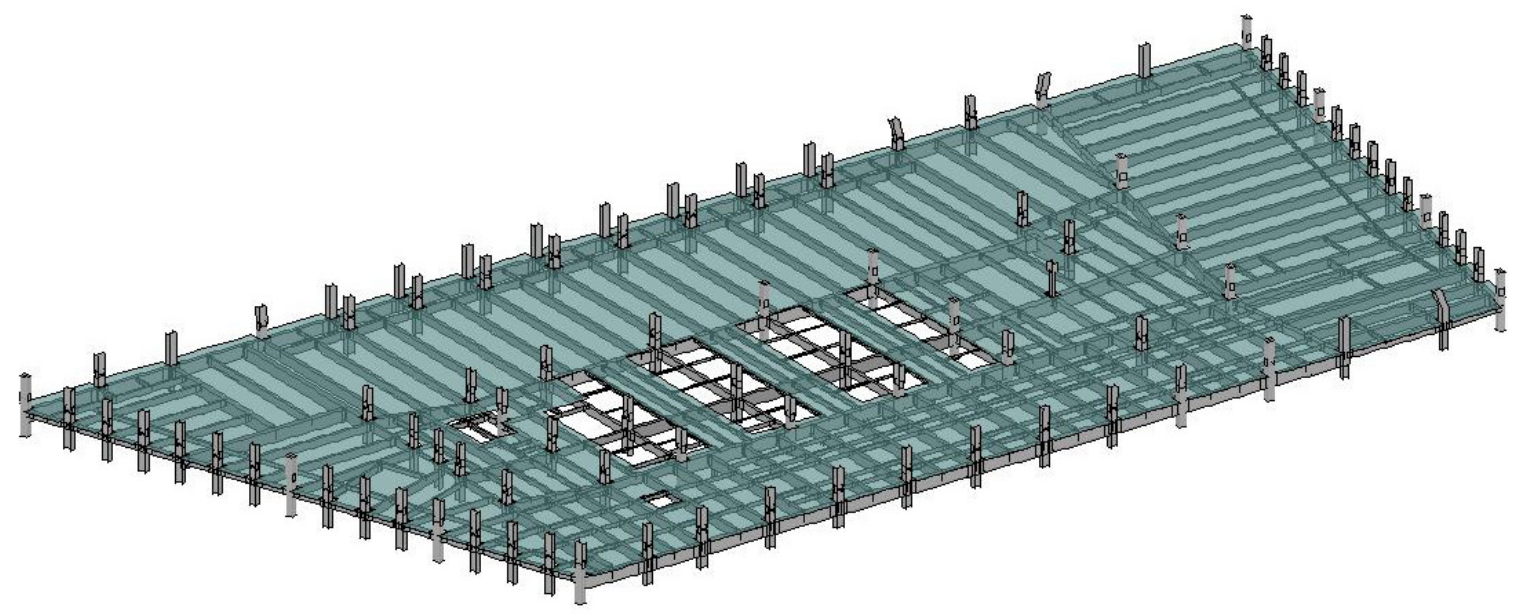

Figure $3-26.5^{\text {th }}$ floor structural framing and slab model.

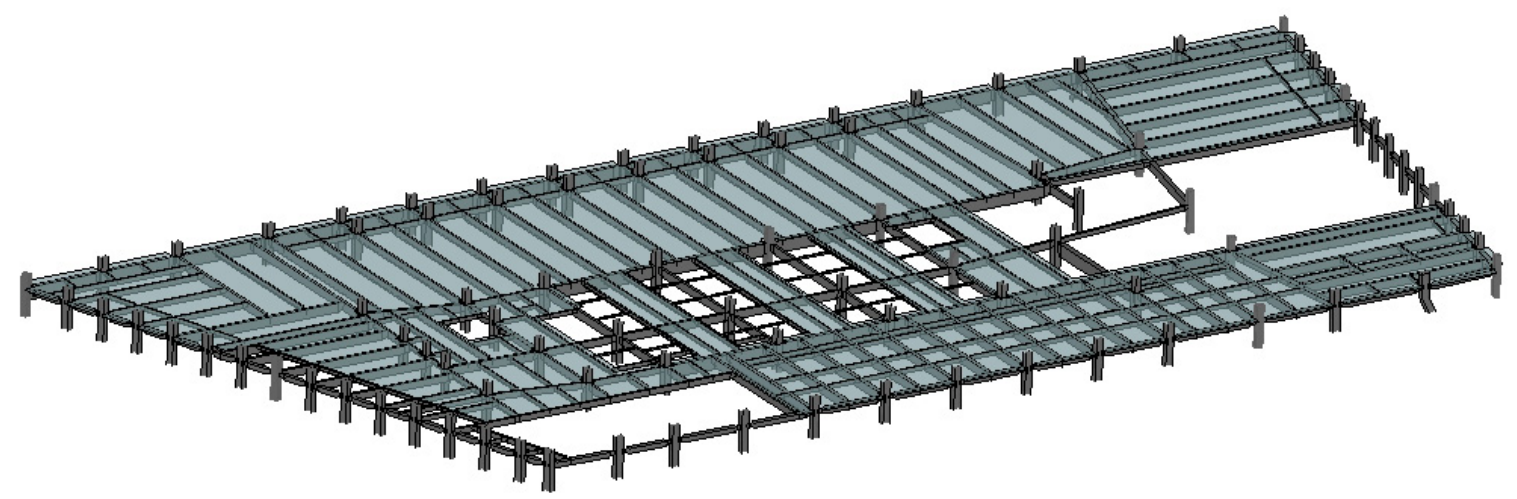

Figure $3-27.6^{\text {th }}$ floor structural framing and slab model. 


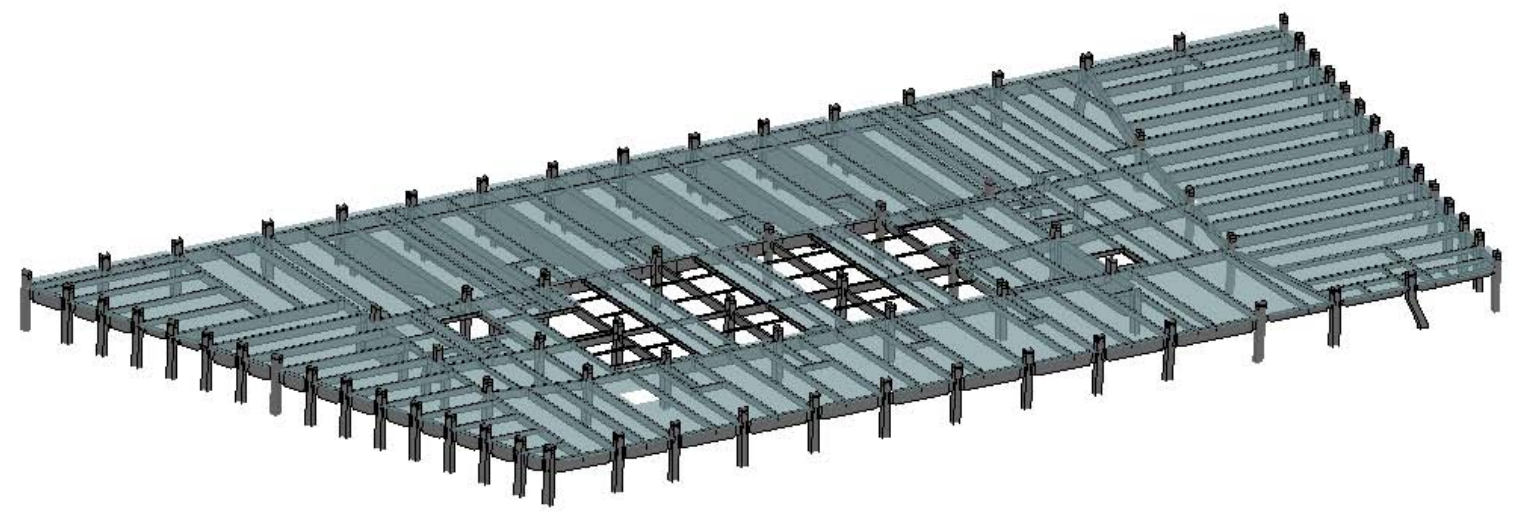

Figure 3-28. $7^{\text {th }}$ floor structural framing and slab model.

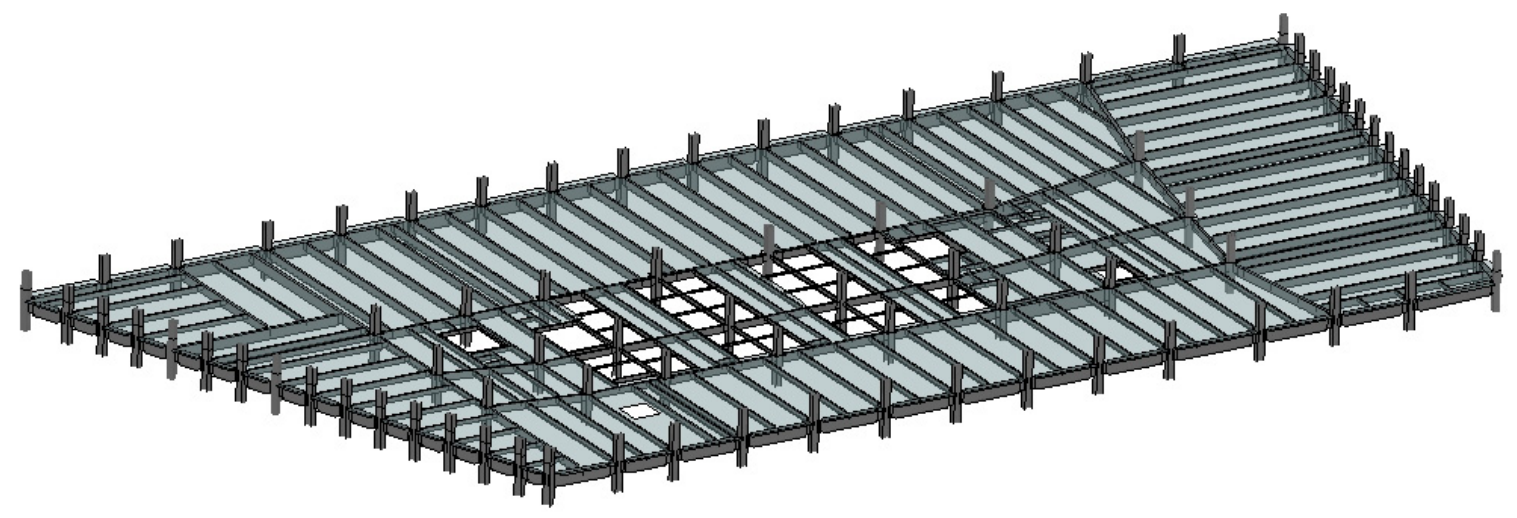

Figure 3-29. Standard tenant floor structural framing and slab model (Floors 8 through 20 and 24 through 45)

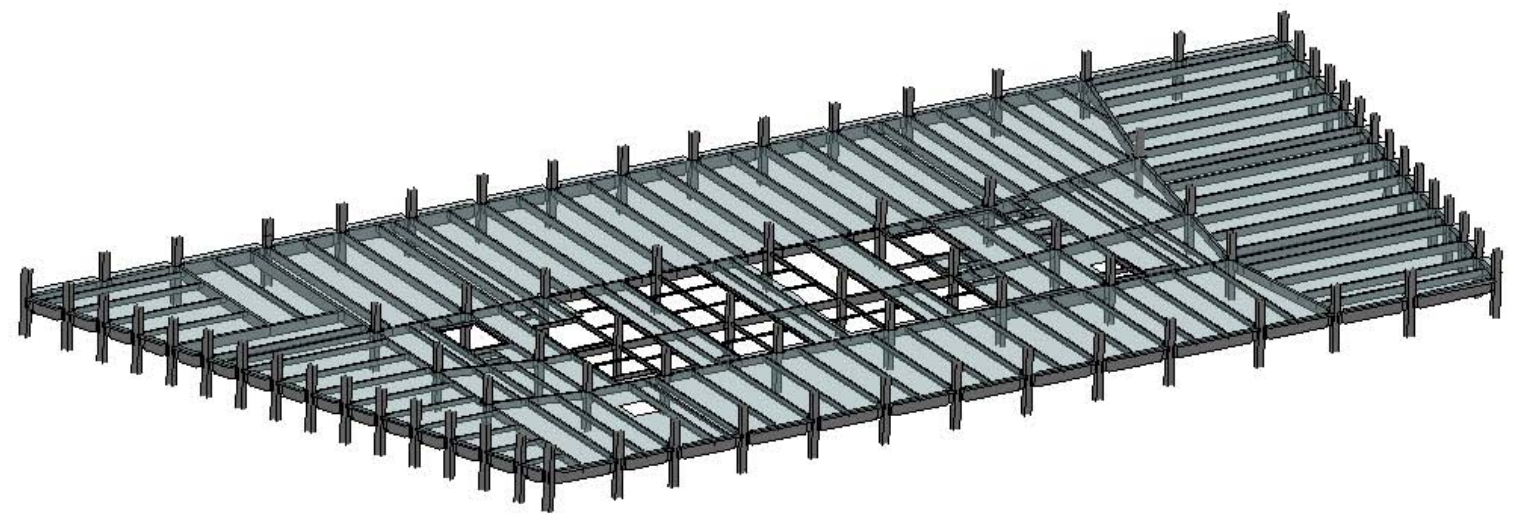

Figure $3-30.21^{\text {st }}$ through $23^{\text {rd }}$ floor structural framing and slab model. 


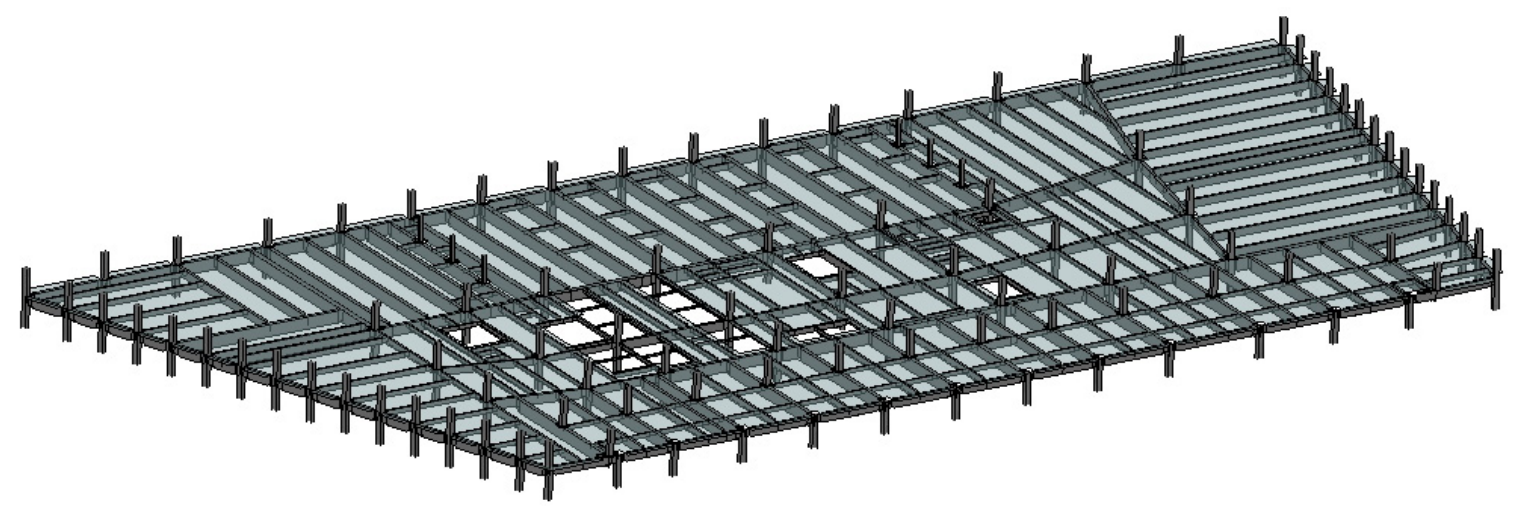

Figure $3-31.46^{\text {th }}$ floor structural framing and slab model.

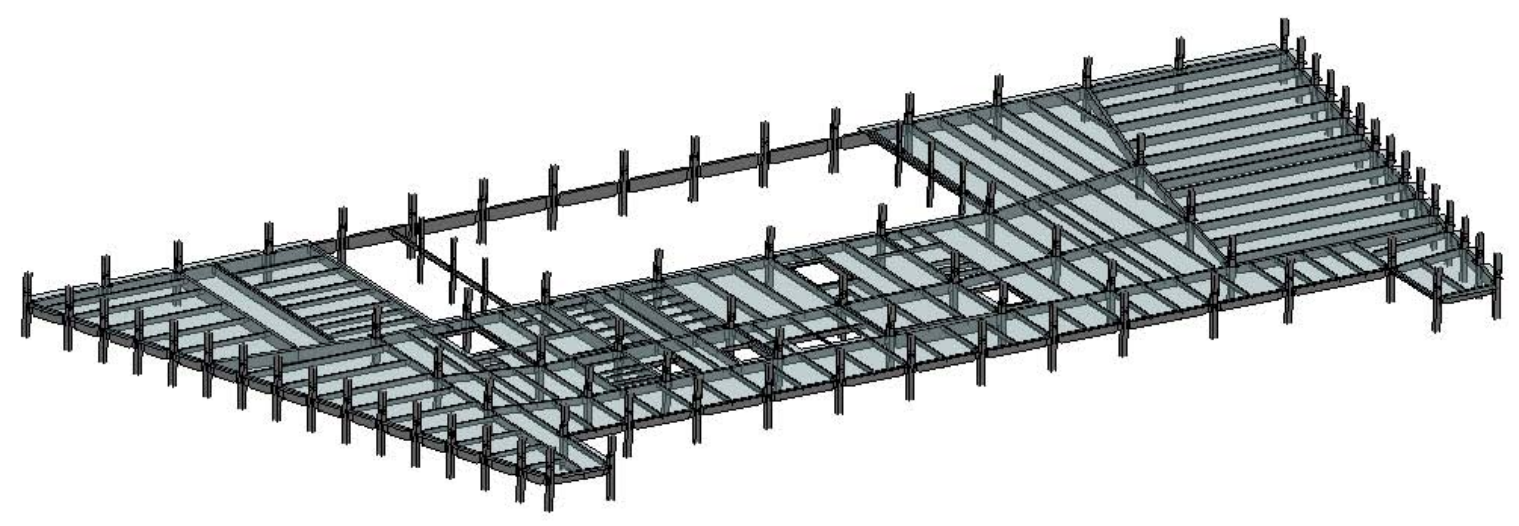

Figure 3-32. $47^{\text {th }}$ floor structural framing and slab model.

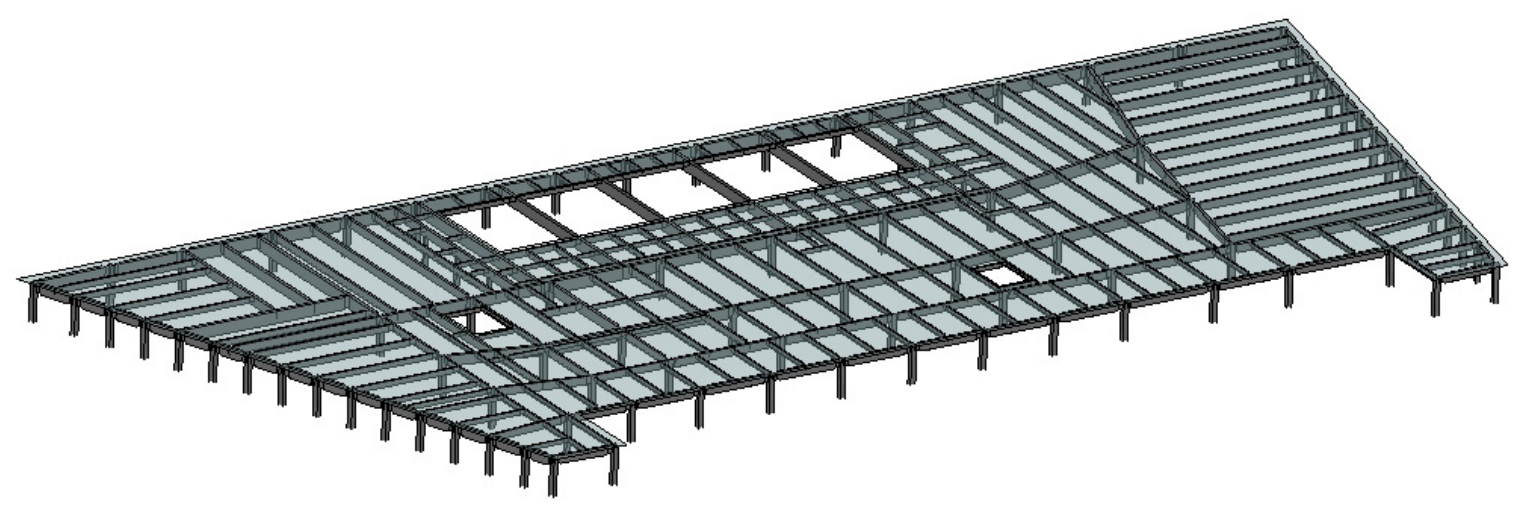

Figure 3-33. Roof structural framing and slab model.

\section{Structural Details}

In this section, truss and column transfer structures, located between Floor 5 and 7, are discussed.

Treatment of wind bracing and Floor 5 slab reinforcement are presented. Finally, the penthouse model is discussed. Trusses and the penthouse framing were modeled with beam elements. Beam element ends were merged directly into nodes of the shell element geometry. No connections were explicitly modeled 
for beam elements. For a beam-shell connection to fail, an element had to reach the material failure criteria.

\section{Truss and Column Transfer Structures}

Isolated views for truss and column transfer structures in Floors 5 through 7 are shown in Figure 3-34 through Figure 3-41. The colors correspond to different material number assignments made in the LSDYNA model. Corresponding views in the structural drawing can be seen in S-23.

Truss 1 is shown in Figure 3-34. An elevation view of Truss 1 (looking from the south) is shown in Figure 3-35. The truss supported Column 76 and transferred Column 76 loads to Column 73 to the west and to columns E3 and E4 to the east. Columns E3 and E4 both started at Floor 7 and carried loads down to the foundation. Moment connections were used to frame the east-west beam at Floor 5 into Column 73 and girder MG-53.

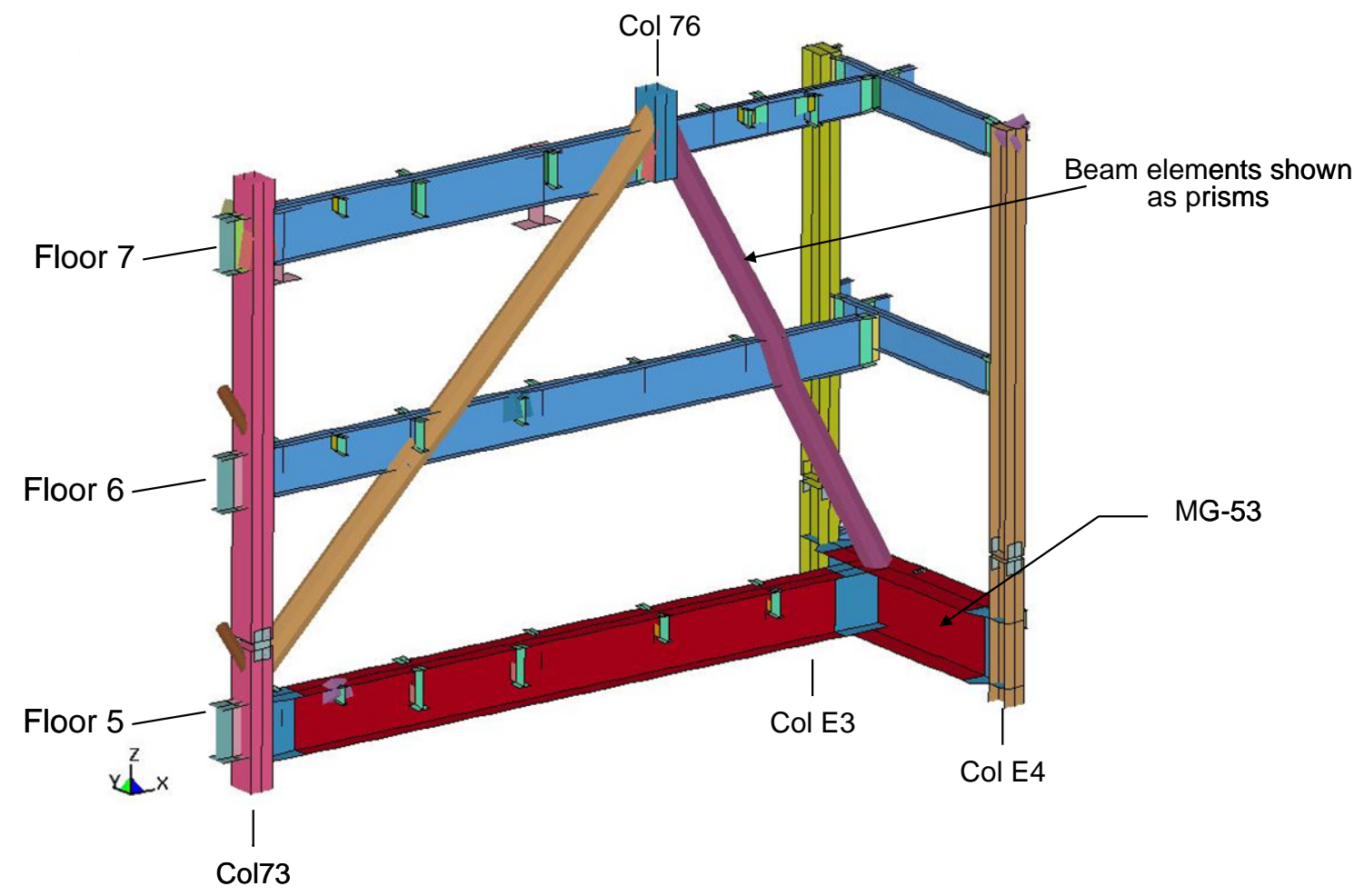

Figure 3-34. Detail of Truss 1 in the WTC 7 global model. 


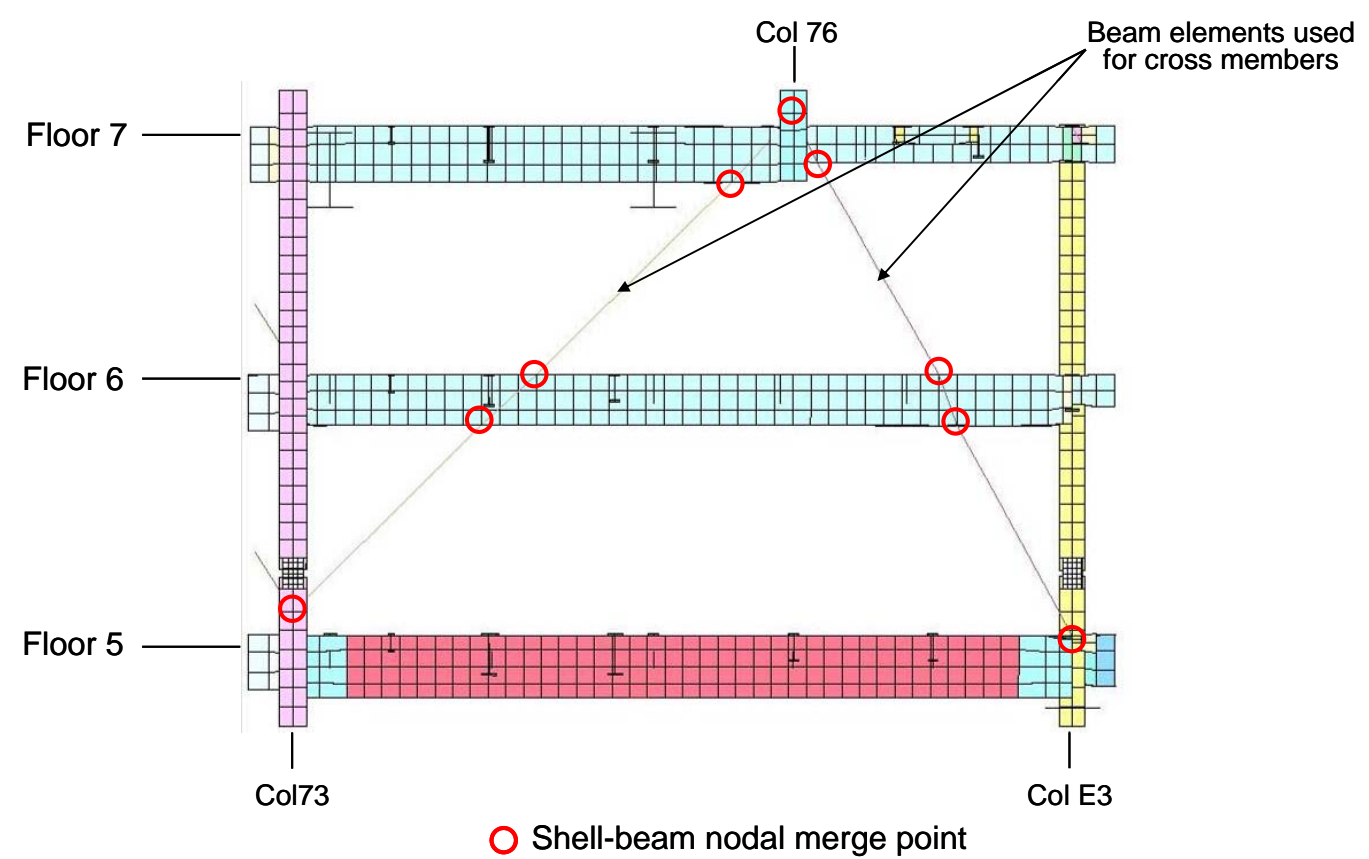

Figure 3-35. Framing connections for the beam elements used in Truss 1.

Truss 2 is shown in perspective and in elevation from the south in Figure 3-36 and Figure 3-37, respectively. Truss 2 supported Column 77 and transferred Column 77 loads to Columns 74 and 80 . Girder MG-23 supported Column 78 and transferred Column 78 loads to Columns 77 and 78A. Column 78A started at Floor 7 and carried loads down to the foundation. Moment connections were used in the Floor 5 girder framing between Columns 74 and 80.

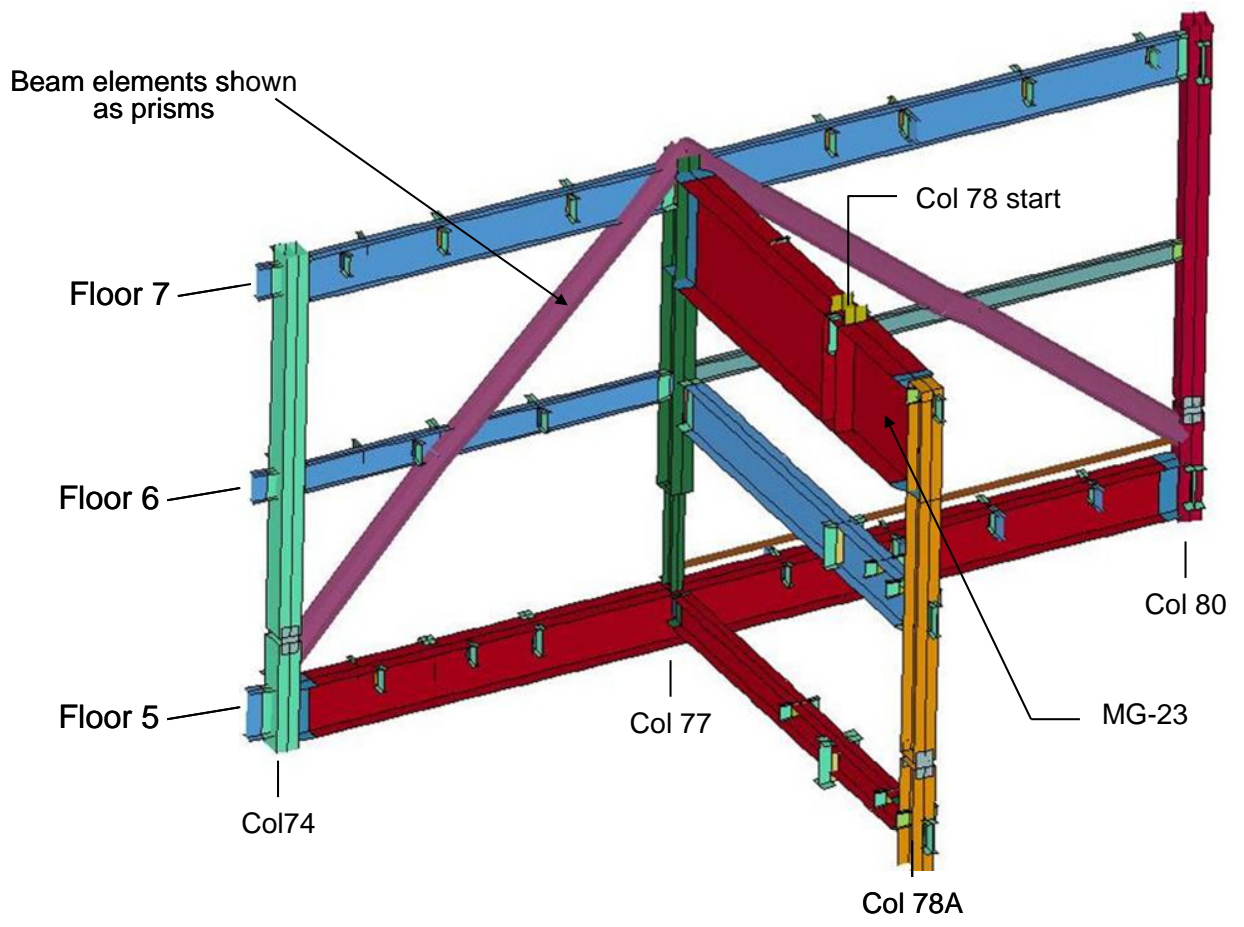

Figure 3-36. Detail of Truss 2 in the WTC 7 global model. 


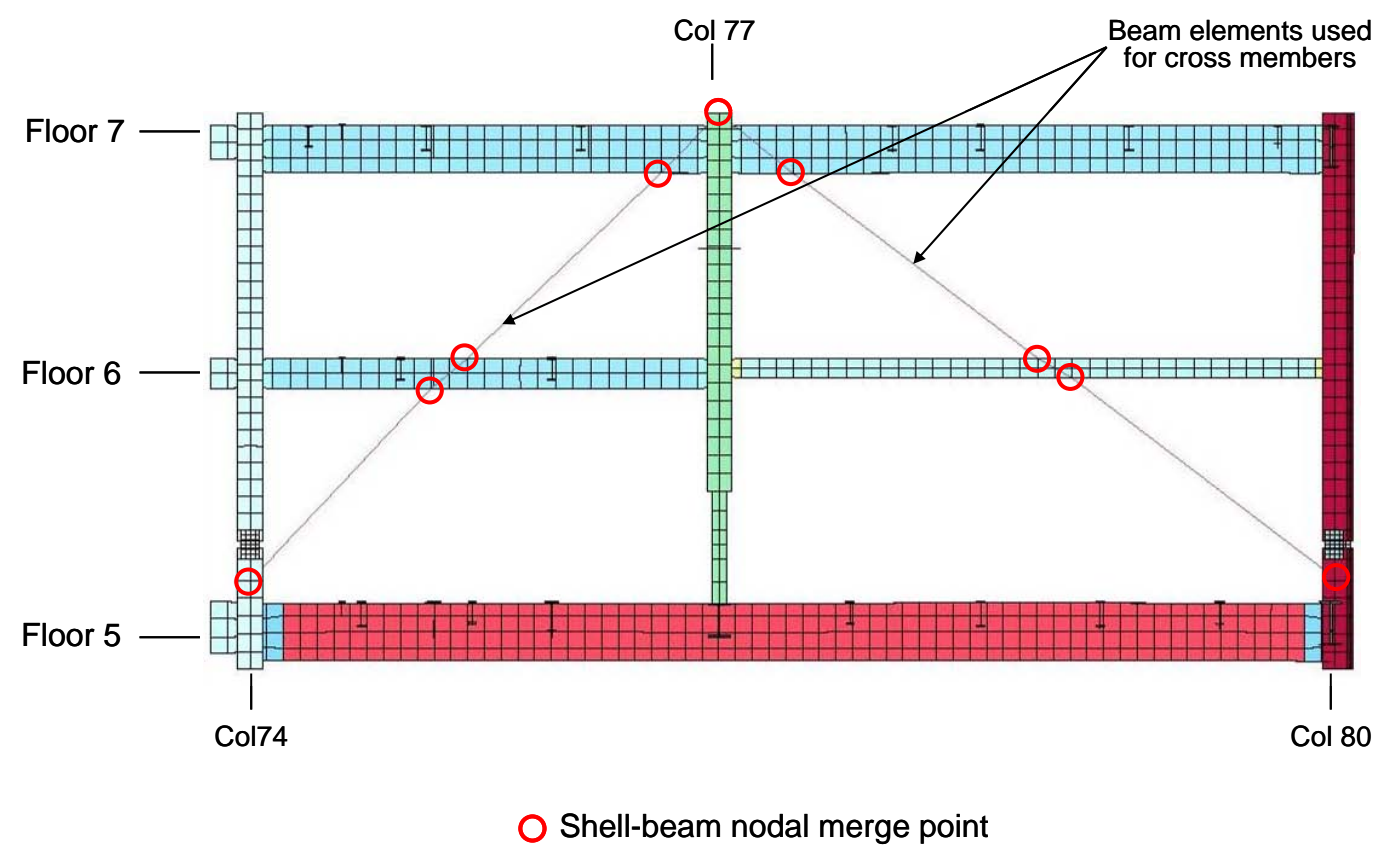

Figure 3-37. Framing connections for the beam elements used in Truss 2.

Two views from the east of Truss 3 are shown in Figure 3-38 and Figure 3-39. The truss transferred loads from Columns 61 and 62 to Column 61A, which started at Floor 7 and carried loads down to the foundation. Moment connections were used in the Floor 5 and 6 girders between all three columns.

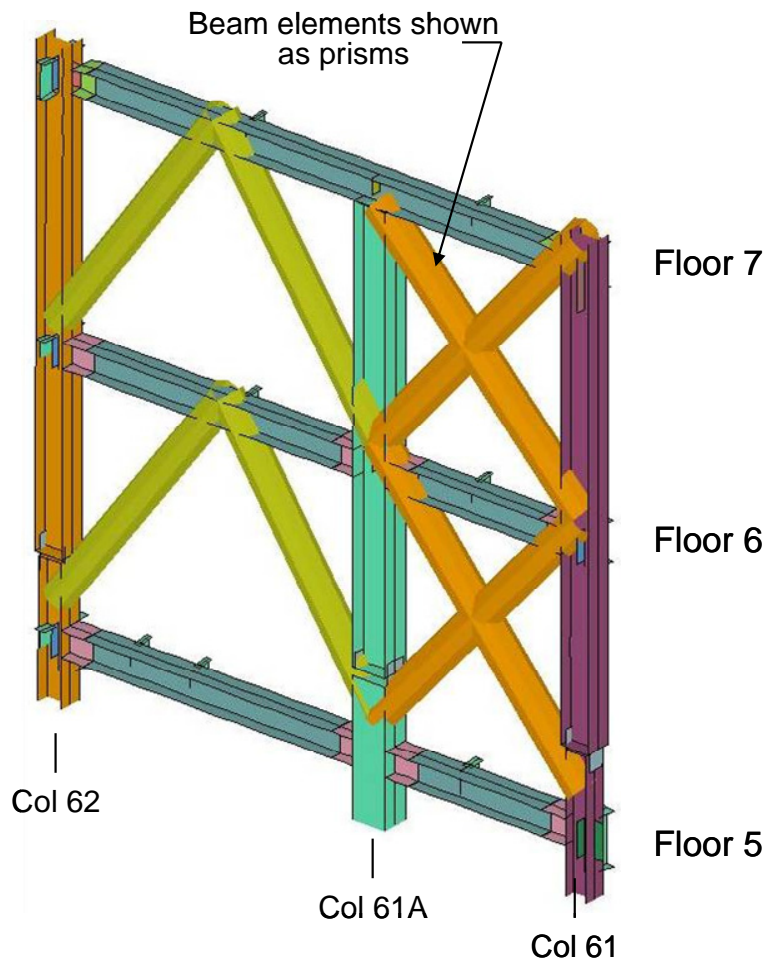

Figure 3-38. Detail of Truss 3 in the WTC 7 global model. 


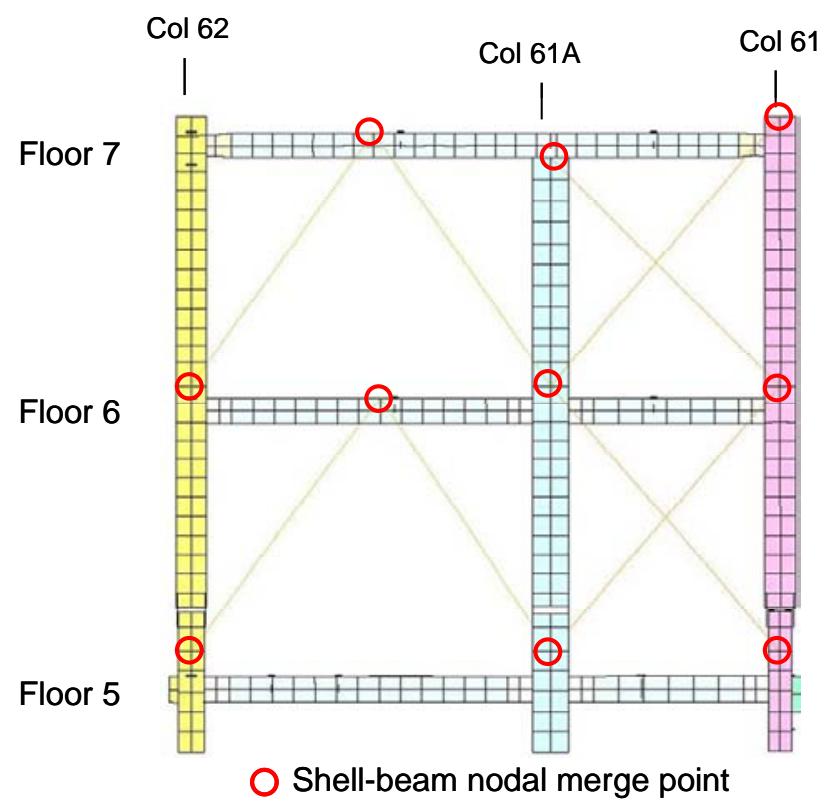

Figure 3-39. Framing connections for the beam elements used in Truss 3.

The transfer girders at the lower end of Columns 58 and 59 are shown in Figure 3-40. The transfer girders, MG-21 and MG-22, were handled as special cases in the TrueGrid models, separate from the standard wide flange beam model prototype used elsewhere. The stiffener plates for Columns 58 and 59 were included. Girder MG-21 supported Column 58 and transferred the Column 58 loads to Columns 58A and 58C. Girder MG-22 supported Column 59 and transferred the Column 59 loads to Columns 59A and 59B. Columns 58A, 58C, 59A, and 59B started at floor 7 and carried loads down to the foundation.

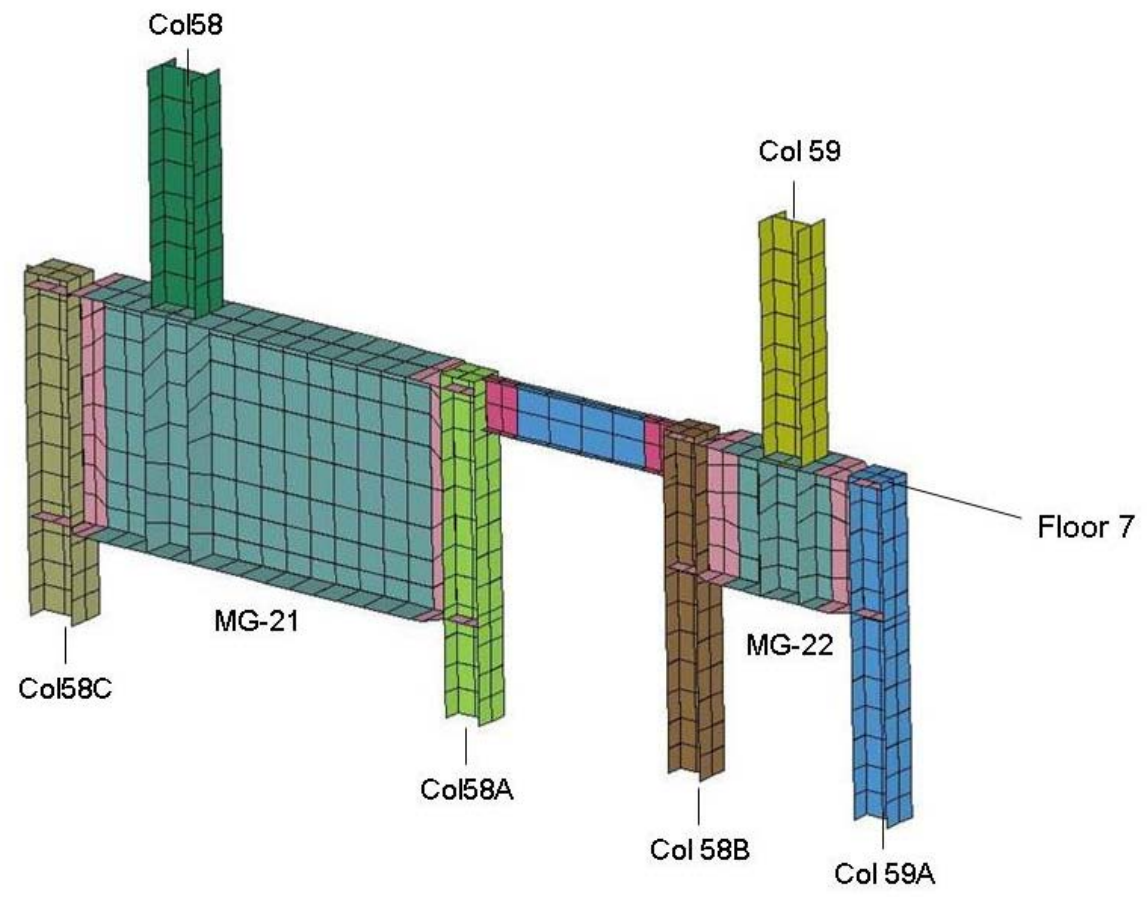

Figure 3-40. Detail of Columns 58 and 59 load transfer connections in the WTC 7 global model. 
Transfer girder MG-27 is shown in Figure 3-41. This girder was located at Floor 7 and spanned from the north face exterior columns to the core columns on the north side of the core. The girder transferred loads from the north face exterior columns above Floor 7 to the north face exterior columns below Floor 7 , which were offset by $6 \mathrm{ft} 9 \mathrm{in}$. The transfer girders were located at Columns 47 to 53 .

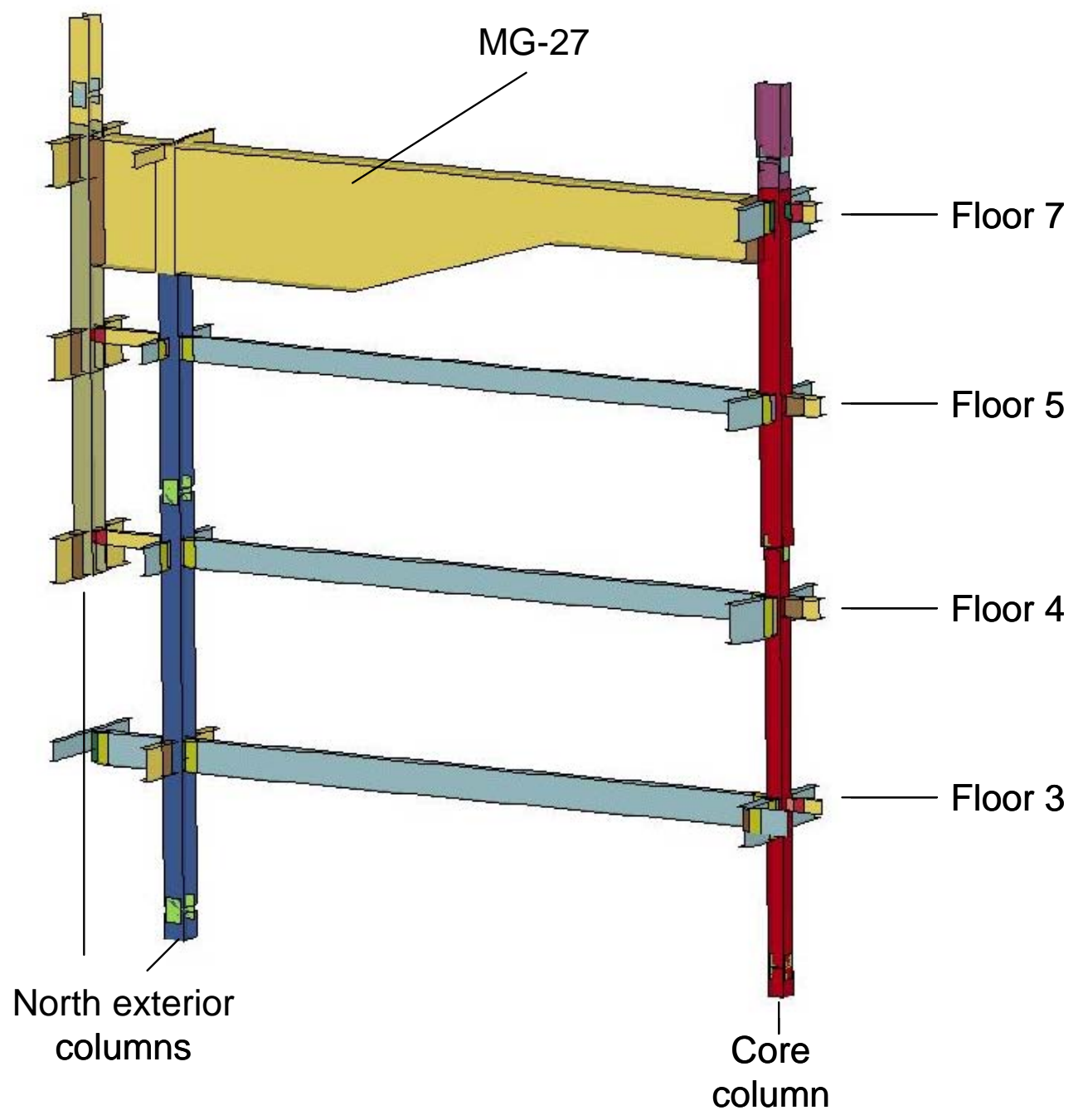

Figure 3-41. Typical north face transfer girder MG-27.

\section{Exterior and Core Wind Bracing}

Wind bracing trusses were added to the lower core and exterior, as described in structural drawings S-19 to S-21. The belt truss at Floors 22 to 24, which was part of the exterior framing, was also included in the global model, as described in drawing S-22. Truss members were included as beam elements, and were merged directly into the columns. The exterior wind bracing at the lower floors in the LS-DYNA model is shown in Figure 3-42. Core wind bracing in the LS-DYNA model is shown in Figure 3-43 . The belt truss in the model is shown in Figure 3-44. 

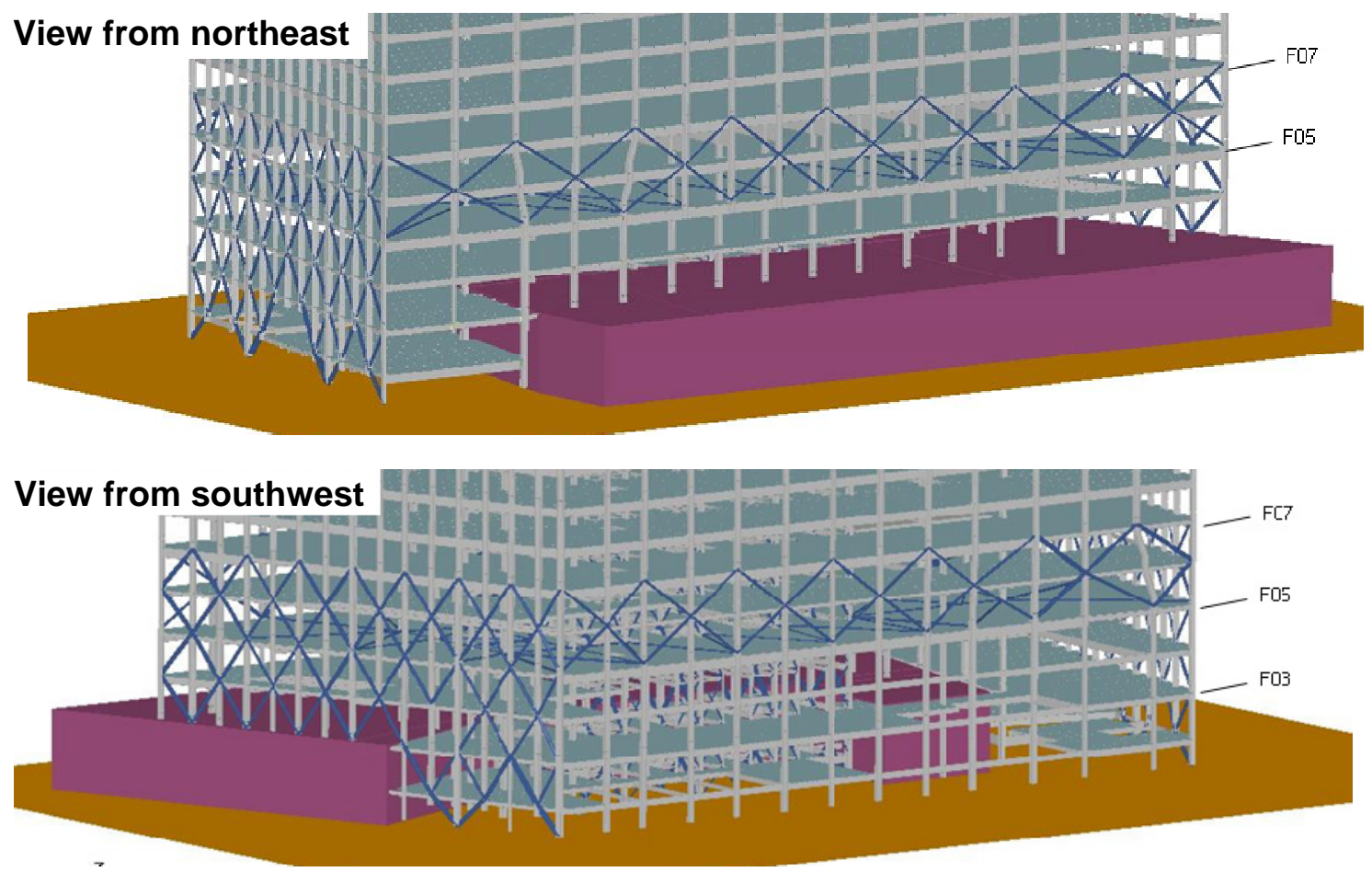

Figure 3-42. Exterior wind bracing in lower floors of the LS-DYNA model.

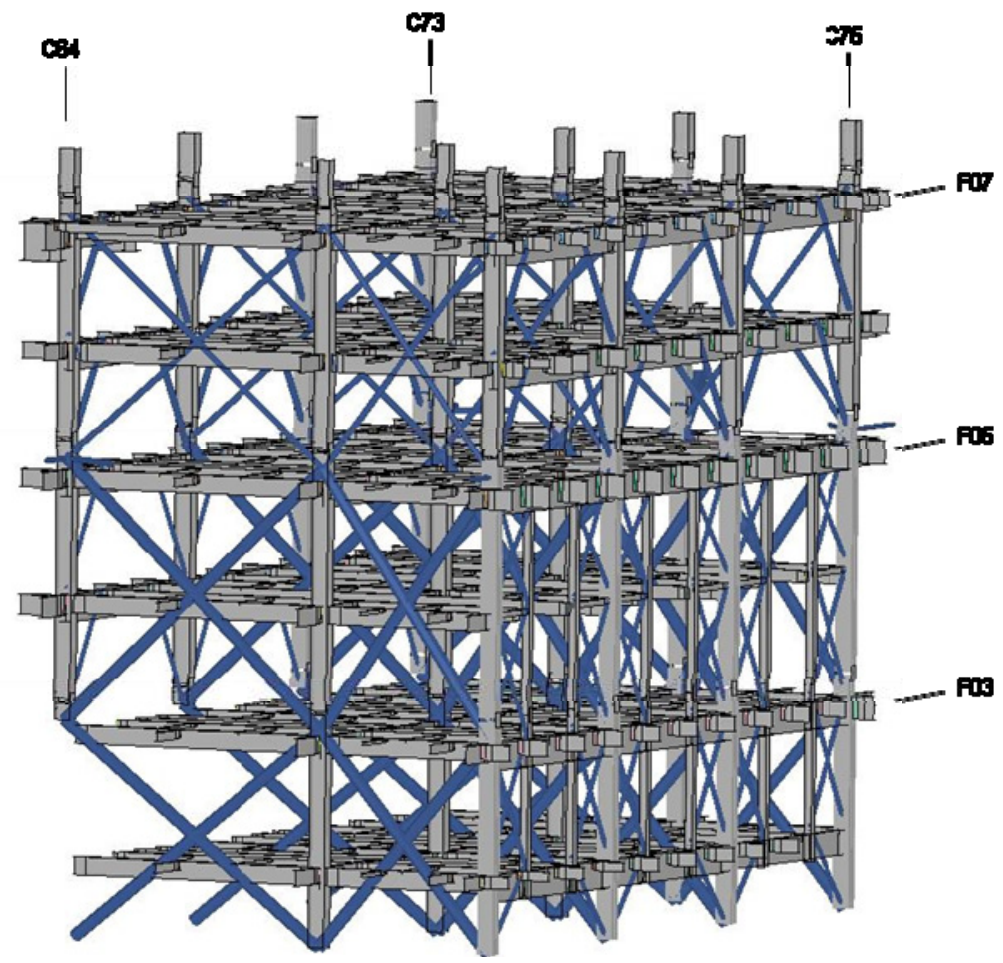

Figure 3-43. Core wind bracing in lower floors of the LS-DYNA model. View from southwest. 

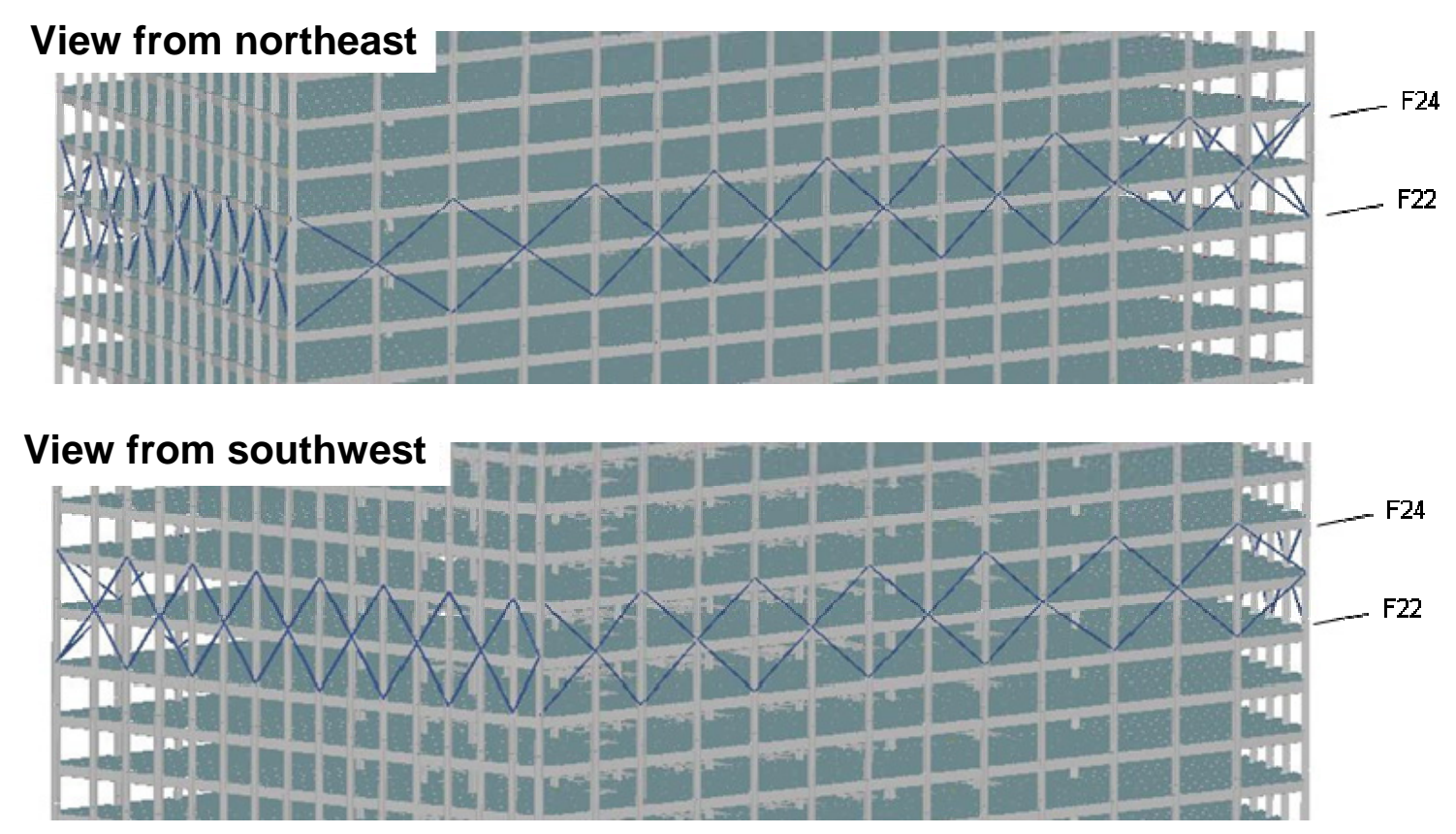

Figure 3-44. Belt Truss cross-bracing in the LS-DYNA model.

\section{Floor 5 Slab Diaphragm}

The Floor 5 slab reinforcement defined in structural drawing S-5A, $5^{\text {th }}$ Floor Diaphragm Framing Plan, was modeled with beam elements. The slab reinforcement, which were WT's, was approximated in the LS-DYNA model with beam elements. Unlike the actual construction, the beam elements in the model were not embedded in the slab since shear studs were not used between the WT's and the floor slab. The major horizontal truss elements were included in the model, as shown in Figure 3-45. 

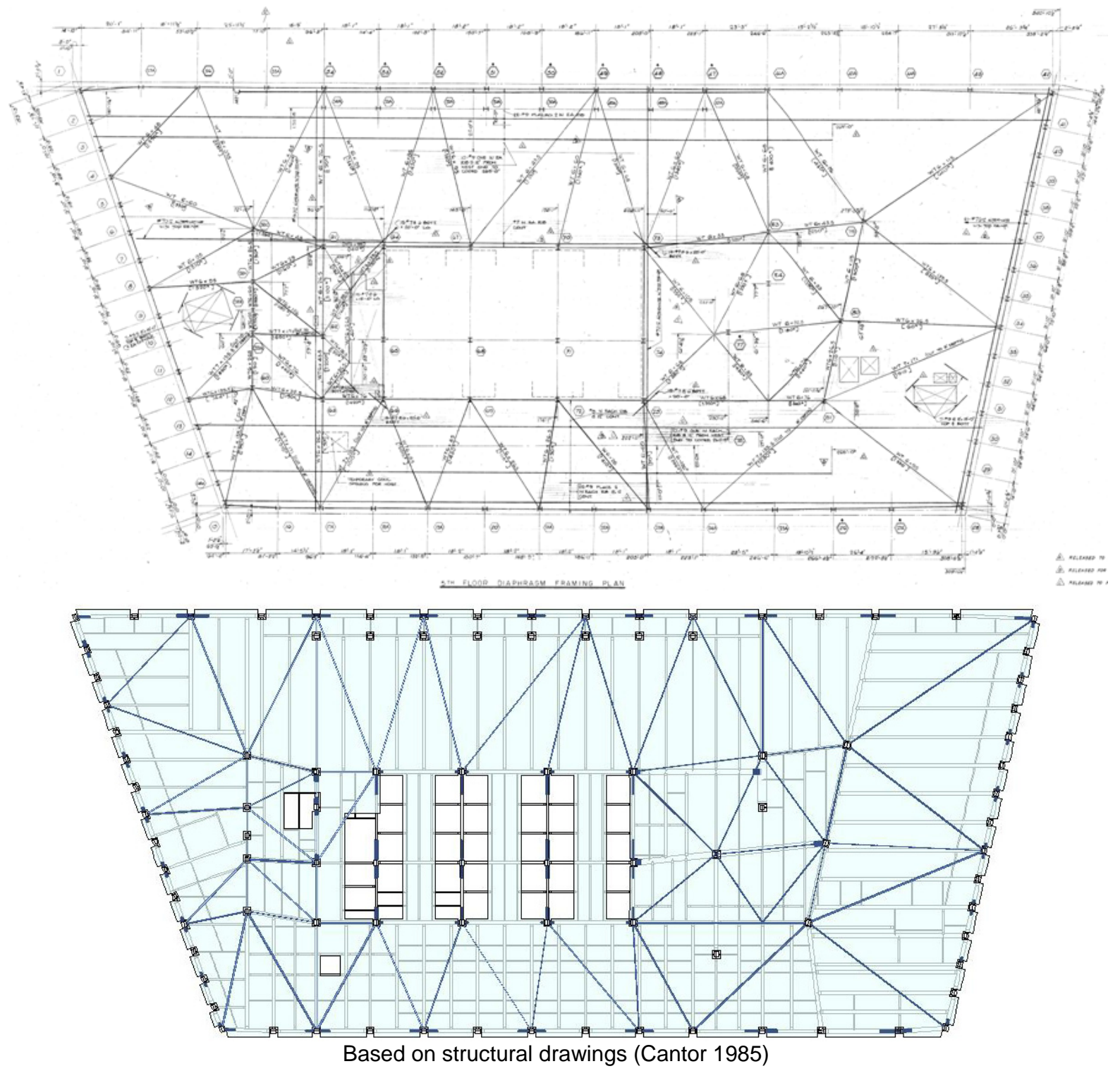

Figure 3-45. Model and drawing comparison of the $5^{\text {th }}$ floor diaphragm framing plan. (Upper view from Drawing S-5A)

\section{Model of Penthouse Structures}

A simplified model of the penthouse structures was generated using beam elements. The penthouse and the roof model are shown in Figure 3-46. Attachment of the penthouse structure to the global WTC 7 model was achieved by merging the beam ends into supporting columns or other framing in the roof structure.

Detailed connection models were not included in the penthouse framing model. To approximate the weak connections between the east penthouse and the screening wall section of the western penthouse, the two structures were decoupled. That is, the beam elements directly connecting the screening walls to the eastern penthouse were deleted from the calculation, as illustrated in Figure 3-47. This operation was performed at the same time that debris impact damage from the collapse of WTC 1 was applied to the model, as described in Section 3.3.3. 


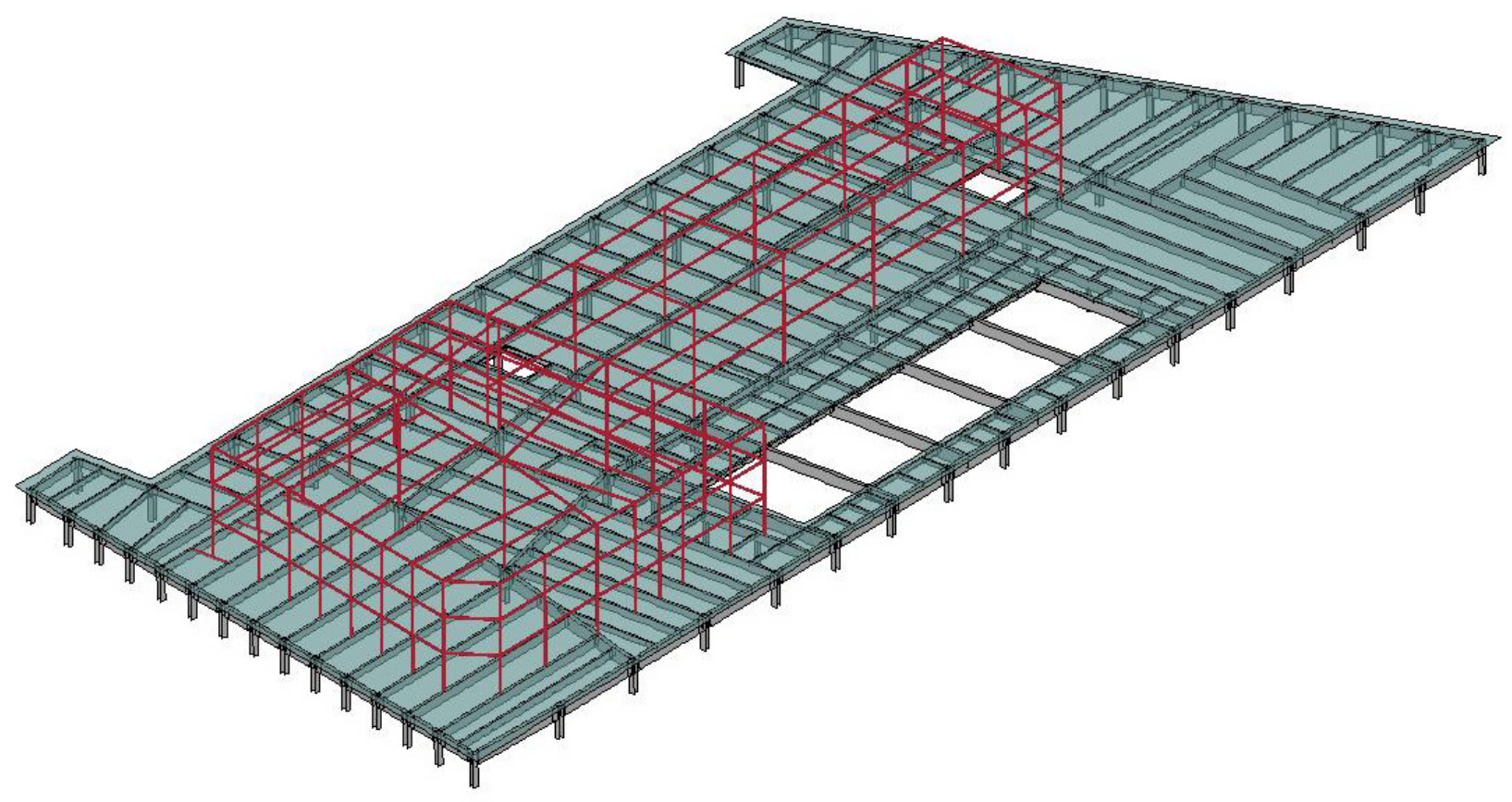

Figure 3-46. Simplified beam element model of the penthouse structure.

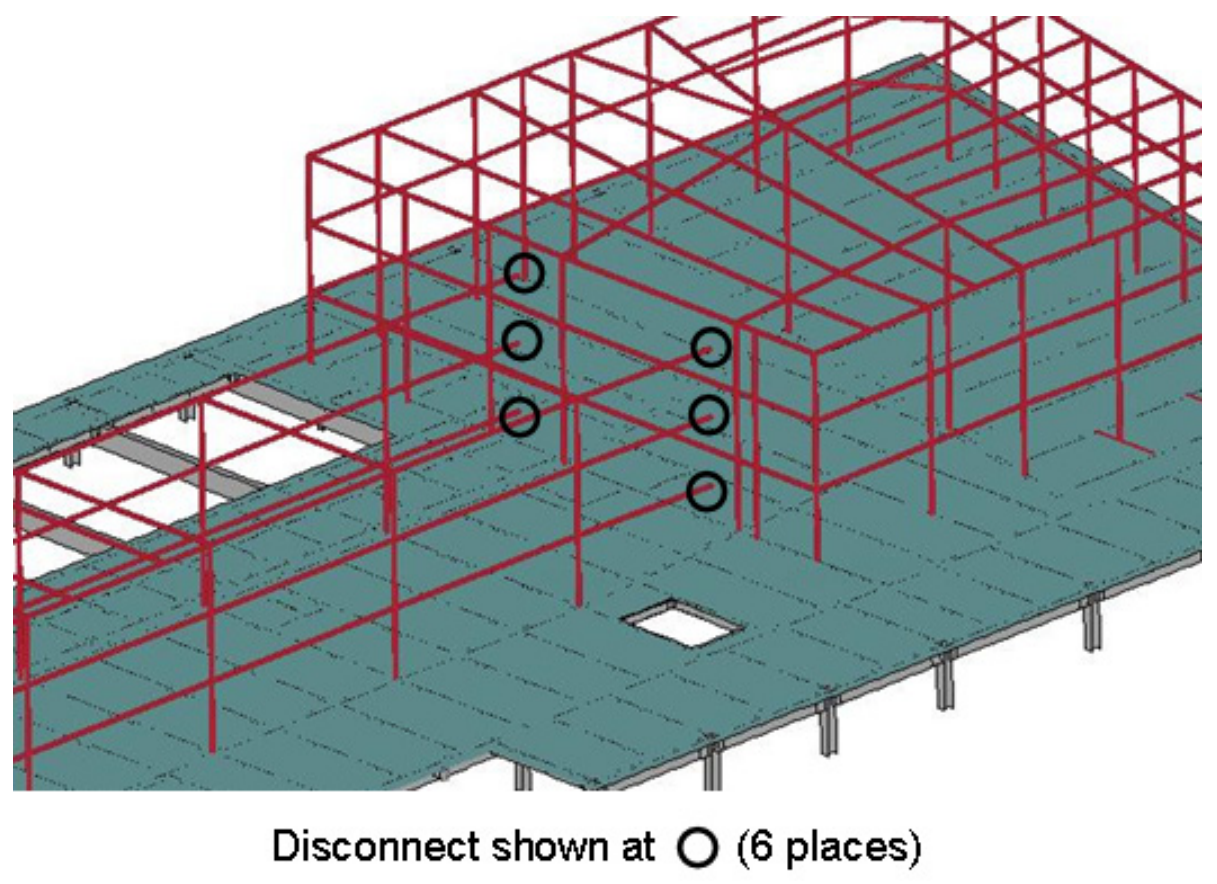

Figure 3-47. Separation of east penthouse from central screening wall structure. 


\subsubsection{Boundary Conditions}

To approximate the building connection to the foundation, the free column ends below the $2^{\text {nd }}$ floor framing were fully constrained in translation and rotation. The base of the Con Edison substation was fully fixed and the substation model itself was treated as a nondeformable rigid body. The columns originating from the top of the substation were, therefore, fully constrained as well with a tied contact interface connecting the base of the columns and the substation. Several beam members in Floors 2 and 3 framed directly into the substation. Ends of the framing members were connected to the substation with a tied interface to the rigid substation. Connections were modeled at the beam ends, as with other beams in the model, so connection failure was allowed, but the connected edge was, in essence, fixed to the rigidly constrained substation. The rest of the model was unconstrained.

\subsubsection{Model Initialization and Loading Sequence}

\section{Introduction}

The global model was initialized as follows to minimize any dynamic effects associated with loading sequence.

- First, gravity was applied slowly to the 47 floor structure, over $4.5 \mathrm{~s}$ of elapsed simulation time to damp residual vibrations and eliminate dynamic response. The loads were applied smoothly with a sinusoidal load curve.

- Then the debris impact damage from the collapse of WTC 1 was applied to the structure instantaneously by removing damaged elements from the model that were no longer capable of bearing their loads. The structure was then allowed to damp residual vibrations for $2 \mathrm{~s}$.

- Next, the structural temperatures were applied at the same time as the damage data from the ANSYS simulation. The temperatures were applied smoothly with a sinusoidal curve and allowed to damp residual vibrations for $2 \mathrm{~s}$.

- Last, the fire-induced damage obtained from the 16-story ANSYS analysis, including damage to floor beams, girders, and connections, was applied instantaneously. The heated, damaged structure was then free to react.

A chart showing the initialization sequence with the load curve profiles used is shown in Figure 3-48. The individual initialization steps and their effect on the global model are summarized in the following subsections. 


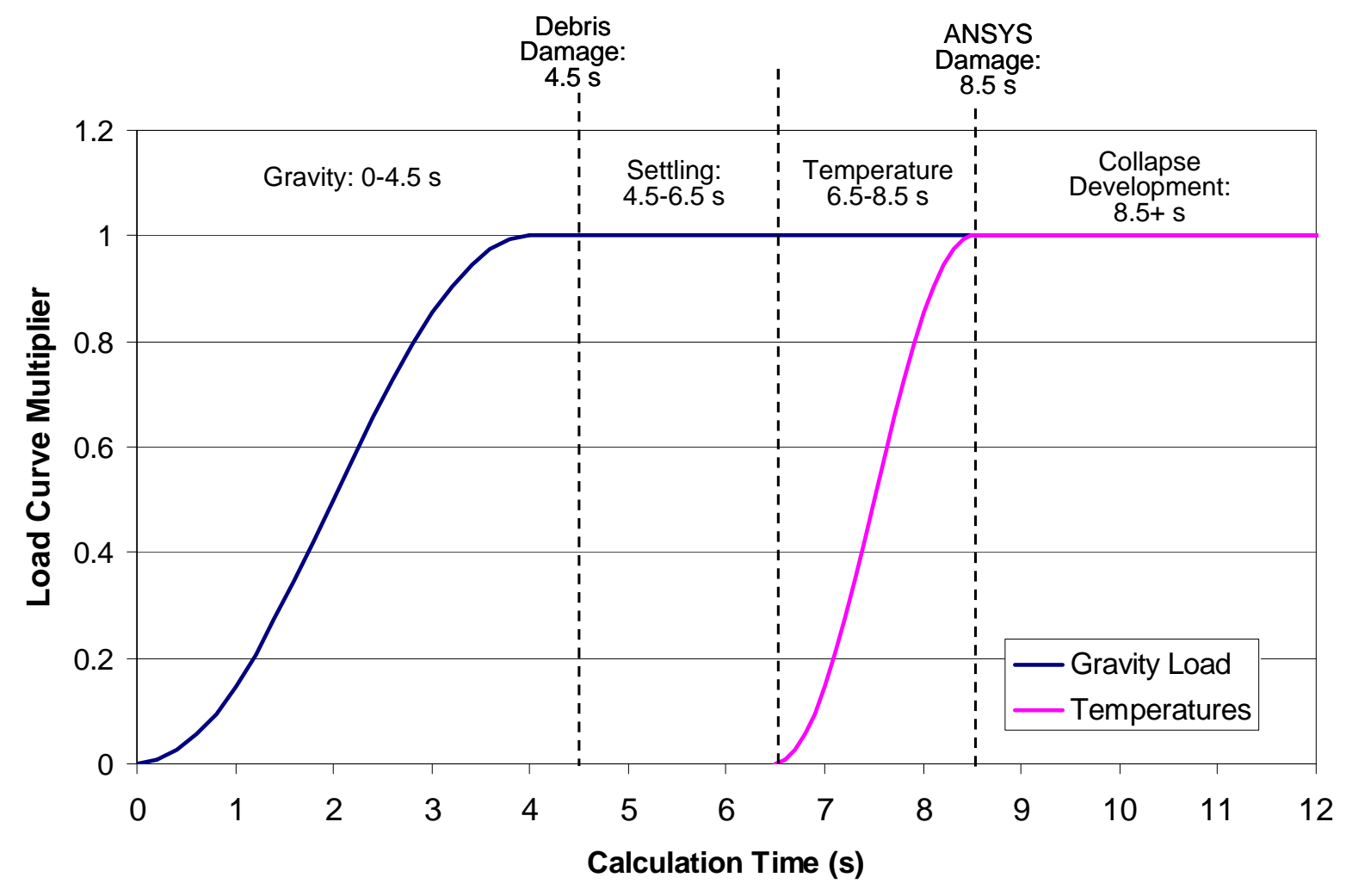

Figure 3-48. Initialization sequence for the global model.

\section{Gravity Application and Load Distribution}

\section{Additional Discrete Loads}

The dead load (DL) of the structure, which was the self-weight of the steel and the concrete slab, was applied throughout the structure. At Floors 7 and 46, discrete loads were added to model heavy equipment loads on the structure.

Mechanical equipment weighing 22 kip $(98 \mathrm{kN})$ was located on Floor 7 between Column 76 and Column 81. In the LS-DYNA model, the load was modeled with two rigid body plates, each weighing 11 kip $(49 \mathrm{kN})$. The plates were placed on top of the slab as shown in Figure 3-49, on either side of Column 76 to 78 , to model the appropriate weight distribution. The plates were not tied into the structure, they were held in place by gravity alone. 


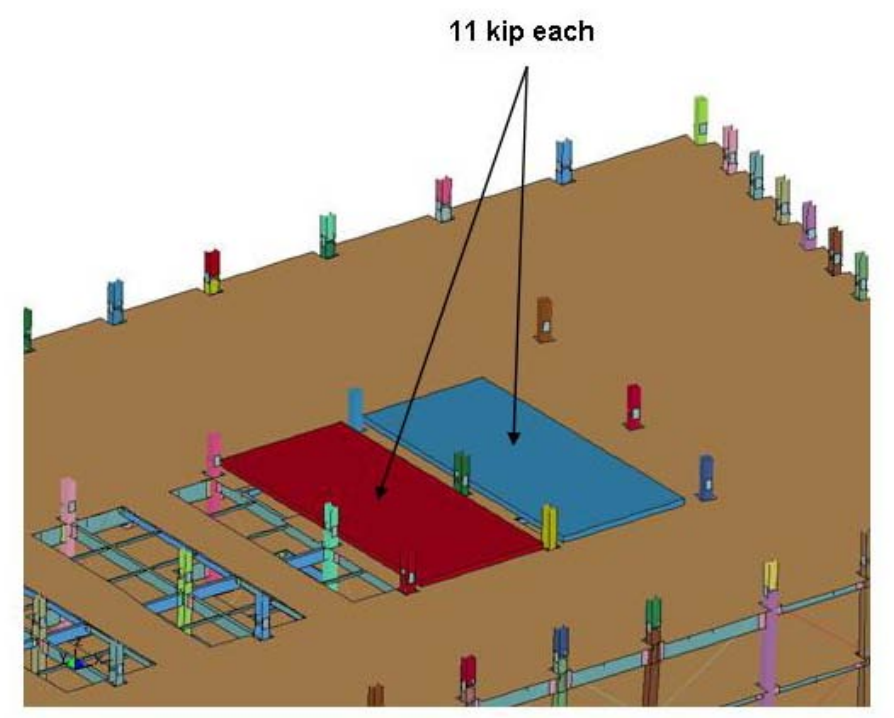

Figure 3-49. Rigid body models for additional loads at Floor 7.

On the northern floor span of Floor 46, there were two areas of discrete loads added to the WTC 7 model. Figure 3-50 illustrates the load distribution from cooling towers that weighed $425 \mathrm{kip}$ (1.89 MN) and mechanical equipment that weighed 667 kip (2.97MN). Two rigid body plates are shown with weights and distributed area tailored to the Floor 46 loads. As with Floor 7, the plates were placed on top of the slab.

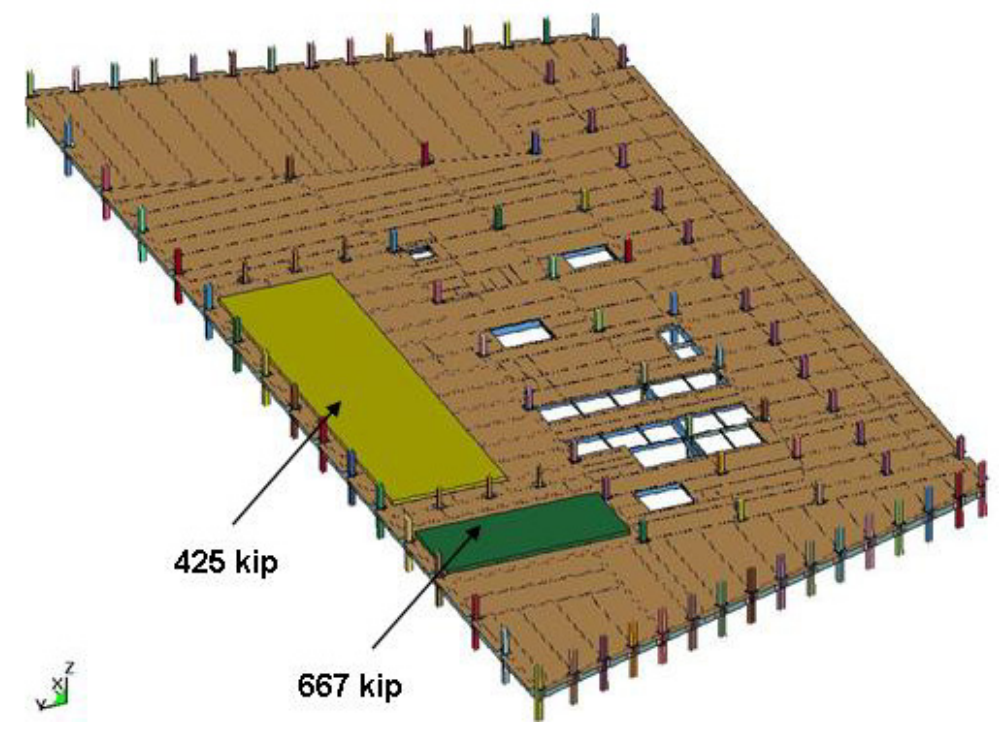

Figure 3-50. Rigid body models for additional loads at Floor 46.

\section{Treatment of Live Load and Comparison with Total Design Load}

Live load (LL) was added at the same time and in the same manner as the dead load, which was distributed evenly throughout the structure. This was accomplished by multiplying the modeled material densities with a common scale factor to achieve the desired total load. A 25 percent live load (0.25LL case) was used, based on estimates of the live loads in the building at the time of collapse. 
To compare to the design load, a check was performed with the modeled building weight after gravity initialization. For the DL + 0.25LL case, the expected design weight above Floor 8 was 174,136 kip $(774,592 \mathrm{kN})$. The initialized model showed a weight of 172,897 kip $(769,080 \mathrm{kN})$, for a difference of $0.7 \%$. Figure 3-51 illustrates the total load in pounds (lbf) above Floor 8 in the model during gravity initialization. The load increased smoothly as expected and without dynamic effects, indicating the gravity initialization duration of $4.5 \mathrm{~s}$ to full load was adequate (response up to $4.0 \mathrm{~s}$ is shown).

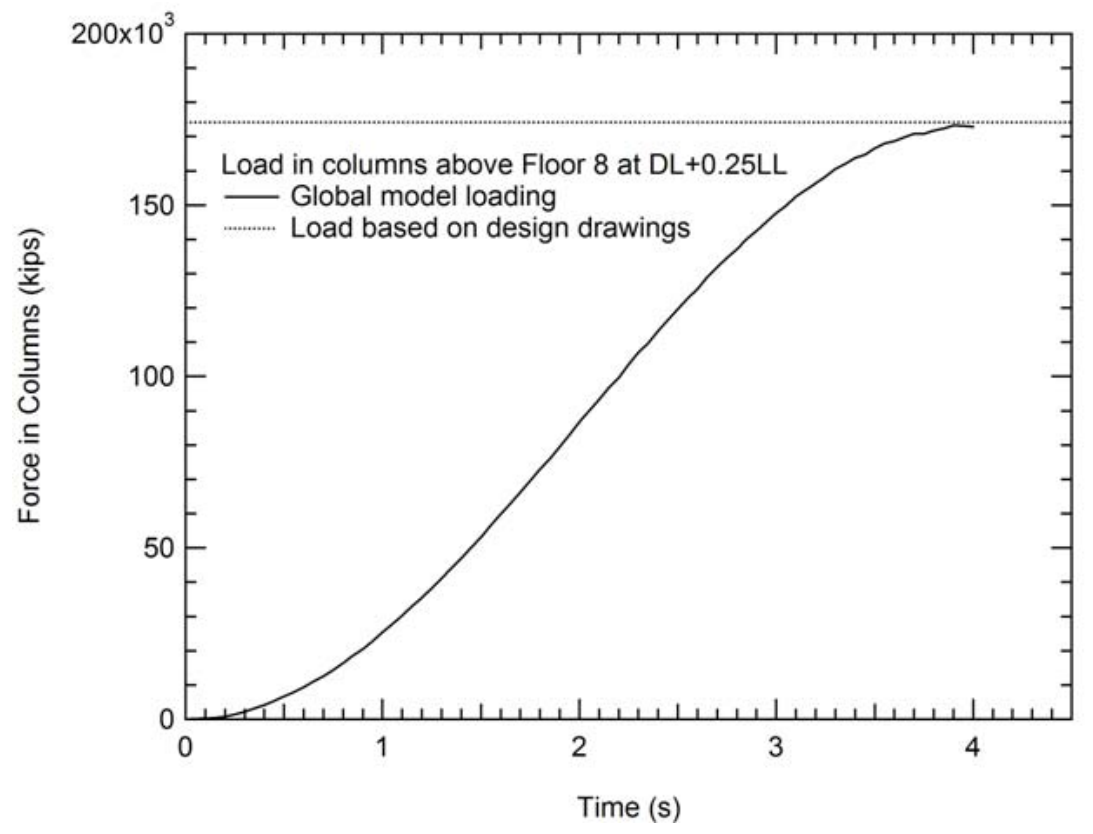

Figure 3-51. Load history (in lbf) above Floor 8 during gravity initialization (25\% live load case).

\section{Debris Impact Damage Input}

After gravity initialization, debris impact damage from the collapse of WTC 1 (NCSTAR NIST 1-9, Section 5.5.3) was applied to the global model instantaneously to approximate the dynamic event. The damage applied was isolated to two zones on the southern side of the building, as shown in Figure 3-52. In the LS-DYNA calculation, the damage was applied during a simple restart where a list of elements to delete was specified. The list of elements to delete was generated using LS-PREPOST by blanking out the damaged areas.

Detail views of the two debris impact zones in the LS-DYNA model are shown in Figure 3-53 and Figure 3-54. Zone 1 was in the lower southwest corner and included damage to the exterior columns and floor framing extending to the south core perimeter. In Zone 1, exterior Columns 14A through 20 were severed above Floor 7. Some floor sections in the debris zone were left cantilevered out from the core. Damage to Zone 2 at the upper floors along the central-southern face was much less extensive than the damage to Zone 1. Column 20 and some floor structure extending to the core perimeter were removed from the calculation above Floor 43.

After the damage was instantaneously applied to the model, the calculation was allowed to progress for $2 \mathrm{~s}$ prior to the start of temperature application. 


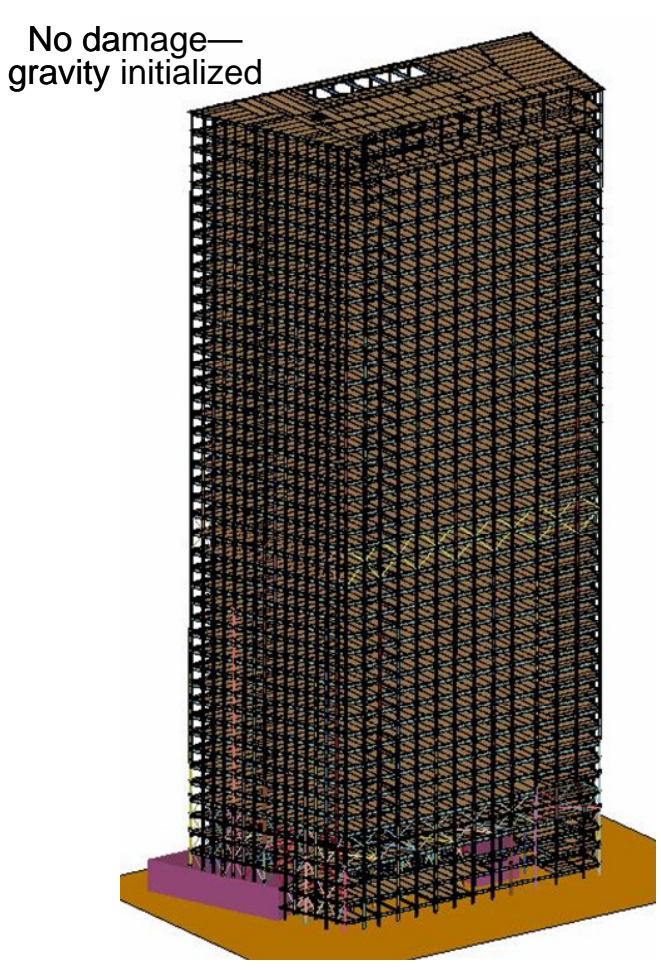

Debris impact damage included

one 2 perimeter

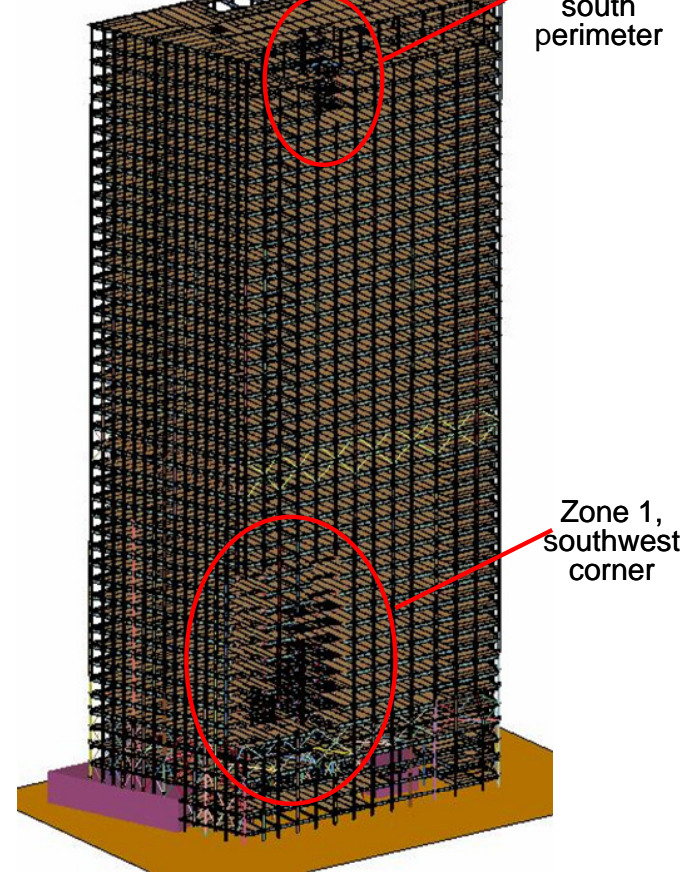

Figure 3-52. WTC 1 debris impact damage application to the global LS-DYNA model.

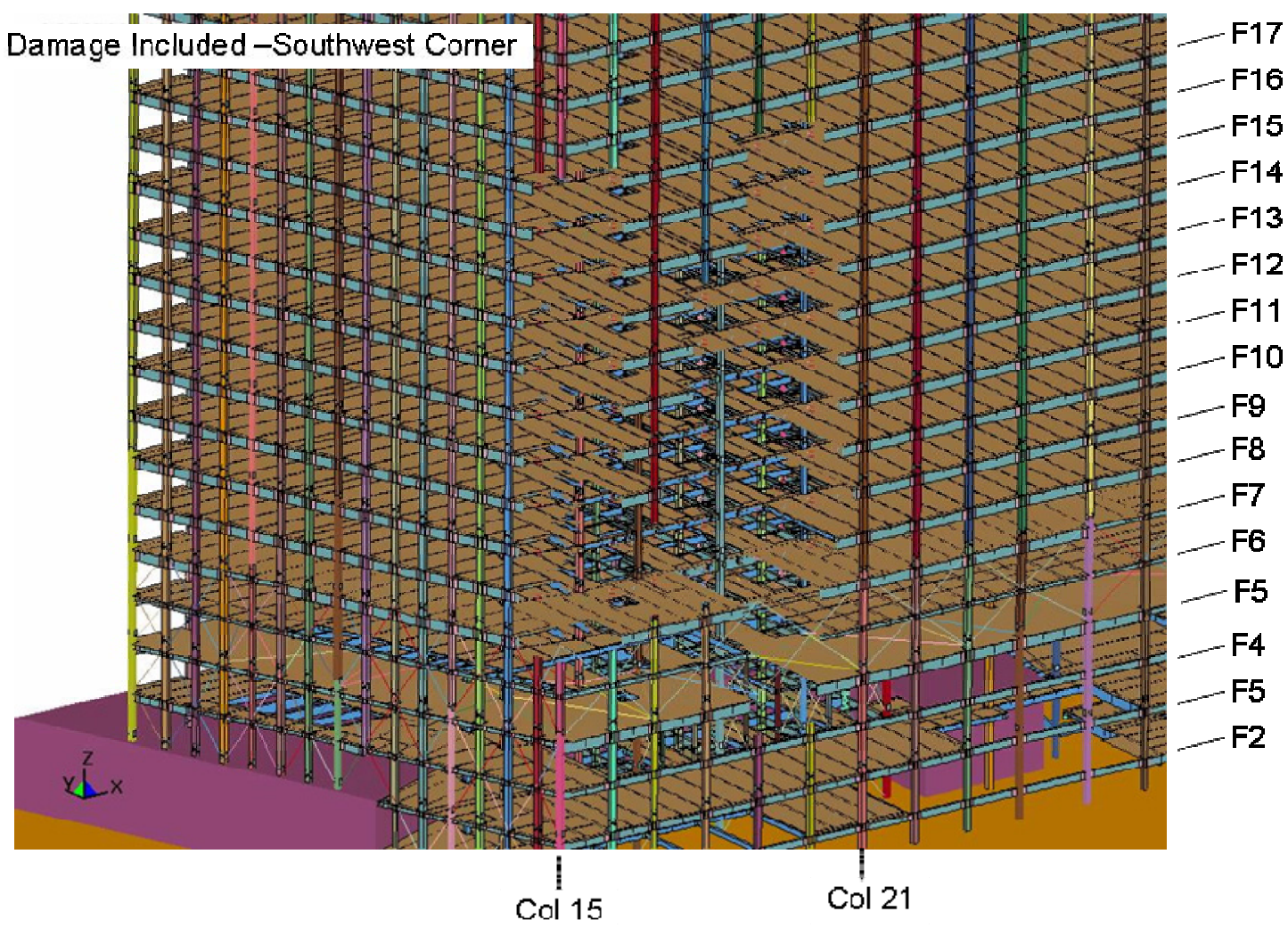

Figure 3-53. Detail view of Zone 1 impact debris damage in the LS-DYNA model. 


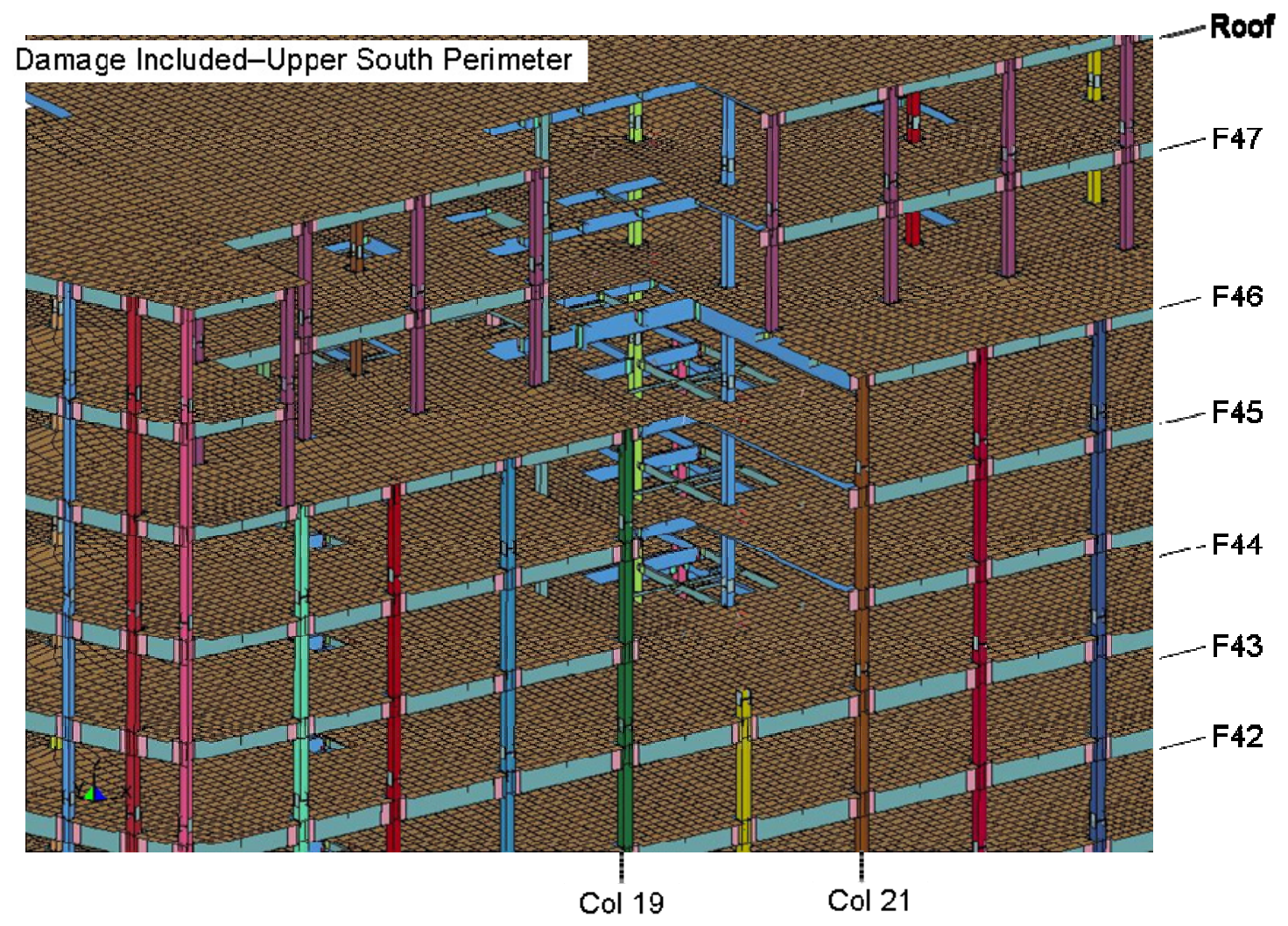

Figure 3-54. Detail view of Zone 2 impact debris damage in the LS-DYNA model.

\section{Temperature Application}

As shown in Figure 3-48, temperatures were applied to the model slowly and smoothly. Temperatures applied in the global model analysis were Case B temperatures at 4.0 hours (NCSTAR NIST 1-9, Section 10.3.3). Elevated temperatures occurred between Floors 7 and 14. Temperature profiles were mapped onto the LS-DYNA model as nodal properties and followed the prescribed time-dependent load curve shown in Figure 3-48. The resulting temperatures applied to the model are shown in Figure 3-55 and Figure 3-56. 


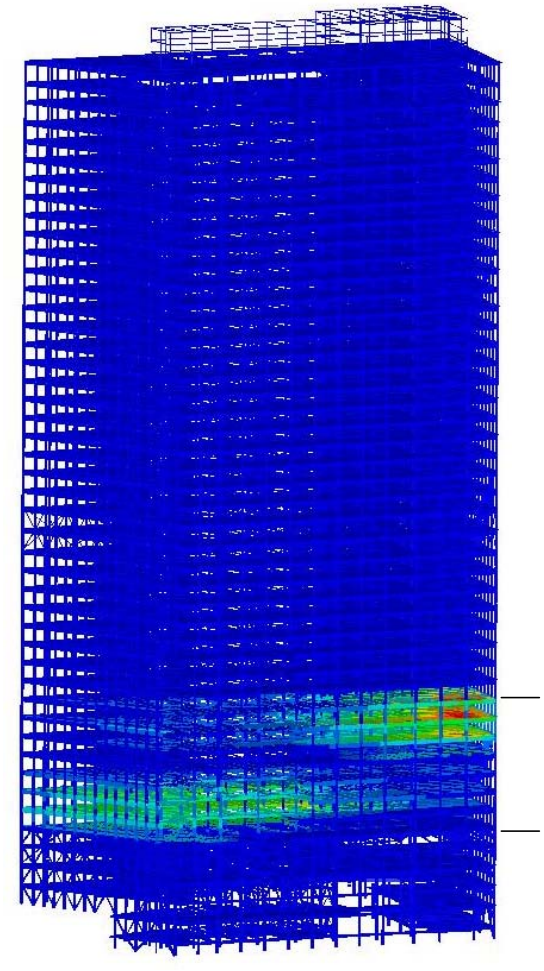

View from Southwest

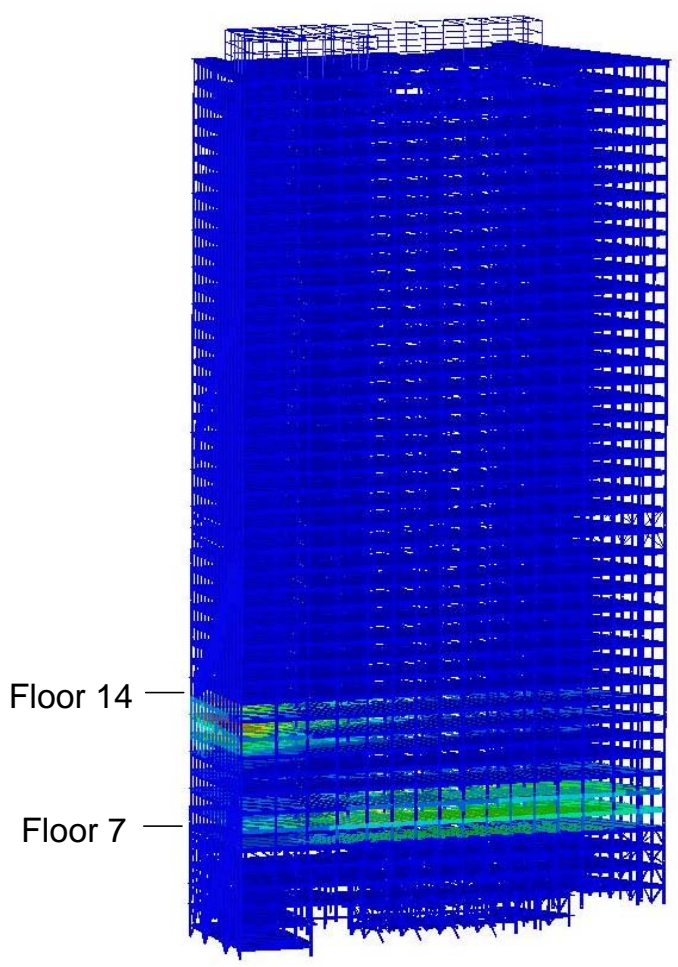

View from Northeast
Temp (C)

$7.356 \mathrm{e}+02$ $6.620 \mathrm{e}+02$

$5.885 \mathrm{e}+02$

$5.149 \mathrm{e}+02$

$4.414 \mathrm{e}+02$

$3.678 \mathrm{e}+02$

$2.942 \mathrm{e}+02$

$2.207 \mathrm{e}+02$

$1.471 \mathrm{e}+02$

$7.356 \mathrm{e}+01$

$0.000 \mathrm{e}+00$

Figure 3-55 Temperature profile (Case B) imposed on the global WTC 7 model.

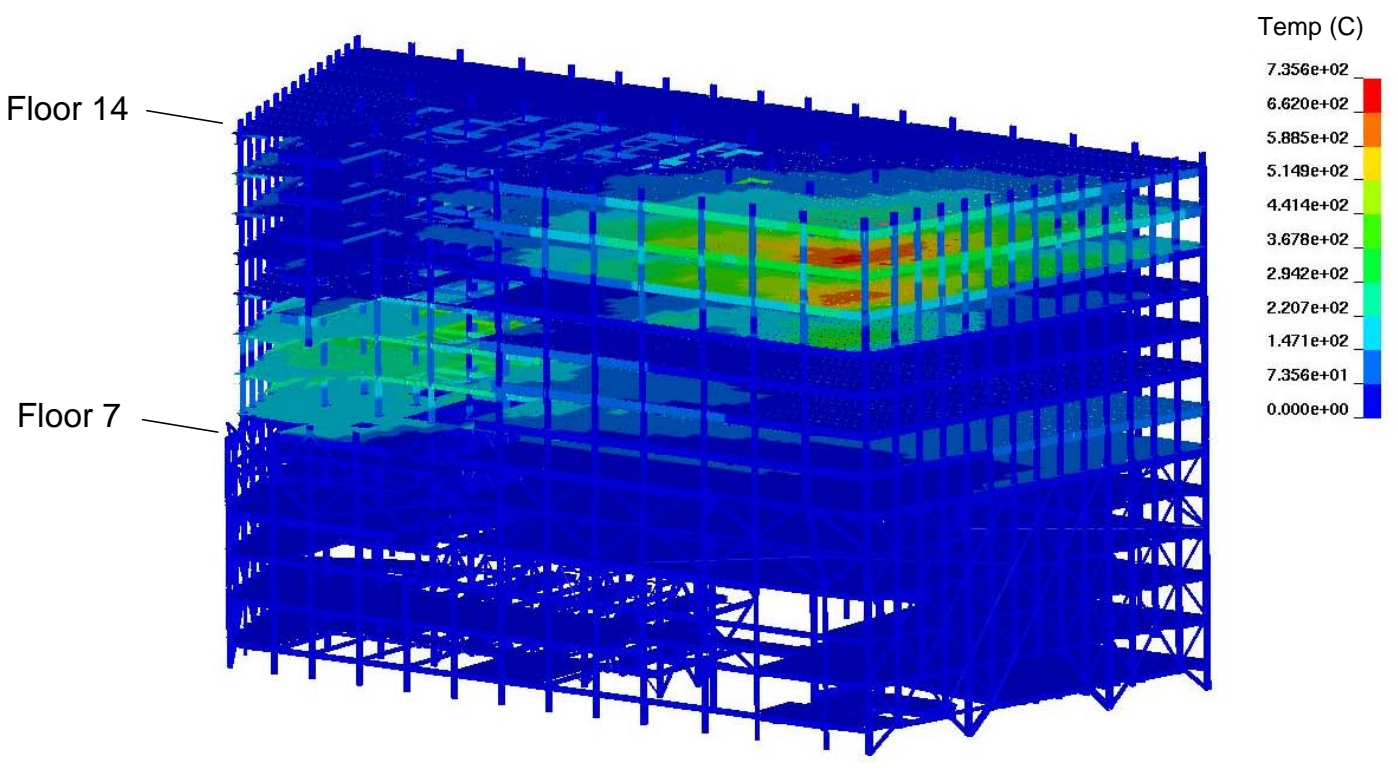

Figure 3-56. Detail view of the temperature profile in Floors 7 through 14.

\section{Thermally-induced Damage Application}

The final step in the initialization process was to apply thermally-induced damage from the ANSYS 16 story model (Chapter 11 of NCSTAR 1-9). The ANSYS model estimated the damage that occurred as the 
fires grew and spread on Floors 7, 8, and 9 and on Floors 11, 12, and 13. The LS-DYNA model, by comparison, considered only a temperature profile at the time when damage was transferred from the ANSYS model. The computed damage from the ANSYS model was added to the LS-DYNA model as the final step before simulating the structural response to the structural temperatures and the structural damage. The damage was specified as a list of elements to delete upon a simple restart.

Buckled beam and connection damage from the ANSYS analysis was superimposed on the LS-DYNA model. Buckled beams were modeled by removing flange and web elements from the specified beams, such that the beam would lose axial load capacity but the mass of the beam would remain in the calculation. An example of buckled beams in the southeast corner in Floor 14 of the global model is shown in Figure 3-57. Contours shown are steel temperatures with a range of $0{ }^{\circ} \mathrm{C}$ to $736{ }^{\circ} \mathrm{C}$.

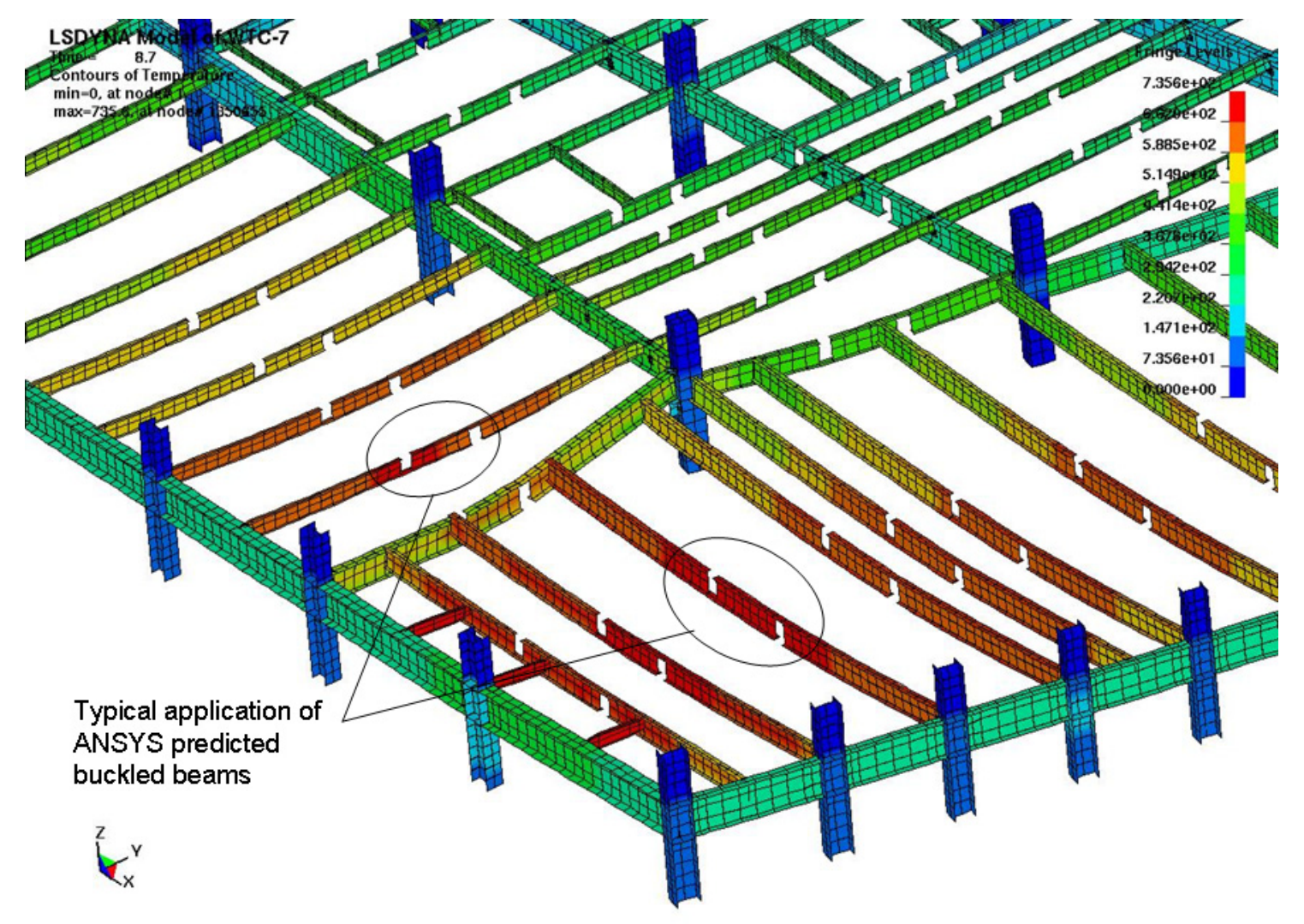

Figure 3-57. Application of ANSYS computed buckled beams in LS-DYNA model.

The connection damage data from ANSYS was transferred to the LS-DYNA global model using a damage index (NCSTAR NIST 1-9, Chapter 12). A connection could be partially damaged if less than all the bolts in a bolted connection had failed. The damage index described the degree of connection damage according to the following criteria: 0 to $0.25,0.25$ to $0.5,0.5$ to 0.75 , and 0.75 to 1.0 , where 0 was no damage and 1.0 was failure. Horizontal support and vertical support were specified separately. Due to the coarseness of the shell element modeling of the fin, knife, and header connections in the LS-DYNA model, approximations of the damage state were made as shown in Figure 3-58. 


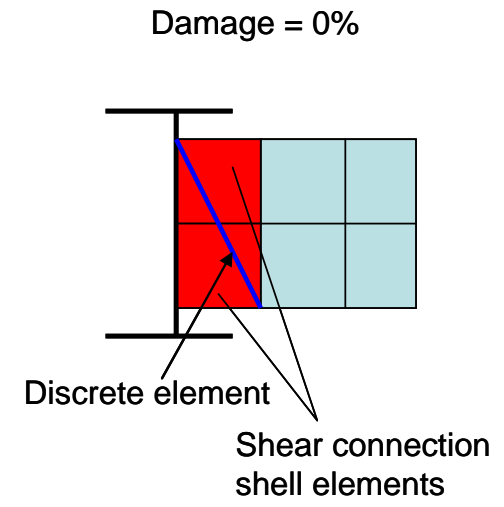

$50 \leq$ Damage $\leq 75 \%$

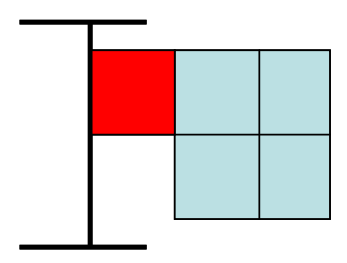

Discrete and lower shell element removed
$0<$ Damage $<50 \%$

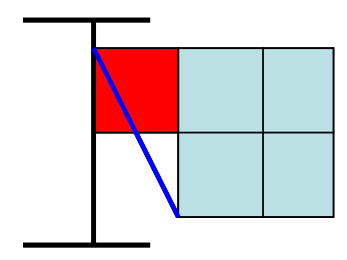

Lower shell element removed

$75 \%<$ Damage $\leq 100 \%$

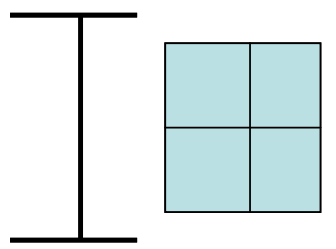

Shear connection failed

\section{Figure 3-58. ANSYS shear connection damage application in LS-DYNA model.}

Damage application to the various seated connections was more straightforward. Discrete elements corresponding to the specified number of failed bolts were removed for a given connection. Also, specified seat or clip damage was applied directly in the LS-DYNA model.

After ANSYS damage application, the model was allowed to progress without further input. The results of the global analysis are described in Chapter 4.

\section{Global Model Initialization Results}

Vertical displacements developed incrementally in the global model, corresponding to the stages of model initialization, as shown in Figure 3-59 through Figure 3-61. Figure 3-59 shows the global model vertical displacements due to gravity loads. Figure 3-60 illustrates the vertical displacement due to debris impact damage application. A pronounced displacement on the southern face toward the zone 1 damage is evident in the figure. Figure 3-61 shows the subsequent change in vertical displacement after Case B, 4.0 hour temperature application. A slight increase in elevation at the upper floors can be seen in the figure, which was due to thermal expansion of column segments in the lower floors. The increase in column length measured at roof level was approximately $0.015 \mathrm{~m}$ (0.6 in.). Also, the heated floors displaced vertically due to damaged floor framing and connections as a result of the elevated temperatures. 


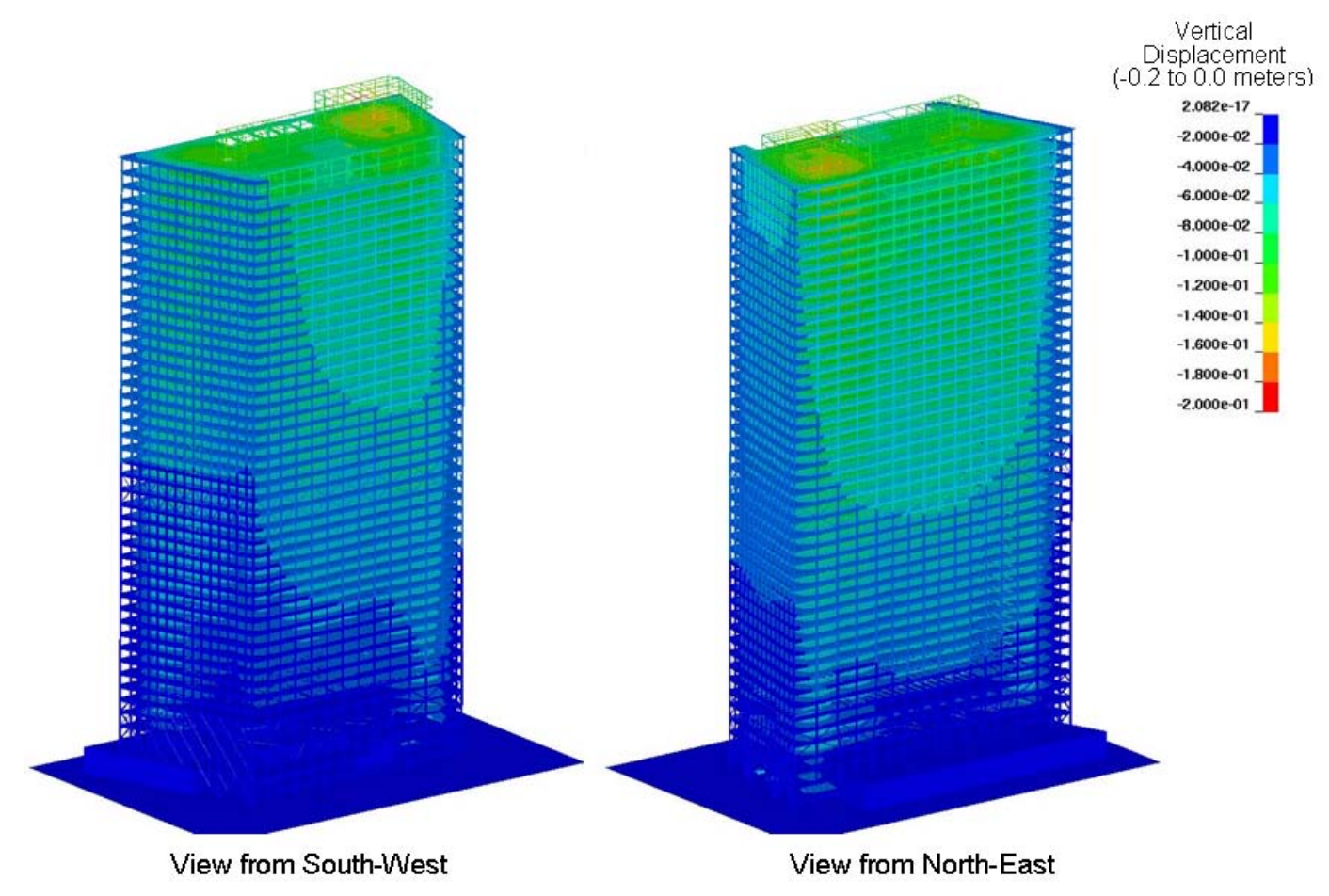

Figure 3-59. Calculated global vertical displacements after gravity initialization.
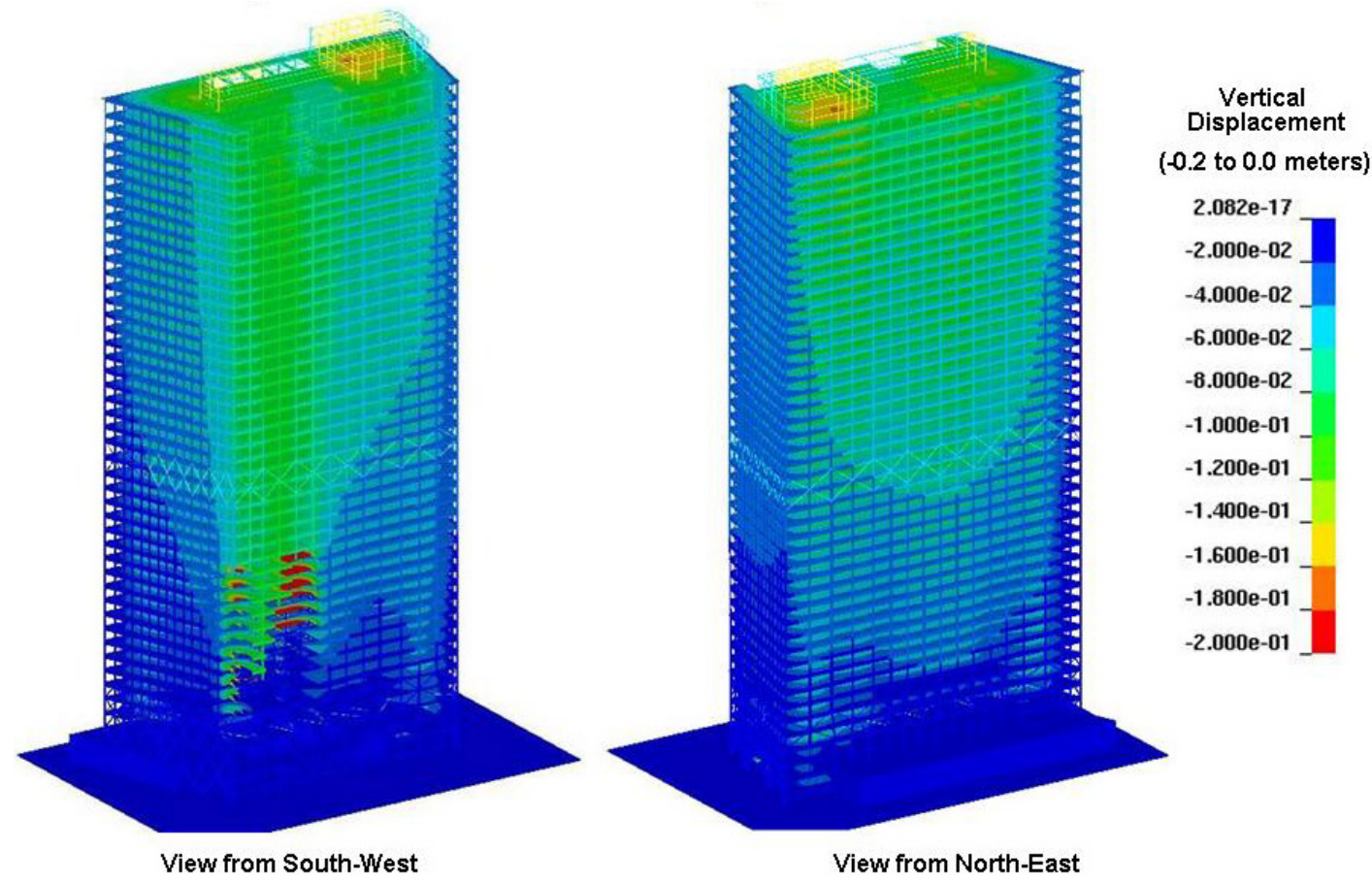

Figure 3-60. Calculated global vertical displacements after initial impact damage. 


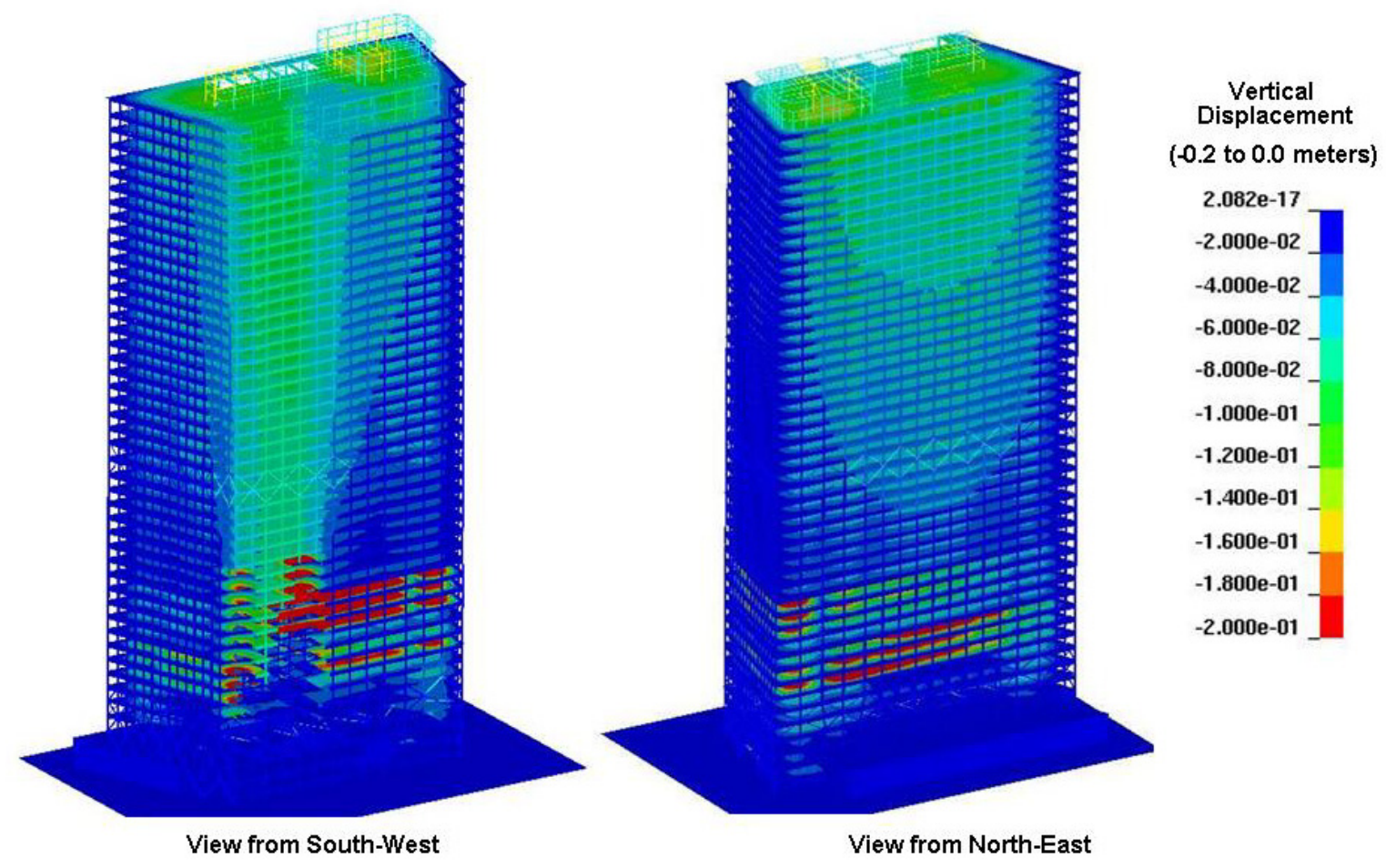

Figure 3-61. Calculated global vertical displacements after temperature initialization.

Detail views illustrating the vertical displacements of the lower floors, from the foundation to Floor 14, are shown in Figure 3-62 (a) after debris impact damage application and (b) after full temperature application. Figure 3-63 shows corresponding views with contours of effective stress overlaid on the structure to illustrate the change in stress from one initialization state to the next. The maximum range was set at $300 \mathrm{MPa}$, which is approximately the yield stress for unsoftened $42 \mathrm{ksi}$ to $50 \mathrm{ksi}$ (290 MPa to $345 \mathrm{MPa})$ steel. 


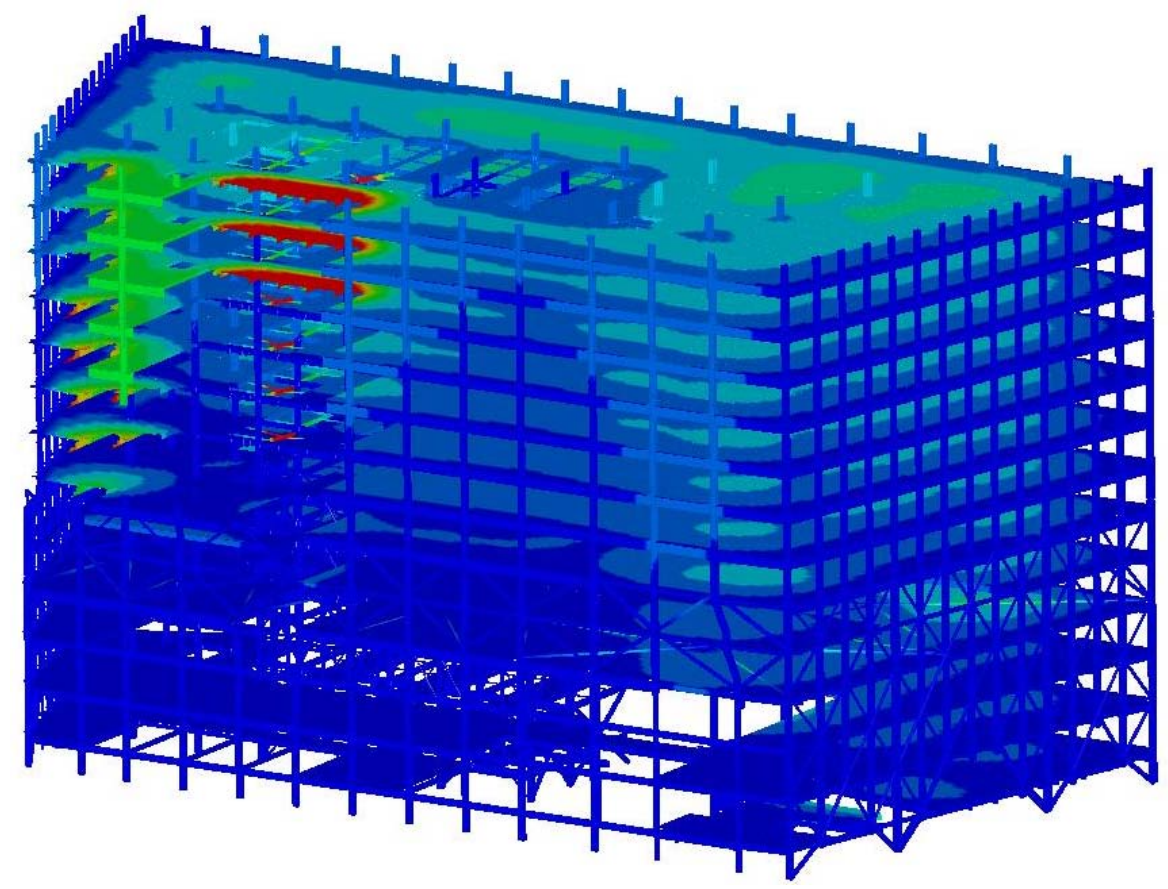

Vertical

Displacement

-0.2 to $0 \mathrm{~m}$

(-8 to 0 in)

2.082e-17

$-2.000 \mathrm{e}-02$

$-4.000 \mathrm{e}-02$

$-6.000 \mathrm{e}-02$

$-8.000 \mathrm{e}-02$

$-1.000 \mathrm{e}-01$

$-1.200 \mathrm{e}-01$

$-1.400 \mathrm{e}-01$

$-1.600 \mathrm{e}-01$

$-1.800 \mathrm{e}-01$

$-2.000 \mathrm{e}-01$

(a) After debris impact damage initialization

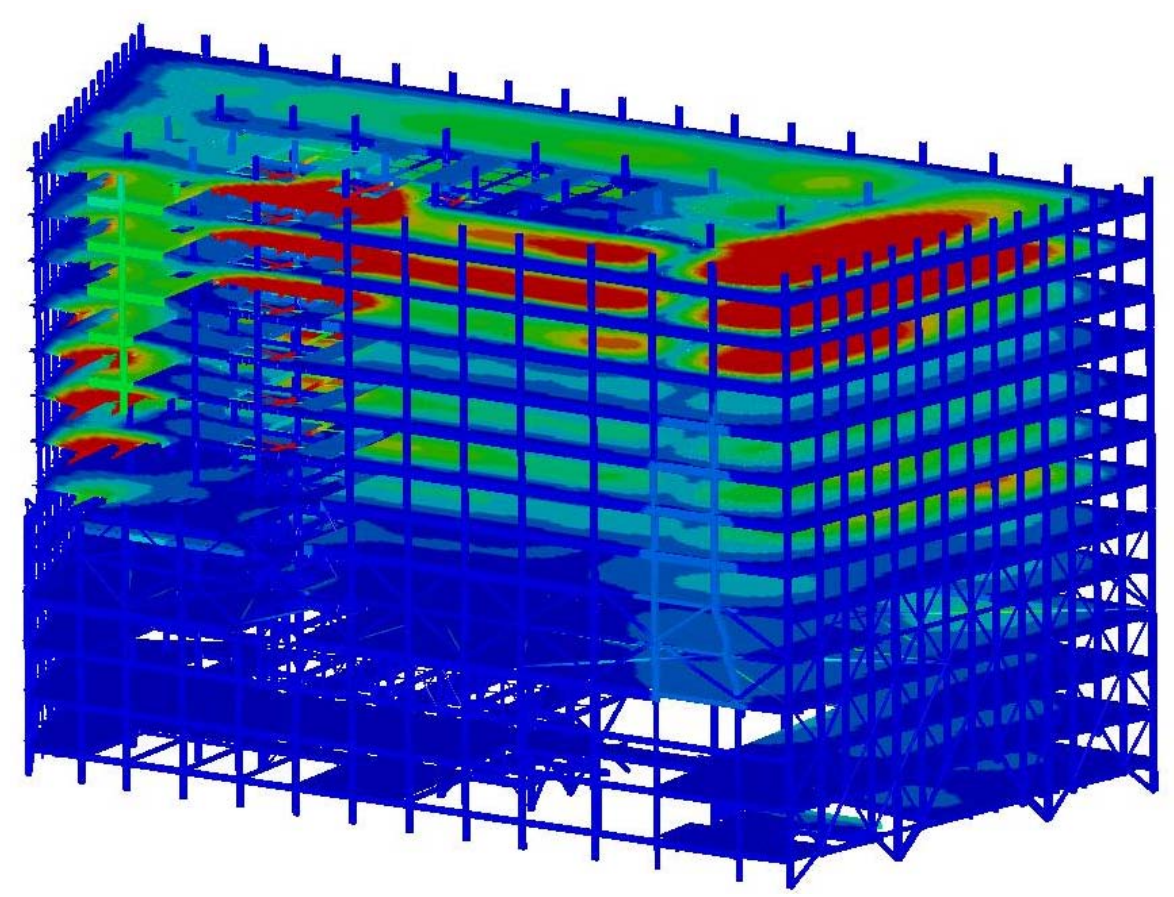

Vertical

Displacement

-0.2 to $0 \mathrm{~m}$

(-8 to 0 in)

2.082e-17

$-2.000 \mathrm{e}-02$

$-4.000 \mathrm{e}-02$

$-6.000 \mathrm{e}-02$

$-8.000 \mathrm{e}-02$

$-1.000 \mathrm{e}-01$

$-1.200 \mathrm{e}-01$

$-1.400 \mathrm{e}-01$

$-1.600 \mathrm{e}-01$

$-1.800 \mathrm{e}-01$

$-2.000 \mathrm{e}-01$

(b) After temperature initialization

Figure 3-62. Detailed comparison of vertical displacements after damage and temperature initializations. 


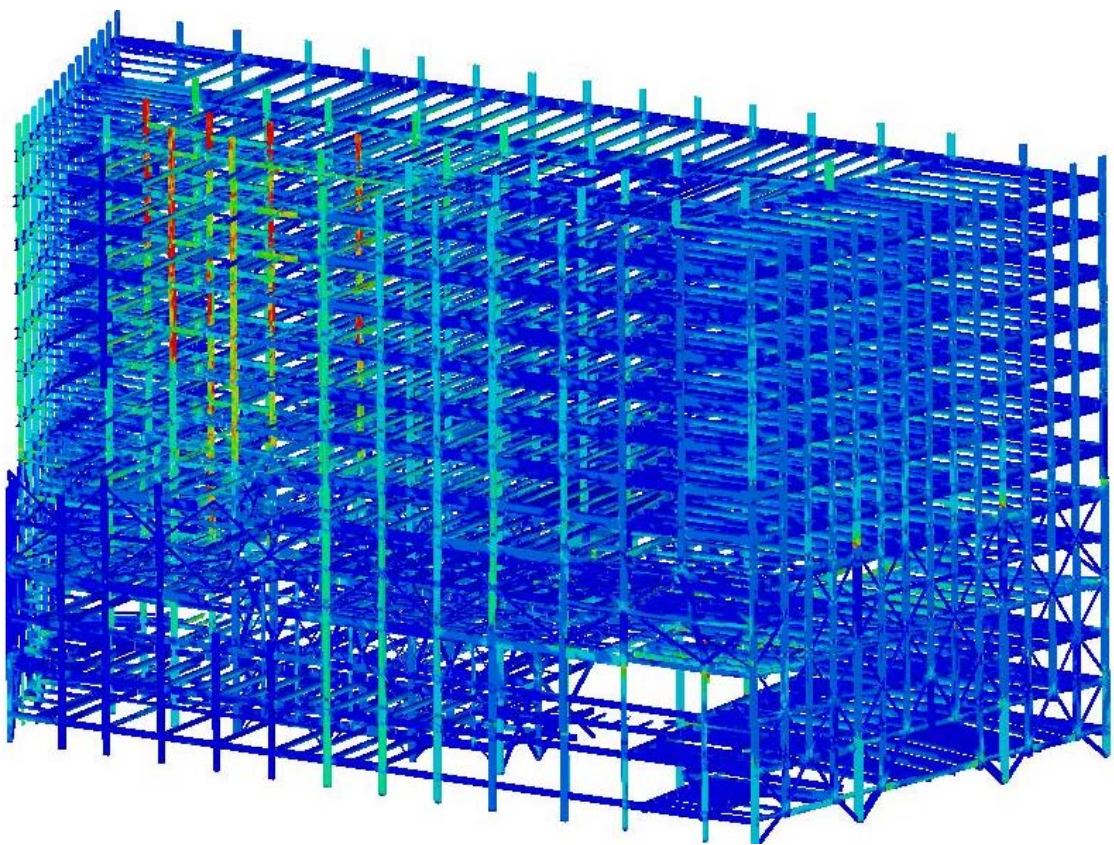

(a) After damage initialization
Effective Stress

0 to $300 \mathrm{MPa}$

(0 to $43.5 \mathrm{ksi}$ )

$3.000 \mathrm{e}+08$

$2.700 \mathrm{e}+08$

$2.400 \mathrm{e}+08$

$2.100 \mathrm{e}+08$

$1.800 \mathrm{e}+08$

$1.500 \mathrm{e}+08$

$1.200 \mathrm{e}+08$

$9.000 \mathrm{e}+07$

$6.000 \mathrm{e}+07$

$3.000 \mathrm{e}+07$

$0.000 \mathrm{e}+00$

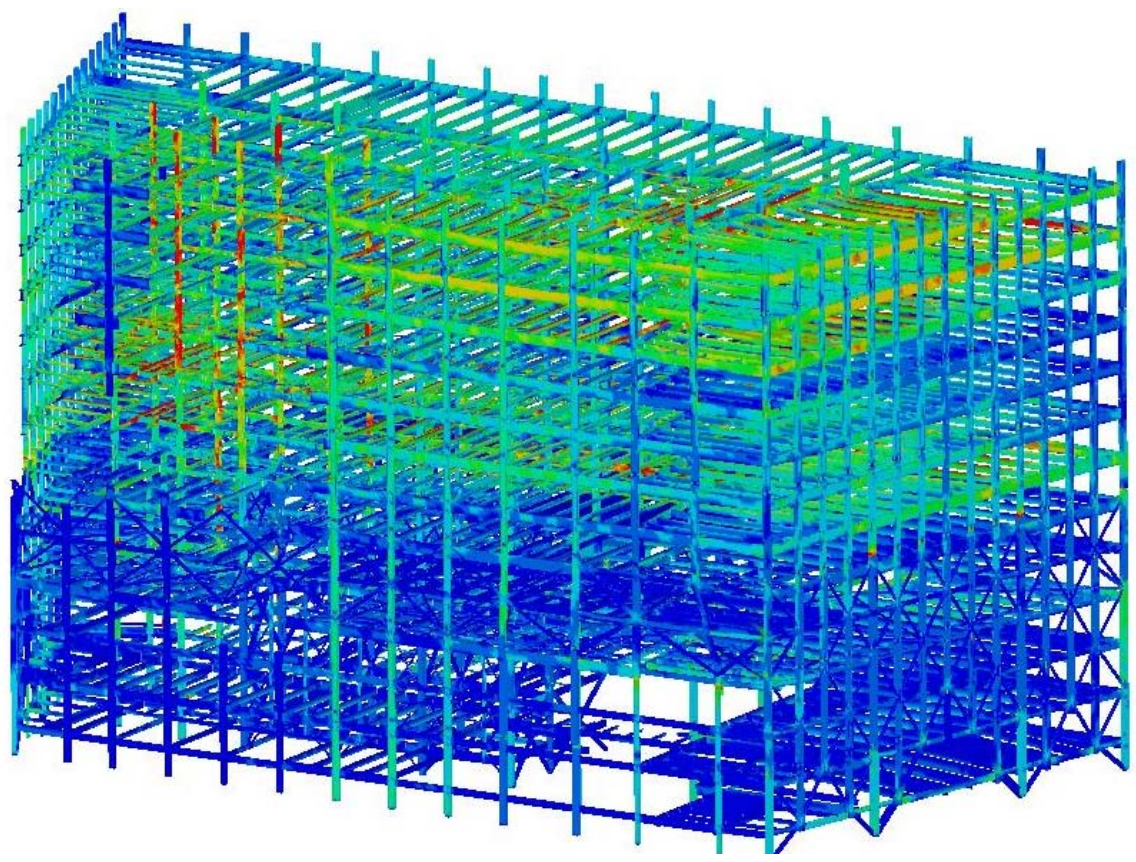

Effective Stress

0 to $300 \mathrm{MPa}$

(0 to $43.5 \mathrm{ksi}$ )

$3.000 \mathrm{e}+08$

$2.700 \mathrm{e}+08$

$2.400 \mathrm{e}+08$

$2.100 \mathrm{e}+08$

$1.800 \mathrm{e}+08$

$1.500 \mathrm{e}+08$

$1.200 \mathrm{e}+08$

$9.000 \mathrm{e}+07$

$6.000 \mathrm{e}+07$

$3.000 \mathrm{e}+07$

$0.000 \mathrm{e}+00$

(b) After temperature initialization

Figure 3-63. Detailed comparison of effective stress after damage and temperature initializations. 


\subsection{SUBASSEMBLY FLOOR MODELS}

Subassembly models, consisting of a subset of floors, were used to assess the model behavior for failure events during the model development and to assess the global model performance (e.g., time step size during the analysis). The primary subassembly model used was a two floor model that was much smaller and faster to execute than the global model of WTC 7. For some aspects of the analysis, the two floor subassembly model was not sufficient. An example is the assessment of the stability of WTC 7 after initialization of the impact damage. This stability analysis required a sufficient assembly of the building over the damaged components in order to transfer and bridge the loads around the missing components. For this case, a 14 floor subassembly model was used. The subassembly models were used to examine the effects of column support removal, temperature application, and fire-induced damage on the floor response. The two floor model is described here, but the same procedure was used to develop the 14 floor subassembly model. The results from these models are presented in Section 4.2

\subsubsection{Model Description}

The two floor subassembly model is a subset of the global model. As described in Section 3.1, the same TrueGrid model files were used to generate the full global model or any part of it. For the subassembly modeling effort, a two floor model of Floors 10 and 11 was used. Both floors had the standard framing layout found in Floors 8 to 20 and 24 to 45. Figure 3-64 shows the model used in the two floor analyses.

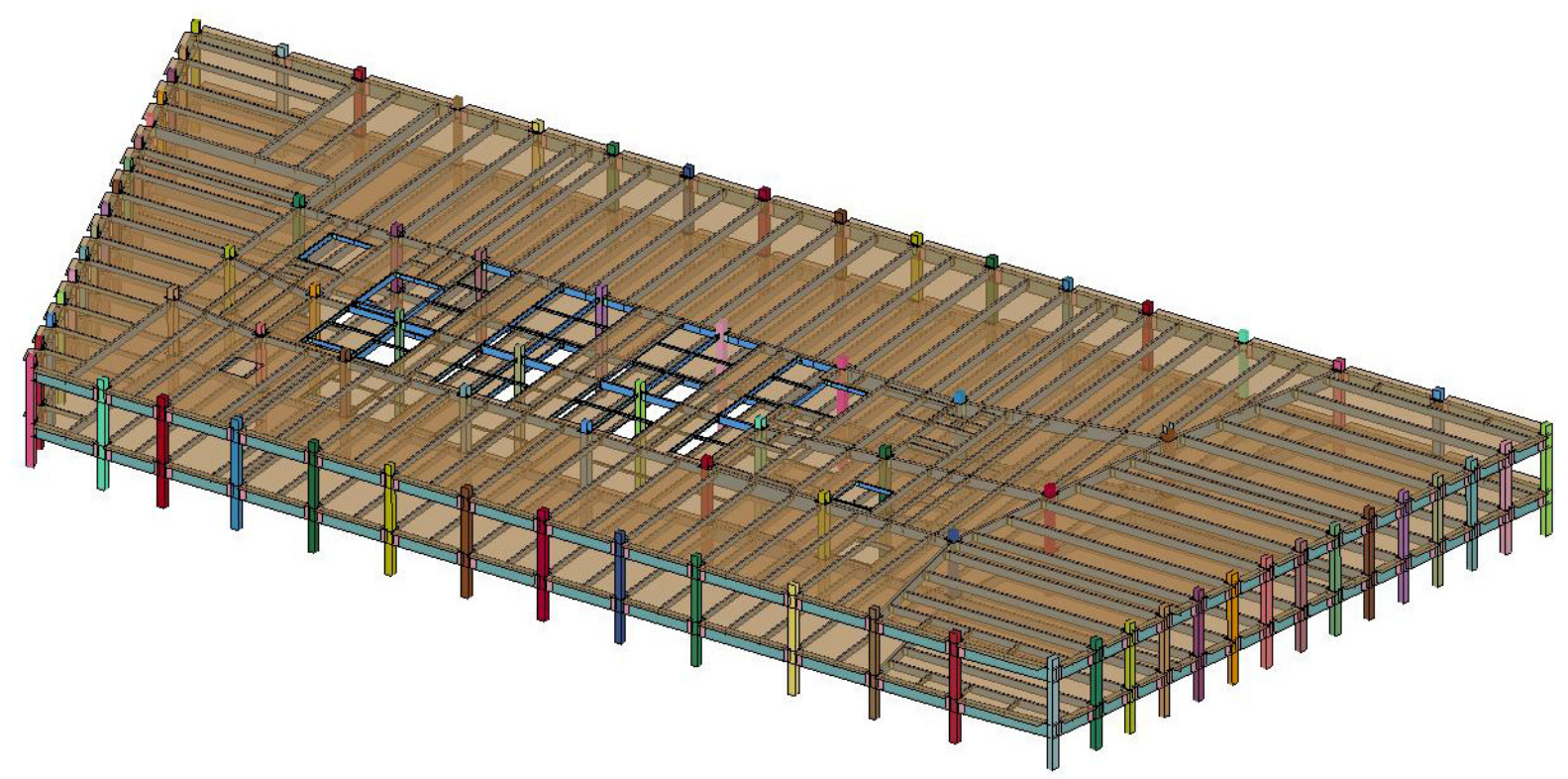

Figure 3-64. Two-floor subassembly model (slabs shown as transparent).

\subsubsection{Boundary Conditions}

Similar to the global model, the free ends at the base of the modeled columns were fully fixed. The free ends at the top of the columns were unconstrained. Boundary conditions were set during the TrueGrid mesh generation process. 


\subsubsection{Model Initialization and Loading Sequence}

The same initialization methodology was used in the two floor model analyses as in the global model analyses. The only difference was that debris damage was not used in the two floor model. It was used in the 14 story subassembly model, which is described in Chapter 4 . For the two floor analyses, a 4 s gravity initialization phase was followed by a $2 \mathrm{~s}$ temperature application phase. Two temperature profiles were considered in the subassembly analyses: Case A and Case B at 5 h (NIST NCSTAR 1-9, Chapter 10). Results from these analyses, described in Chapter 4, were used to refine the format of the temperature profiles for the subsequent global model analysis. Any imposed structural damage was applied instantaneously immediately following temperature initialization.

Vertical displacements predicted for the two floor model after gravity initialization are shown in Figure 3-65. Figure 3-66 illustrates the change in vertical displacement after Case A, $5.0 \mathrm{~h}$ temperatures were applied to the model.

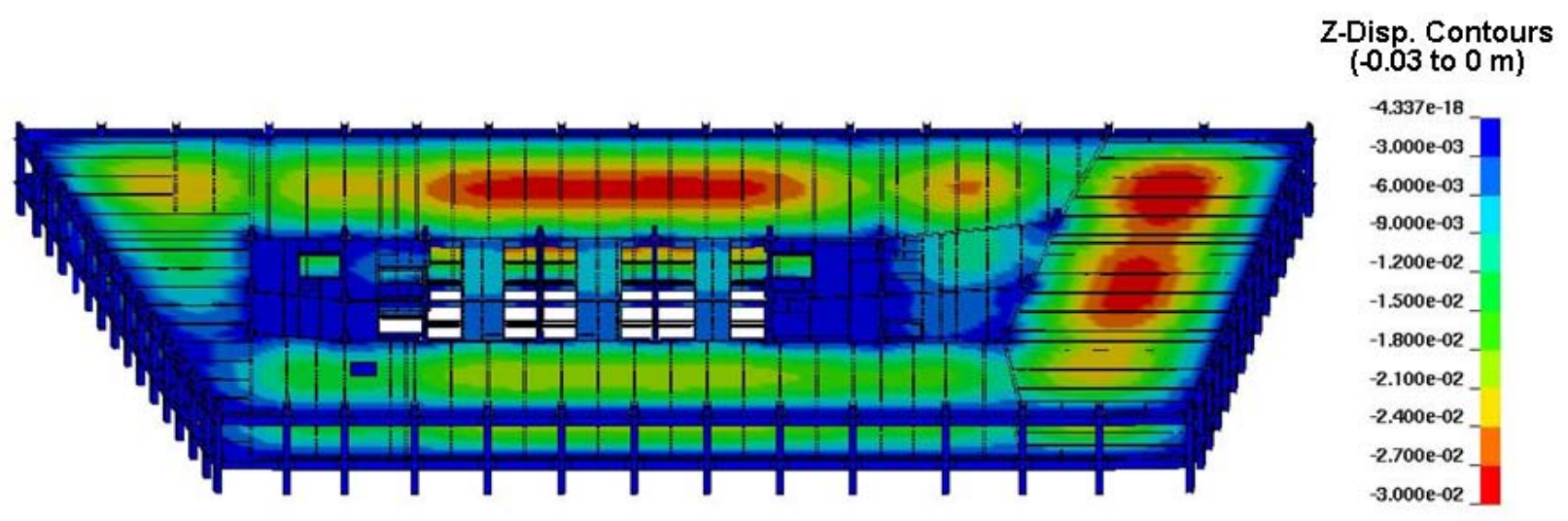

Figure 3-65. Vertical displacement in the two floor model after gravity initialization.

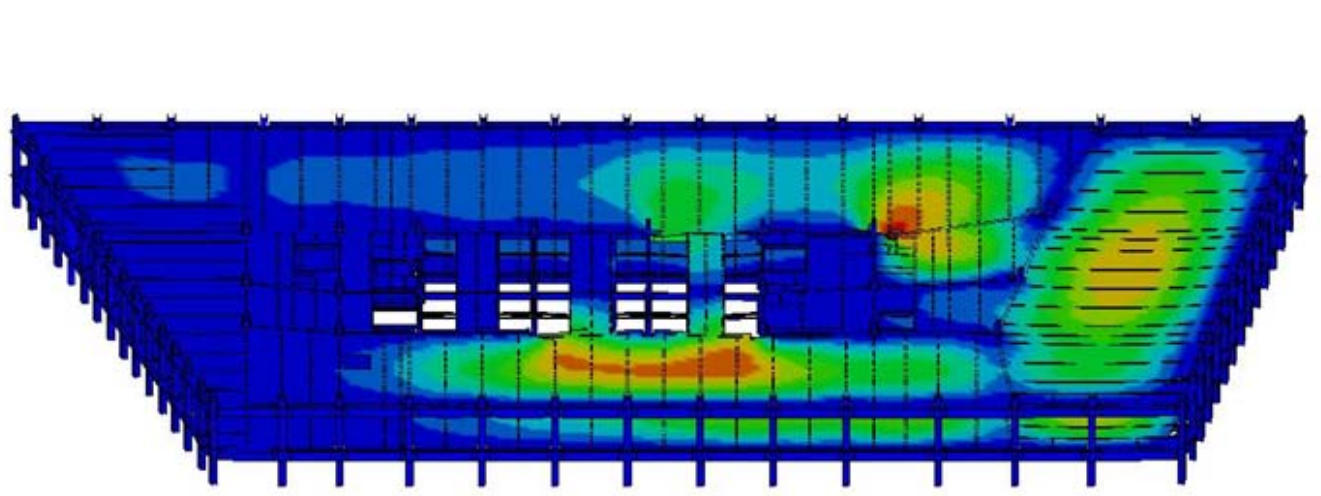

Z-Disp. Contours $(-0.5$ to $0 \mathrm{~m})$

$-6.939 \mathrm{e}-17$
$5.000 \mathrm{e}-02$
$-1.000 \mathrm{e}-01$
$-1.500 \mathrm{e}-01$
$-2.000 \mathrm{e}-01$
$-2.500 \mathrm{e}-01$
$-3.000 \mathrm{e}-01$
$3.500 \mathrm{e}-01$
$-4.000 \mathrm{e}-01$
$4.500 \mathrm{e}-01$
$5.000 \mathrm{e}-01$

Figure 3-66. Vertical displacement in the two floor model after Case A $5 \mathrm{~h}$ temperature initialization. 


\subsection{COMPUTING CONSIDERATIONS}

\subsubsection{System Specifications}

All simulations were run on ARA's high speed Linux Beowulf computer cluster. The system consisted of a head node and eight compute nodes. The head node housed two 64 bit AMD Opteron $2502.4 \mathrm{GHz}$ processors. The head node had 4 GB of RAM and housed 1.5 terabytes of RAID 5 disk storage. Each compute node housed two 64 bit AMD Opteron dual-core $2852.6 \mathrm{GHz}$ processors. Six of the compute nodes had 8 GB of RAM, and the remaining two nodes had 16 GB RAM. The compute nodes communicated using Silverstorm Infiniband Interconnects.

\subsubsection{Model Size and Typical Run Time}

The global model was constructed with 3,593,049 nodes and 3,045,925 total elements. The type and number of the elements were: 3,006,910 shells, 3,190 beams, 2,461 solids, 33,364 discrete elements, and 3,050 rigid elements.

The global simulation was first initialized under gravity loading over $4.5 \mathrm{~s}$ of simulation time. Then damage and temperature initialization states were applied over 4 additional seconds. Collapse propagation in the global model required approximately 16 additional seconds after initialization, for a total of close to 25 seconds of simulated time, which generally took up to 8 weeks using 12 CPUs across 3 nodes (4 CPUs per node).

\subsubsection{LS-DYNA Version}

The analyses were performed with the LS-DYNA finite element code (Version mpp971dR4 beta, revision 41161). Use of this double precision code results in longer run times than a single precision version would require. However, a double precision version was necessary. In structural models where there are physically large dimensions (spatial extents of the building) compared to the characteristic element length, and long time scales compared to the explicit time step size, rounding errors can occur and accumulate when using a single-precision analysis. To address this issue, the double precision version of LS-DYNA was used for the global analyses.

\subsection{REFERENCES}

Cantor 1985. Irwin G. Cantor P.C., Structural Engineers, Structural Drawings, 7 World Trade Center.

Frankel 1985a. Frankel Steel Limited, Fabrication Shop Drawings, 7 World Trade Center (drawing set was not sealed).

Sadek, F., El-Tawil, S., Lew, H.S. 2008. Robustness of Composite Floor Systems with Shear Connections: Modeling, Simulation, and Evaluation, J. Struct. Eng., ASCE, Vol 134, No. 11, pg 1717-1725.

XYZ. 2006. TrueGrid User’s Manual, Volume 1 and 2, Version 2.3.0, XYZ Scientific Applications, Inc., April 2006. 


\section{Chapter 4 \\ ANALYSIS RESULTS}

\subsection{OVERVIEW}

This chapter presents the analysis results of the global model of WTC 7. The analyses simulated the response of the full 47 story structure to the initial failure event due to impact damage and fire and the resulting component and subsystem failures to determine the events that led to the collapse of WTC 7. The results of the fire-induced damage from the 16 story ANSYS analysis (NIST NCSTAR 1-9, Chapter 11) were used as an input into the global LS-DYNA model.

Section 4.2 provides the results of subassembly floor models that were used to provide an insight into and guide the global 47 story development and analysis. Section 4.3 provides details of the response of the global model to debris impact damage, temperature effects (Case B, ${ }^{1} 4.0 \mathrm{~h}$ temperatures), and fire induced damage based on the 16 story ANSYS analysis (Case B, $4.0 \mathrm{~h}$ damage). Two variations to this analysis were performed and are presented in Sections 4.4 and 4.5. Section 4.4 describes the results of a global analysis with the same loading sequence and parameters as those in Section 4.3 except that the fireinduced damage was applied at $3.5 \mathrm{~h}$ instead of $4.0 \mathrm{~h}$ to determine if an earlier fire-induced damage state was sufficient to initiate a global collapse of WTC 7. Section 4.5 describes the results of a global analysis with the same loading sequence and parameters as those in Section 4.3, but without the debris impact damage. The purpose of this analysis was to determine the contribution of debris impact to the global collapse sequence and whether WTC 7 would have collapsed solely due to the effects of the fires. Section 4.6 describes the results of a global progressive collapse analysis without debris impact and fireinduced damage, where the initiating event was the removal of a two-story length of Column 79.

\subsection{SUBASSEMBLY FLOOR MODELS}

\subsubsection{Results for the Two-Floor Subassembly Model}

The majority of the subassembly analyses were performed using a simplified two floor model of Floors 10 and 11 in WTC 7. This model was primarily used to evaluate the modeling approaches, such as initialization of the thermal behaviors and damage or to investigate the response of the building to removal of different column supports.

An example analysis of a potential initial failure event is shown in Figure 4-1. No damage from either the debris impact or the subsequent fires and thermal loading were applied in this analysis. The gravitational loads were applied first. Subsequently, the support boundary conditions for Column 79 were removed. The response that occurred was an unstable collapse of the entire bay surrounding the column. Although there was a significant extent of damage, the remaining structures in the two floor model were stable.

\footnotetext{
${ }^{1}$ Case A used the air temperatures generated in the fire simulations (NCSTAR 1-9, Chapter 9), Case B used air temperatures augmented by 10 percent. The rationale for these cases is discussed in NIST NCSTAR 1-9, Chapter 10.
} 
The two floor model was also used to develop a methodology for applying the thermal loads to the WTC 7 global model, and to evaluate the structural response under thermal loading. For this set of analyses the two floor model applied temperatures from Floors 12 and 13 (where high thermal loads were present). For these analyses, the gravitational loads were first applied, then the final temperature distribution was applied to the structures. The two floor model results for $5 \mathrm{~h}$ temperatures from Cases A and B are shown in Figure 4-2 and Figure 4-3. The color fringes shown on the model correspond to the temperatures in Celsius throughout the two floor models.

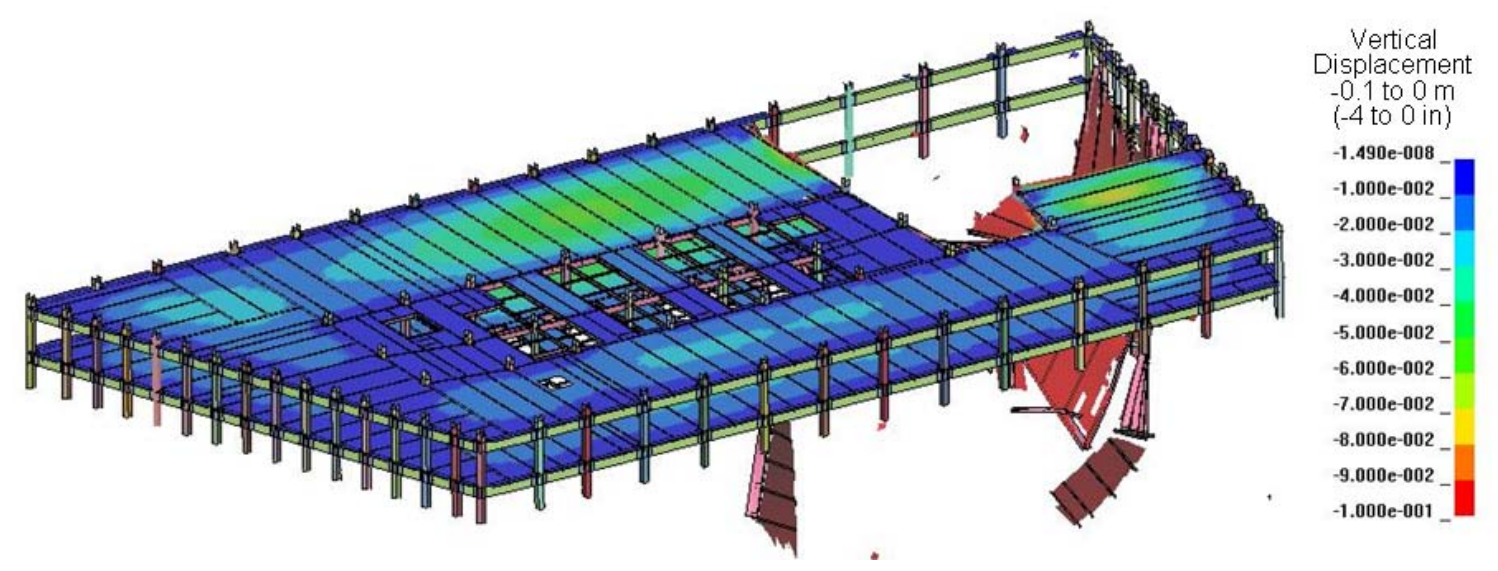

Figure 4-1. Calculated collapse behavior from Column 79 support removal (two floor model).

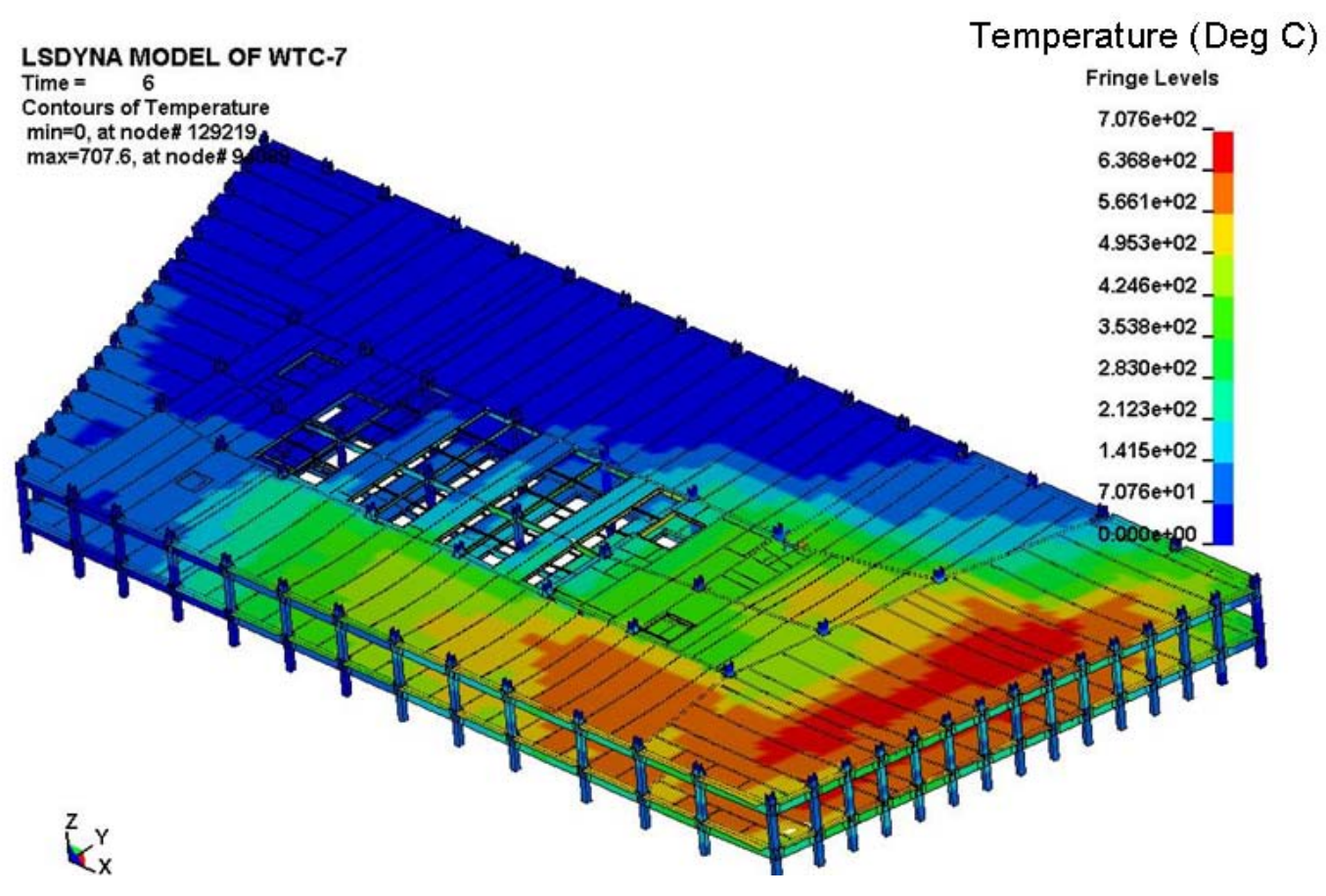

Figure 4-2. Two-Floor model for Case A $5 \mathrm{~h}$ temperatures. 


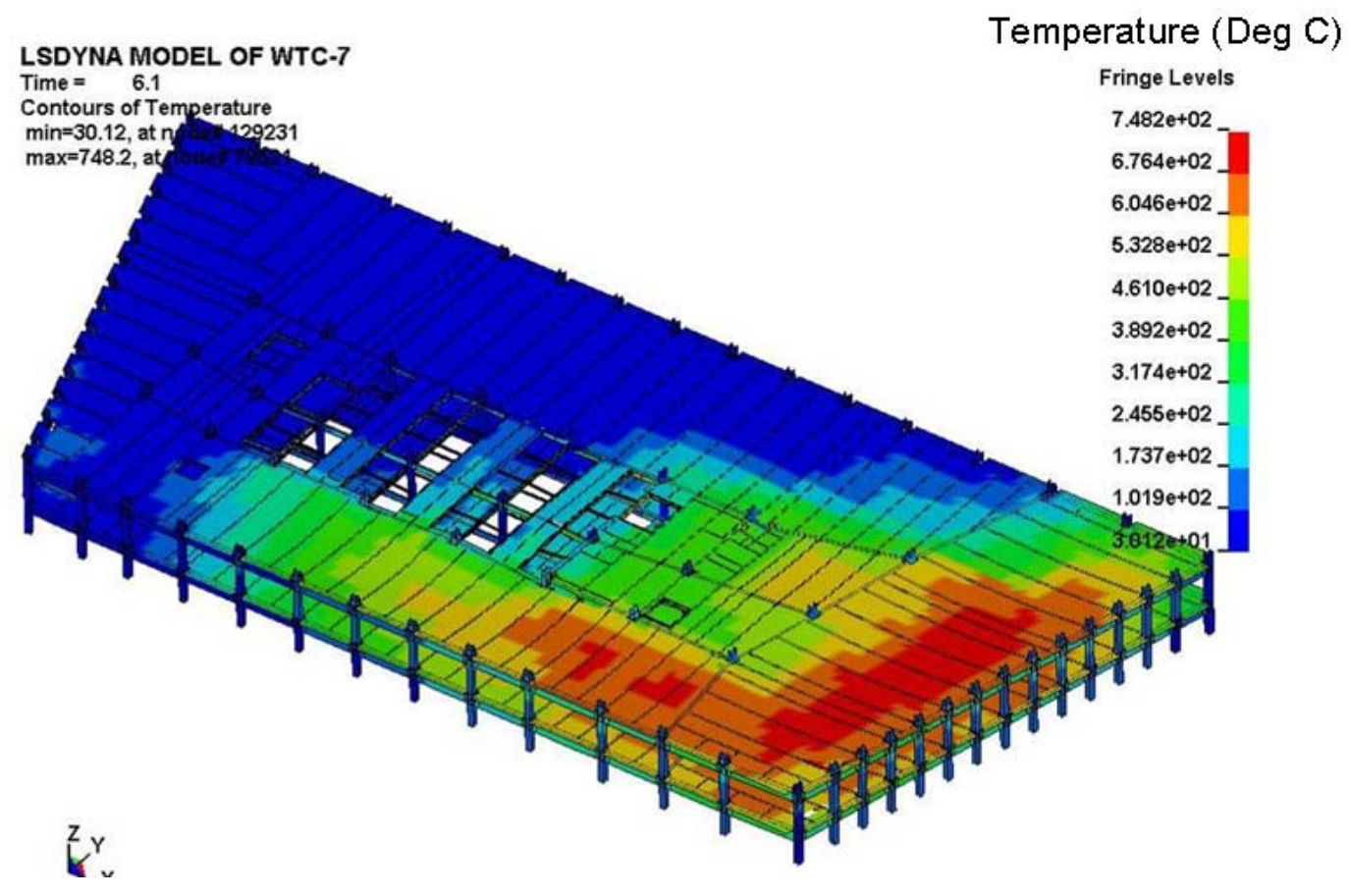

Figure 4-3. Two-Floor model for Case B, $5 \mathrm{~h}$ temperatures.

The corresponding column connection damage that developed as part of the temperature application process is illustrated for Case A and B temperatures in Figure 4-4 and Figure 4-5, respectively. Similar thermally induced damage was developed for both cases, due to a combination of thermal expansion and thermally degraded material properties. As the figures indicate, Case B, which had higher temperatures, resulted in more connection damage. The resulting damage was consistent with the damage estimated within the range of reasonable and realistic scenarios by the ANSYS 16 story model (NIST NCSTAR 1-9, Chapter 11).

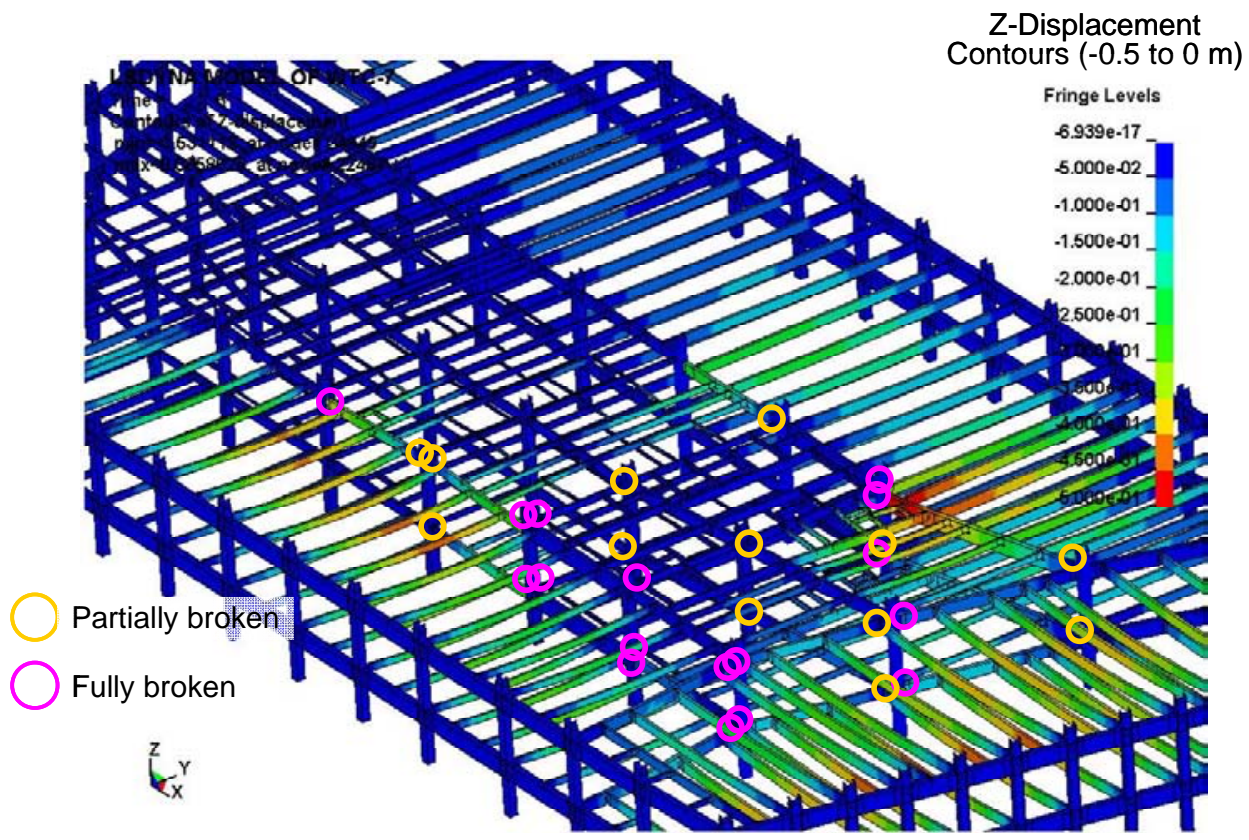

Figure 4-4. Connection damage in the two floor model for Case A, $5 \mathrm{~h}$ temperatures. 


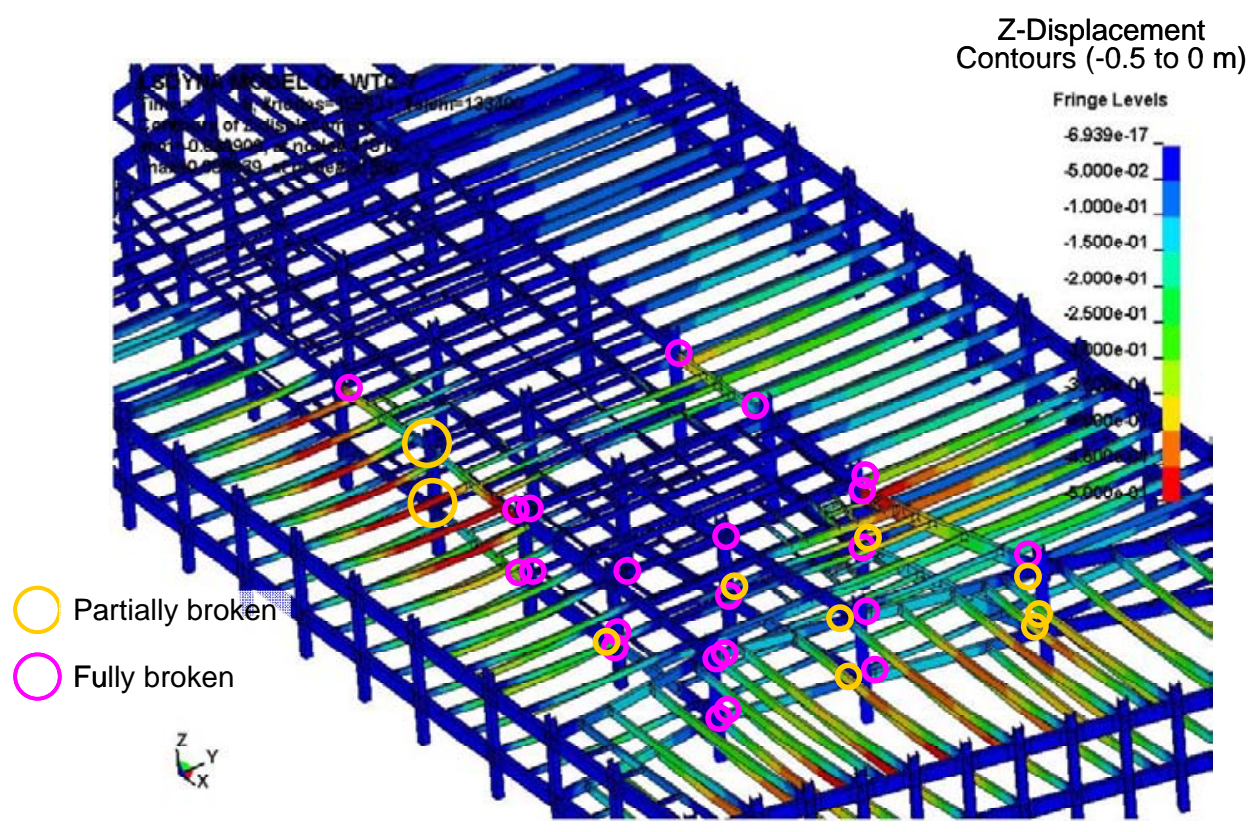

Figure 4-5. Connection damage in the two floor model for Case B, $5 \mathrm{~h}$ temperatures.

Following the gravitational and thermal initialization processes, a set of specific load cases were considered to investigate the structural behavior and effects of potential initial failure events. The load cases investigated with the two floor model were:

- Load Case 1 - the model progressed after temperature initialization without any additional imposed connection or support failures

- Load Case 2 - suddenly released (failed) the connections surrounding Column 79 on the upper floor after temperature initialization

- Load Case 3 - suddenly released (failed) the connections surrounding Column 81 on the upper floor after temperature initialization

The calculated responses of the two floor model after the Case 1 loading is shown in Figure 4-6, for both the Case A and Case B, $5 \mathrm{~h}$ temperatures. The analyses show that under Case A temperatures and thermal connection damage, the floor structures were still stable. The effects of the thermal softening and connection damage did result in some significant deflections of the floor structures (regions shown in red are in excess of $0.5 \mathrm{~m}$ (20 in.) downward deflection), but no collapse occurred. The Case B temperature profile (shown as the lower model in Figure 4-6) initiated a partial collapse in the model. 


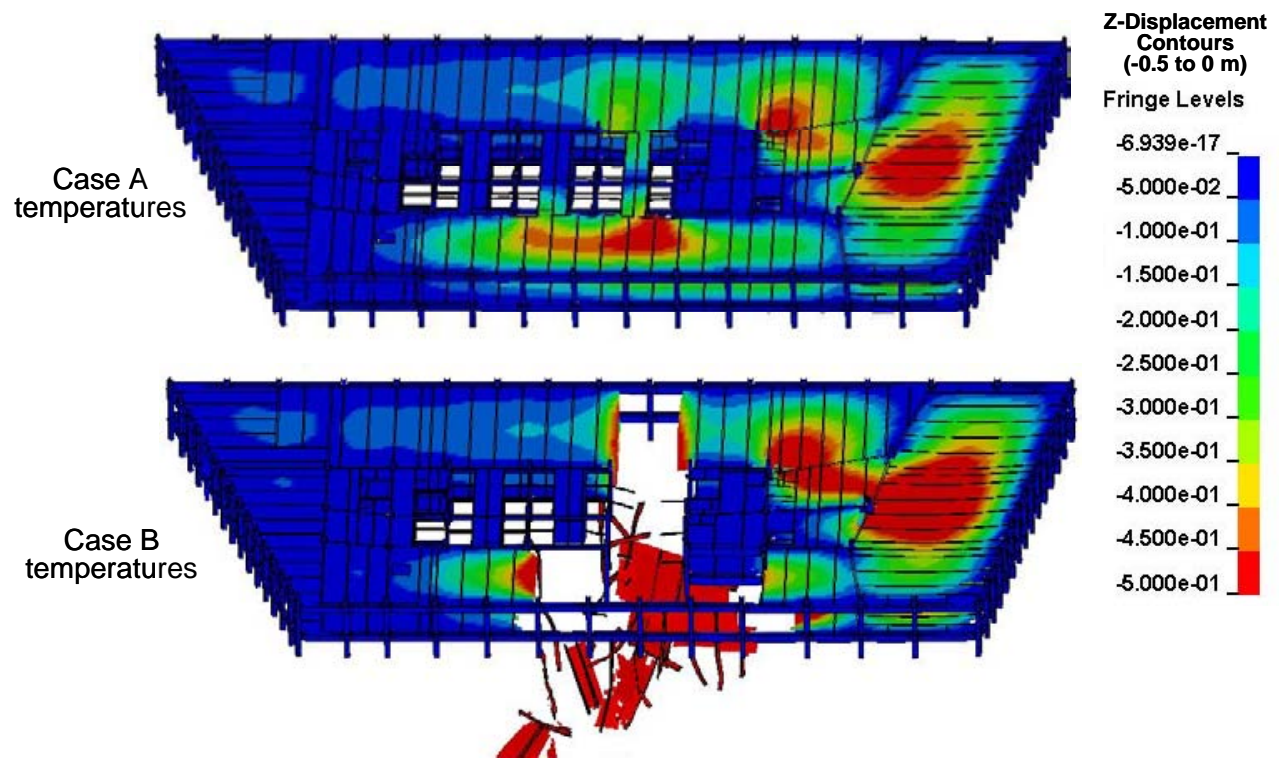

Figure 4-6. Load Case 1 results, $9 \mathrm{~s}$ after applying $5 \mathrm{~h}$ temperatures.

The calculated responses of the two floor model after the Case 2 loading is shown in Figure 4-7, for both the Case A and Case B, $5 \mathrm{~h}$ temperatures. In the Case 2 loading, the three girder connections surrounding Column 79 on the upper floor were released and the surrounding floor structures fell down onto the lower floor. The analyses showed that, with the Case A temperatures, a floor collapse was initiated in the floor structures between Columns 79 and 81. The lower floor structures in the northeast corner of WTC 7 had sufficient strength (note cooler temperatures in Figure 4-2) to support much of the sagging upper floor structures. However the extent of the floor collapse was larger on the lower floor, as shown in Figure 4-8. The response of the structure to the Case B $5 \mathrm{~h}$ temperature profile (shown as the lower model in Figure 4-7) was a collapse of a large portion of both floors on the east end of WTC 7.

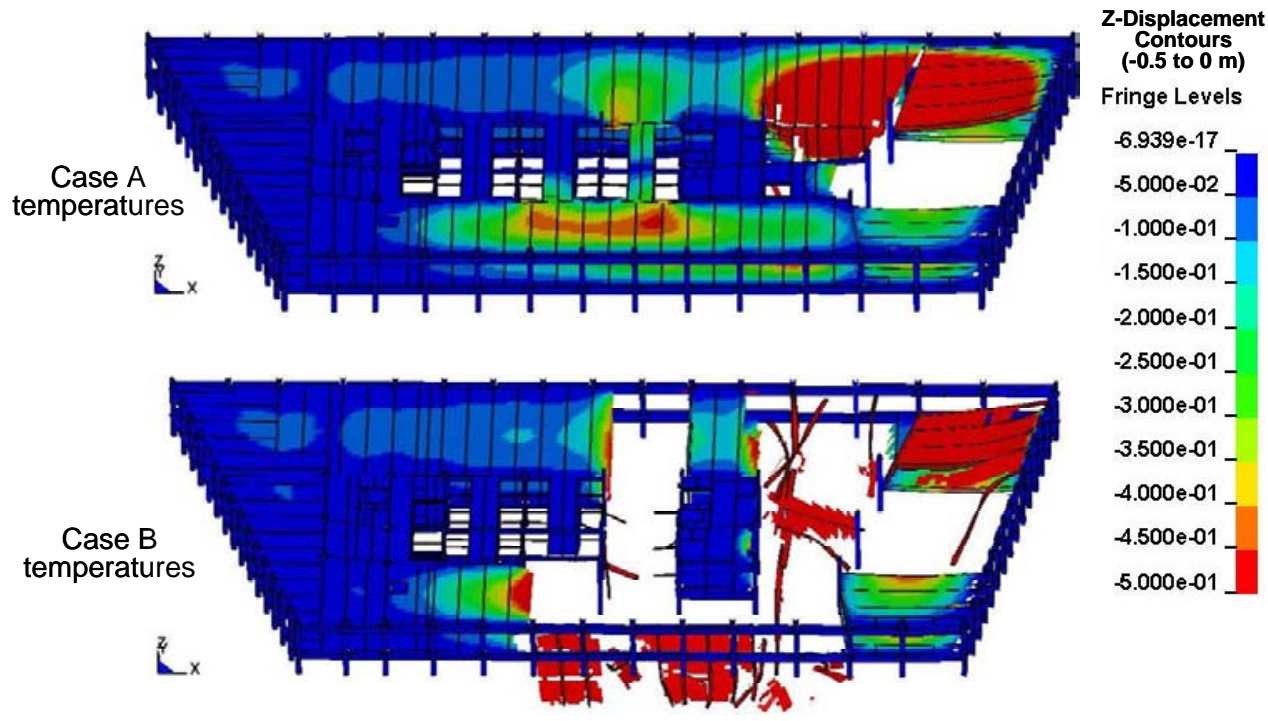

Figure 4-7. Load Case 2 results, $9 \mathrm{~s}$ after applying $5 \mathrm{~h}$ temperatures. 


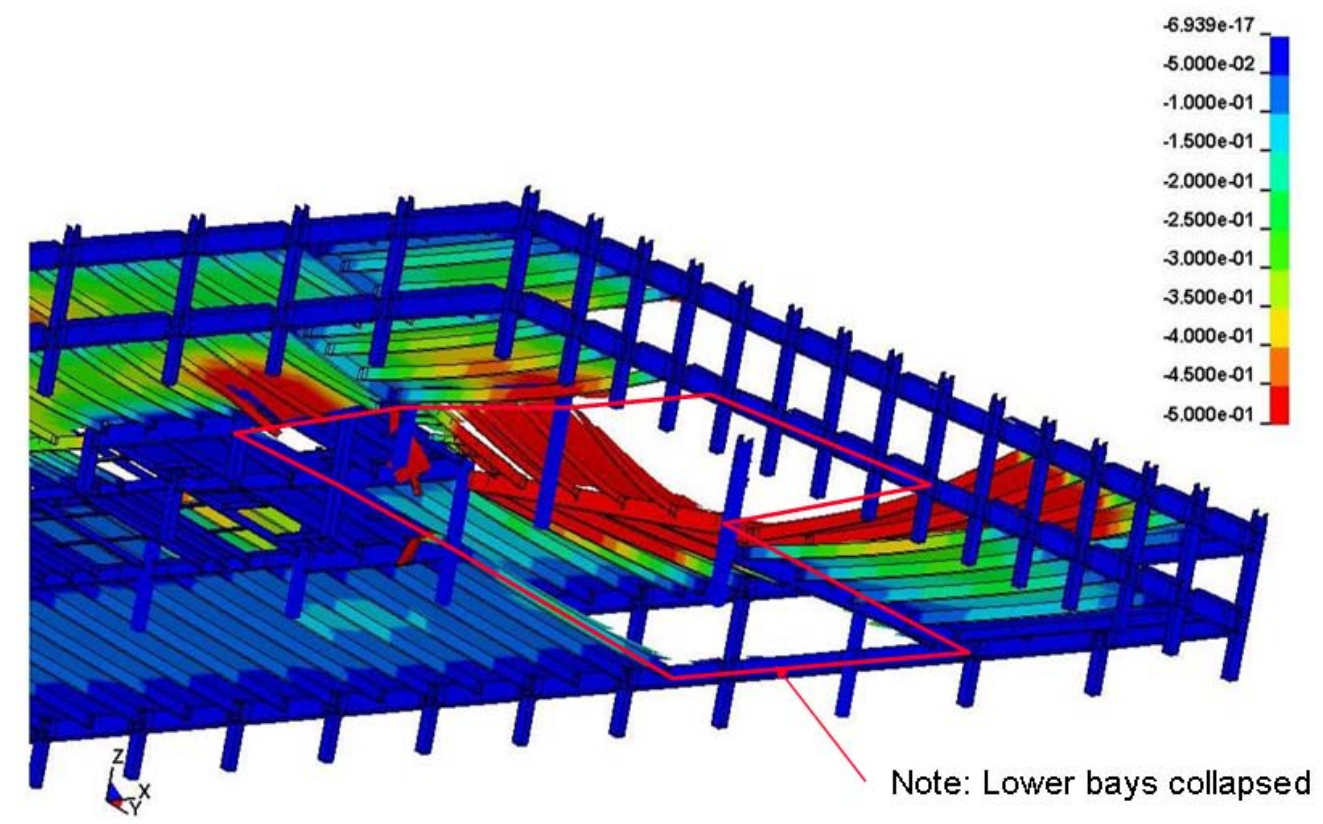

Figure 4-8. Detail of Load 2, with Case A, $5 \mathrm{~h}$ temperatures illustrating collapse of floor sections below sagging upper floor.

The calculated responses of the two floor model after the Case 3 loading is shown in Figure 4-9, for both the Case A and Case B temperatures. In the Case 3 loading, the connections surrounding Column 81 on the upper floor were released and the surrounding floor structure was allowed to fall down onto the lower floor. The analyses showed that, for both temperature cases, a floor collapse was initiated in the southeast corner of WTC 7.

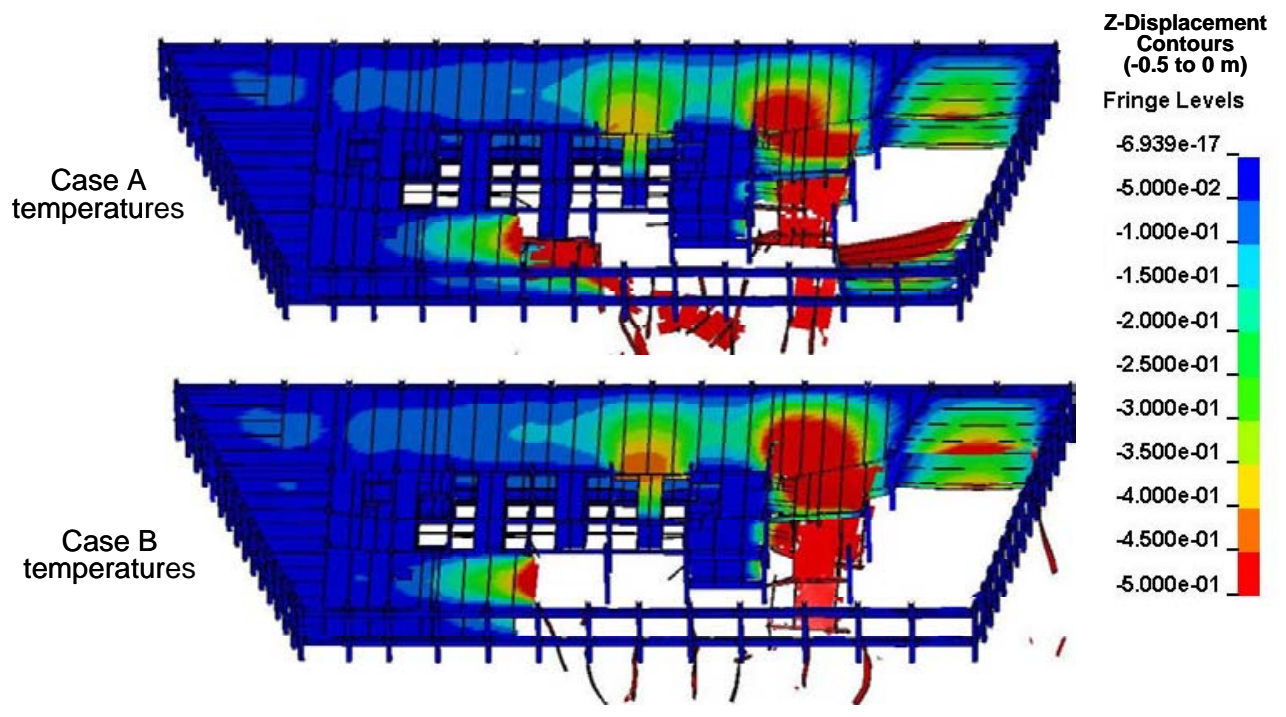

Figure 4-9. Load Case 3 results, $9 \mathrm{~s}$ after applying $5 \mathrm{~h}$ temperatures. 


\subsubsection{Results for the 14-Floor Subassembly Model}

The collapse of WTC 1 resulted in the severance of 7 columns at the southwest quadrant of WTC 7 between Floors 5 and 17. The 14 floor model was used to assess the stability of the tower structures after the application of the debris impact damage. The model extended several floors above the damaged region to transfer the loads around the missing components. Similar to the two floor model, this model was also used to investigate the interaction of different initial failure events. The inclusion of multiple floors ensured that the boundary conditions at the top and the bottom of the model had only a minor effect on the regions where failures were occurring.

The 14 floor model generated for Floors 10 to 23 of WTC 7 is shown in Figure 4-10 with the debris impact damage imposed on the structure. With this 14 floor model, there were six intact floors above the damage zone that were able to transfer the loads to the surrounding structure. The calculated vertical displacements in the model following the sequential application of gravity loads and debris impact damage are shown in Figure 4-11. The structures above the impact zone had moved downward by approximately $0.15 \mathrm{~m}$ (6 in.). The analysis shows that the columns and floors above the damaged zone were able to redistribute the loads through Vierendeel truss action without collapse. Thus, the 14 floor model was used to demonstrate that the approach to initialize debris impact damage by dynamically removing the structures within the impact damage zone was successful.

The 14 floor model was also used to evaluate a possible initial failure event as shown in Figure 4-12. This figure presents the subsequent failures that occurred from the removal of the support boundary condition at the bottom of Column 79. The entire bay surrounding the column collapsed. The gravitational loads were applied, then the Column 79 support was abruptly removed. A similar collapse of the bay was observed in Figure 4-1.

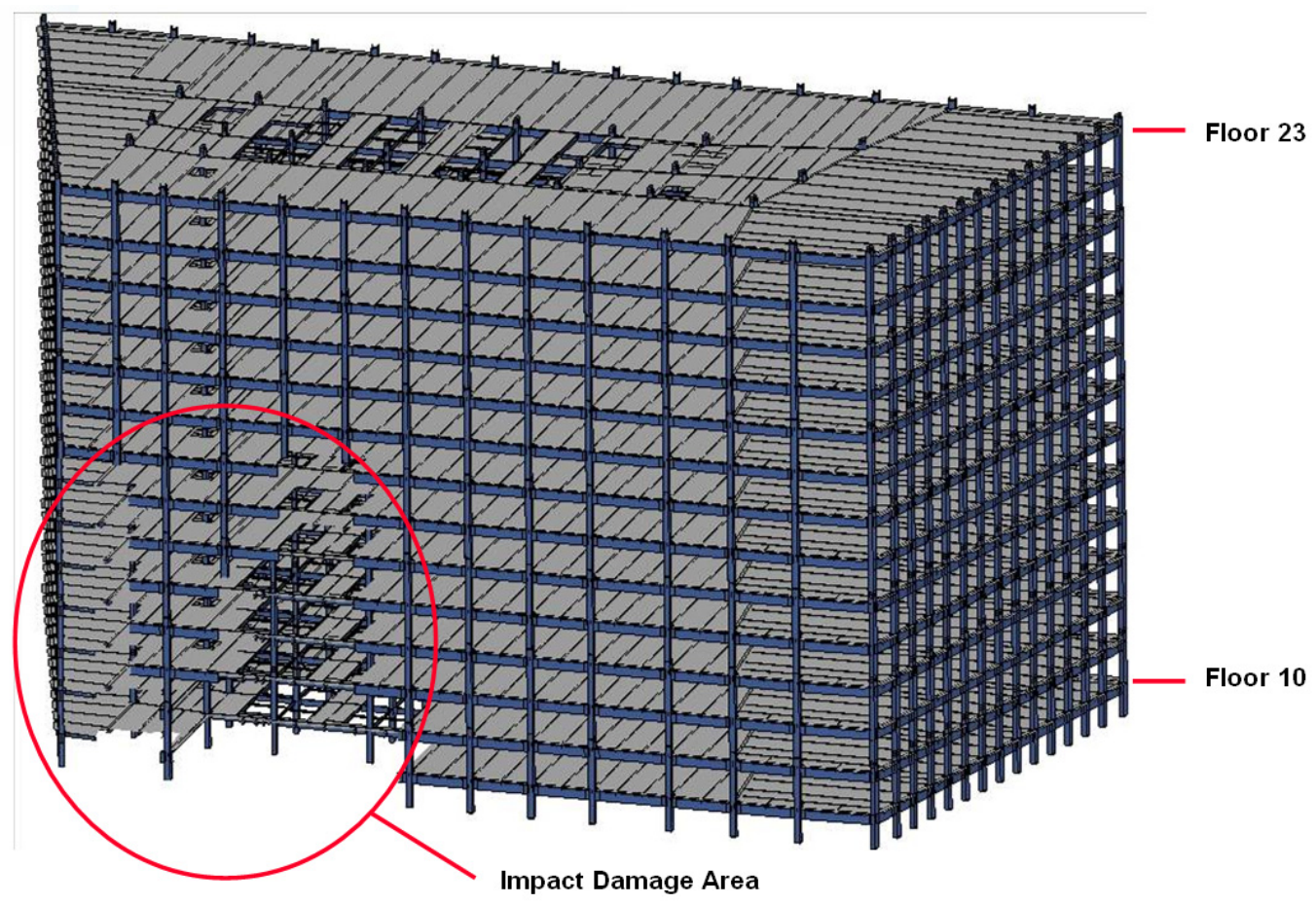

Figure 4-10. Assessment of impact damage on the 14-floor subassembly model. 


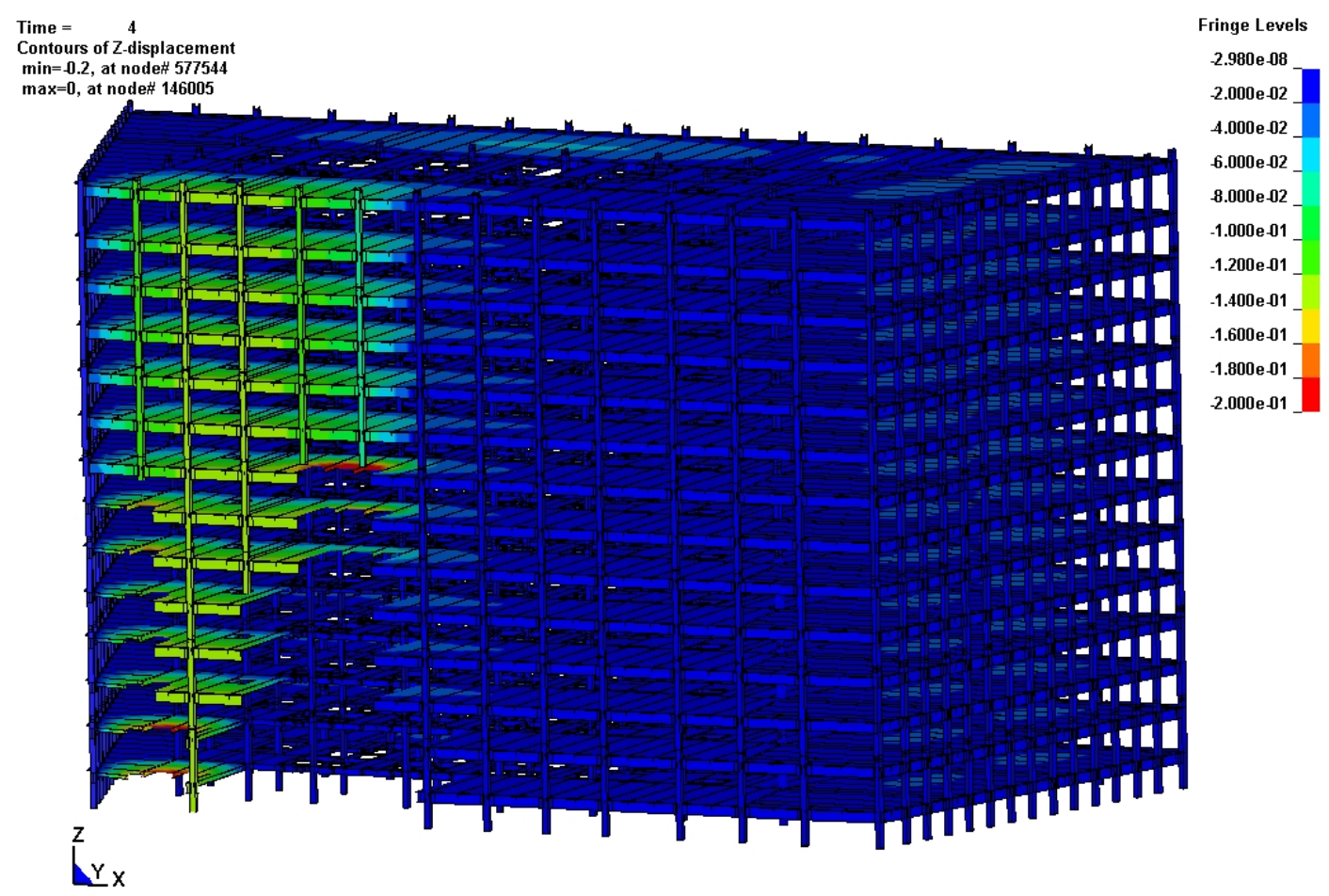

Figure 4-11. Calculated impact damage displacements on the 14-floor model. Vertical displacement contours shown: -0.2 to $0 \mathrm{~m}$ (-8 to 0 in).

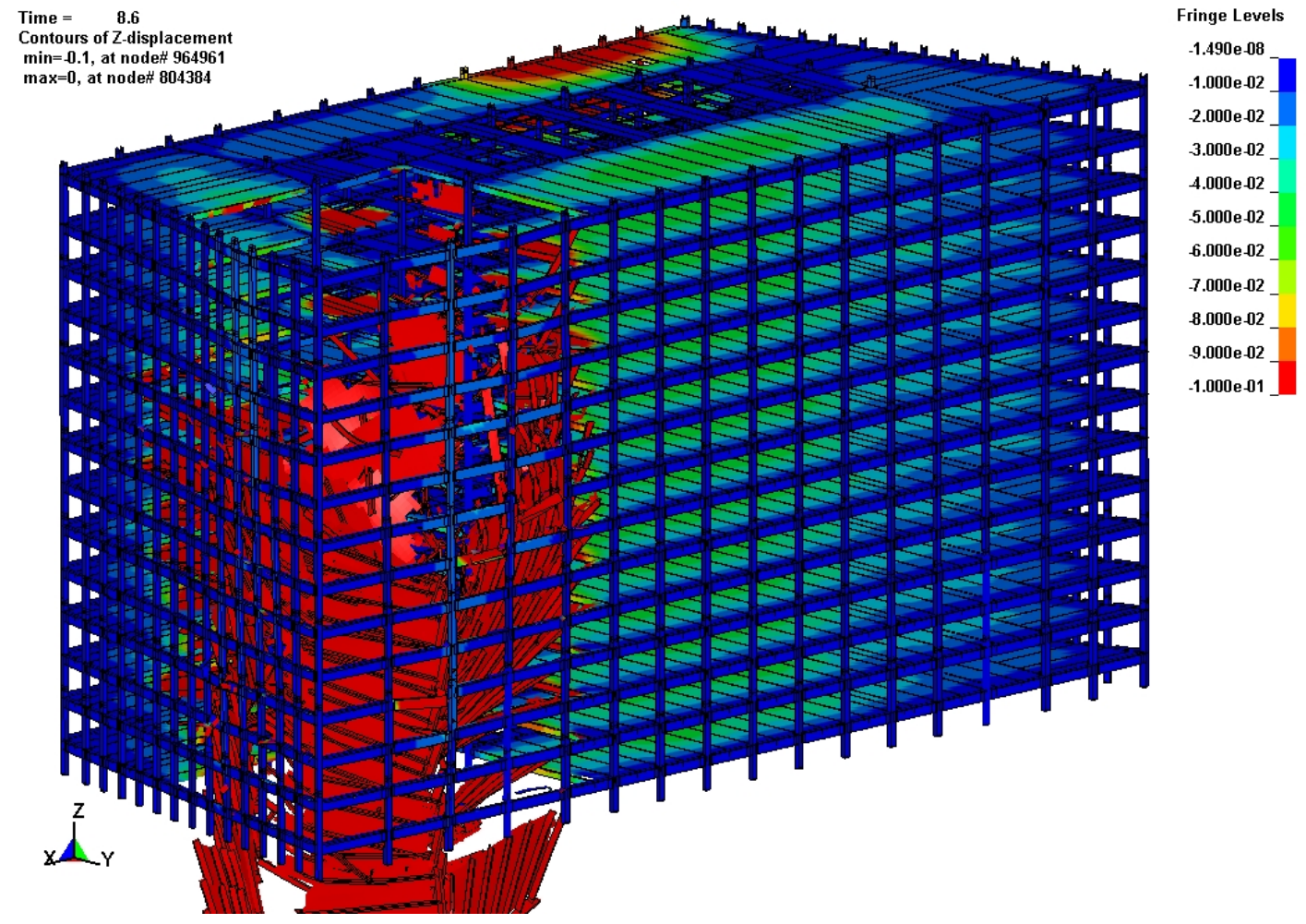

Figure 4-12. Calculated collapse behavior for Column 79 support removal (14-floor Model). Vertical displacement contours shown: -0.1 to $0 \mathrm{~m}$ ( -4 to 0 in). 


\subsection{GLOBAL ANALYSIS RESULTS WITH DEBRIS IMPACT DAMAGE}

Results from the global, 47 story LS-DYNA model of WTC 7 are discussed in this section. First an overview highlighting the major events - the initial failure event, vertical progression of failure, horizontal progression of failure, and global collapse - is presented. Then, subsections detailing these events are discussed. Finally, a comparison of the result from the LS-DYNA analysis to observed behavior from photos and videos is included.

\subsubsection{Reference Frames for Timing}

Two timing reference frames are used when discussing global model results: a calculation reference frame and a collapse reference frame.

The calculation reference frame coincides with the calculation start time discussed in Section 3.3.2. The calculation started at $0.0 \mathrm{~s}$ and included gravity applied over $4.5 \mathrm{~s}$, followed by an instantaneous application of debris impact damage (NIST NCSTAR 1-9, Chapter 5) at $4.5 \mathrm{~s}$, and temperatures applied over $2 \mathrm{~s}$ (NIST NCSTAR 1-9, Chapter 10) starting at $6.5 \mathrm{~s}$. The thermally-induced damage from the ANSYS analysis (NIST NCSTAR 1-9, Chapter 11) was applied at 8.5 seconds.

The collapse reference frame is based on observations from photo and video records. The collapse reference time of $0.0 \mathrm{~s}$ starts when the east penthouse began to descend and a kink was observed in its roofline, as viewed from the north. This event was used as a reference point to time subsequent observed events (NIST NCSTAR 1-9, Chapter 5), such as the western penthouse collapse and the downward global motion at the building roofline.

In the global analysis, the kink in the roofline of the east penthouse occurred at $16.0 \mathrm{~s}$ in the calculation reference frame. This corresponds to $0.0 \mathrm{~s}$ in the collapse reference frame. In the following graphics, if both times are quoted, the syntax used is "collapse reference frame (calculation reference frame)." Otherwise, the reference frame being used is specified.

\subsubsection{Overview of Global Collapse Results from the LS-DYNA 47 story Analysis}

The 47 story model calculation which combined fire-induced damage, thermal loads, and debris impact damage resulted in the global collapse of WTC 7. The key events that occurred in the global analysis are summarized below.

- $\quad-16.0$ to -7.5 (0 to 8.5) s: Model was initialized.

o Gravity, WTC 1 debris impact damage, and temperatures were applied to the LS-DYNA model.

0 The structure sustained damage as a result of the load redistribution due to debris impact damage and Case B, $4.0 \mathrm{~h}$ temperatures.

o The structure was stable at the end of initialization.

- $\quad-7.5$ (8.5) s: Fire-induced floor damage from the ANSYS analysis was added.

o Sections of Floors 13 and 14 collapsed in the northeast region around Columns 79, 80, and 81. 
o Floor areas below, also weakened by fires, collapsed from the falling debris until Column 79 was unsupported between Floors 5 and 14 and Column 80 was unsupported between Floors 5 and 15. Column 81 was unsupported between Floors 7 and 15.

- $\quad-1.3$ (14.7) s: The initial failure event occurred and started the vertical progression of failure.

o Column 79 buckled between Floors 5 and 14 .

o Columns 80 and 81 buckled quickly in succession, both within 1 s of Column 79 buckling.

o Following buckling of Columns 79, 80, and 81, the remaining column sections above the buckled lengths began to move downward, and the floors sections above were pulled downward, first by Column 79, then by Columns 80 and 81 .

o A global southward sway developed and grew in the upper floors, emanating from the collapsed east floor area.

- $\quad 0.0-1.5+(16.0-17.5+)$ s: Kink in east penthouse roofline appeared.

o 0 (16.0) s: The floor collapse progressed upward and a kink near the middle of the east penthouse roofline appeared on the north side.

o $\quad 0.7+(16.7+)$ s: The east face near the top of the building deflected westward as floors surrounding Columns 79 to 81 pulled the exterior wall inward .

- 2.0 (18.0) s: The east penthouse fell completely below the WTC 7 roofline.

- 2.7-5.3+ (18.7-21.3+) s: The horizontal progression of failure started.

o 2.7 (18.7) s: The Truss 2 eastern diagonal member buckled due to the impact of falling debris, compromising the support of Columns 77, 78, and 78A.

o $\quad 3.3$ to 3.7 (19.3 to 19.7) s: Columns 77 and 78 buckled as a result of the Truss 2 failure. Column 76 buckled due to the impact of falling debris and load redistribution.

o 3.9 to 6.1 (19.9 to 22.1) s: The remaining interior columns buckled sequentially, as loads transferred from adjacent buckled columns and as the columns were impacted by falling debris.

o $4.3+(20.3+)$ s: West core columns buckled between Floor 9 and 13.

- $\quad$ 5.5-7.4 (21.5-23.4) s: Exterior collapse occurred.

o 5.5 (21.5) s: Exterior column buckling began at the southwest corner Column 14, adjacent to the debris impact zone, between Floor 10 and 12.

o 5.5-7.4 (21.5-23.4) s: Exterior columns buckled along the south and west faces between Floors 7 and 14 . The buckling of exterior columns rapidly spread to the north and then east faces.

o $7.4(23.4) \mathrm{s}$ : All interior and exterior columns buckled on the lower floors.

- 5.7 to 7.7 (21.7 to 23.7) s: The west penthouse and screenwall fell below the WTC 7 roofline.

o Collapse in the western core caused the west penthouse and screening wall to fall below the building roofline.

- 6.2 to 8.5 (22.2 to 24.5) s: Global vertical motion began.

o 6.2 to 6.3 (22.2 to 22.3 ) s: The east side of the north face roofline began moving downward. 
o 6.5 to 7.5 (22.5 to 23.5) s: Global vertical motion spread across to the west side of the north face roofline.

$0 \quad 7.5^{+}\left(23.5^{+}\right)$s: The entire building was falling and the upper floors continued accelerating downward.

o At 8.5 (24.5) s: The roof was falling with a speed of approximately 10 to $15 \mathrm{~m} / \mathrm{s}$ as the building continued to accelerate downward under gravitational forces.

\section{- 8.59 (24.59) s: The calculation was terminated.}

Figure 4-13 and Figure 4-14 show the progression of collapse as viewed from the northwest. The figures present contours of vertical displacement of the structure with a range between $-2.0 \mathrm{~m}$ and $0 \mathrm{~m}(-80 \mathrm{in}$. to 0 in.).

At -1.1 (14.9) s, floor segments had started collapsing around Columns 79, 80, and 81 between Floor 14 and Floor 5. The floor collapses were due to fire-induced structural damage obtained from the ANSYS analysis.

At 2.3 (18.3) s, Columns 79 to 81 had buckled and the floor sections above were pulled downward by the unsupported columns, resulting in a vertical progression of collapse up to the east penthouse on the roof.

At 7.3 (23.3) s, column buckling had spread horizontally across the entire core. As the core columns fell downward, buckling of the exterior columns developed as the floors attached to the west face pulled inward at the lower floors. There were no fires on Floors 9 to 14 on the west floor area, so the floors were not thermally weakened in this area. Note that the north exterior wall appears generally intact, while most of the structure behind the north face is collapsing. Much of the interior structure and the south wall were falling downward at that point.

By 8.6 (24.6) s, buckling had occurred in all the exterior columns and global downward vertical movement had started. The calculation was stopped after the building had fallen downward approximately $10 \mathrm{~m}$, as global collapse occurred.

The critical events that led to the global collapse are detailed in the following subsections. 


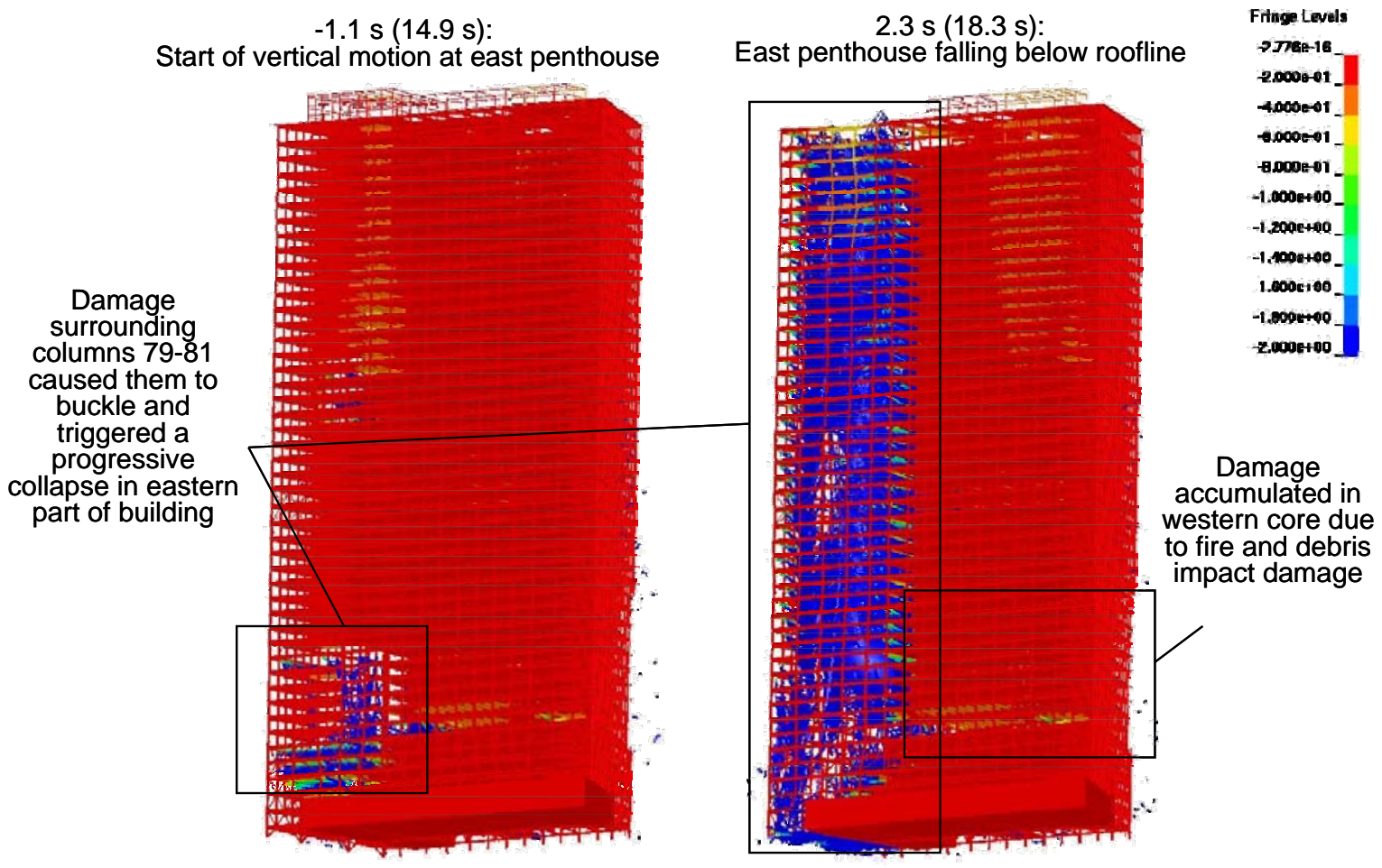

Figure 4-13. Global response: vertical displacement contours (-2 $\mathrm{m}$ to $0 \mathrm{~m})$, view from the northwest.

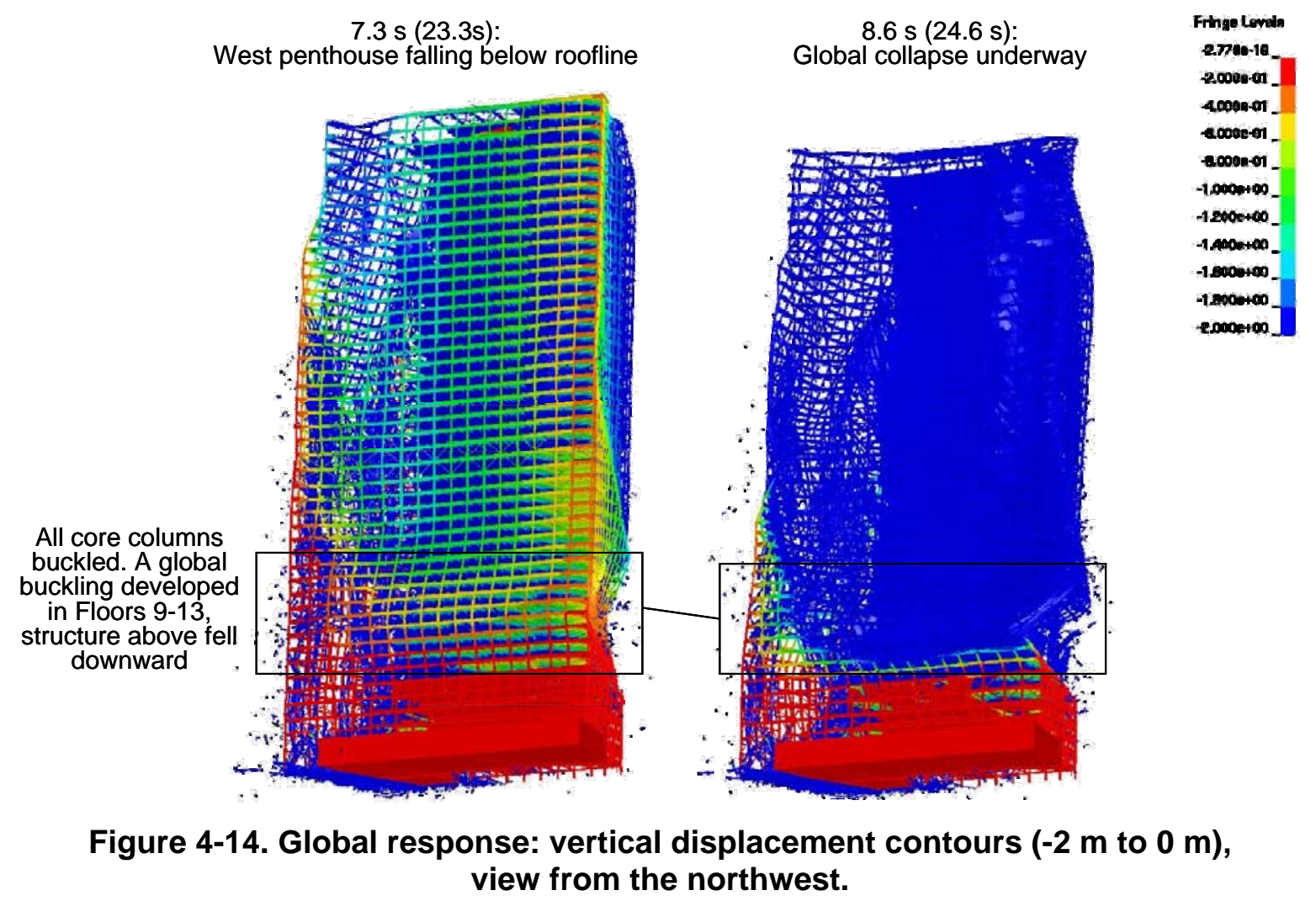




\subsubsection{Initial Failure Event and Vertical Progression of Collapse}

The initial failure event occurred with the buckling of Column 79. This event was quickly followed by the buckling of adjacent Columns 80 and 81.

The floor framing structure was thermally weakened at Floors 8 to 14, with the most substantial damage occurring in the east region of Floors 12, 13, and 14. During the temperature application cycle in the LSDYNA analysis, combined thermal expansion and thermally degraded material properties resulted in beam and girder connection damage throughout the heated floor structures. The connection damage and buckled beam data transferred from the 16 story ANSYS analysis were then applied. The LS-DYNA analysis calculated the dynamic response of the floor failures and resulting impact on the surrounding structure. After the fire-induced ANSYS damage was applied, floor sections surrounding Columns 79 to 81 on Floors 13 and 14 collapsed onto the floors below.

The thermally weakened floors below Floors 13 and 14 could not withstand the impact from the collapsing floors, and resulted in sequential floor collapses, which removed lateral support to Columns 79 to 81. Eventually, critical conditions developed for column buckling due to a large unsupported length. Once the Column 79 buckled, the column section above Floor 14 began to descend downward and pulled the floor structures downward with them, thereby creating a vertical progression of floor collapse up to roof level. The floor failures around Column 79 led to the subsequent buckling of Columns 80 and 81, which in turn resulted in a vertical progression of failure of floor systems across the east side of the building. The east penthouse, which was supported by Columns 79, 80, and 81, fell downward.

Figure 4-15 is a cutaway view that illustrates the structural condition surrounding Columns 79, 80, and 81 when they buckled. Included in the figure are resultant lateral displacements and column axial stress histories for the three columns. Note that a rapid lateral displacement developed, indicating column buckling. Likewise, the column stresses indicated a rapid loss of stress at the time, signifying column buckling. The buckling of Columns 80 and 81 was preceded by a slight increase in compressive stress due to load redistribution and pulling on the column from floor systems being pulled downward by Column 79, then by Column 80 . Consistent with the rapid loss of column loads in the lower floors, vertical displacement histories at the top of Columns 79 through 81 in Figure 4-16 show a sudden, rapid descent of the columns at the time of column buckling.

Figure 4-17 illustrates the girder-to-column connection status at the time of buckling of Columns 79 through 81. The figure indicates large unsupported or partially supported (in one direction) lengths for each column at the time of buckling for each column.

For Column 79, the girder spanning north-south between Columns 44 and 79 was still in place at Floors 8 to 12 and Floor 14, but these girders had no lateral restraint since all the bolts failed. The girders in those floors possibly provided some resistance against northward Column 79 motion, but they could not provide any lateral restraint in the east, west, or south directions. At Floor 14, the girder to the west of Column 79 was still attached, so there was constraint from the west. Column 79 buckled in an easterly direction. Girder failure between Columns 79 and 80, and Columns 80 and 81, occurred immediately after $8.5 \mathrm{~s}$. Most of the east floor beams fell immediately, due to the amount of thermally-induced damage in the connections. 
In addition to axial compressive loads that could cause buckling, the columns were in a dynamic environment where lateral loads from falling debris and failure of girder connections occurred frequently. These lateral perturbations aided the onset of column buckling.

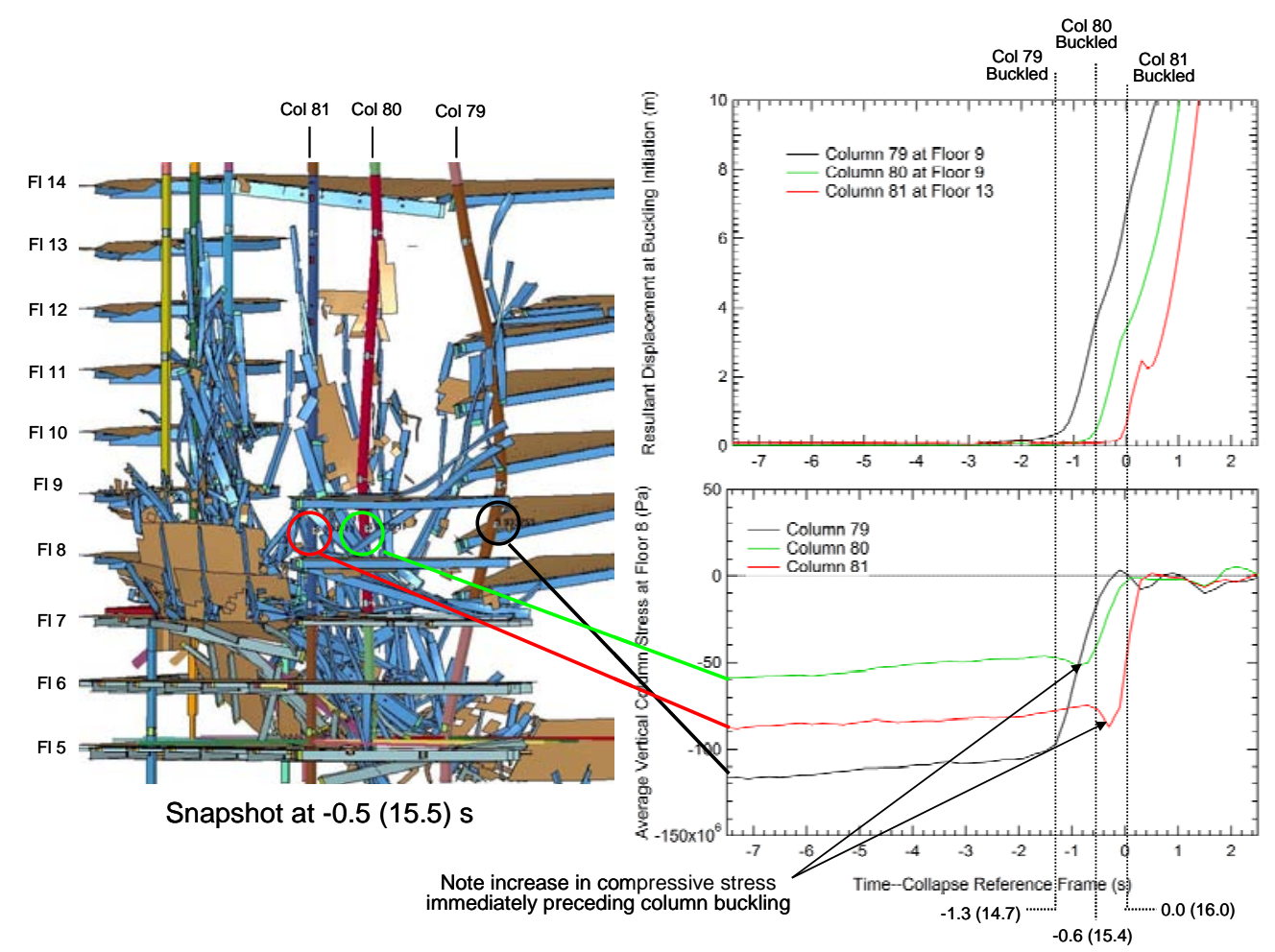

Figure 4-15. Column 79 to 81 stress and displacement time-histories.

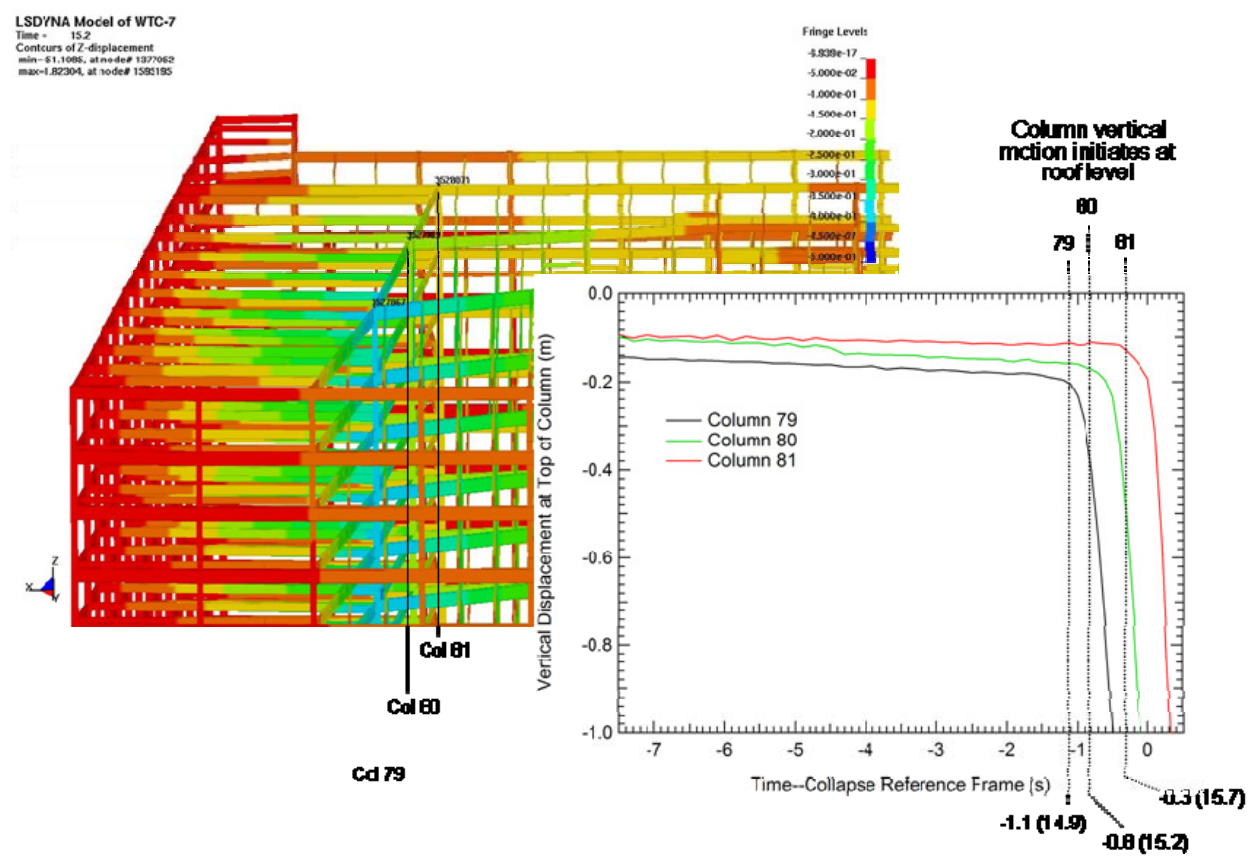

Figure 4-16. Column 79 to 81 vertical displacement with contours from $-0.5 \mathrm{~m}$ to $0 \mathrm{~m}$. 

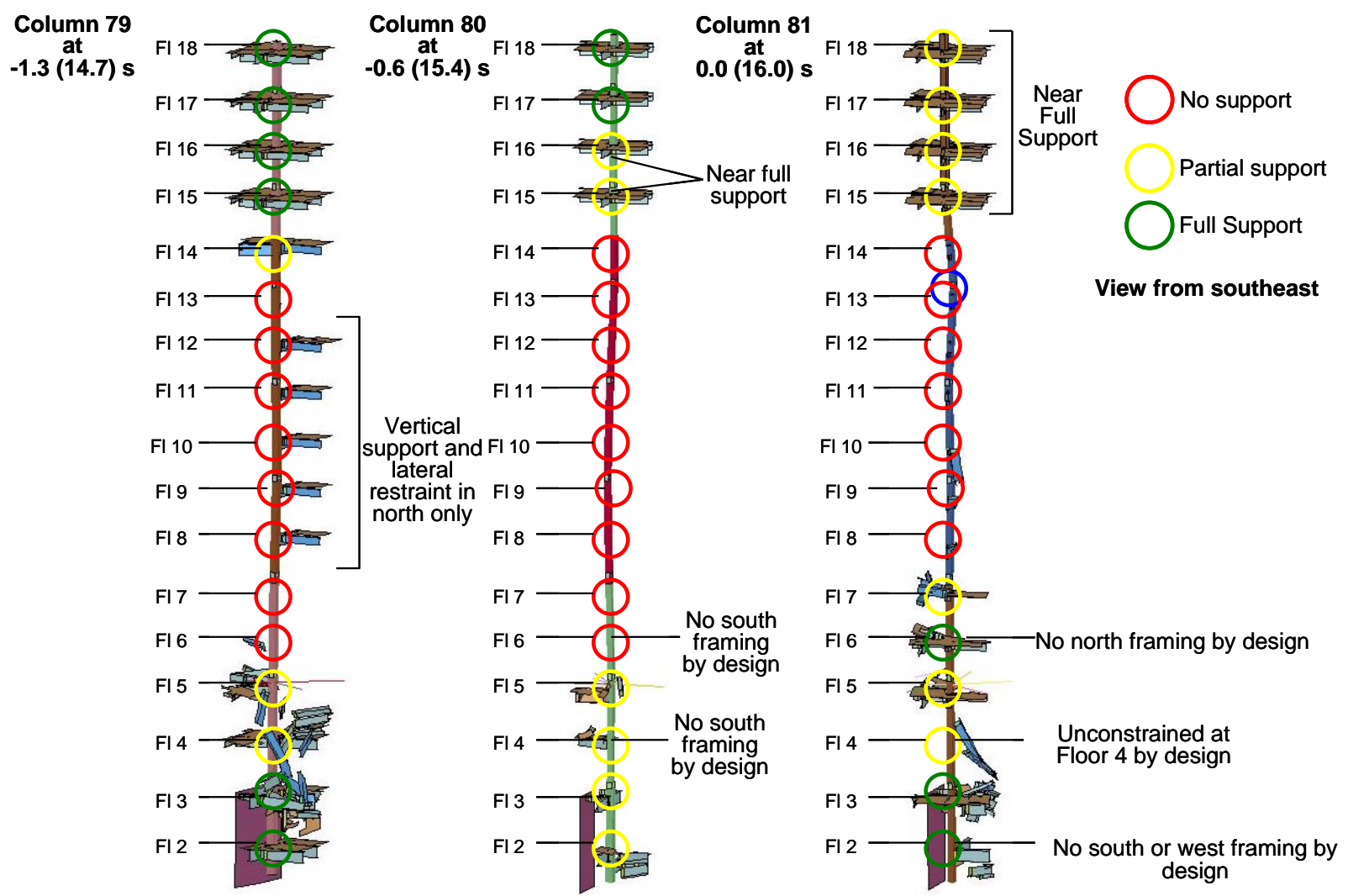

Figure 4-17. Column 79 to 81 lateral supports at initiation of buckling.

A series of snapshots of the interior columns and floor systems are shown, with the label "Core lateral displacement," to illustrate the progression of failures in the floors and columns in WTC 7. Each figure shows the model from the base of the building up to Floor 18. Views are from the southwest. Exterior columns and some of the tenant floor structure spanning between the core and the exterior are removed for an unobstructed view of the core.

In each figure, vertical and lateral displacements are shown, and contours of resultant lateral displacements are further indicated with the blue and red colors. For comparison between snapshots, a constant range of $0 \mathrm{~m}$ to $0.15 \mathrm{~m}$ ( 0 in. to 6 in.) was used. Since a resultant lateral displacement is presented, negative and positive values cannot be distinguished, and only absolute values are displayed. Any value greater than $0.15 \mathrm{~m}$ (6 in.) remains red in the figure. Subsequent figures are included with component $\mathrm{X}$ or $\mathrm{Y}$ displacements that illustrate positive and negative contours.

Figure 4-18 and Figure 4-19 show the early development of floor failures and collapses around Columns 79 to 81, as well as the damage in the western core that developed during the application of debris impact damage from the collapse of WTC 1 . The two events started around -7.5 (8.5) s but were independent events (Figure 4-18). They appear to coincide in the analysis due to the sequential application of loads, damage, and temperatures in the initialization sequence; the actual events occurred over approximately seven hours. Figure 4-19 shows sections of Floors 13 and 14 first failing around Column 79 to 81. 


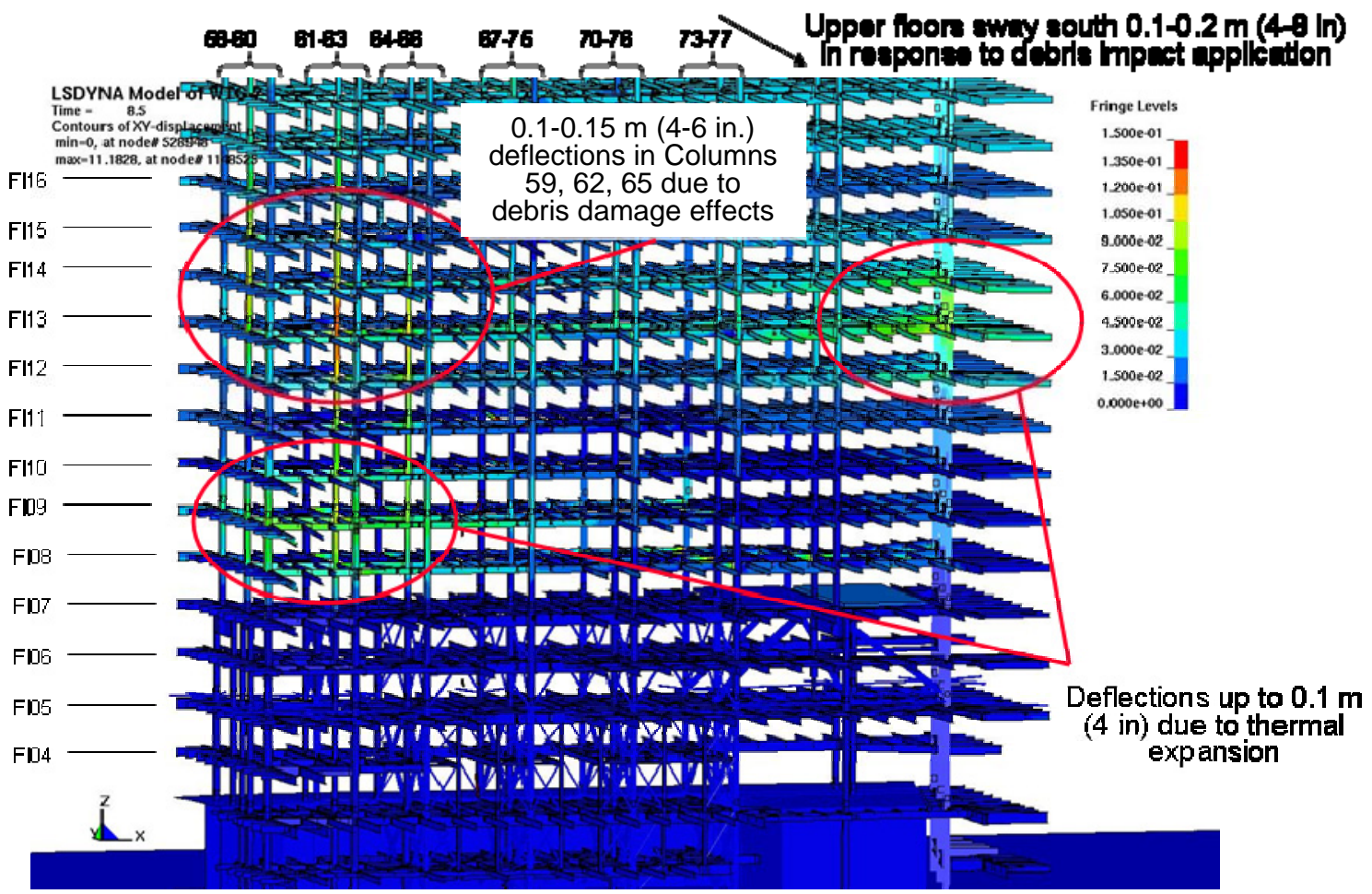

Figure 4-18. Core lateral displacement at -7.5 (8.5) s; end of temperature application.

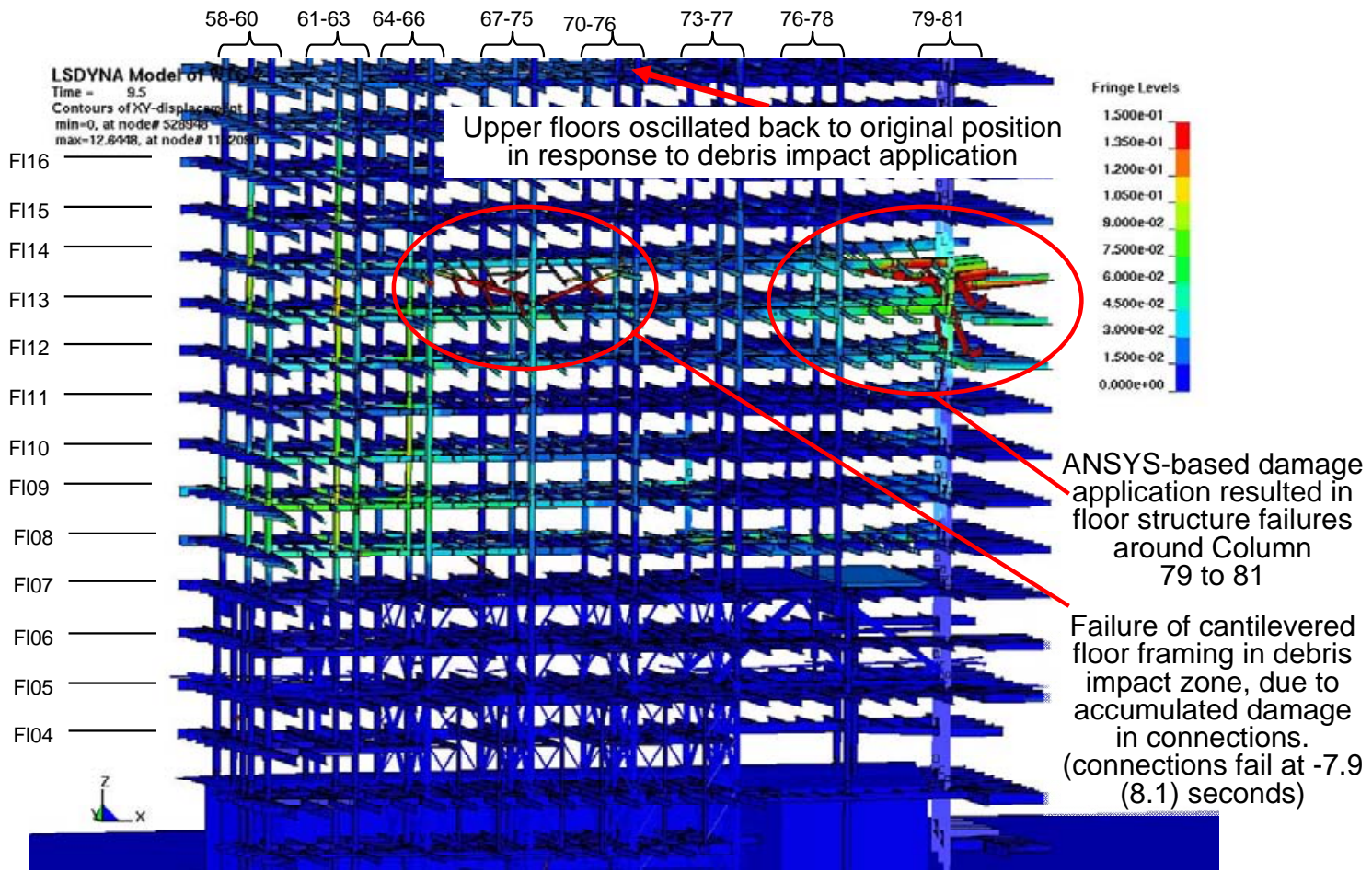

Figure 4-19. Core lateral displacement at -6.5 (9.5) s; start of failure of Floors 13 and 14 start around Column 79. 
Damage to the western core developed early in the initialization process as a result of the WTC 1 debris impact damage. In the model, the debris damage was instantaneously applied to approximate the actual dynamic event. This damage application resulted in a sudden redistribution of loads and displacements within the structure.

Figure 4-20 illustrates broken connections in the western core of Floor 13 at the end of the debris and temperature initialization phases. The figure shows typical damage near the debris impact zone. Surrounding floors had similar levels of damage. The connection damage developed mostly after application of the debris impact damage but increased slightly after applying the temperatures, giving rise to further displacements. The figure shows degraded north-south lateral restraint for Columns 59, 62 and 65 due to broken north-south girder connections, which allowed displacements relative to the surrounding structure. Figure 4-21 highlights the lower west core column displacements after full initialization.

Figure 4-22 and Figure 4-23 show the continued failure of floor sections down to Floor 5 around Columns 79, 80, and 81. Buckling of Columns 79 to 81, and the subsequent vertical upward progression of floor collapses around Columns 79 to 81, are illustrated in Figure 4-24 and Figure 4-25.

\section{-9.5 (6.5) s: End of debris damage cycle}

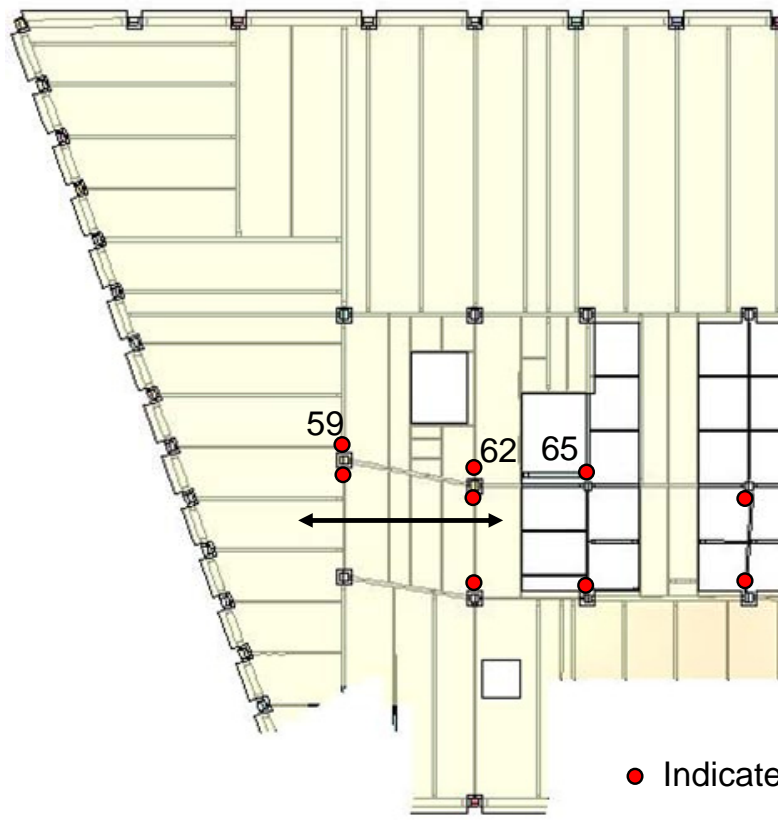

Figure 4-20. Columns 59, 62 and 65 connection damage at the $13^{\text {th }}$ floor. Slab is transparent

\section{-7.5 (8.5) s: End of temperature cycle}

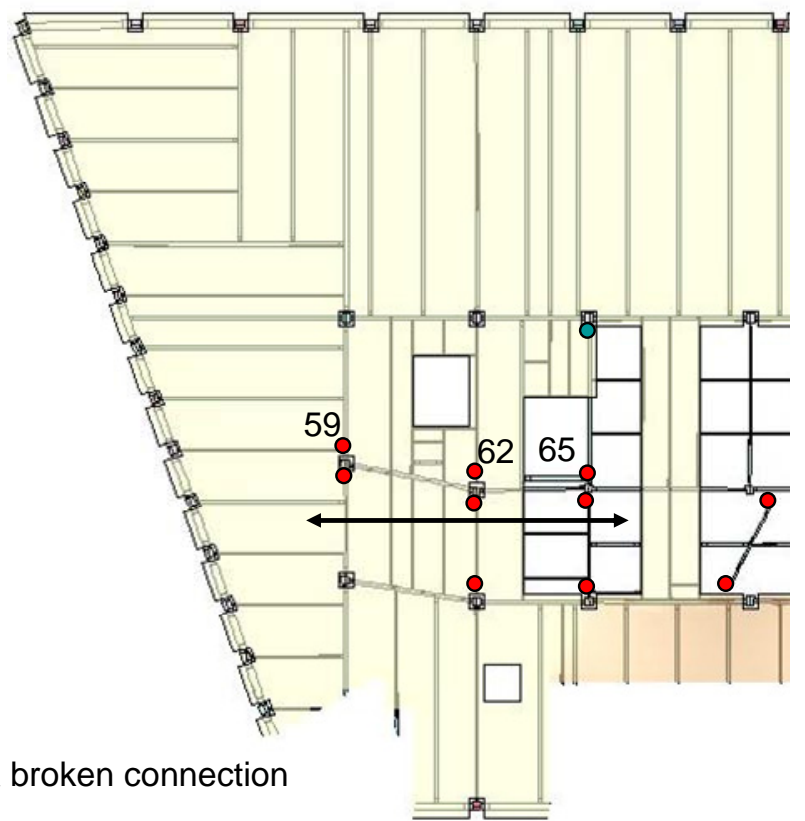




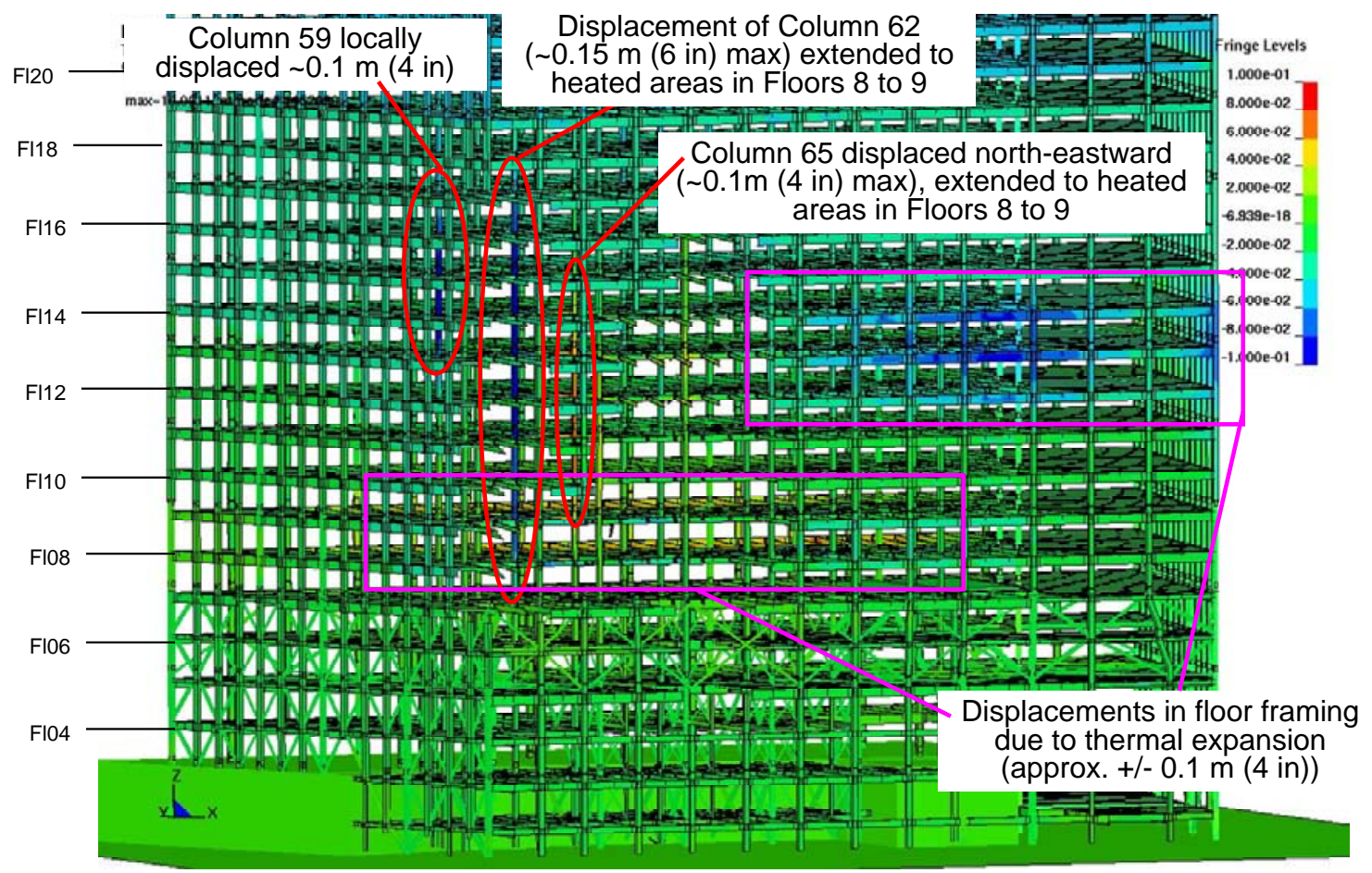

Figure 4-21. East-west displacement history including exterior framing at -7.5 (8.5) s; completion of temperature application.

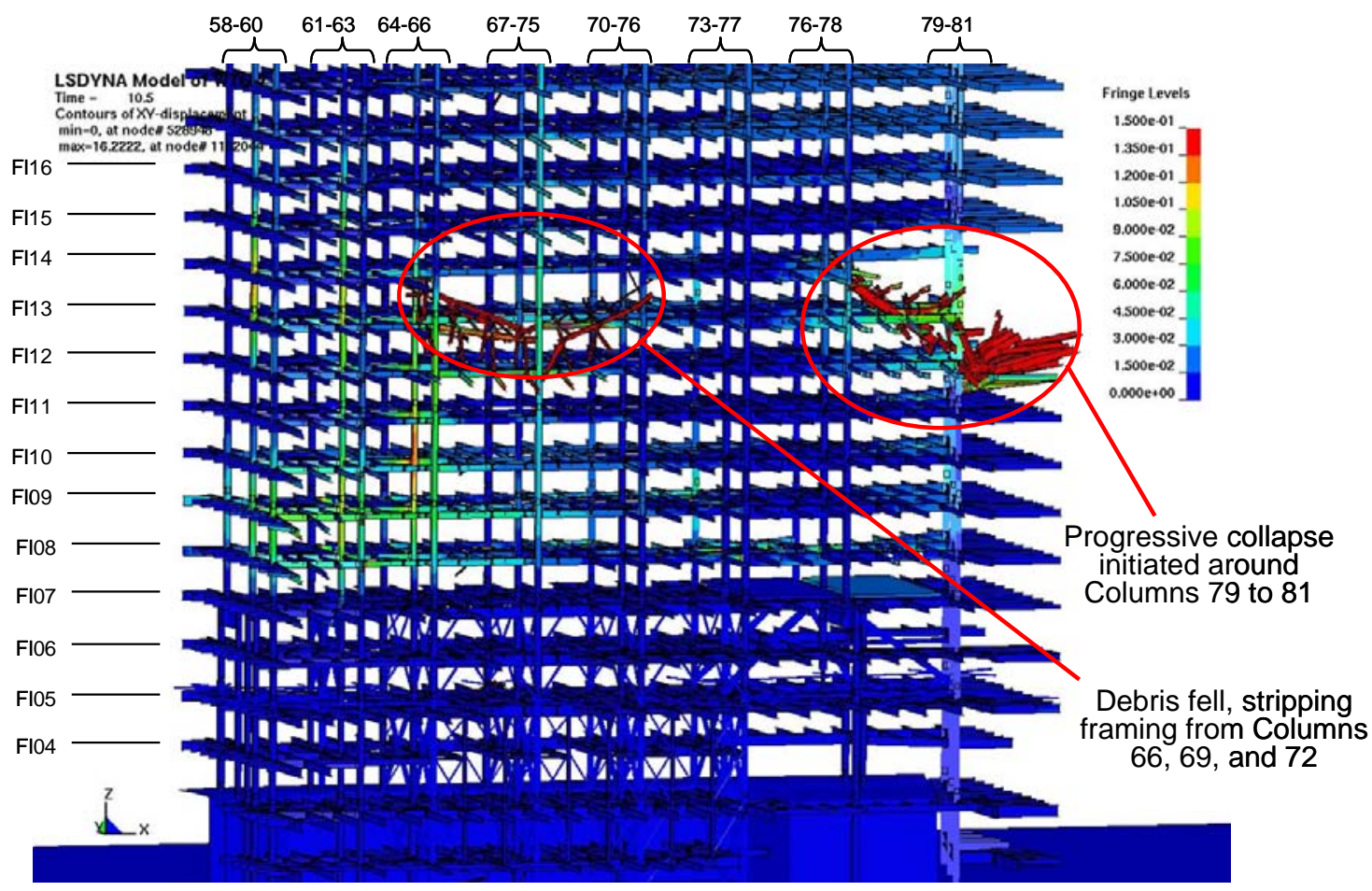

Figure 4-22. Core lateral displacement at -5.5 (10.5) s; collapse of floors onto the floor below around Columns 79, 80, and 81. 


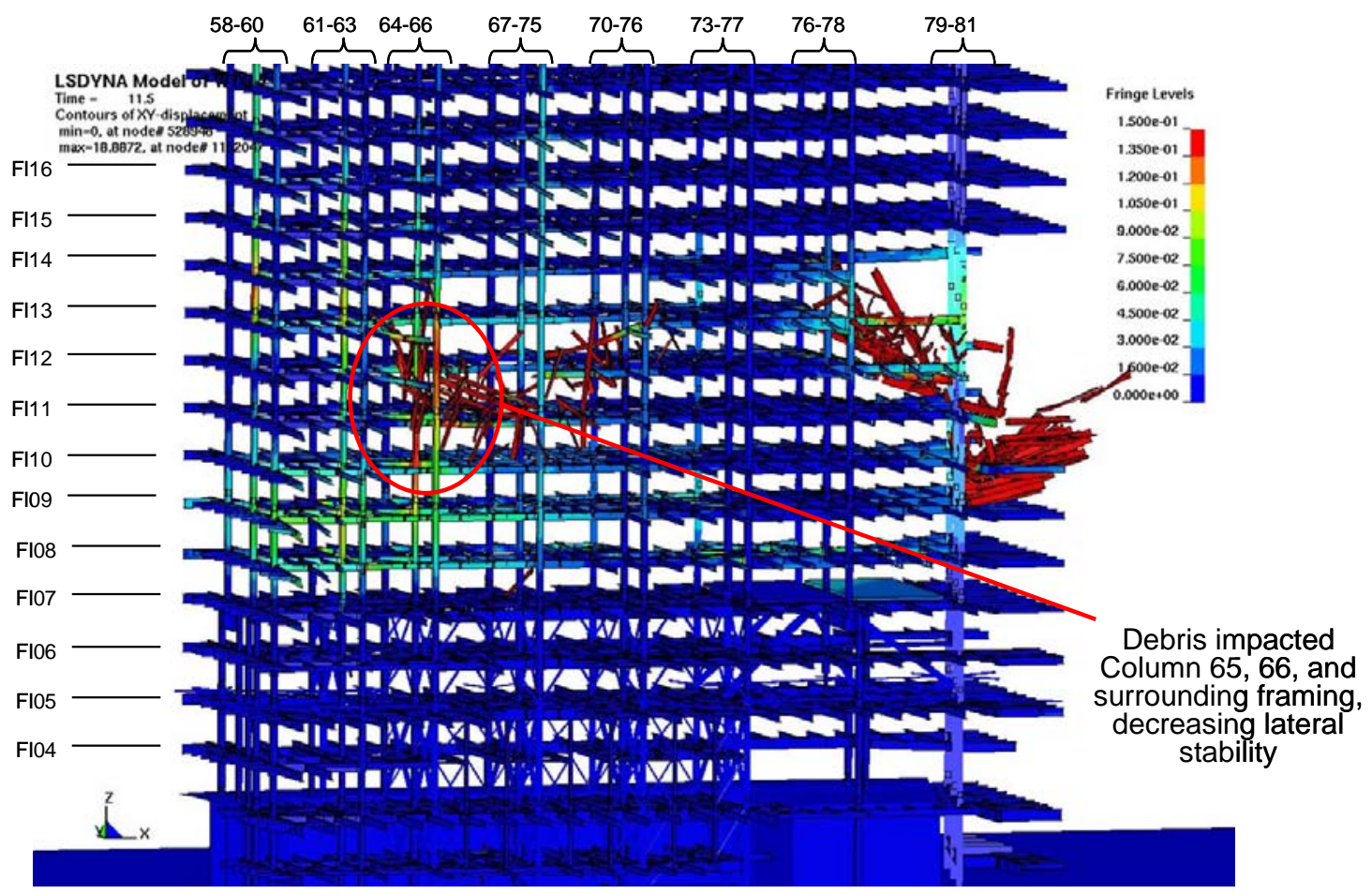

Figure 4-23. Core lateral displacement at -4.5 (11.5) s; continuation of floors collapsing onto the floor below around Columns 79, 80, and 81 and debris continuing to fall around Columns 65 and 66.

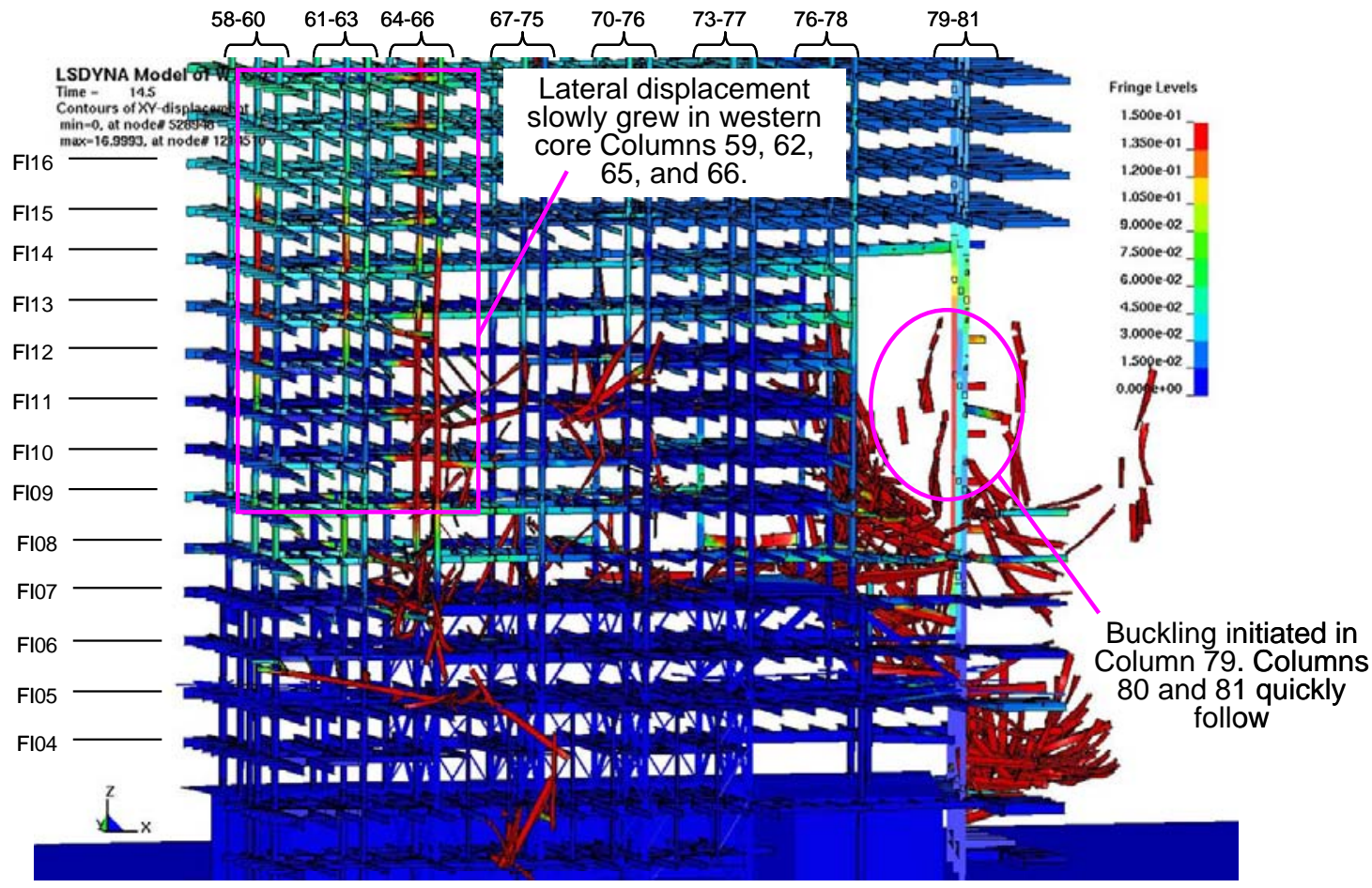

Figure 4-24. Core lateral displacement at -1.5 (14.5) s; buckling of Column 79 followed by the buckling of Column 80 , then Column 81. 


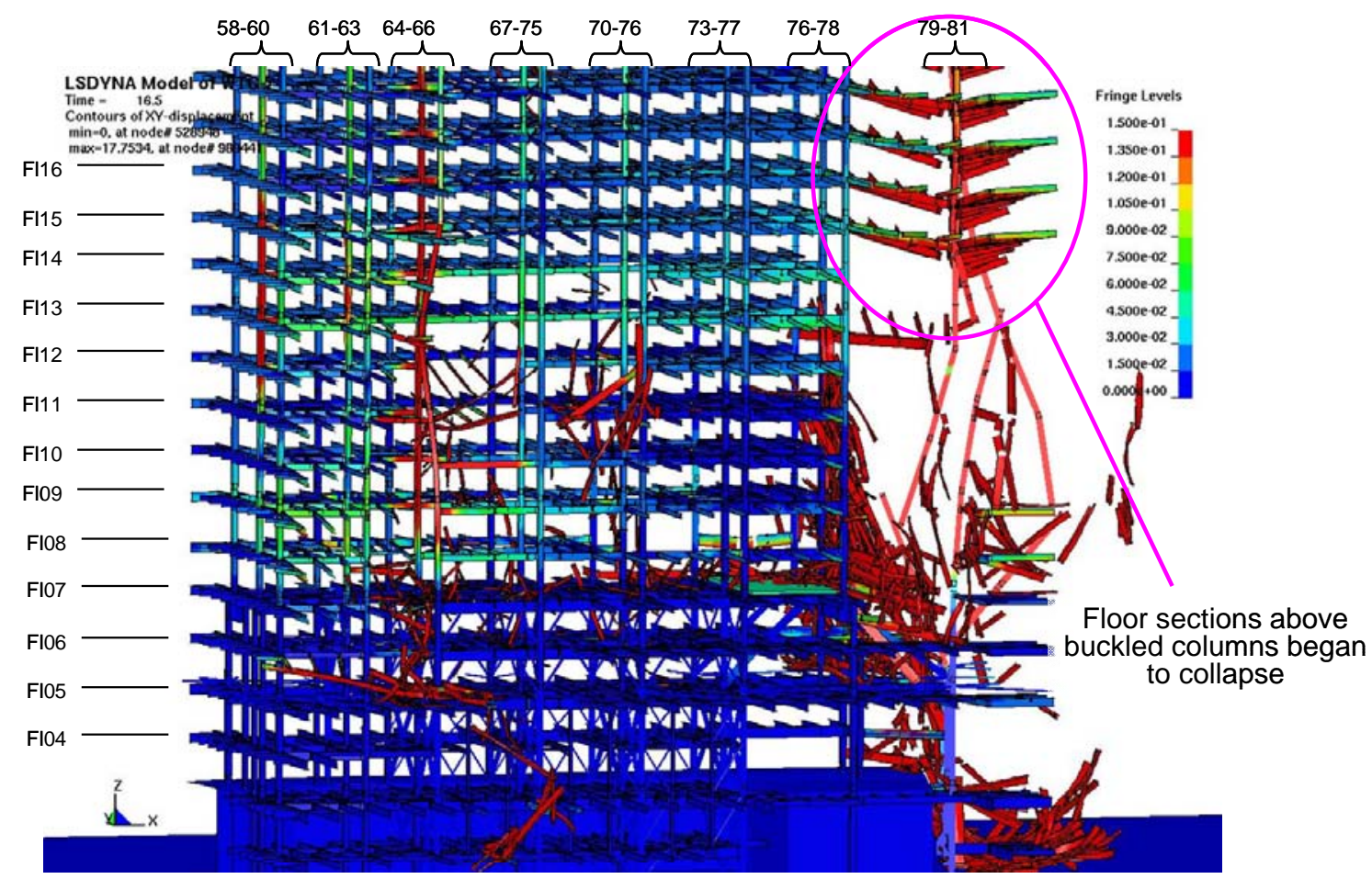

Figure 4-25. Core lateral displacement at $0.5(16.5) \mathrm{s}$; descent of the column sections above the buckled columns and progression of the failure vertically upward to the roof of WTC 7.

\subsubsection{Horizontal Progression of Collapse}

After the vertical progression of failure around Columns 79, 80, and 81, the failures continued to propagate from east to west across the interior columns on the lower floors due to (1) loss of lateral support from floor system failures, (2) forces exerted by falling debris impact, and (3) load distribution from other buckled columns. The lateral support for Columns 76 to 78 was lost on the east side, when the floor connections failed. In addition, as the vertical failures progressed, floor and column debris fell from the upper floors, impacting adjacent intact columns and floors, including Truss 1 and Truss 2 . The accumulation of debris and debris impacts eventually caused Truss 2 to fail, as noted in Figure 4-26 through Figure 4-28.

Truss 2 collapsed in the LS-DYNA calculation at approximately 2.7 (18.7) s due to accumulated weight and impact loads from falling debris. Figure 4-27 shows the Truss 2 east diagonal between Columns 77 and 80 just prior to failure. Most of the fallen debris is removed from view for clarity. Truss 2 supported Column 77. Truss 1 , which can be seen behind Truss 2, had similar construction with diagonal members, and supported Column 76. Unlike Truss 2, Truss 1 did not collapse in the calculation.

Figure 4-28 illustrates the status of the structure after the diagonal member buckled and plots the axial force in the diagonal member. The plot shows two large impact events as a sudden change in axial force. The first event is associated with the initial collapse of Floors 8 to 14. The second impact event was caused by the debris impact from the floors above Floor 14 . 


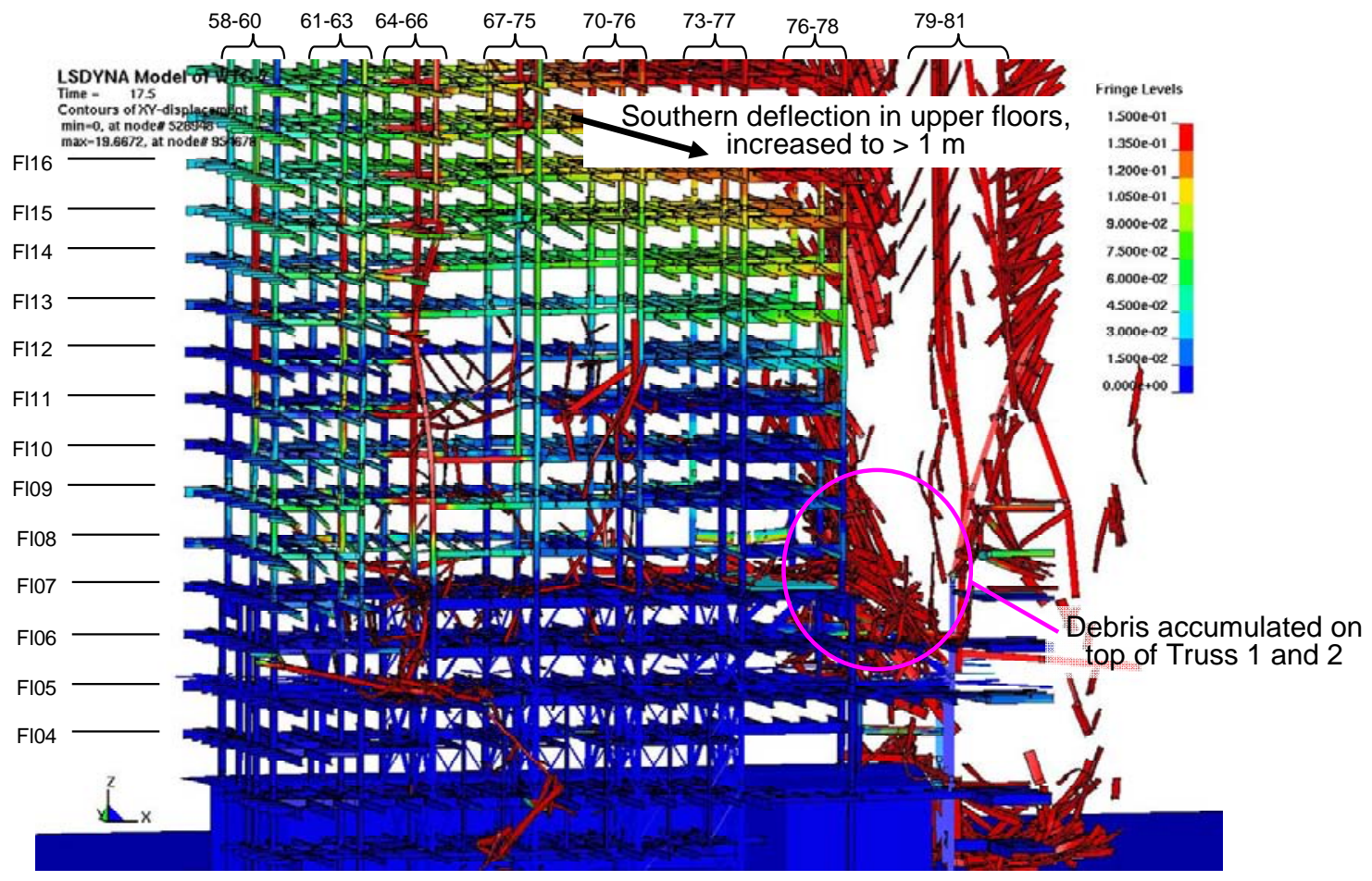

Figure 4-26. Core lateral displacement at 1.5 (17.5) s; falling of debris from the collapsing floors onto the lower floors, including Trusses 1 and 2, impacting Columns 76, 77, and 78.

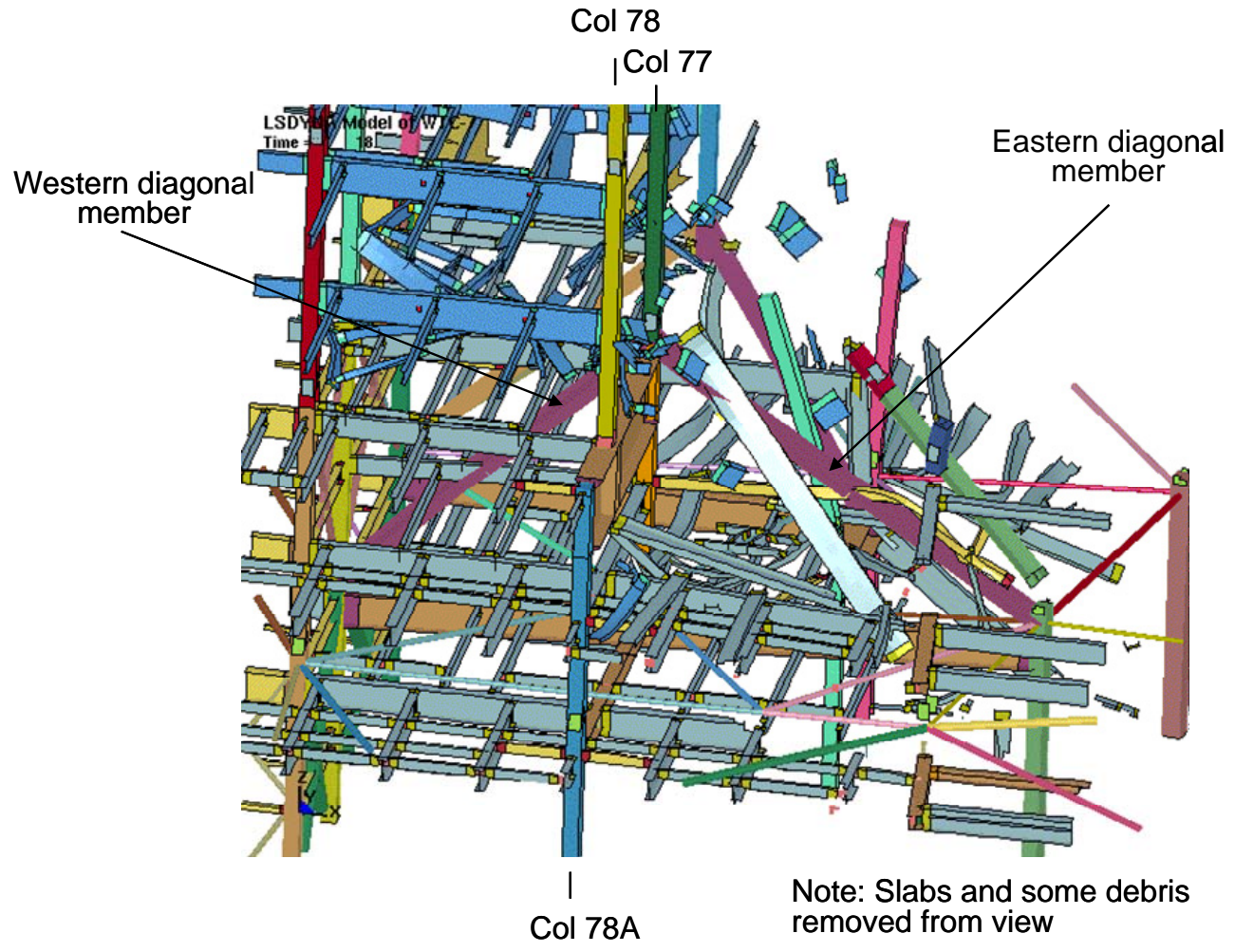

Figure 4-27. Failure of Truss 2 east diagonal, viewed from the southeast and above. 


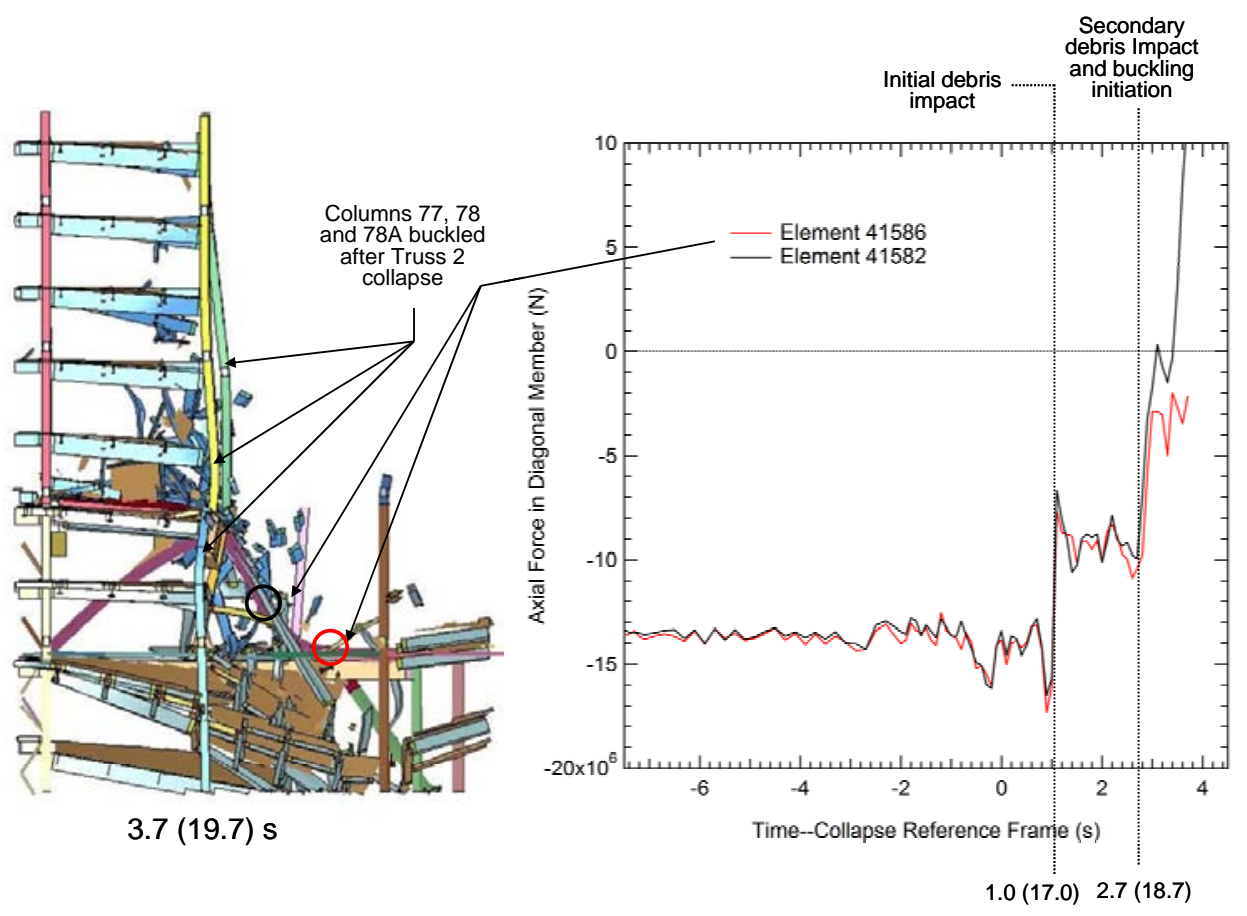

Figure 4-28. Truss 2 collapse, viewed from the south with most of debris removed from view.

The failure of Truss 2 precipitated the buckling of Columns 77 and 78, which together with Column 76 had already lost lateral support (Figure 4-29 and Figure 4-30). The loss of the Truss 2 diagonal resulted in a loss of support for Column 77. To the south of Truss 2, girder MG-23 framed between Column 78A and Column 77 at Floor 7, and supported Column 78. When the Truss 2 diagonal member buckled, support for MG-23 was lost at Column 77, which led to loss of support for Column 78. Column 76 buckled due to the loss of lateral support, impact of falling debris and load redistribution from Columns 77 and 79.

Column buckling progressed westward (Figure 4-31) and the interior columns continued to deflect due to load redistribution and global motion of the floors above. Eventually all core columns buckled (Figure 4-32 to Figure 4-33) between Floors 9 and 14.

An overview showing the progression of collapse in the interior column and floor structure for all floors is shown in Figure 4-34 and Figure 4-35. Contours of north-south displacement (north is positive and south is negative in the Y-direction) are overlaid on the core structure, indicating directionality of the motion. A southward motion caused by structural failure surrounding buckled Columns 79 to 81 is shown starting around 1.5 (17.5) s. This motion grew with time. In addition to the southward tilt of the east floor region, which then spread across the interior structure, the interior columns between Floors 9 and 13 buckled northward, as shown in Figure 3-36. The buckling of all the interior columns extended to the building exterior columns, resulting in total loss of column support to the floors above, thereby initiating a global downward motion in the upper floors. 


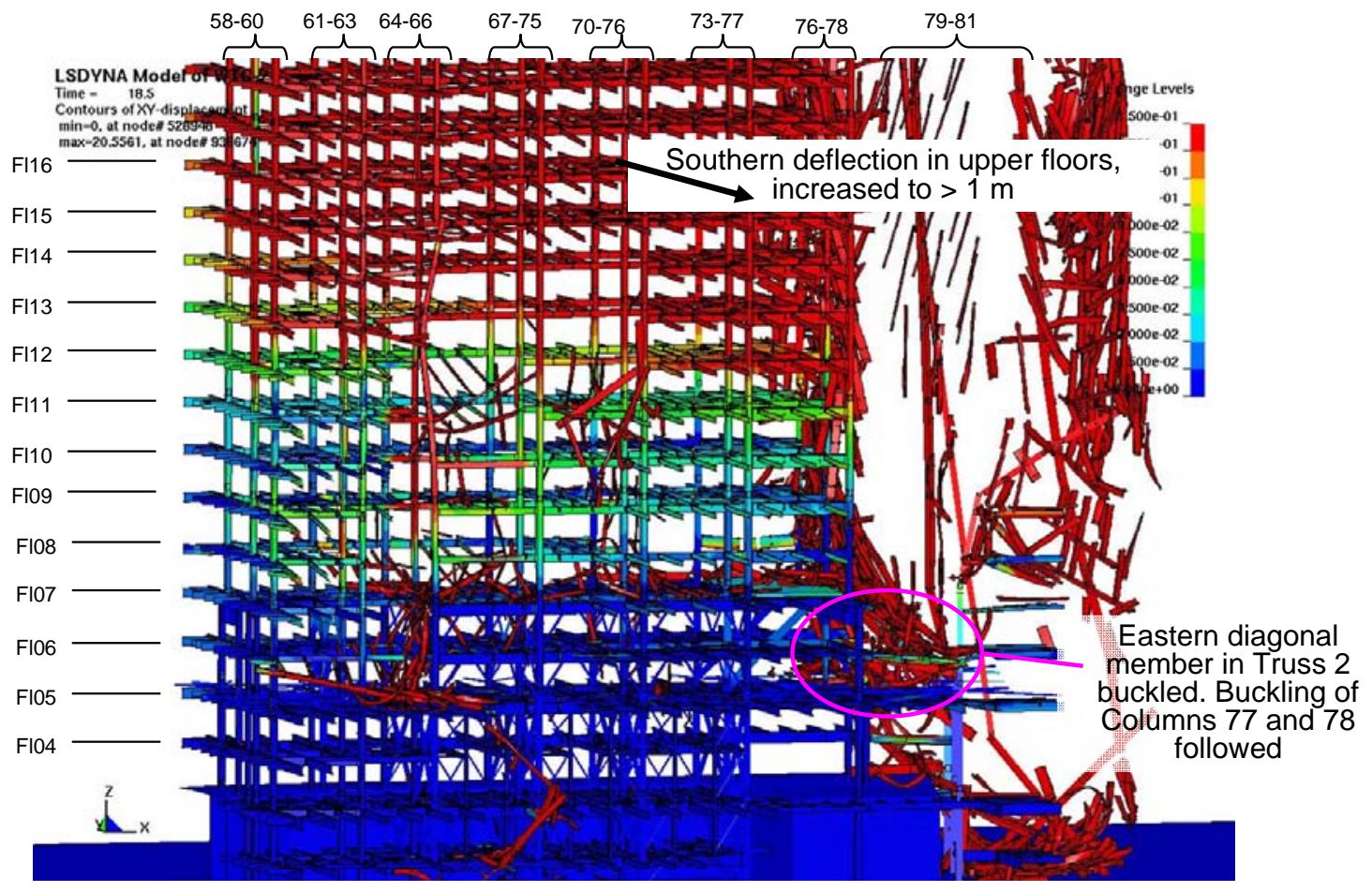

Figure 4-29. Core lateral displacement at 2.5 (18.5) s; buckling of Columns 77 and 78 buckled when Truss 2 failed from debris loads.

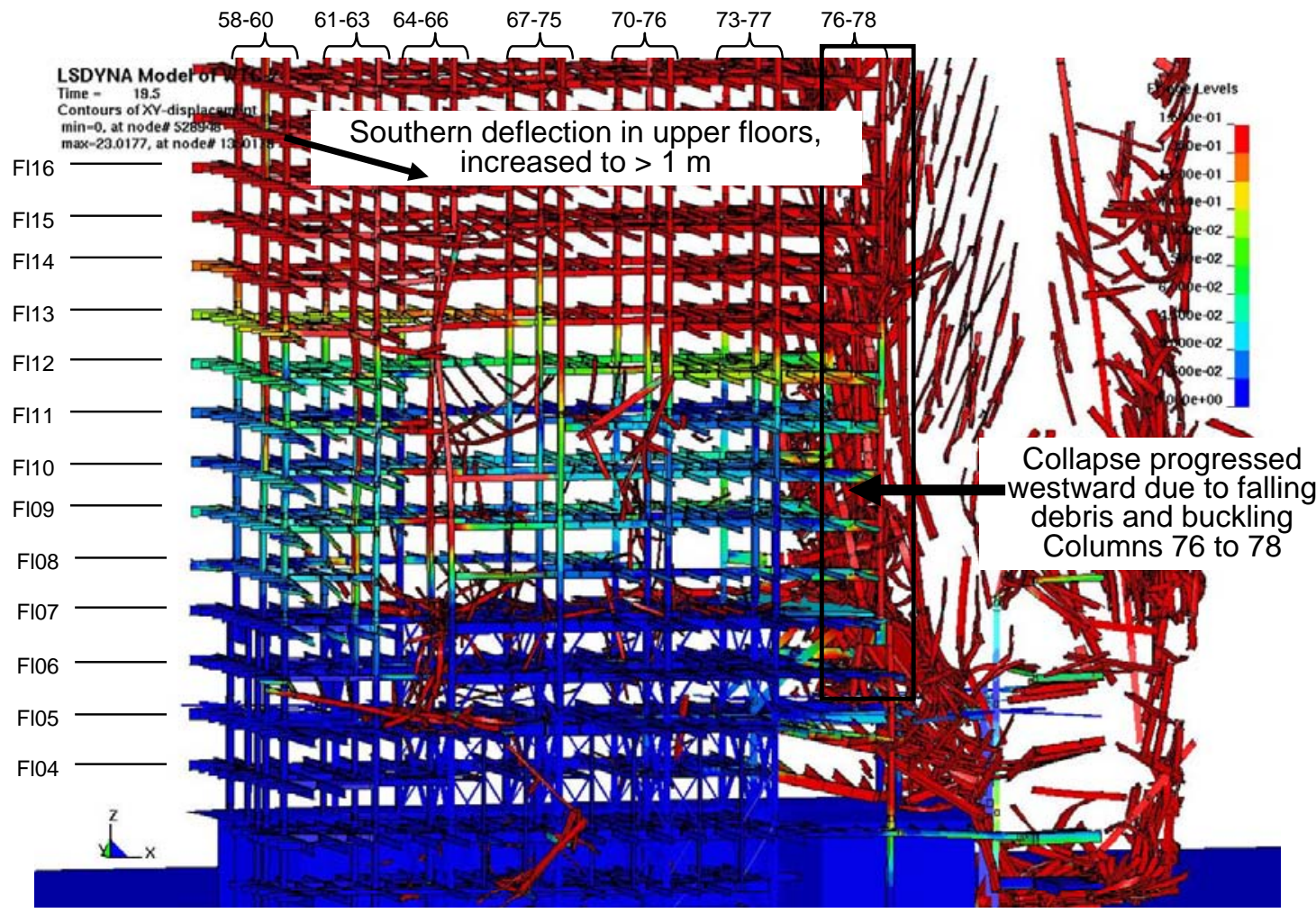

Figure 4-30. Core lateral displacement at 3.5 (19.5) s; buckling Column 76 buckled and start of horizontal progression of the failure. 


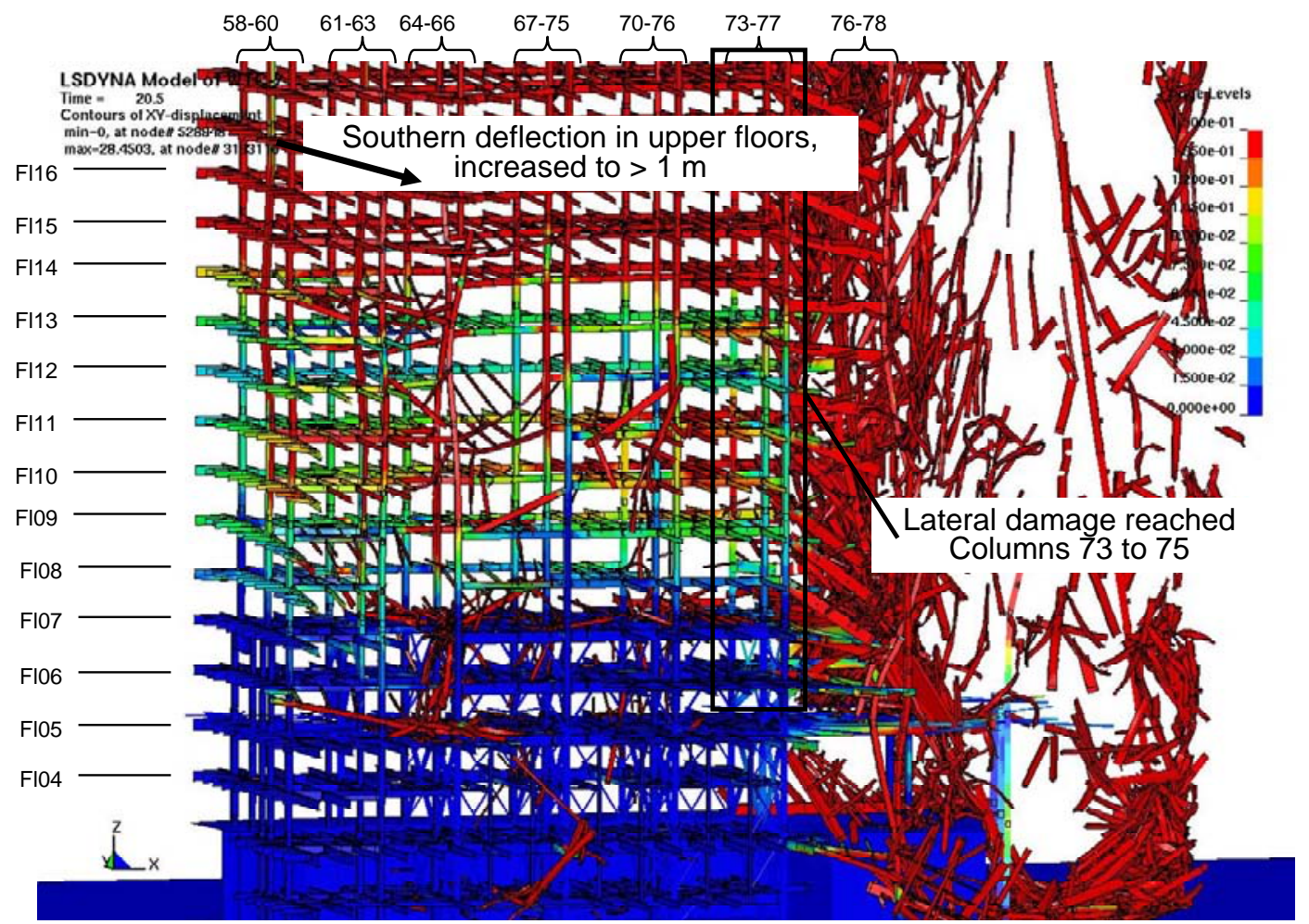

Figure 4-31. Core lateral displacement at $4.5(20.5) \mathrm{s}$; failure of Columns 73 to 75.

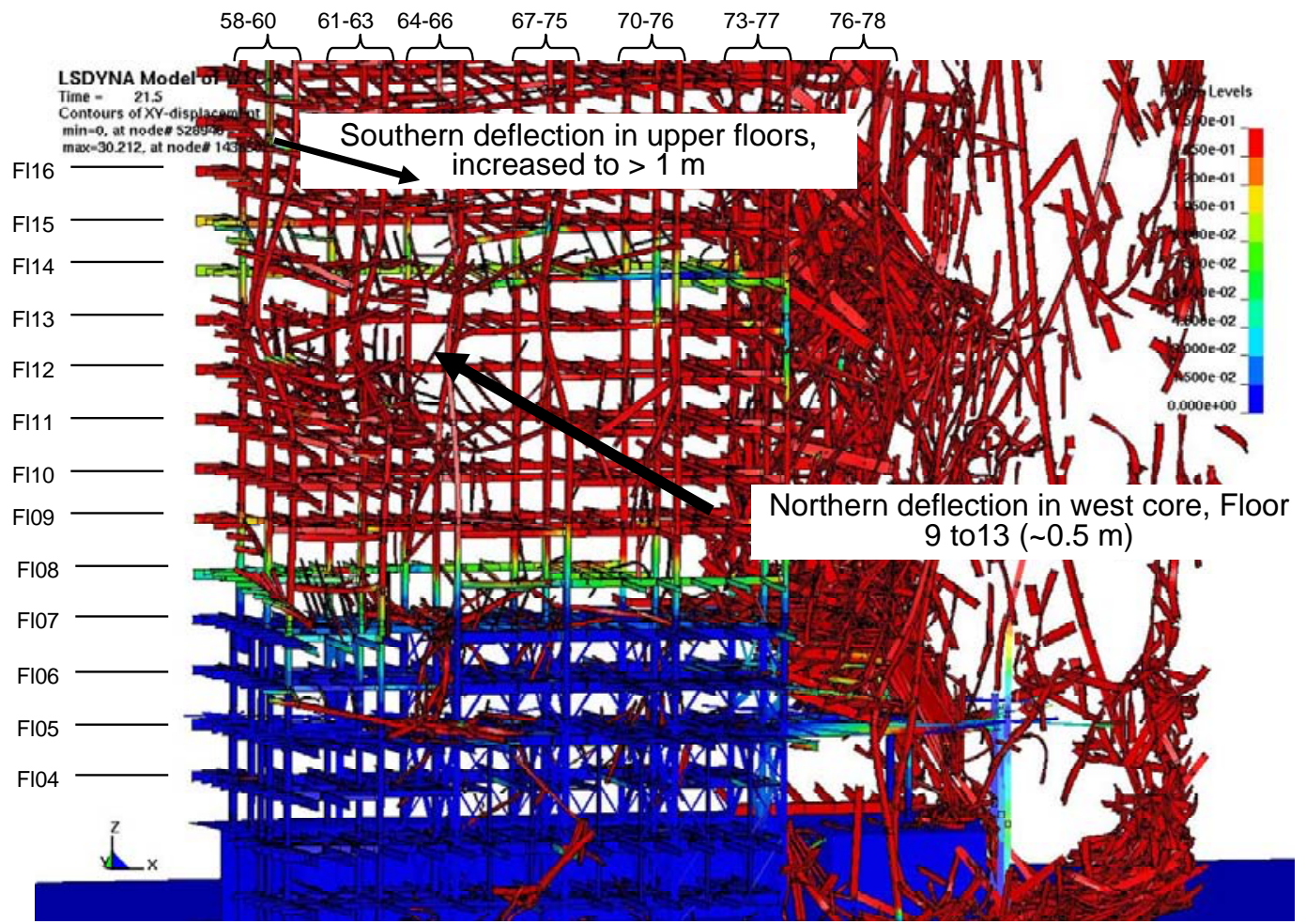

Figure 4-32. Core lateral displacement at 5.5 (21.5) s; all interior columns buckled. 


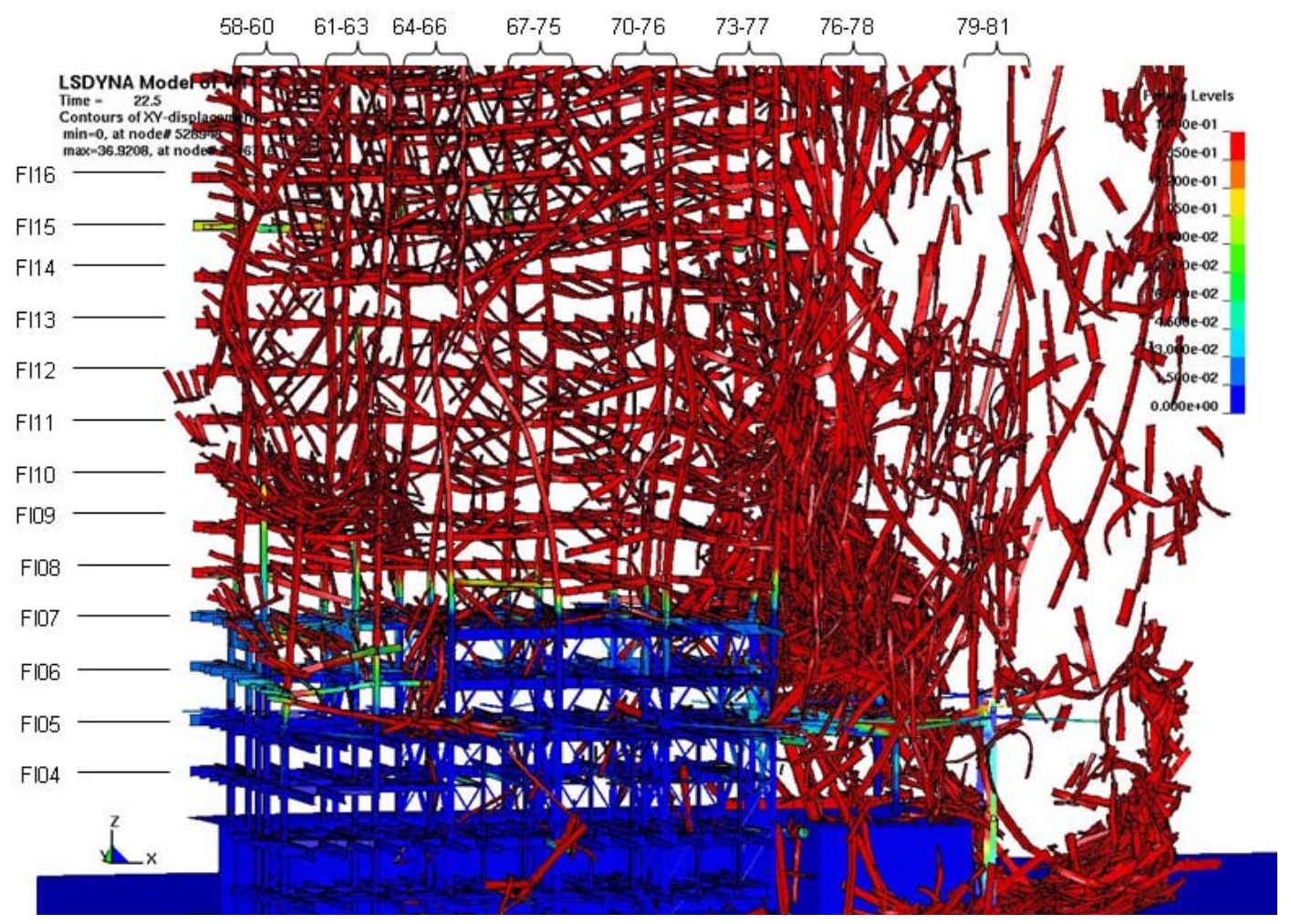

Figure 4-33. Core lateral displacement at 6.5 (22.5) s; global collapse underway.

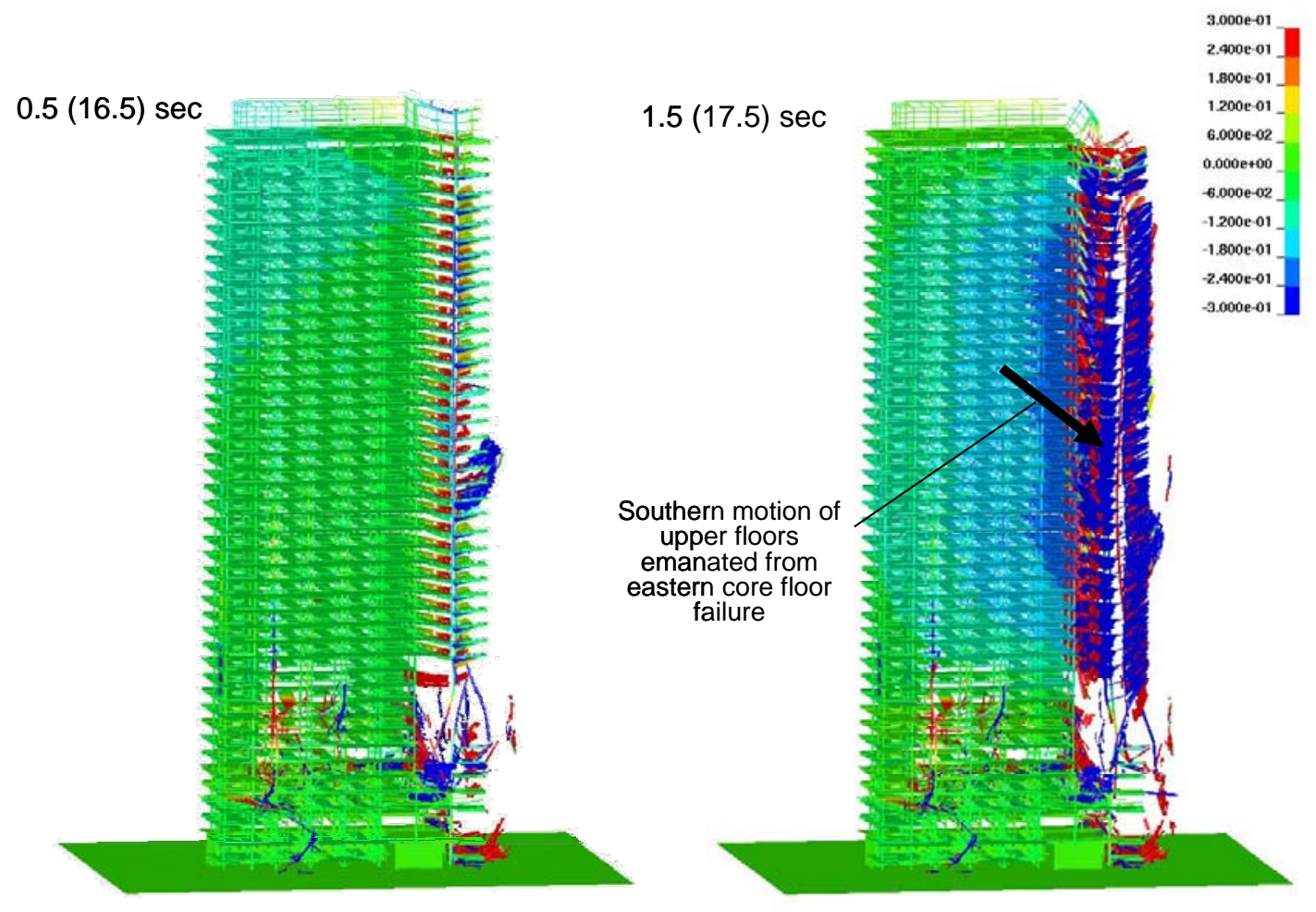

Figure 4-34. Core north-south displacement history, viewed from the south. 

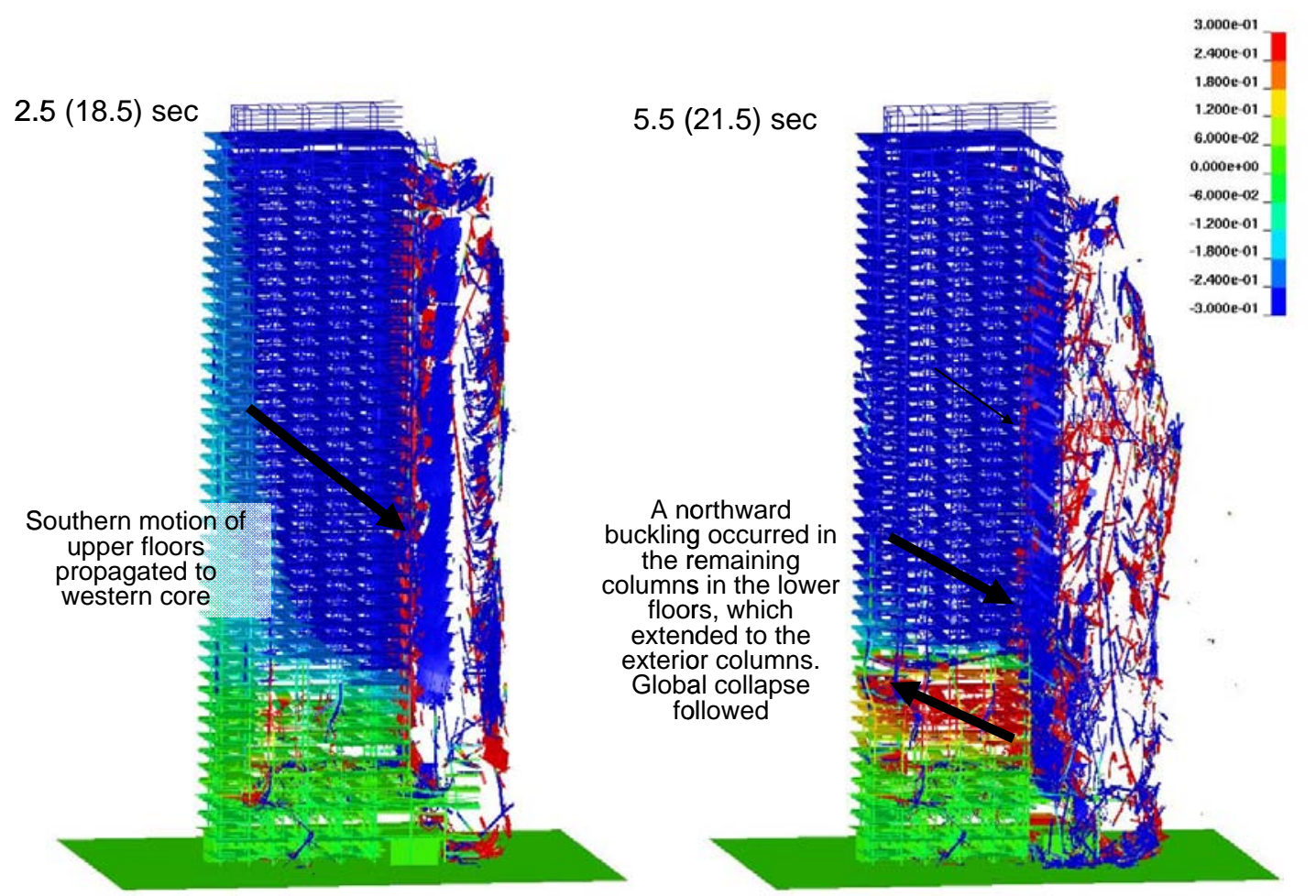

Figure 4-35. Core north-south displacement history, viewed from the south.

To better understand the progression of interior column failures, it is helpful to consider how column loads changed with time in the LS-DYNA analysis. Column loads are grouped according to the groupings shown in Figure 4-36. The figure shows the general westward progression of interior column failure. Corresponding loads for the progressive buckling of columns in groups 1 to 5 are shown in Figure 4-37. When the columns in a group buckled, the column load decreased. The buckling of the interior columns propagated westward from Columns 79, 80, and 81. About $6 \mathrm{~s}$ later, the west core columns also began to buckle. Column loads corresponding to column groups 6 to 8 are shown in Figure 4-38. All interior column support was lost by 6.3 (22.3) s.

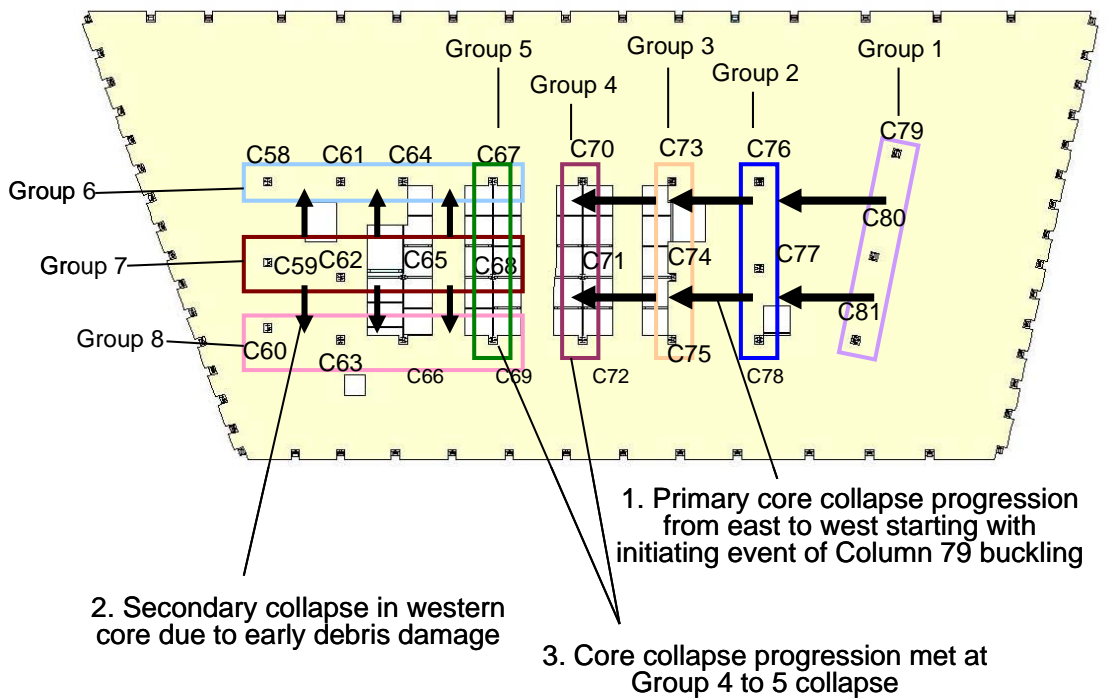

Figure 4-36. Horizontal progression of column buckling. 


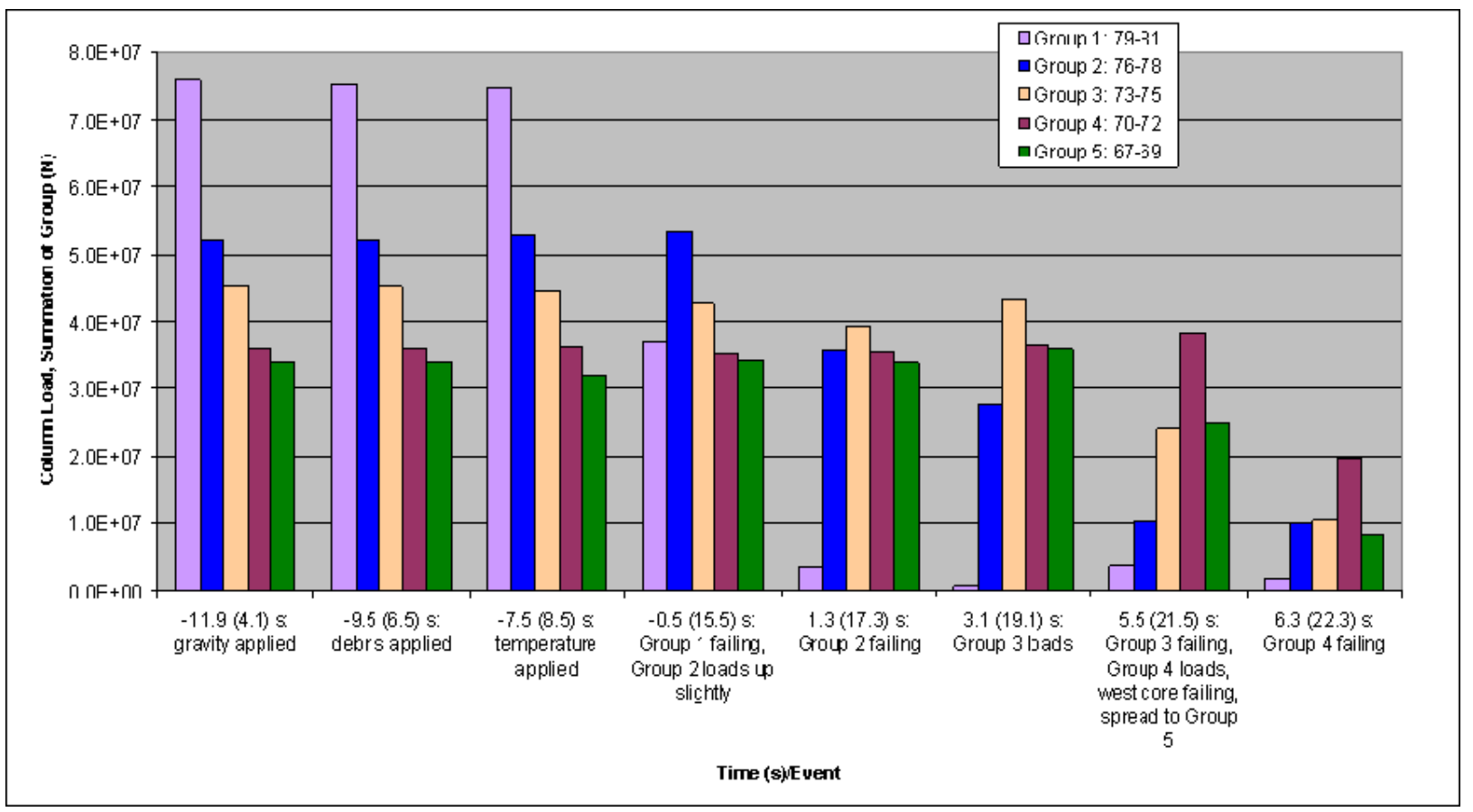

Figure 4-37. Interior column loads, illustrating east to west collapse progression.

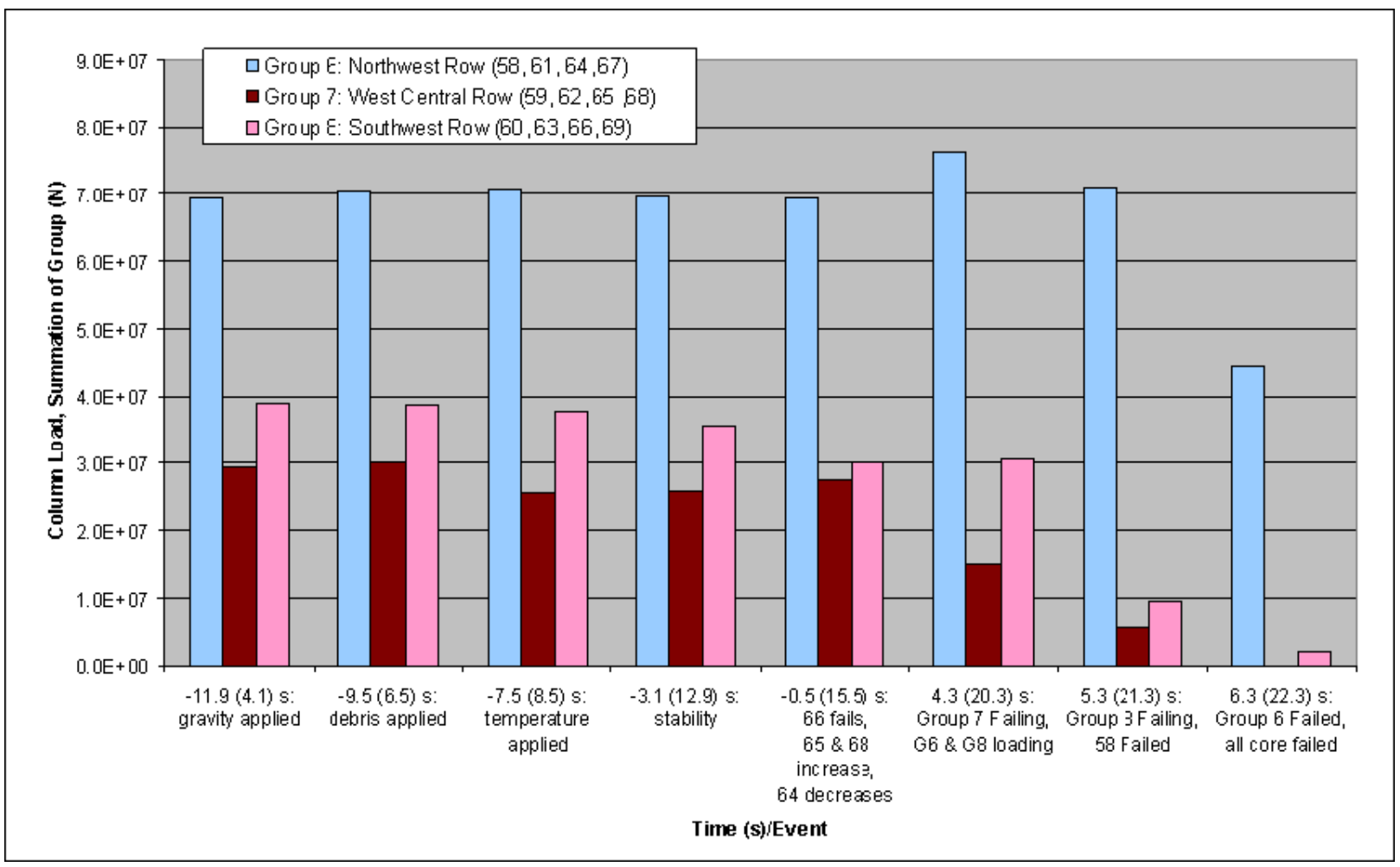

Figure 4-38. West interior column loads, illustrating progression of failure. 
Although the structure was stable at the end of initialization, when Columns 79, 80, and 81 buckled, resulting global motions and load redistributions contributed to the onset of buckling in Columns 65 and 66. Buckling of these columns was partially due to a girder connection failure at Column 69. After applying the estimated impact damage to the southwest corner, floor sections were left hanging at the south core perimeter, as indicated in Figure 4-39. Accumulated damage during the initialization phase caused the connections to the east and west of Column 69 at Floor 14 to fail. Note that, at the location of debris damage, the southern core perimeter girders were smaller wide flange sections for Floor 14 than in the other adjacent floors.

Figure 4-40 shows vertical displacement at the top of Columns 59, 62, 65, and 66. In the figure, a plot of vertical displacement history is included for the four columns as along with Column 79. A quick descent of Column 79 was noted while the descent of Column 66 was slower. It wasn't until about 6 s later when horizontal progression of column failures had occurred and Columns 59, 62, and 65 had buckled and started their descent that Column 66 was pulled down with them.

-8.5 (7.5) s: Halfway through temperature application

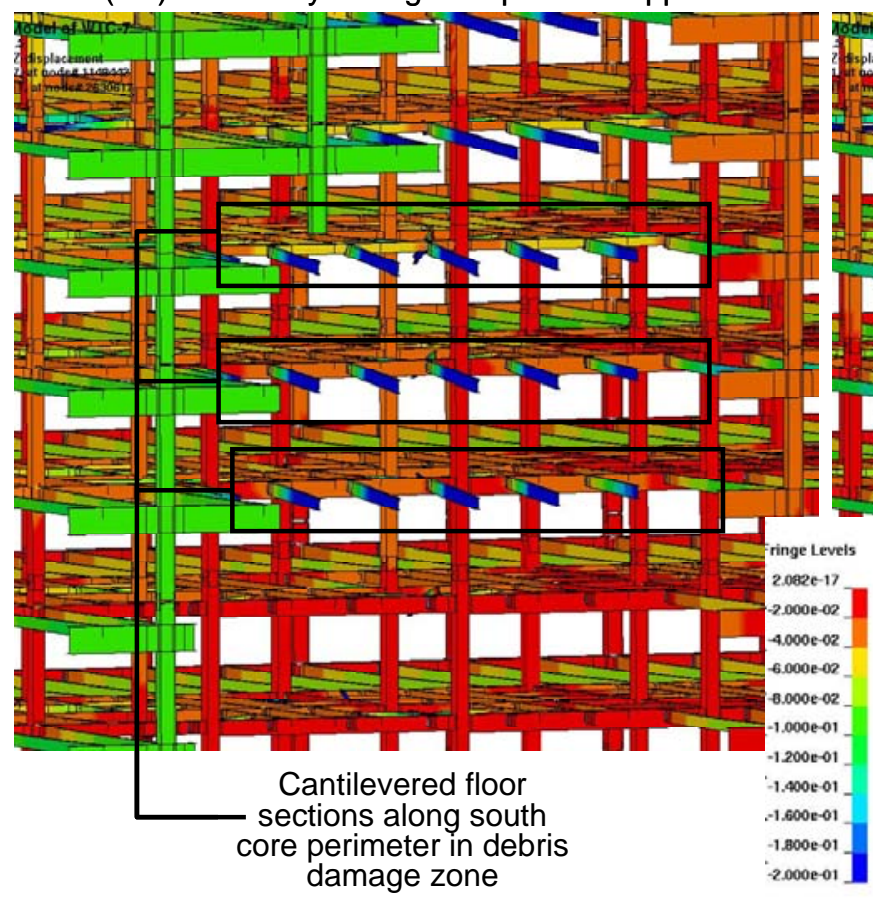

-7.5 (8.5) s: Temperature application completed

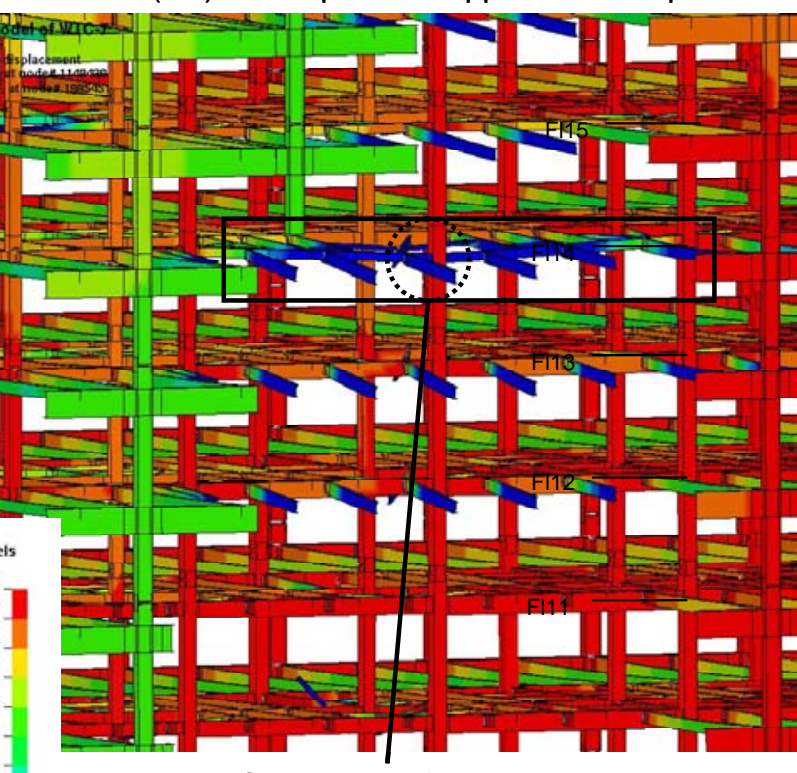

Connections failed at Floor 14 preferentially due to smaller girder supporting same bending loads at Floor 13 and below

Figure 4-39. Close-up of cantilevered floor sections, vertical displacement contours, $-0.2 \mathrm{~m}$ to $0 \mathrm{~m}$ (-8 in. to $0 \mathrm{in})$, viewed from the southwest. 


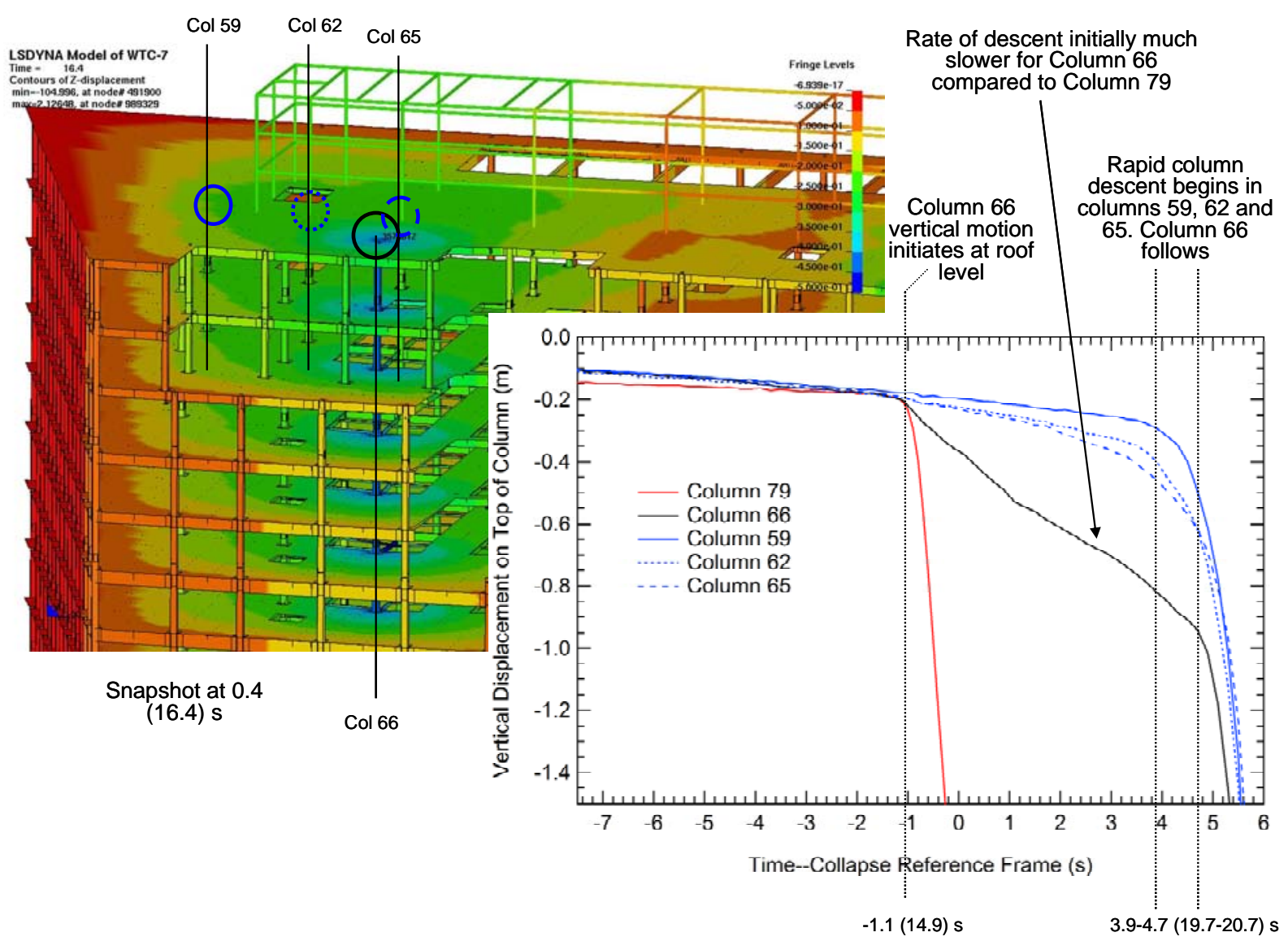

Figure 4-40. Western core column vertical displacements (contours: $-0.5 \mathrm{~m}$ to $0 \mathrm{~m}$ ).

\subsubsection{Global Collapse}

The buckling of the interior columns in the LS-DYNA analysis was followed by the buckling of the exterior columns.

Figure 4-41 shows a plan view of Floor 8 that highlights the exterior columns that were used to track the column load history for each face. Also noted on the figure is the debris impact zone, which shows the southwest columns that were severed. Loads were extracted just above Floor 8 from three columns per face and averaged to produce Figure 4-42.

Figure 4-42 shows column loads increasing as gravity was applied over $4.5 \mathrm{~s}$ (compressive loads are negative). There was an increase in compressive load on the west and south faces after debris impact damage was applied at -11.5 (4.5) s. The remaining west and south columns were able to support the loads and the structure was stable after the debris impact damage was applied.

As Columns 79 to 81 failed and their floor systems began to fall (indicated near 15 s to $16 \mathrm{~s}$ on Figure 4-42), the loads reduced somewhat in the east and north face columns as the floor framing fell away and separated from the exterior. The southward sway of the upper floors associated with the initial collapse of Columns 79 to 81 put increased loads in lower floor column sections on the south and west walls. The west face column load average was dominated by the loads in Column 14 near the southwest corner. 
The east face columns, which had lost lateral support from the floor systems during the vertical progression, increasingly displaced laterally with time. The displacement was most pronounced at the top of the building, where the roof edge deflected inward (Figure 4-14).

As the core columns buckled across the building, the exterior columns were impacted by falling debris and loads redistributed from the interior columns. All exterior columns buckled between approximately Floors 7 and 14. Figure 4-42 shows that the south and west columns buckled first around 6 (22) s, followed by the north and east face columns. Once column support was lost in the lower floors, the remaining structure above began to fall vertically as a unit.

Figures illustrating the events described are included as a sequence of global model snapshots in Figure 4-43 through Figure 4-46. Four snapshots are shown in each figure. There are two perspectives per figure, one from the southwest and one from the northeast (both from above). Additionally, there are two contours, overlaid on both views. There is a north-south (Y-direction) and an east-west (X-direction) contour for each perspective. The separate lateral displacement contours are used to illustrate positive and negative displacements on all four faces.

Figure 4-43 illustrates the loss of lateral support of exterior columns associated with the vertical progression of collapse around Columns 79 to 81 . Figure 4-44 shows the lateral displacements that developed in the east face. Also shown is the start of the southward global motion that developed as the east interior region collapsed. Figure 4-45 illustrates the increase of lateral deflections of the east face and the start of exterior column buckling in Floors 7 and 14, which began in the southwest corner at 5.5 (21.5) s. Figures 4-46 and 4-47 show the buckling of the exterior columns as the global collapse began. Detailed views of the lower floor exterior column buckle modes are shown in Figure 4-48.

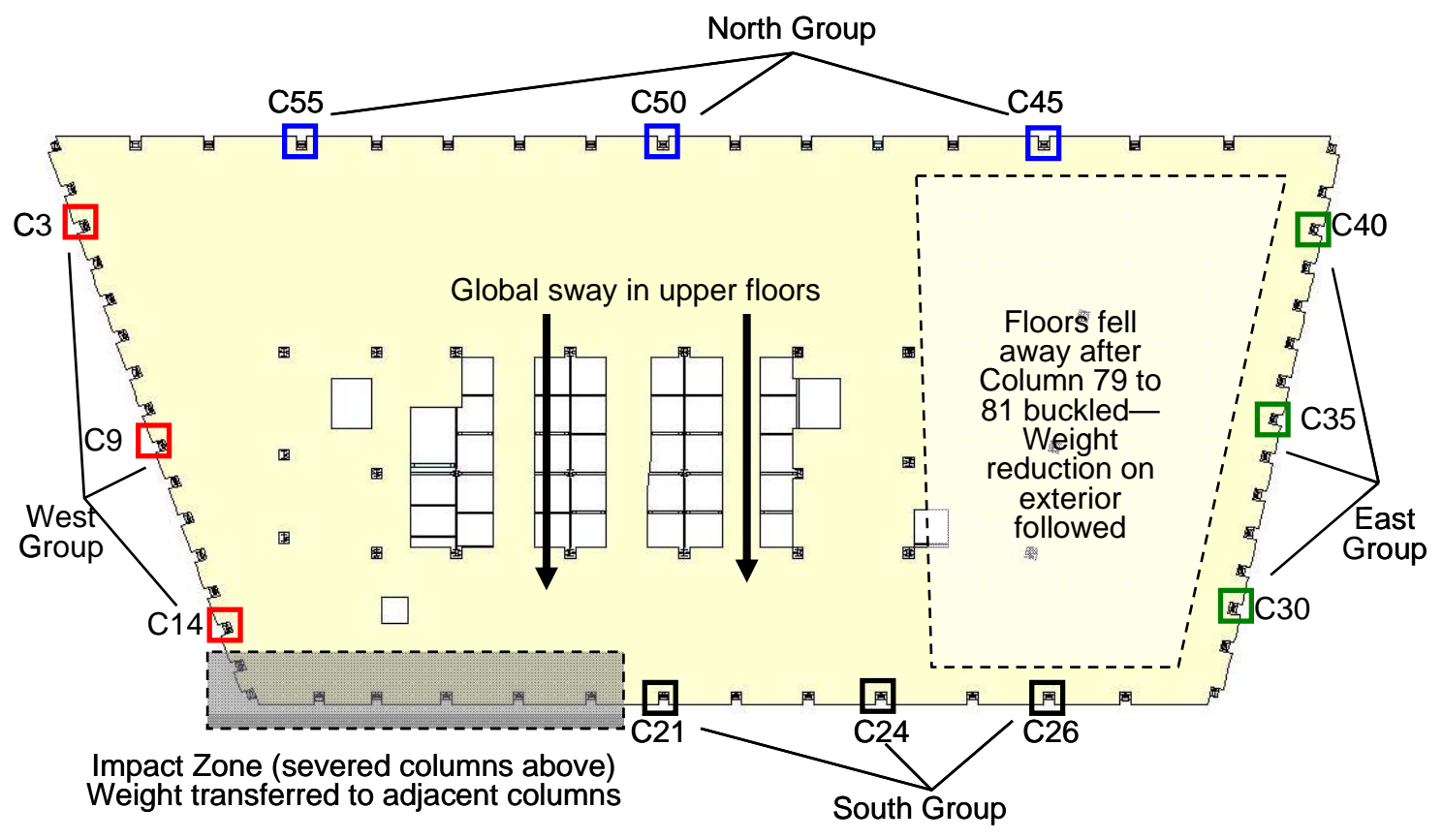

Figure 4-41. Exterior columns used in load groupings. 


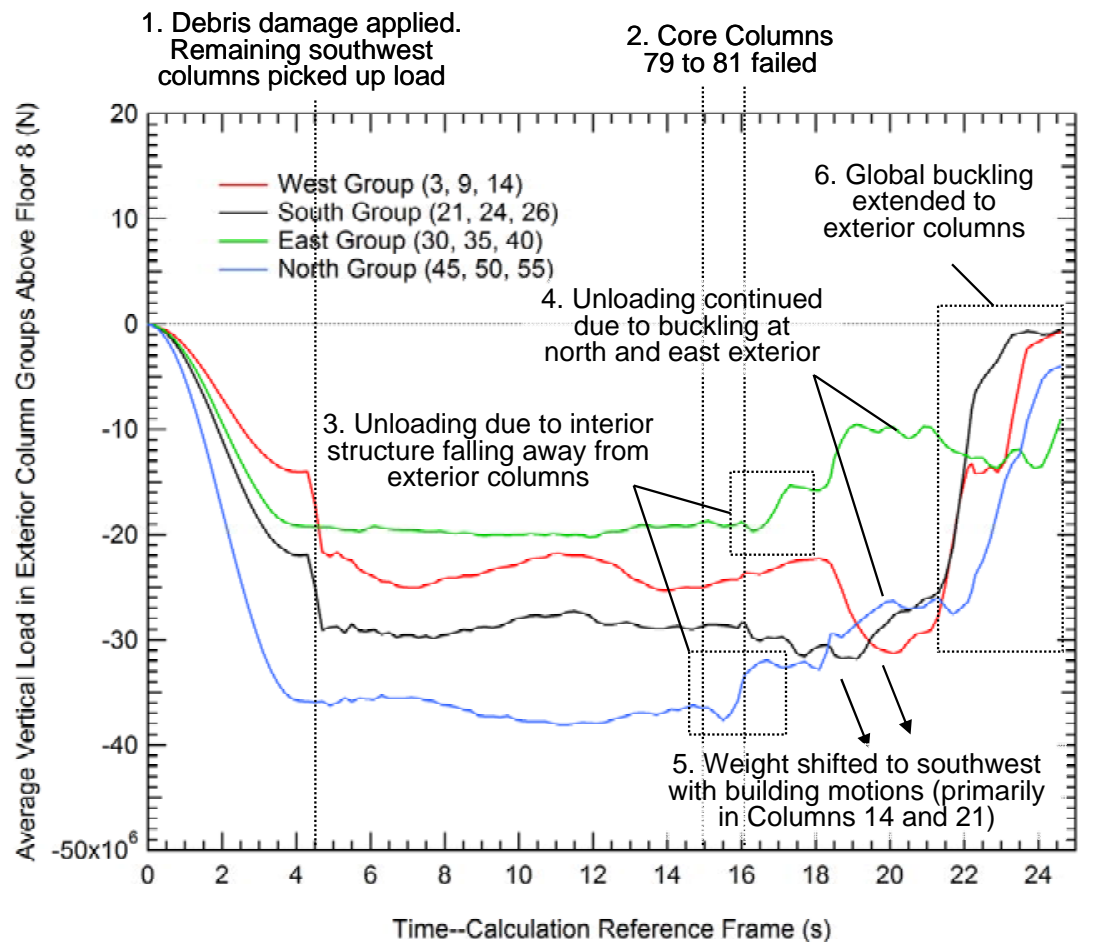

Figure 4-42. Sampling of average perimeter column load by group.

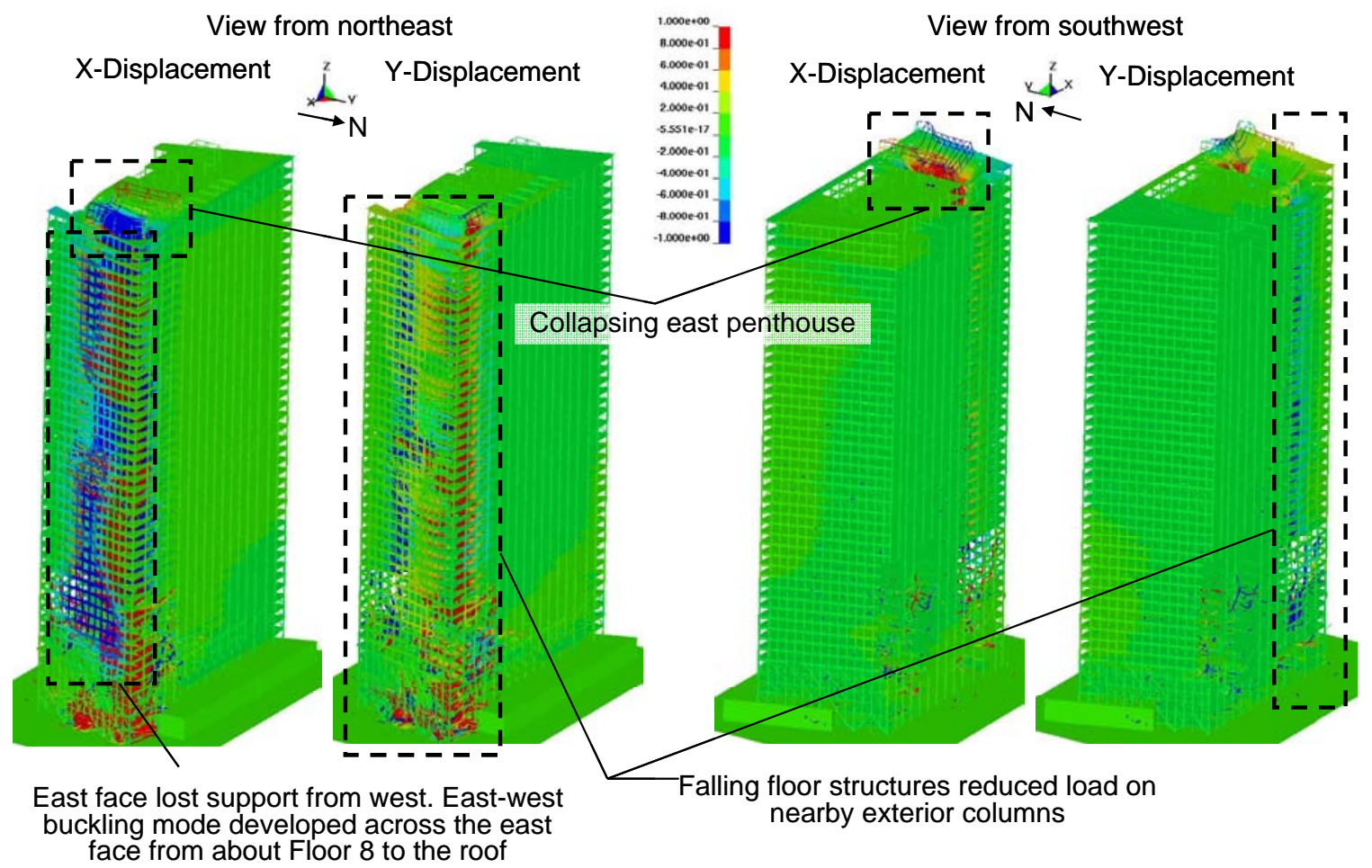

Figure 4-43. Global model with lateral displacement contours (-1 $\mathrm{m}$ to $1 \mathrm{~m})$ at 1.1 (17.1) $\mathrm{s}$. 


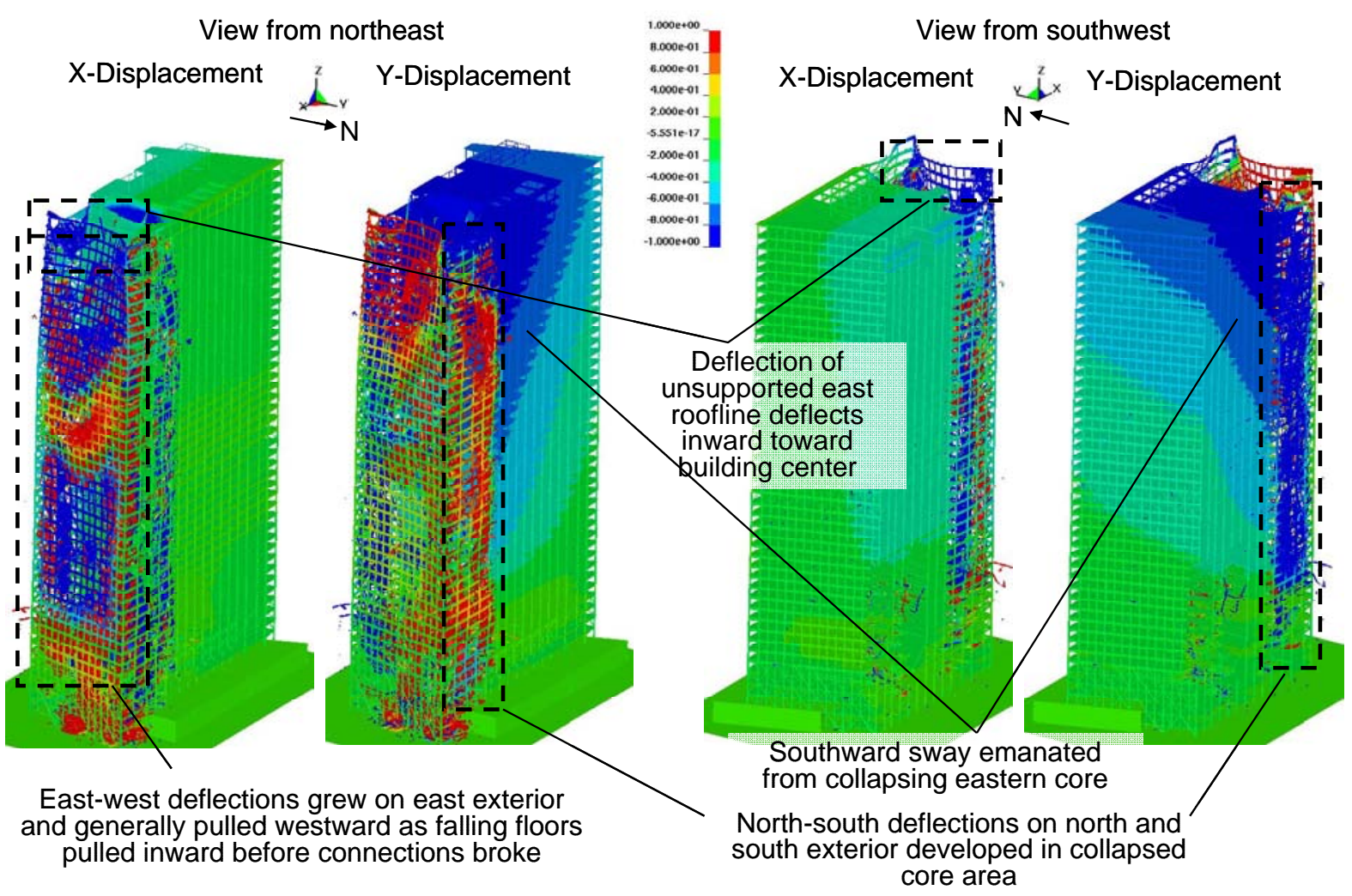

Figure 4-44. Global model with lateral displacement contours (-1 m to $1 \mathrm{~m}$ ) at 3.5 (19.5) s.

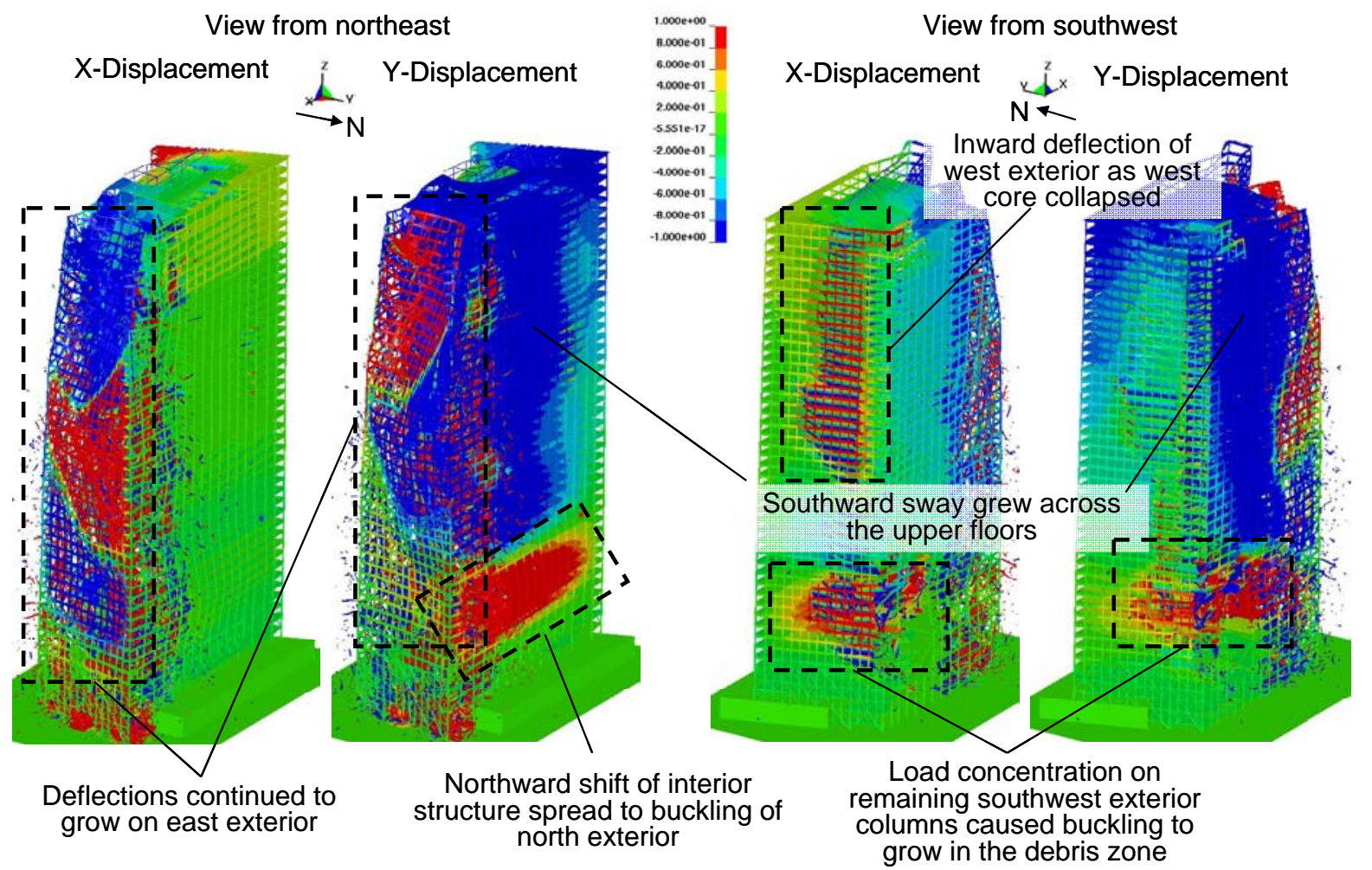

Figure 4-45. Global model with lateral displacement contours (-1 m to $1 \mathrm{~m})$ at $6.5(22.5) \mathrm{s}$. 


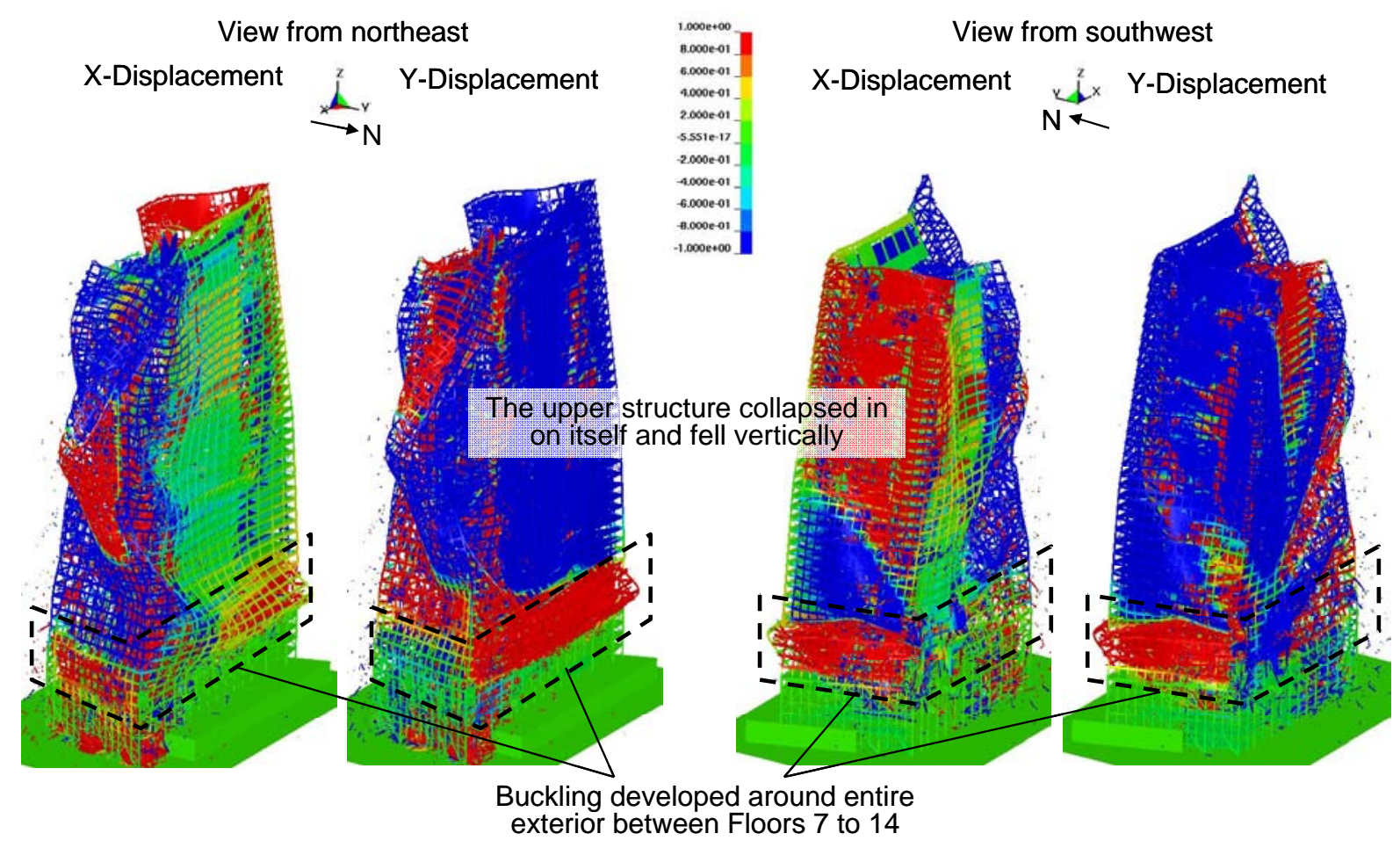

Figure 4-46. Global model with lateral displacement contours (-1 m to $1 \mathrm{~m}$ ) at $8.6(24.6) \mathrm{s}$.

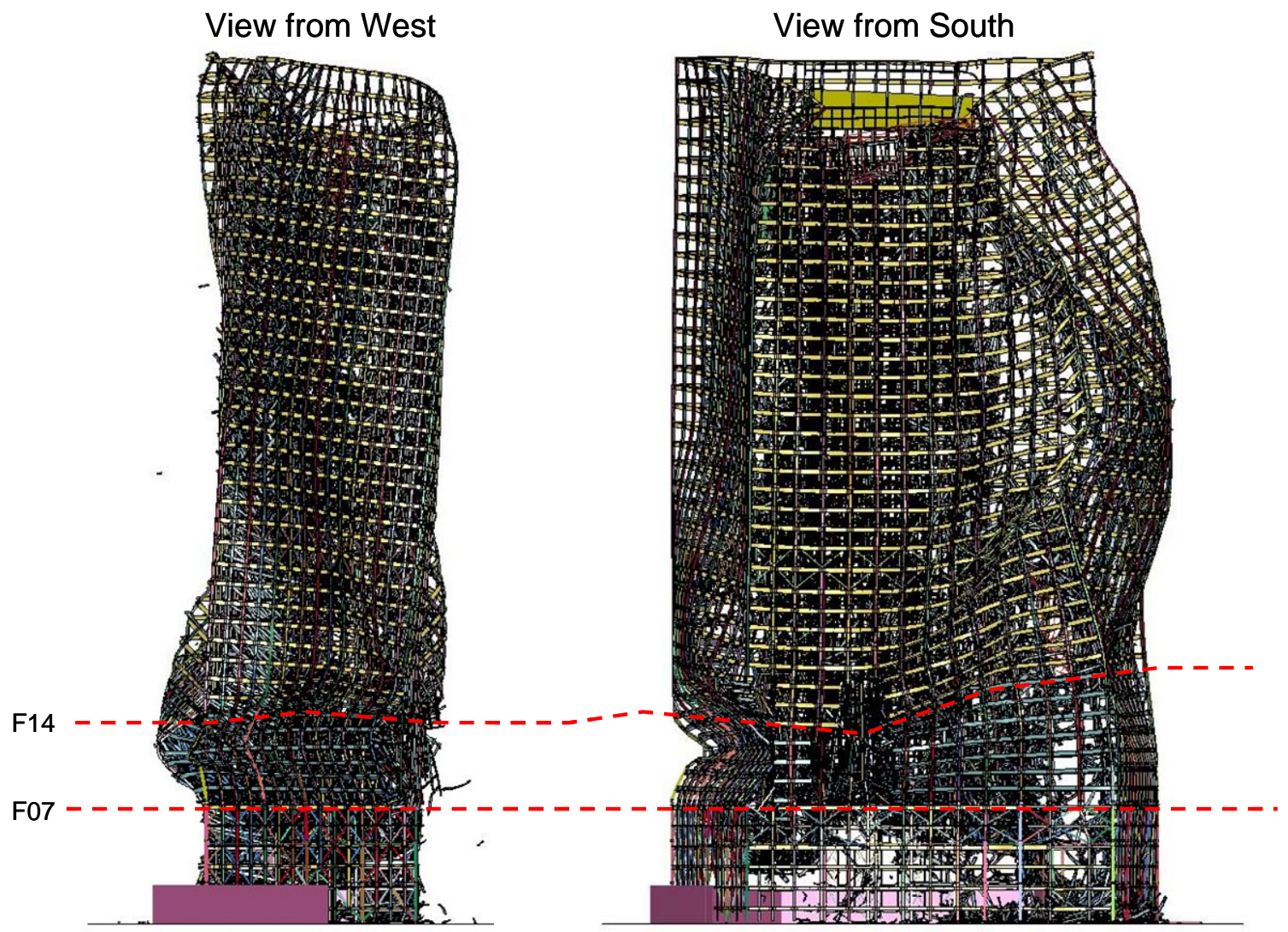

Figure 4-47. Global model with lateral displacement contours (-1 $\mathrm{m}$ to $1 \mathrm{~m})$ at $8.6(24.6) \mathrm{s}$. 


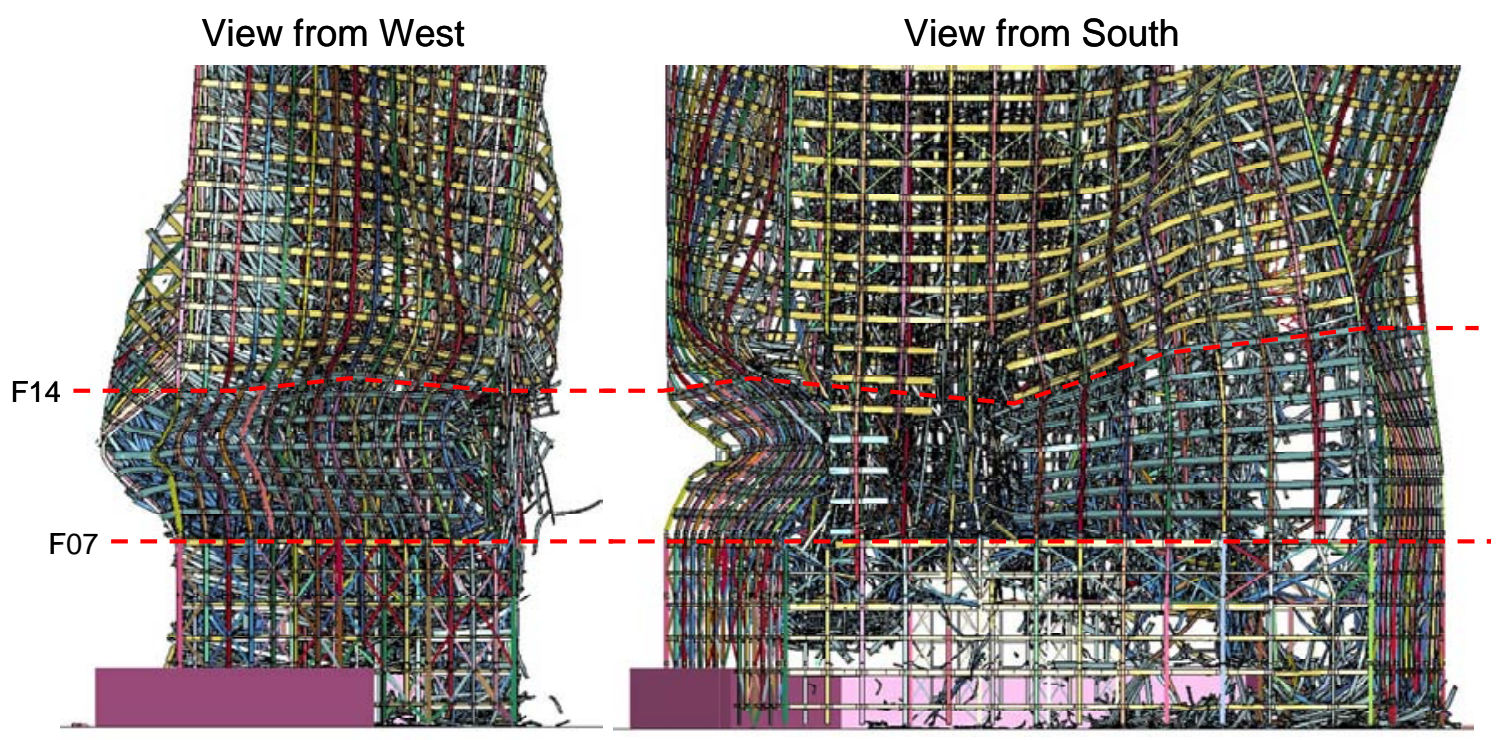

Figure 4-48. Lower floor exterior column buckling, with floor slabs removed from view.

\subsubsection{Comparison with Observables}

Observed collapse events (NIST NCSTAR 1-9, Chapter 5) are compared to the results of the global analysis with debris impact damage. Table 4-1 lists events with corresponding times from observed events and from the analysis.

Table 4-1. Comparison of observable events: Case B and WTC 7 timeline.

\begin{tabular}{|c|c|l|}
\hline Observation Time (s) & Collapse Analysis Time (s) & \multicolumn{1}{|c|}{ Event } \\
\hline N/A (not observable) & -1.3 & Col 79 buckles, quickly followed by Cols 80 and 81 \\
\hline 0 & 0 & East penthouse begins to move downward \\
\hline 2.0 & $2.4-2.7$ & $\begin{array}{l}\text { East penthouse falls below roofline (first value } \\
\text { observed from the northwest and below, second } \\
\text { from north at roofline) }\end{array}$ \\
\hline N/A (not observable) & $3.5-6.1$ & Buckling of core columns across core taking place \\
\hline 6.9 & 6.3 & $\begin{array}{l}\text { Initial downward motion of the north face roofline } \\
\text { of eastern section of building }\end{array}$ \\
\hline 8.5 & $7.3-7.7$ & $\begin{array}{l}\text { East end of screening wall falls below roofline (first } \\
\text { value observed from the northwest and below, } \\
\text { second from north at roofline) }\end{array}$ \\
\hline 9.3 & $6.9,7.3$ & $\begin{array}{l}\text { West penthouse falls below roofline (first value } \\
\text { observed from the northwest and below, second } \\
\text { from north at roofline) }\end{array}$ \\
\hline
\end{tabular}

The upper floors of the model are shown in Figure 4-49 through Figure 4-55 to illustrate the sequence of events occurring at the roofline, up to and including global downward motion. Contours of vertical velocity are overlaid on the structure with a range of $-1 \mathrm{~m} / \mathrm{s}$ to $0 \mathrm{~m} / \mathrm{s}(-39 \mathrm{in} . / \mathrm{s}$ to $0 \mathrm{in} . / \mathrm{s})$ to give an indication of detectable motion. All views are from the north, similar to the perspective of available videographic records of the collapse. 
Figure 4-49 illustrates that a kink developed in the center of the north face of the east penthouse. In the model, this occurs $1.3 \mathrm{~s}$ after Column 79 buckled. The east penthouse began to fall downward shortly after loss of column support.

Figure 4-50 and Figure 4-51 show the vertical progression of collapse on the east side of the building.

Figure 4-52, Figure 4-53, and Figure 4-54 show the horizontal progression of collapse of the interior columns across the building. These figures also show the west penthouse falling downward, followed by the screen wall.

Figure 4-55 shows the global collapse, where the entire structure is falling downward.

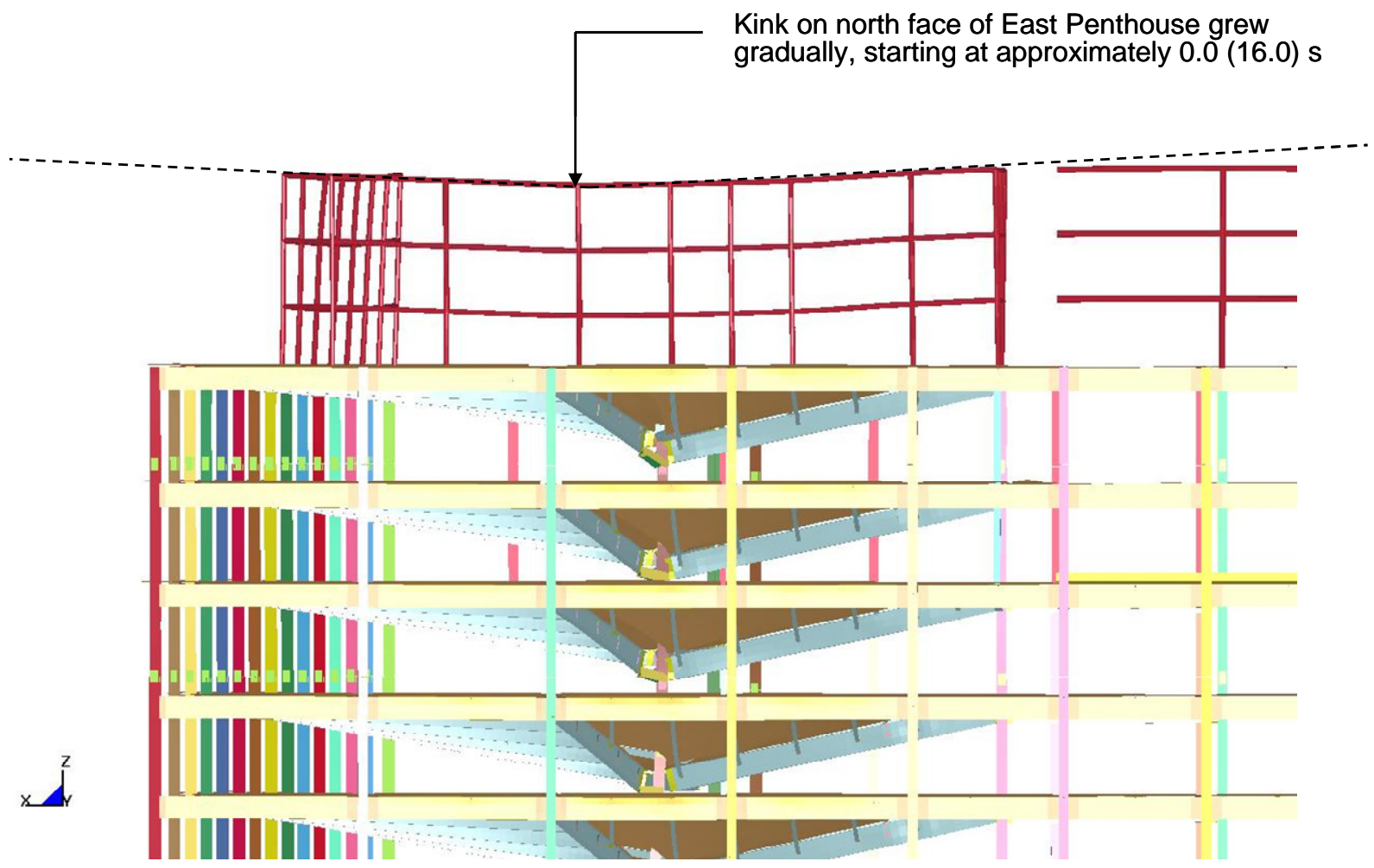

Figure 4-49. Kink on east penthouse: 0.2 (16.2) s. View from north. 


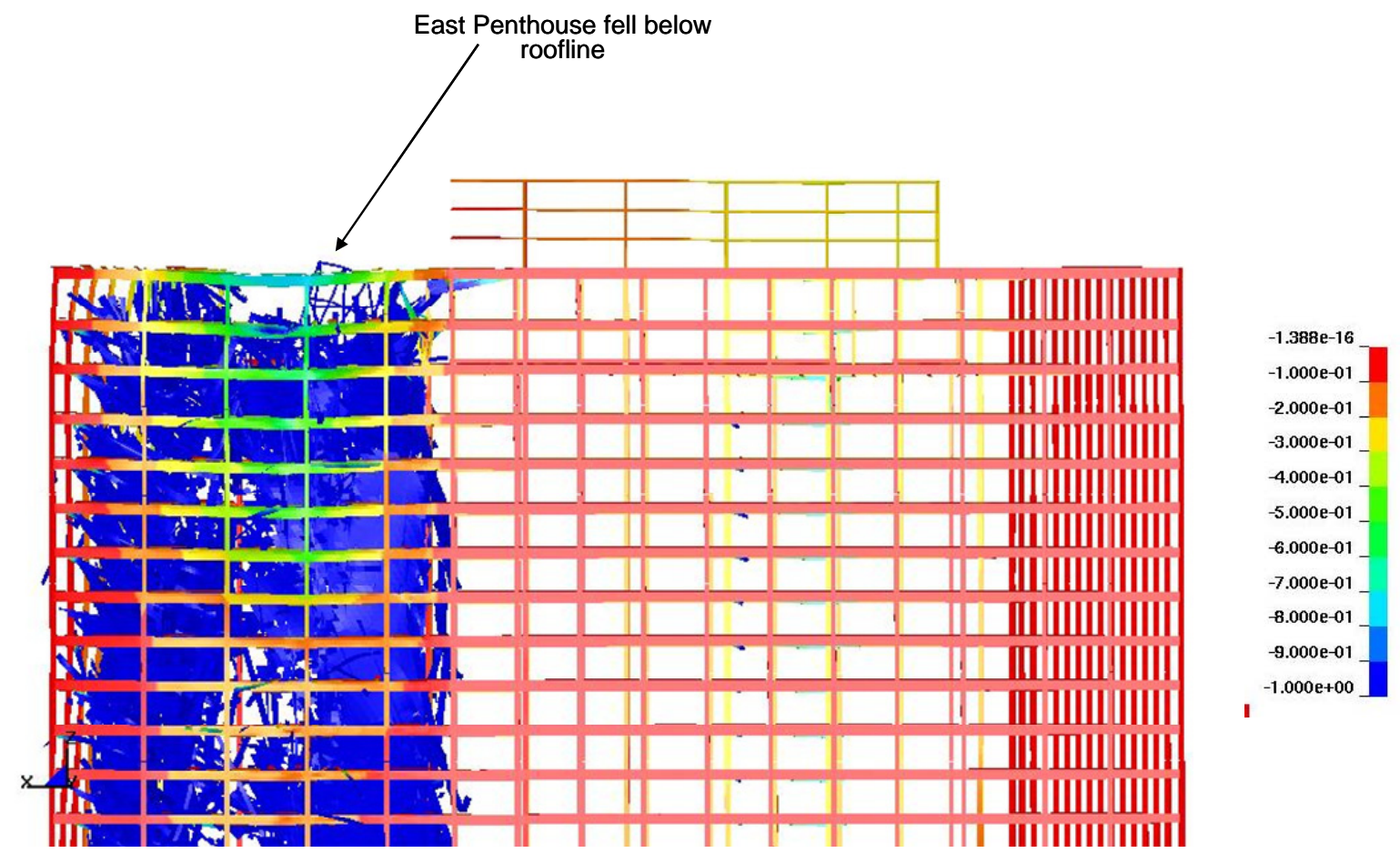

Figure 4-50. Collapse sequence at roofline: $2.7(18.7) \mathrm{s}$, viewed from the north. Fringes of vertical velocity: $-1 \mathrm{~m} / \mathrm{s}$ to $0 \mathrm{~m} / \mathrm{s}$

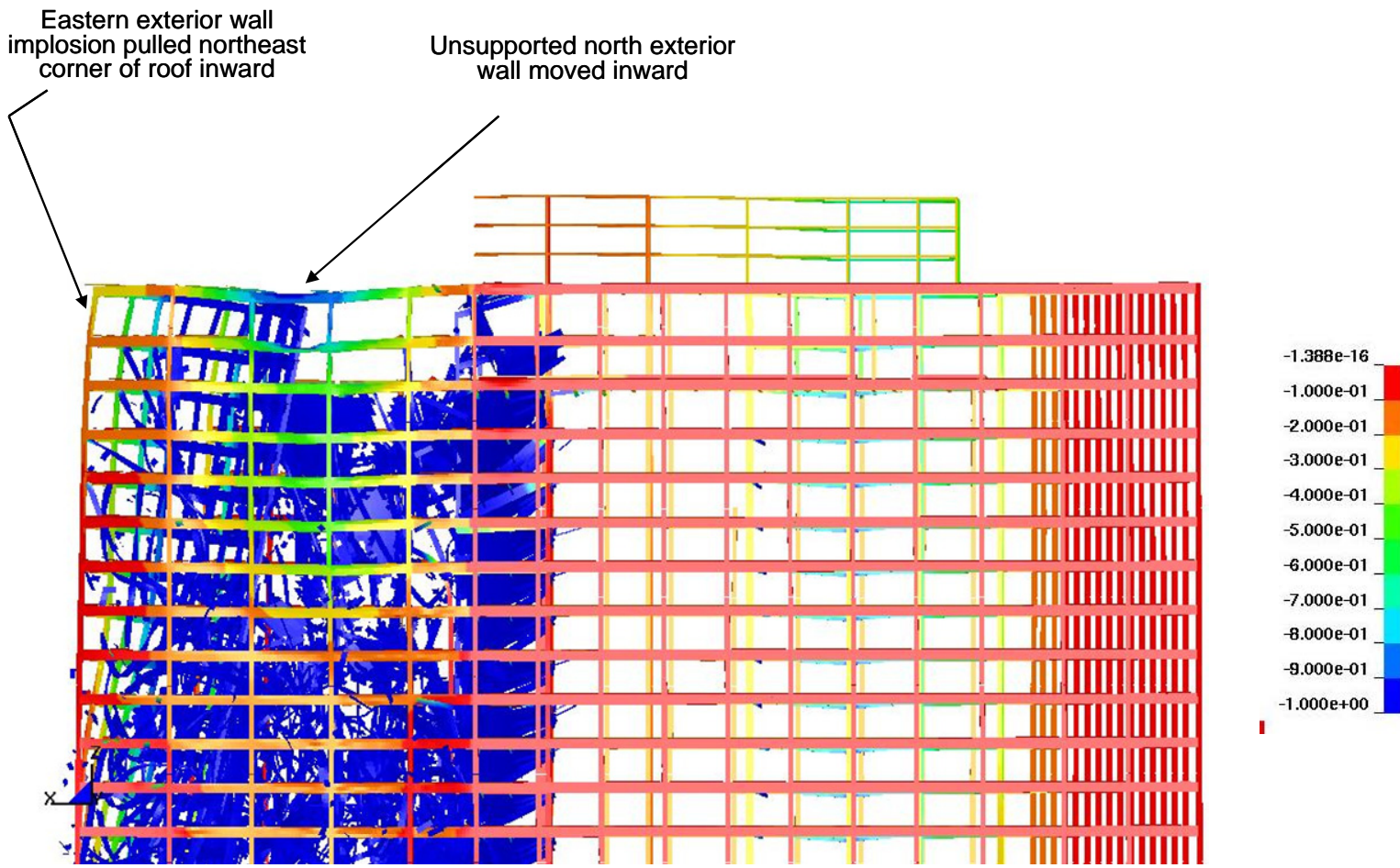

Figure 4-51. Collapse sequence at roofline: $4.7(20.7) \mathrm{s}$, viewed from the north. Fringes of vertical velocity: $-1 \mathrm{~m} / \mathrm{s}$ to $0 \mathrm{~m} / \mathrm{s}$ 


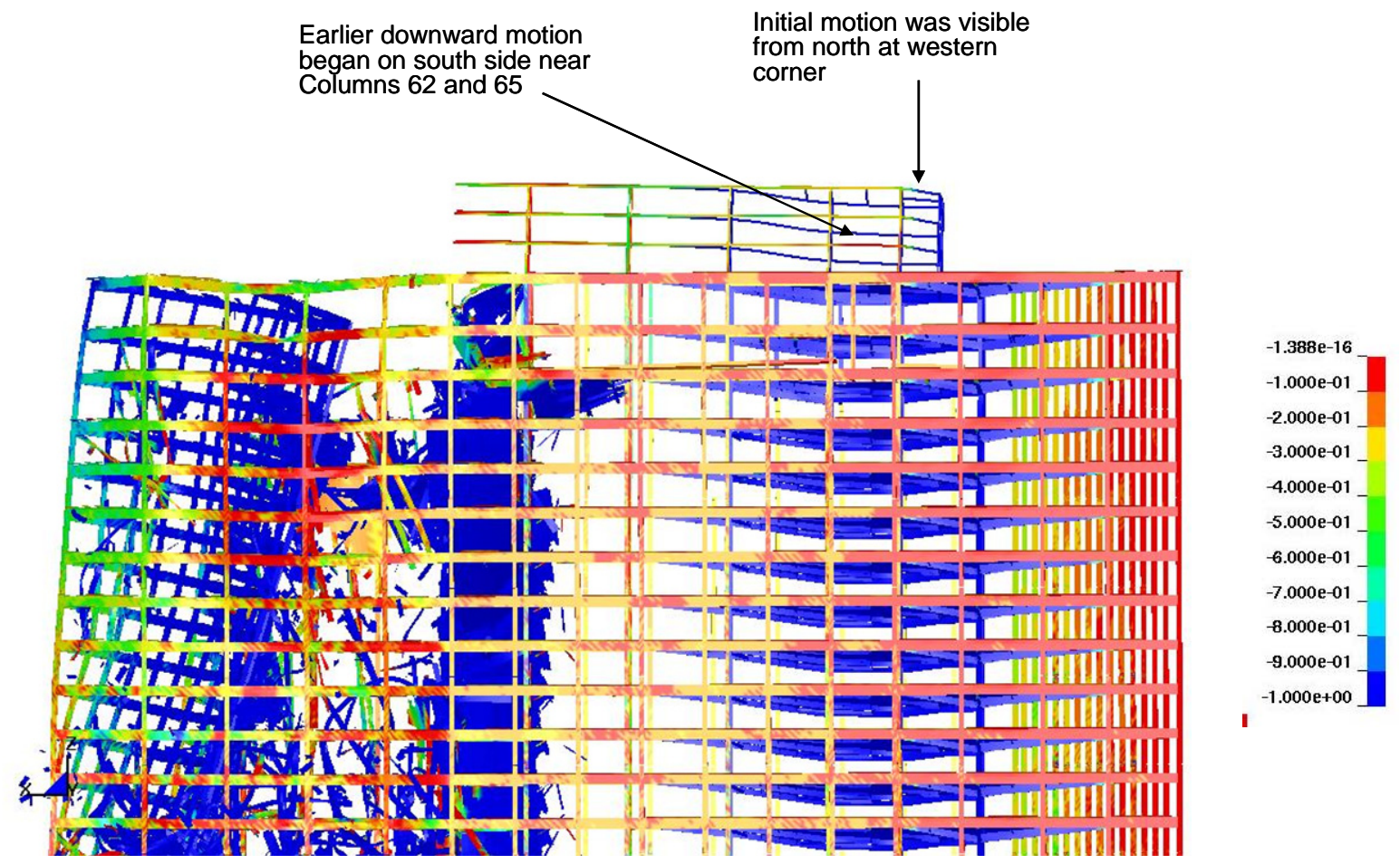

Figure 4-52. Collapse sequence at roofline: $5.7(21.7) \mathrm{s}$, viewed from the north. Fringes of vertical velocity: $-1 \mathrm{~m} / \mathrm{s}$ to $0 \mathrm{~m} / \mathrm{s}$.

Downward motion initiated in eastern part of building, as viewed from north

\section{Downward motion \\ developed across rest of \\ roofline, east to west}

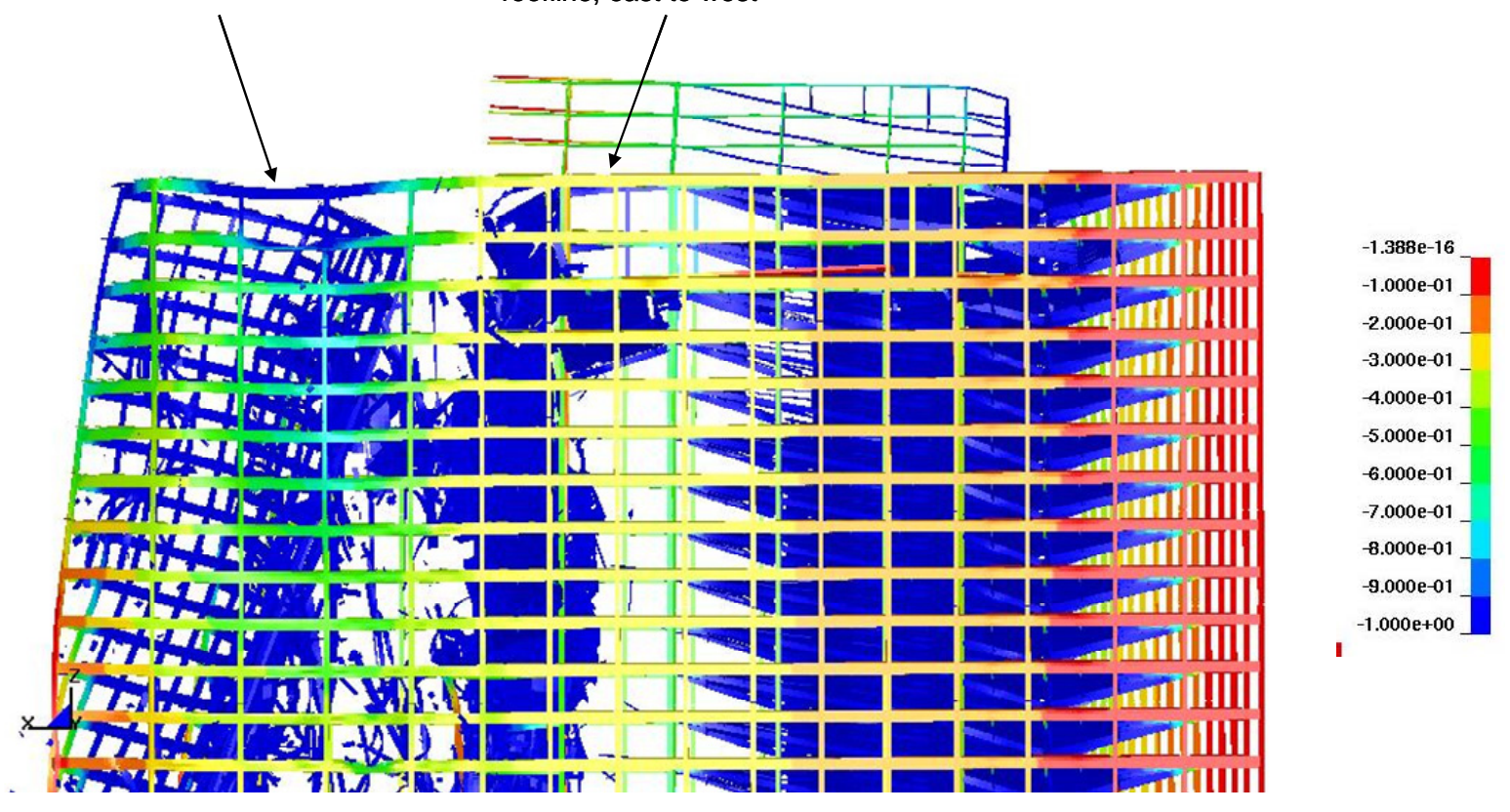

Figure 4-53. Collapse sequence at roofline: $6.2(22.2) \mathrm{s}$, viewed from the north. Fringes of vertical velocity: $-1 \mathrm{~m} / \mathrm{s}$ to $0 \mathrm{~m} / \mathrm{s}$ 


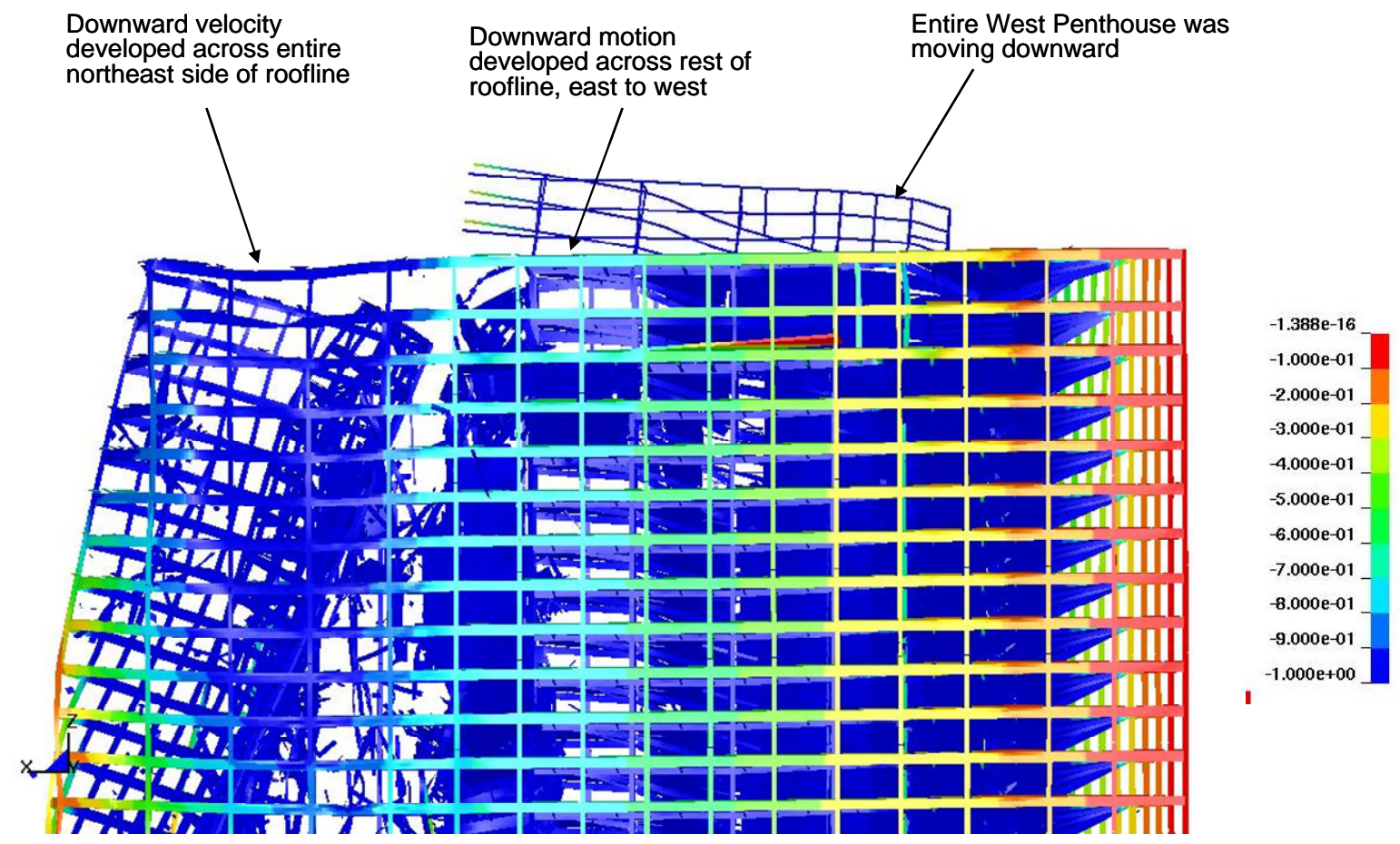

Figure 4-54. Collapse sequence at roofline: $7.7(23.7) \mathrm{s}$, viewed from the north. Fringes of vertical velocity: $-1 \mathrm{~m} / \mathrm{s}$ to $0 \mathrm{~m} / \mathrm{s}$

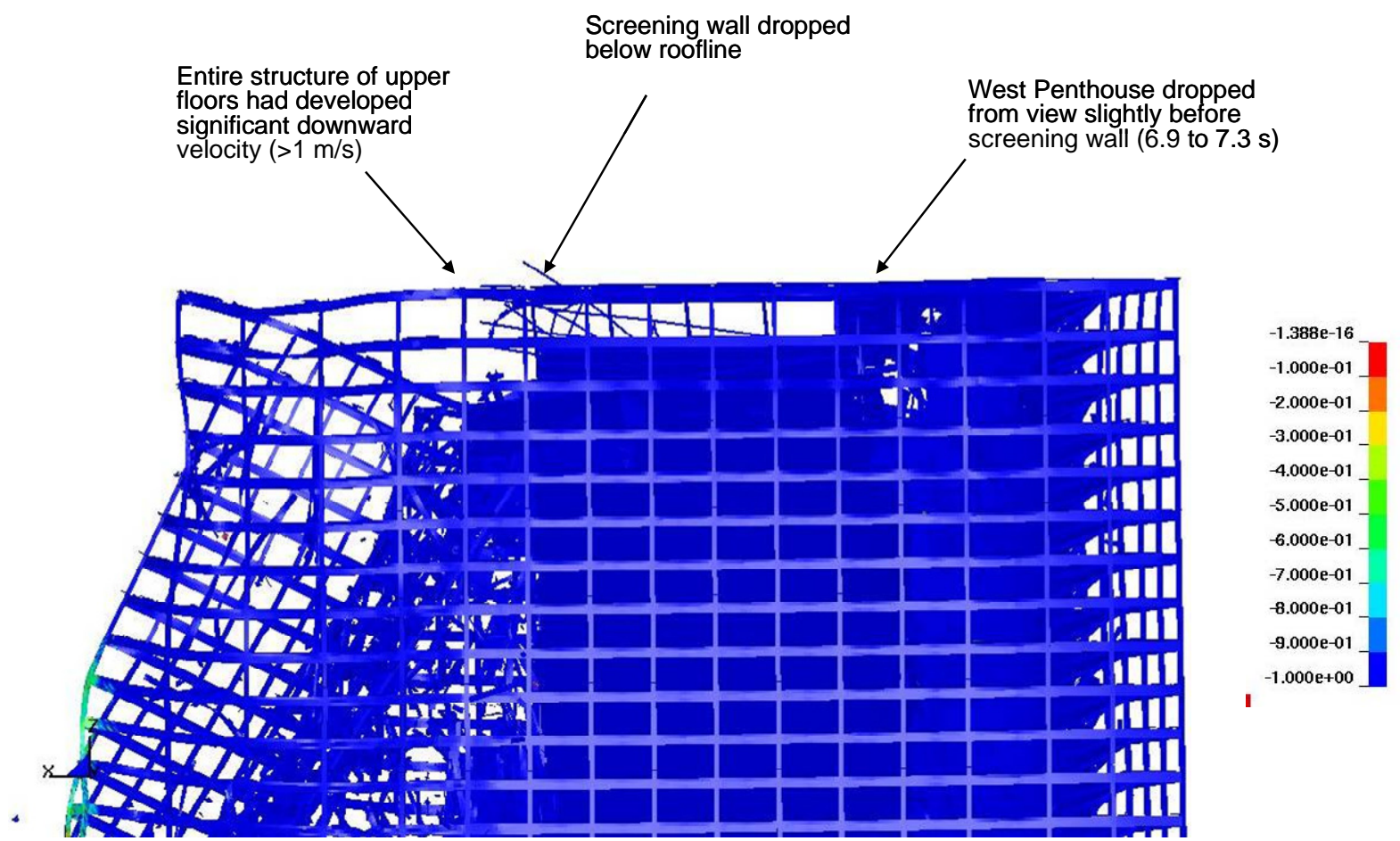

Figure 4-55. Collapse sequence at roofline: $7.7(23.7) \mathrm{s}$, viewed from the north. Fringes of vertical velocity: $-1 \mathrm{~m} / \mathrm{s}$ to $0 \mathrm{~m} / \mathrm{s}$ 


\subsection{GLOBAL ANALYSIS RESULTS WITH FIRE INDUCED DAMAGE AT 3.5 H}

This global analysis was similar to the analysis in Section 4.3 as it was conducted with the same loading sequence and parameters, except that the fire-induced damage obtained from the 16 story ANSYS analysis was input at $3.5 \mathrm{~h}$ instead of $4.0 \mathrm{~h}$, to determine if an earlier fire-induced damage state was sufficient to initiate a global collapse of WTC 7.

After applying the $3.5 \mathrm{~h}$ ANSYS damage at $8.5 \mathrm{~s}$, a few girders connected to Columns 79, 80 and 81 in Floors 12 to 14 fell to floors below, as shown in Figure 4-56. However, the damage was not sufficient to fail other floor structures below Floor 12 or to propagate a vertical collapse. Vertical displacement contours in Figure 4-56 show some significant vertical displacements, but the structure was stable at the end of the analysis. Comparison to Figure 4-15 from the $4.0 \mathrm{~h}$ ANSYS damage case in Section 4.3 shows that the overall damage is significantly less severe surrounding Columns 79 to 81 . The calculation for 3.5 $\mathrm{h}$ fire-induced damage was terminated $4.26 \mathrm{~s}$ after ANSYS damage application (4.26 s plus $8.5 \mathrm{~s}$ gives $12.76 \mathrm{~s}$ in the calculation reference frame) since the structure was stable and an initiating event had not developed.

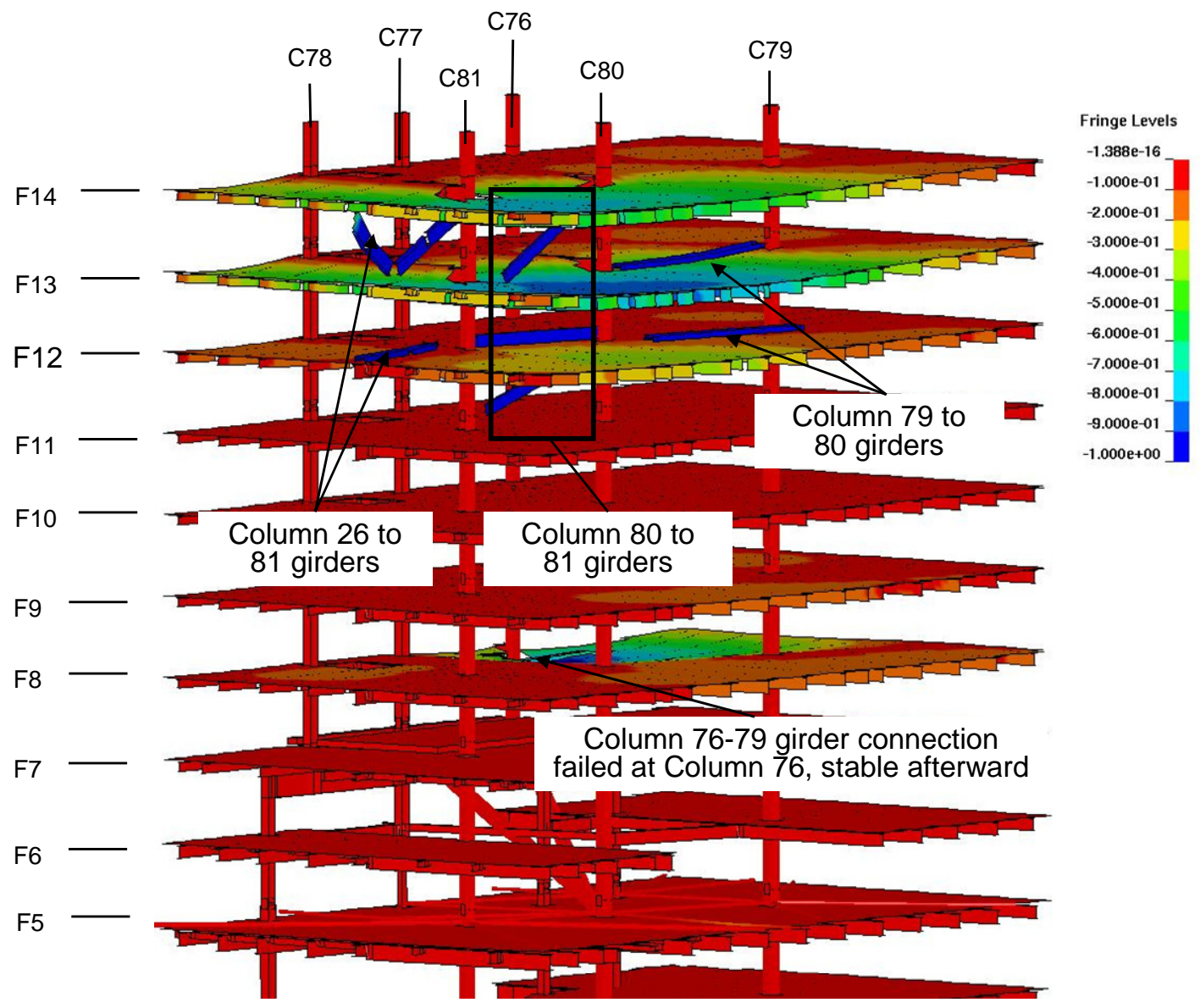

Figure 4-56. Floor framing damage around Columns 76 to 81 after stability has been reached.

Contours of vertical displacement shown -39 in. to 0 in. (-1 m to $0 \mathrm{~m})$. 
Figure 4-57 illustrates the full extent of structural failures in the lower floors after the application of the $3.5 \mathrm{hr}$ ANSYS damage. Similar to the $4.0 \mathrm{~h}$ ANSYS damage case (Figure 4-23), there were failures resulting from the WTC 1 debris impact damage, including damage to connections to several west core column over 11 stories. However, the structure remained stable due to the lack of an initiating event (i.e., buckling of an interior column).

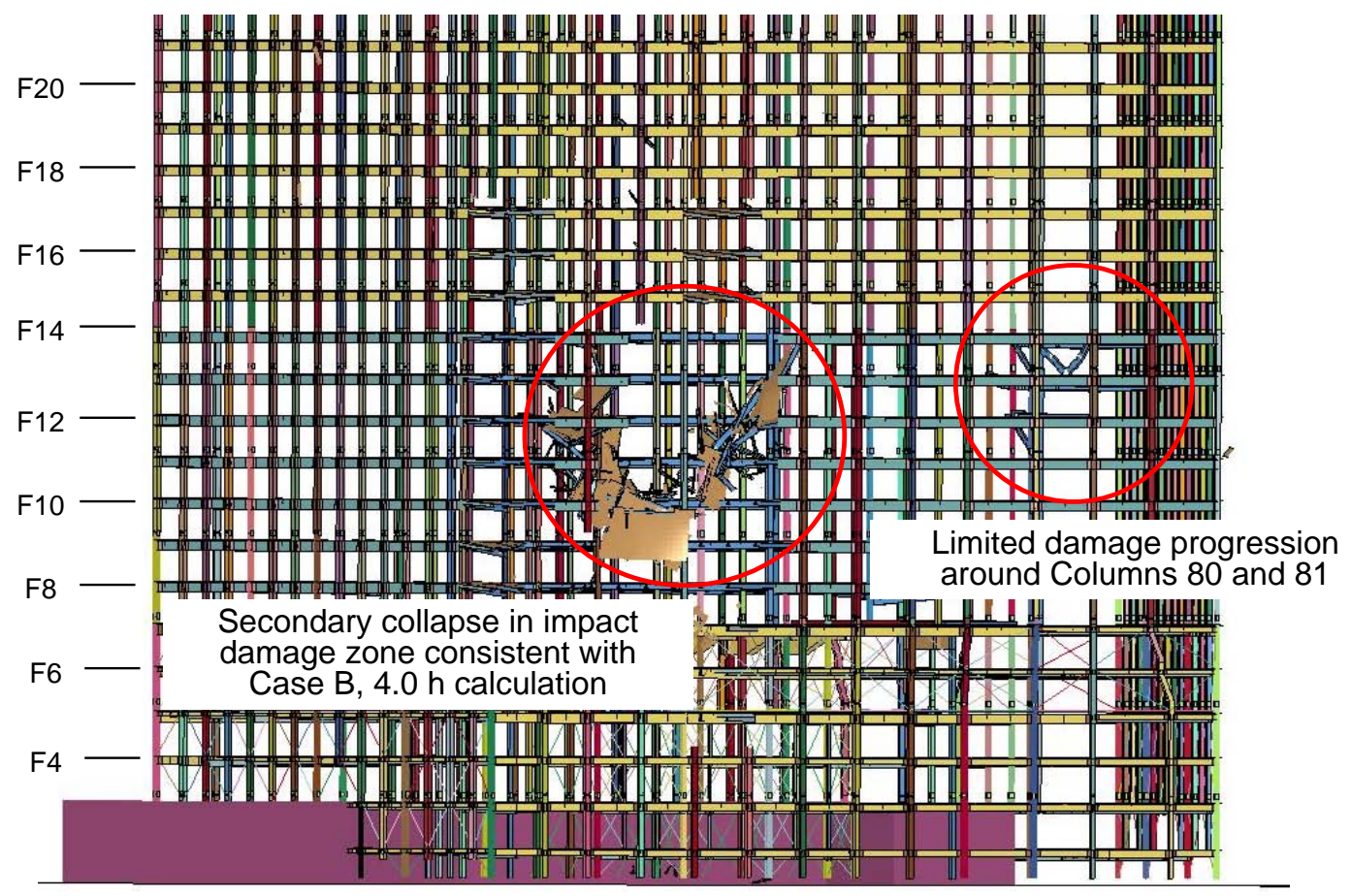

Figure 4-57. Lower floor damage in stable structure at -3.8 s (12.2 s), viewed from the southwest.

\subsection{GLOBAL ANALYSIS RESULTS WITHOUT DEBRIS IMPACT DAMAGE}

This global analysis was similar to the analysis in Section 4.3, except that the debris impact damage due to the collapse of WTC 1 was not included. The purpose of this analysis was to determine the contribution of debris impact damage to the global collapse sequence of WTC 7.

As with the global analysis in Section 4.3, the collapse reference frame was timed from the observed downward motion of the east penthouse. The events occurred earlier in the calculation reported in this section because the debris impact damage was not applied during initialization of the global analysis, thereby eliminating $2.0 \mathrm{~s}$ from the initialization process. Figure 3-48 shows the initialization sequence for the global model. The removal of the debris impact step shifted the east penthouse kink time to $13.3 \mathrm{~s}$ in this analysis, compared to $16.0 \mathrm{~s}$ in the Section 4.3 calculation. To make direct comparison with results in Section 4.3, the times are listed relative to the East Penthouse kink developing at $13.3 \mathrm{~s}$.

The initial failure event, vertical progression of failure, and early stages of the horizontal progression of failure occurred in the same order and at essentially the same times as those described for the global analysis in Section 4.3. This is illustrated in Figure 4-58 and Figure 4-59 which show the sequence of 
failure progression from $1.0 \mathrm{~s}$ after the application of fire-induced damage at $-5.8 \mathrm{~s}(7.5 \mathrm{~s})$ to $4.2 \mathrm{~s}$ after the kink in the east penthouse was observed, or $3.2 \mathrm{~s}$ (17.5 s).

Figure 4-58 shows the structural response from just after the application of the fire-induced damage to $1.3 \mathrm{~s}$ prior to the kink formation in the east penthouse. The left and center images show the failures that started in Floors 13 and 14, and the cascade of floor failures that occurred subsequently, due to their thermally weakened condition. The right image shows the loss of lateral support around Column 79 and the start of Column 79 buckling. Similar response was previously shown in Figure 4-19, Figure 4-23, and Figure 4-24 for the global analysis with impact damage. Note that in this stage of the analysis, relative to the analysis with debris impact damage, there was no early development of western core column buckling that was caused by the application of debris impact damage.

Figure 4-59 shows the structural response from $0.7 \mathrm{~s}$ (14.0 s), shortly after the east penthouse kink was observed, to $3.2 \mathrm{~s}$ (17.5 s), when Columns 76 to 78 buckled as the horizontal progression of failure began. The left image shows the vertical progression of failure. The center image shows the loss of lateral support to Columns 76 to 78, as well as the failure of Truss 2, due to the effects of floor debris accumulation and impact during the vertical progression of failure. The right image shows the buckling of Columns 76 to 78. Similar responses were shown in Figure 4-25, Figure 4-26, and Figure 4-30 for the global analysis with impact damage.

The progression of horizontal failure in the analysis without debris impact damage was due to loss of lateral support as floors failed, the effect of debris impact from adjacent failing floors and columns, and load redistribution. The right image shows that the screening wall fell downward prior to the West Penthouse (view is from the southwest), which is consistent with the observed sequence of events. In the analysis without impact damage, the horizontal progression continued to move westward after Columns 70 to 72 buckled. In the analysis with impact damage, the horizontal progression moved westward until Columns 70 to 72 buckled, after which the damaged west core columns also buckled.

As the horizontal progression moved from east to west, some differences began to occur relative to the analysis with impact damage, as shown in Figure 4-60 and Figure 4-61. Some floors failed at mid-height of the building around Columns 73 to 75 , leading to the buckling of some interior columns at this location, rather than at lower floors. Between 6.2 (19.5) s and 13.5 (26.8) s, the damage progressed westward and downward across the core as floor structures failed and fell to floors below. The buckling at lower floor elevations in the analysis with impact damage was influenced by the damage around the west core columns when the debris impact damage was applied.

Figure 4-32 and Figure 4-33 show that, at this point in the analysis with debris impact damage, all the interior columns had buckled and that the global collapse (i.e., buckling of exterior columns) was underway. The relatively rapid failure of the west core columns was due to the damage from the debris impact damage (see Figure 4-36 and Figure 4-42). As shown in Figure 4-60 and Figure 4-61, the analysis without debris impact damage showed that the horizontal failure progression moved from east to west over a longer duration. This was due to the lack of western core damage that was caused by debris impact damage in the earlier calculation. 
$-5.8(7.5) \mathrm{s}$

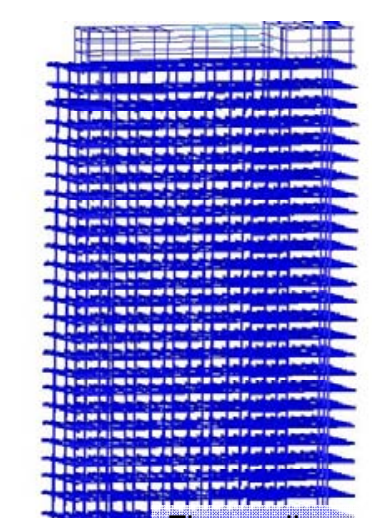

Floor collapse

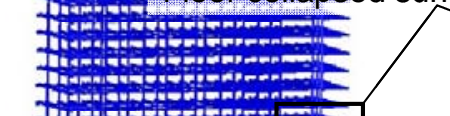

H. +15 flate

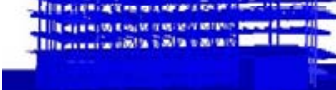

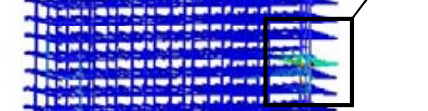

$-3.8(9.5) \mathrm{s}$

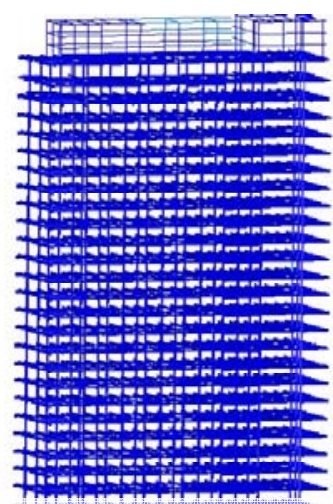

unding Columns 79-81

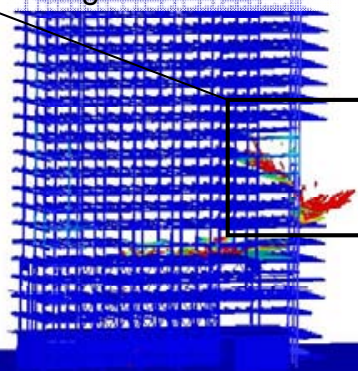

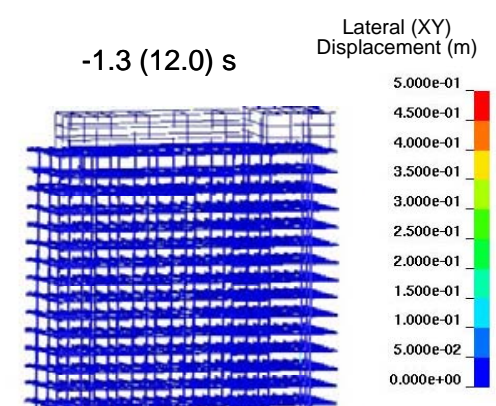

Figure 4-58. Core collapse sequence at $\mathbf{- 5 . 8}$ to $\mathbf{- 1 . 3} \mathrm{s}$ ( 7.5 to $\mathbf{1 2 . 0} \mathrm{s})$. Contours of resultant lateral displacement 0 in. to -20 in. ( $0 \mathrm{~m}$ to $-0.5 \mathrm{~m}$ )
$0.7(14.0) \mathrm{s}$

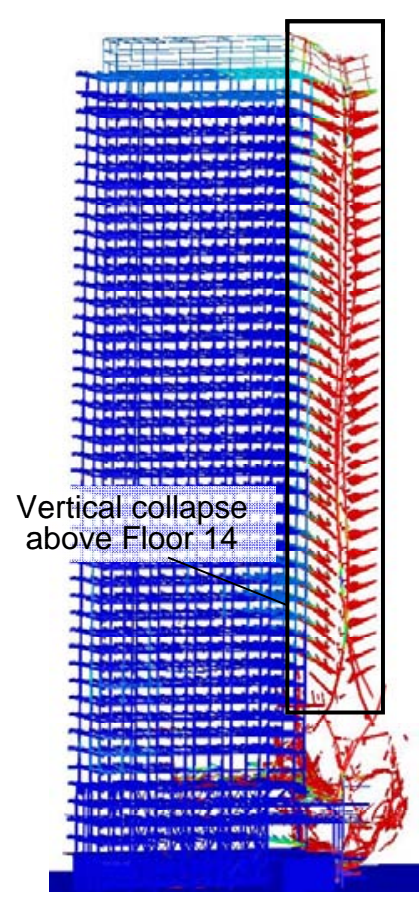

2.3 (15.6) s

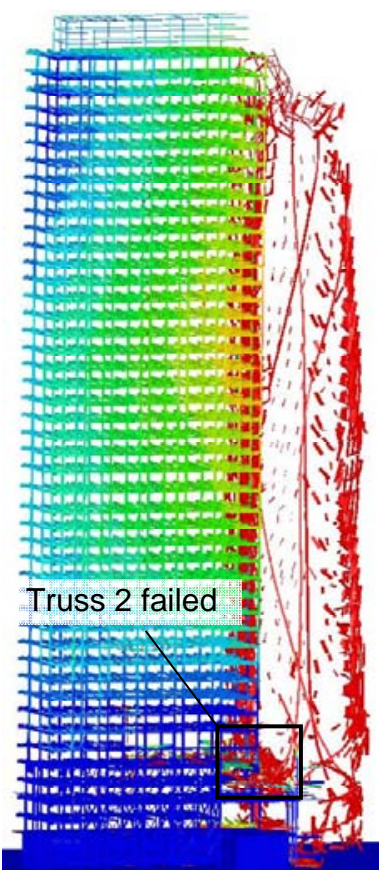

$3.2(17.5) \mathrm{s}$

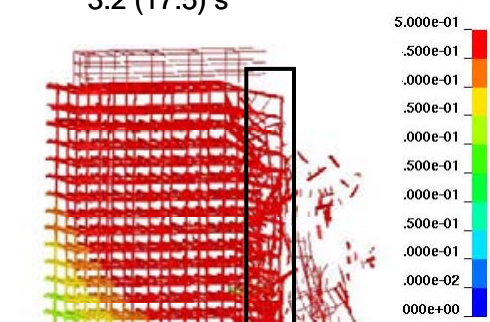

Figure 4-59. Core collapse sequence at 0.7 to $3.2 \mathrm{~s}$ (14.0 to $17.5 \mathrm{~s}$ ).

Contours of resultant lateral displacement 0 in. to -20 in. ( $0 \mathrm{~m}$ to $-0.5 \mathrm{~m}$ ) 


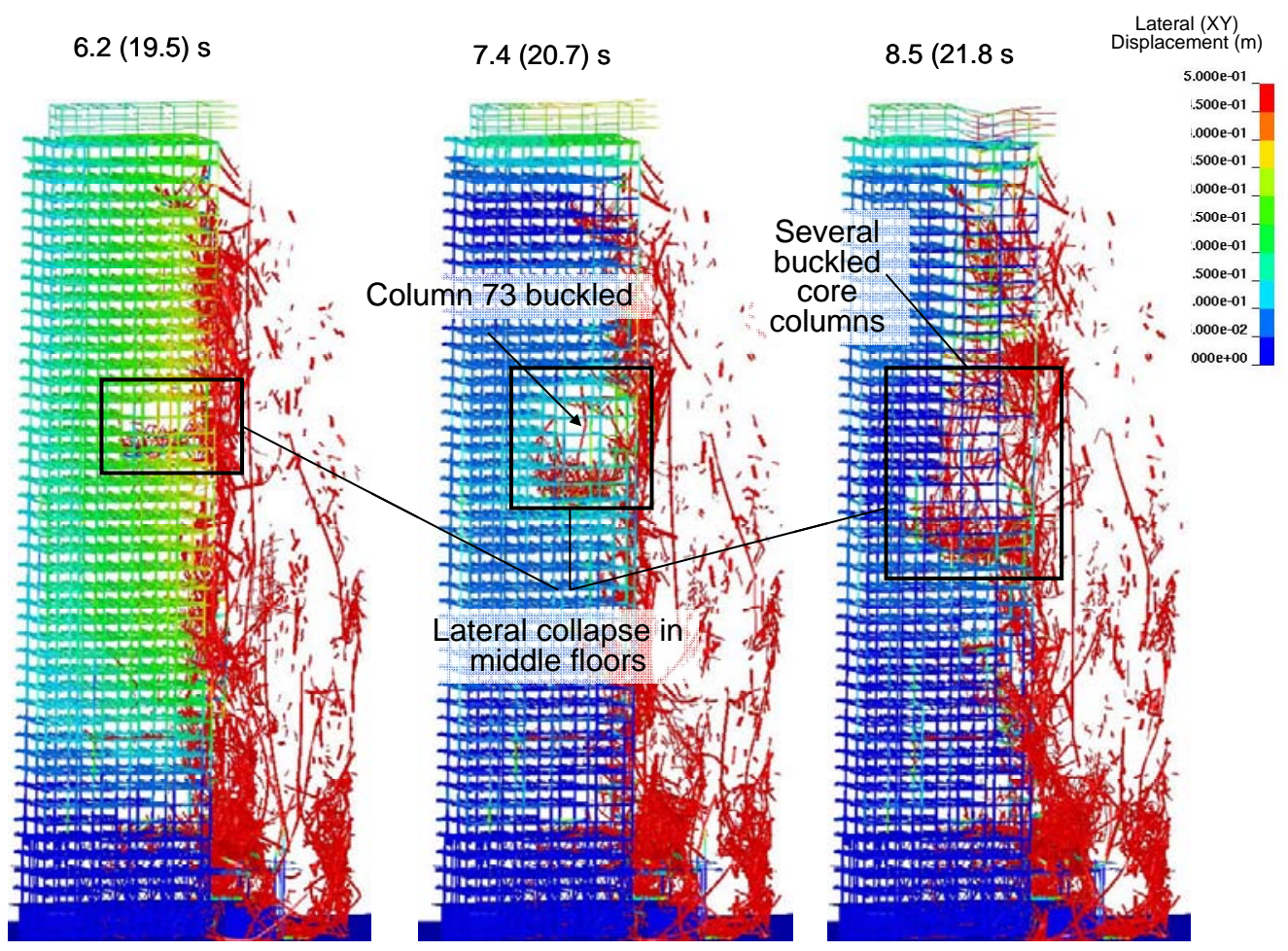

Figure 4-60. Core collapse sequence at 6.2 to $8.5 \mathrm{~s}$ (14.5 to $21.8 \mathrm{~s}$ ). Contours of resultant lateral displacement 0 in. to -20 in. (0 $\mathrm{m}$ to $-0.5 \mathrm{~m}$ )

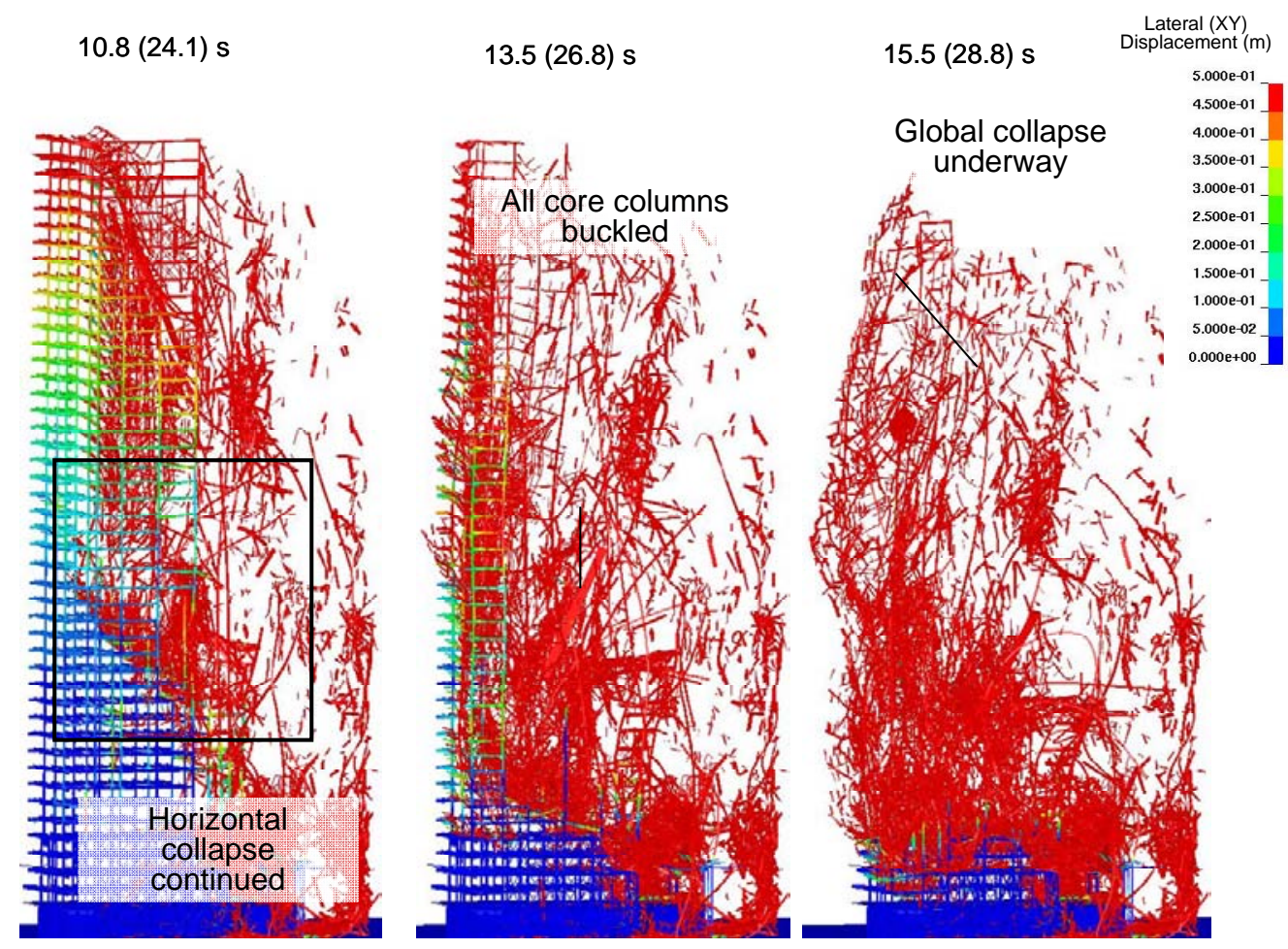

Figure 4-61. Core collapse sequence at 10.8 to $15.5 \mathrm{~s}$ (24.1 to $28.8 \mathrm{~s}$ ). Contours of resultant lateral displacement 0 in. to -20 in. (0 $\mathrm{m}$ to $-0.5 \mathrm{~m}$ ) 
Exterior damage after the global collapse was underway is shown in Figure 4-62 and Figure 4-63. Component lateral displacement contours are overlaid on the structure in Figure 4-62, which can be compared to Figure 4-46 from the case with initial debris impact damage. The analysis without debris impact damage developed exterior column buckling at a higher level in the building compared to the analysis with debris impact damage. Similar to the first analysis (Section 4.3), the eastern exterior wall at roof level deflected inward as the structure became unsupported after the vertical collapse event. The western wall also deflected inward for the analysis without debris impact damage, as it gradually became unsupported.

In the analysis with debris impact damage, the western roofline fell more uniformly downward due to a more rapid loss of core and exterior column support between Floors 7 to 14. In the analysis without debris impact damage, the exterior columns buckled near the building mid-height, approximately between Floors 17 and 29. Figure 4-63 further illustrates the buckling modes along the exterior structure as well as the inward deflection of both the east and west exterior rooflines.

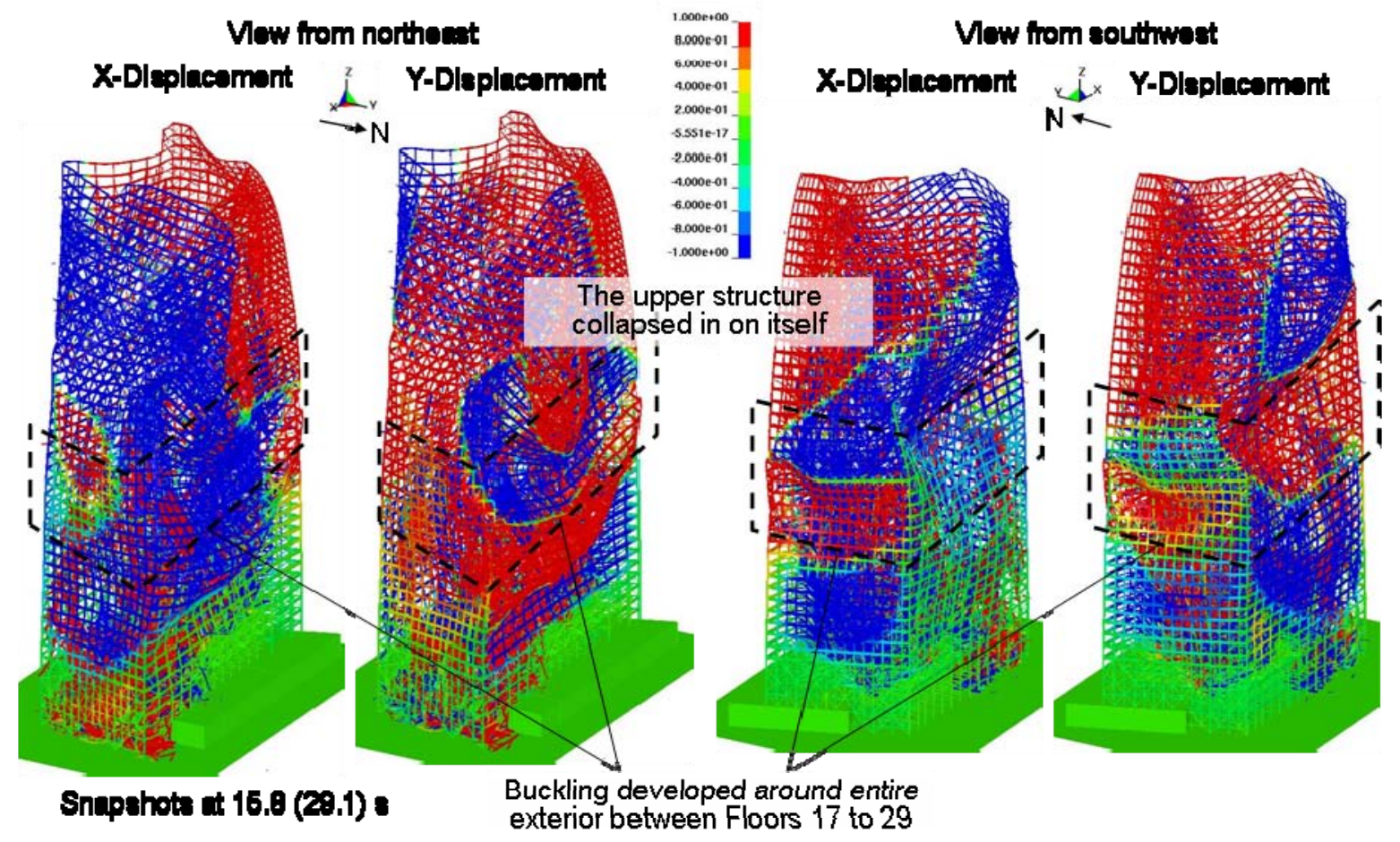

Figure 4-62. Global model with lateral displacement contours $(-1 \mathrm{~m}$ to $1 \mathrm{~m})$ at $15.8(29.1) \mathrm{s}$. 


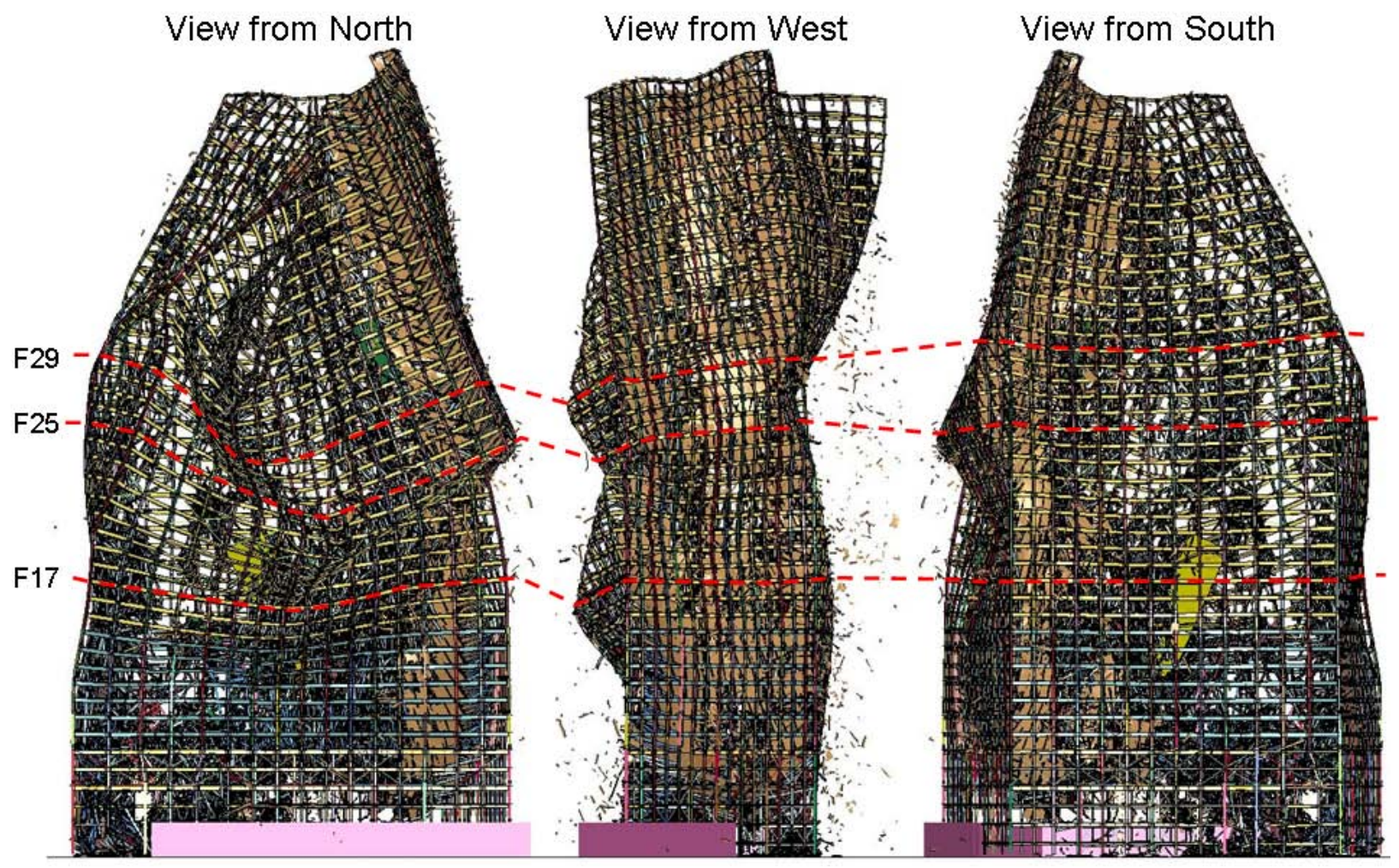

Figure 4-63. Exterior buckling after global collapse initiation.

Observed events in the collapse of WTC 7 are compared to both cases (with and without initial debris impact damage) in Table 4-2. The timing of early collapse events associated with the vertical collapse progression are quite similar for both calculations and the observed behavior. The core collapse occurred over a longer duration for the case without debris impact damage-10.6 s without impact damage, compared to $2.6 \mathrm{~s}$ with impact damage, based on the times shown in Table 4-2. This was due to the lack of induced west core damage and to the time required for the core damage to fully traverse from east to west across the building. By comparison, the core collapse in the east and west occurred essentially simultaneously in the calculation with impact damage.

The events of the east screenwall and west penthouse falling below the roofline occurred in the correct sequence but later in the analysis without debris impact damage compared to both the calculation with damage and the observed time. However, the analysis times are close to the observed event times. 
Table 4-2. Comparison of observable events: Case B with and without initial damage and WTC 7 timeline.

\begin{tabular}{|c|c|c|l|}
\hline $\begin{array}{c}\text { Observation } \\
\text { Time (s) }\end{array}$ & $\begin{array}{c}\text { Analysis Time (s) } \\
\text { with debris } \\
\text { impact damage }\end{array}$ & $\begin{array}{c}\text { Analysis Time (s) } \\
\text { without debris } \\
\text { impact damage }\end{array}$ & \multicolumn{1}{|c|}{ Event } \\
\hline $\begin{array}{c}\text { N/A (not } \\
\text { observable) }\end{array}$ & -1.3 & -1.4 & $\begin{array}{l}\text { Column 79 buckled, quickly followed by } \\
\text { buckling of Columns 80 and 81 }\end{array}$ \\
\hline 0 & 0 & 0 & East penthouse began to move downward \\
\hline 2.0 & $2.4-2.7$ & $2.3-2.6$ & $\begin{array}{l}\text { East penthouse fell below roofline (first value } \\
\text { observed from the northwest and below, second } \\
\text { from north at roofline) }\end{array}$ \\
\hline $\begin{array}{c}\text { N/A (not } \\
\text { observable) }\end{array}$ & $3.5-6.1$ & $2.9-13.5$ & $\begin{array}{l}\text { Columns across core buckle, starting with } \\
\text { Columns 76 }\end{array}$ \\
\hline 6.9 & 6.3 & 9.8 & $\begin{array}{l}\text { Initial downward motion of the north face } \\
\text { roofline at the eastern section of building } \\
\text { (threshold used in calculation: 1 m/s vertical } \\
\text { speed) }\end{array}$ \\
\hline 8.5 & $7.3-7.7$ & $8.7-9.2$ & $\begin{array}{l}\text { East end of the screenwall fell below roofline } \\
\text { (first value observed from the northwest and } \\
\text { below, second from north at roofline) }\end{array}$ \\
\hline 9.3 & $6.9-7.3$ & $10.6-10.9$ & $\begin{array}{l}\text { West penthouse fell below the roofline (first } \\
\text { value observed from the northwest and below, } \\
\text { second from north at roofline) }\end{array}$ \\
\hline
\end{tabular}

\subsection{CLASSIC GLOBAL PROGRESSIVE COLLAPSE ANALYSIS RESULTS WITHOUT FIRE OR DEBRIS IMPACT DAMAGE}

A global analysis was conducted to determine whether a progressive collapse might occur, due to the removal of a section of Column 79, in the absence of debris impact and fire-induced damage.

The only imposed damage in this analysis was the removal of Column 79 between Floors 11 and 13 after gravity initialization. After removing the two-floor segment of Column 79 at $-0.8 \mathrm{~s}(4.5 \mathrm{~s})$, the floors around Column 79 collapsed all the way to the roof. A kink formed in the east penthouse roof framing at 0 s (5.3 s). Column 80 buckled between Floors 37 and 39 at 6.6 s, followed by sections of Column 81 failing at the roof level due to lateral loads. As Column 81 buckled at lower stories, there was a sharp reduction in its axial load (at Floor 8 ) between about $7.9 \mathrm{~s}$ and $10.4 \mathrm{~s}$, followed by a continued but more gradual reduction in load.

The Truss 2 diagonal partially buckled at $4.9 \mathrm{~s} \mathrm{(10.2} \mathrm{s)} \mathrm{due} \mathrm{to} \mathrm{falling} \mathrm{debris} \mathrm{from} \mathrm{the} \mathrm{failure} \mathrm{of} \mathrm{Columns}$ 79, 80, and 81. However, the Truss 2 damage did not lead to buckling of Columns 77 and 78.

Figure 4-64 shows the structural response of the interior columns between $0.7 \mathrm{~s}(6.0 \mathrm{~s})$ and $12.7 \mathrm{~s}$ (18.0 s). The east penthouse fell into the building at $7.5 \mathrm{~s}$ (12.8 s). Most of the east penthouse above Columns 79 and 80 sagged into the building after Columns 79 and 80 buckled, but the east penthouse did 
not fall into the building until the upper sections of Column 81 failed. The east penthouse was not disconnected from the screening wall structure until $7.5 \mathrm{~s}$ (12.8 s). Column 76 was impacted by the east penthouse and other structural debris around Floor 35 at about $10.8 \mathrm{~s}$ (16.1 s), causing the column to deflect northward. Column 77 buckled at about 11.0 s (16.3 s) around Floor 36. Column 78 then buckled at about $9.5 \mathrm{~s}$

(19.3 s) between Floors 25 and 33.

$0.7(6.0) \mathrm{s}$

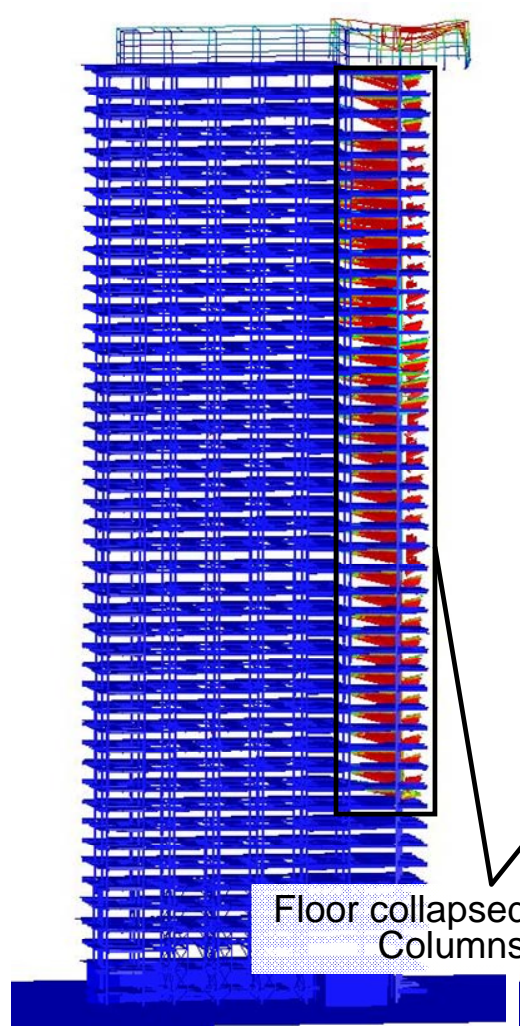

$4.9(10.2) \mathrm{s}$

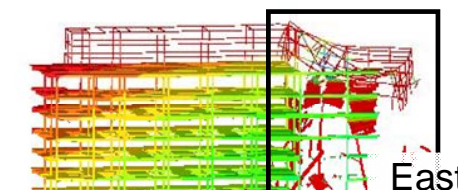

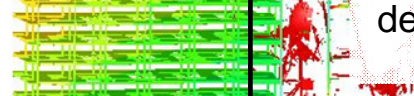

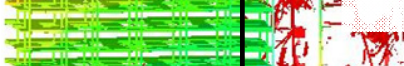
Heve $=$ une $=0$ ure

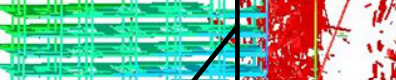
inene

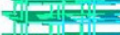
सer:me: Hense

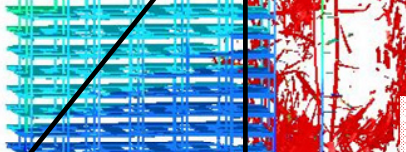
$y=1.2=$ (1)

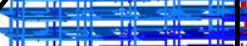

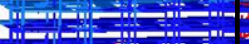

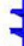

urrounding 79-81

Figure 4-64. Collapse of the north interior columns from $0.7 \mathrm{~s}(6.0 \mathrm{~s})$ to $12.7 \mathrm{~s}(18.0 \mathrm{~s})$. Contours of resultant lateral displacement 0 in. to 16 in. ( $0 \mathrm{~m}$ to $0.4 \mathrm{~m})$.

Figure 4-65 shows the structural response of the interior columns between $15.7 \mathrm{~s} \mathrm{(21.0} \mathrm{s)} \mathrm{and} 21.2 \mathrm{~s}$ (26.5 s). Column damage continued to spread westward with Column 73 buckling at about $15.0 \mathrm{~s}$ (20.3 s) between Floors 35 and 37. Column 58 buckled at $14.7 \mathrm{~s}(20.0 \mathrm{~s})$, following a column splice failure at Floor 31 that occurred $8 \mathrm{~s}$ earlier, at about $6.9 \mathrm{~s}$ (12.2 s), but did not cause column failure. The column splice initially failed due to relative twisting and shearing motions between floors that were most acute in the northwest corner of the building. The global building motions grew in response to the column and floor structure failures in the eastern interior. The relative motions at the Column 58 splice were magnified compared to other surrounding columns due to the relatively large area supported by Column 58 and the limited shear stud connections in the northwest corner of the building, which together provided relatively less twisting resistance from the composite floor slab. As a result, the Column 58 splice above Floor 31 and some surrounding framing connections sustained damage, which continued to accumulate with subsequent building motions. 
After Column 58 buckled, floor and column collapse propagated horizontally throughout the interior. By $21.2 \mathrm{~s}$ (26.5 s), all the interior columns had buckled above Floor 23, and the west penthouse and screening wall had fallen into the building, as indicated in Figure 4-66. Vertical motion at the roofline indicated buckling of the exterior columns, and the start of global collapse.

Figure 4-67 is a plot of the kinetic energy in the global model during the analysis, where the kinetic energy is due to falling debris and debris impact. An initial peak kinetic energy occurred around $3.7 \mathrm{~s}$ (9.0 s), when Columns 79, 80, and 81 had buckled between $6.6 \mathrm{~s}$ to $10.4 \mathrm{~s}$ and the surrounding floors and columns were falling. After the debris had fallen, the collapse progression slowed, as Columns 76, 77, and 78 did not buckle until $10.8 \mathrm{~s}$ (16.1 s) to $14.0 \mathrm{~s}$ (19.3 s), respectively. The kinetic energy levels decreased during this period until between 14.7 s (20 s) to $16.7 \mathrm{~s} \mathrm{(22} \mathrm{s),} \mathrm{after} \mathrm{which} \mathrm{all} \mathrm{the} \mathrm{interior}$ columns rapidly buckled and led to a sharp increase in kinetic energy.

$15.7(21.0) \mathrm{s}$

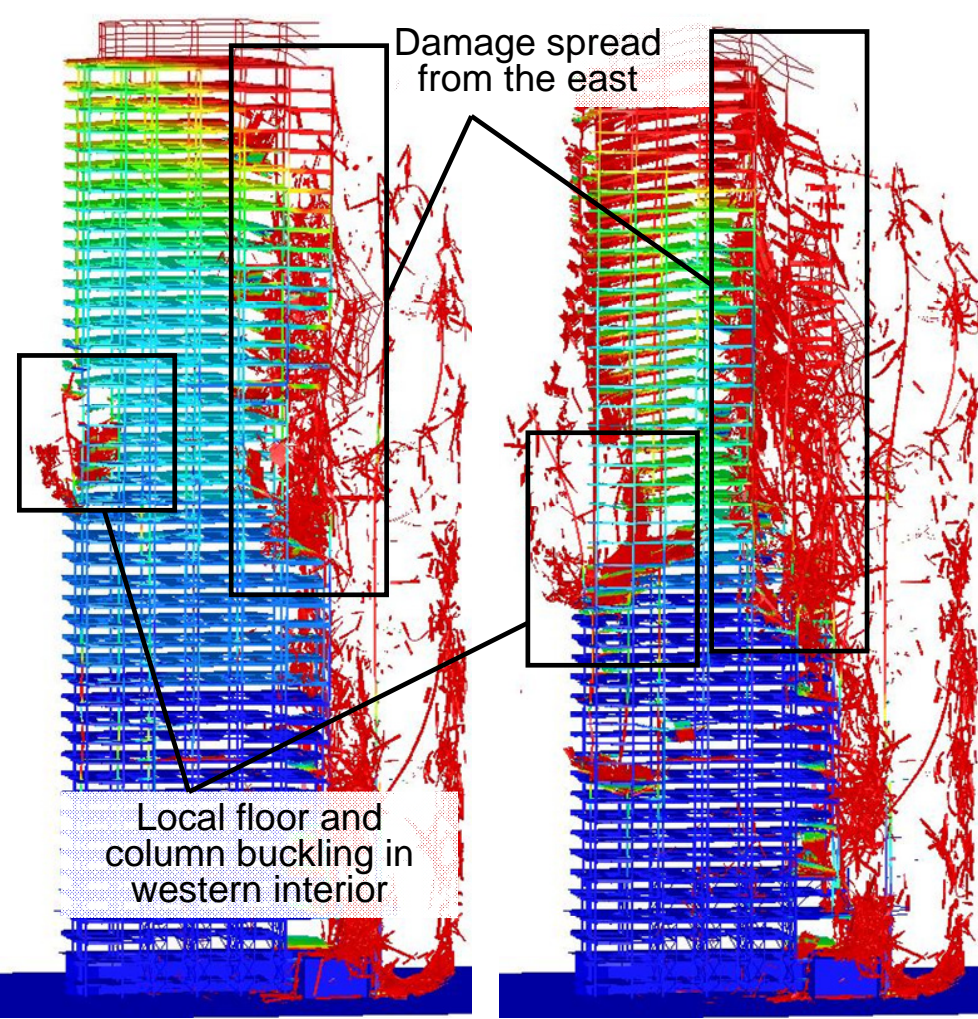

$21.2(26.5) \mathrm{s} \quad \begin{gathered}\text { Lateral }(\mathrm{XY}) \\ \text { Displacement }(\mathrm{m})\end{gathered}$

Collapse spread throughout interior until all columns buckled

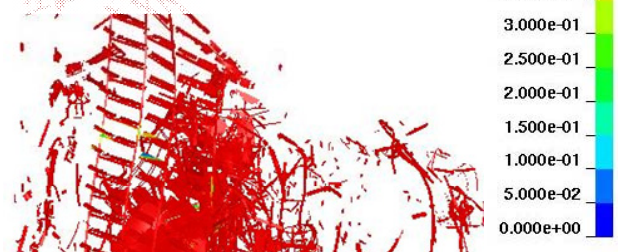

Figure 4-65. Collapse of the north interior columns from $15.7 \mathrm{~s}(21.0 \mathrm{~s})$ to $21.2 \mathrm{~s}(26.5 \mathrm{~s})$. Contours of resultant lateral displacement 0 in. to 16 in. $(0 \mathrm{~m}$ to $0.4 \mathrm{~m})$. 


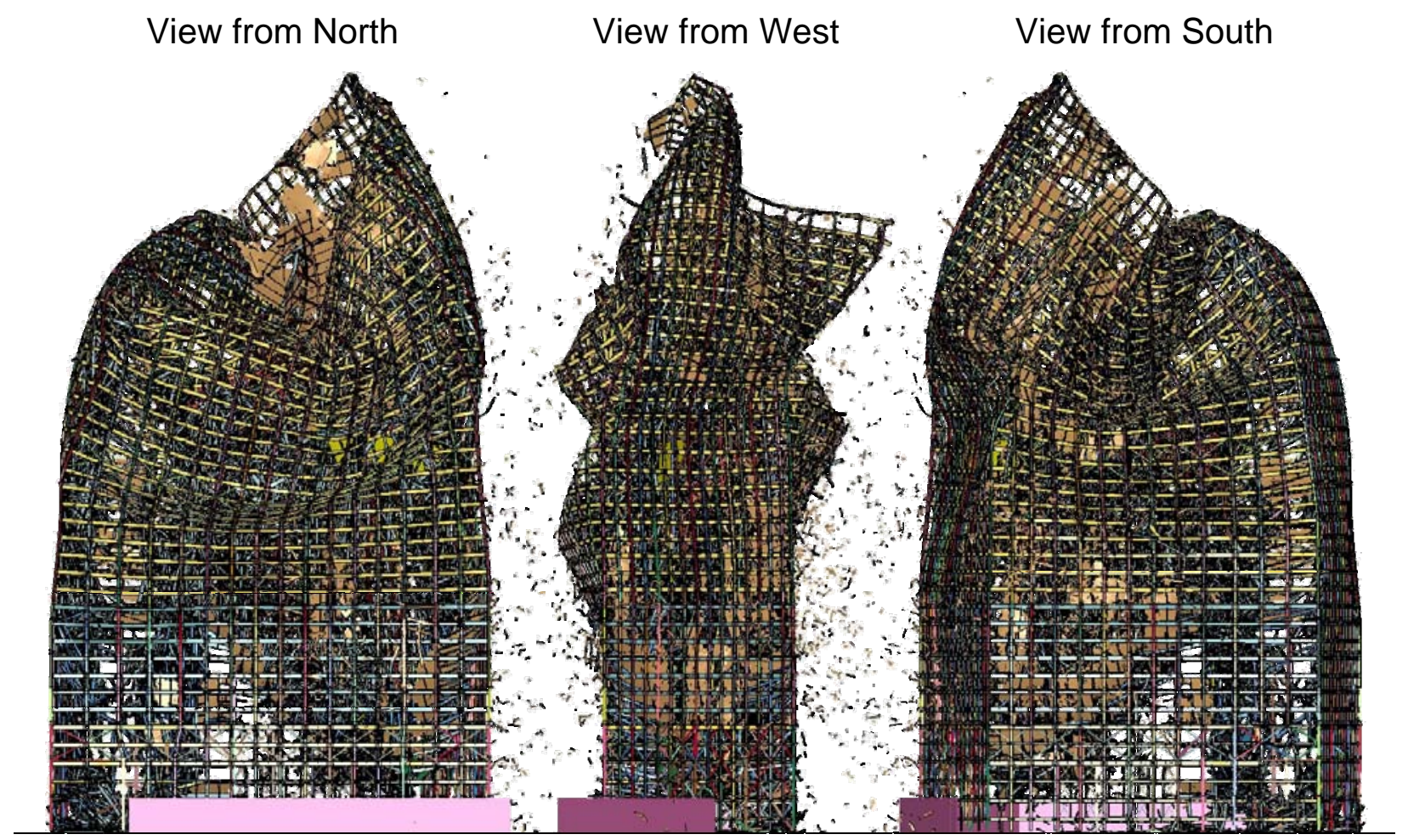

Figure 4-66. Global collapse at 21.2 (26.5 s).

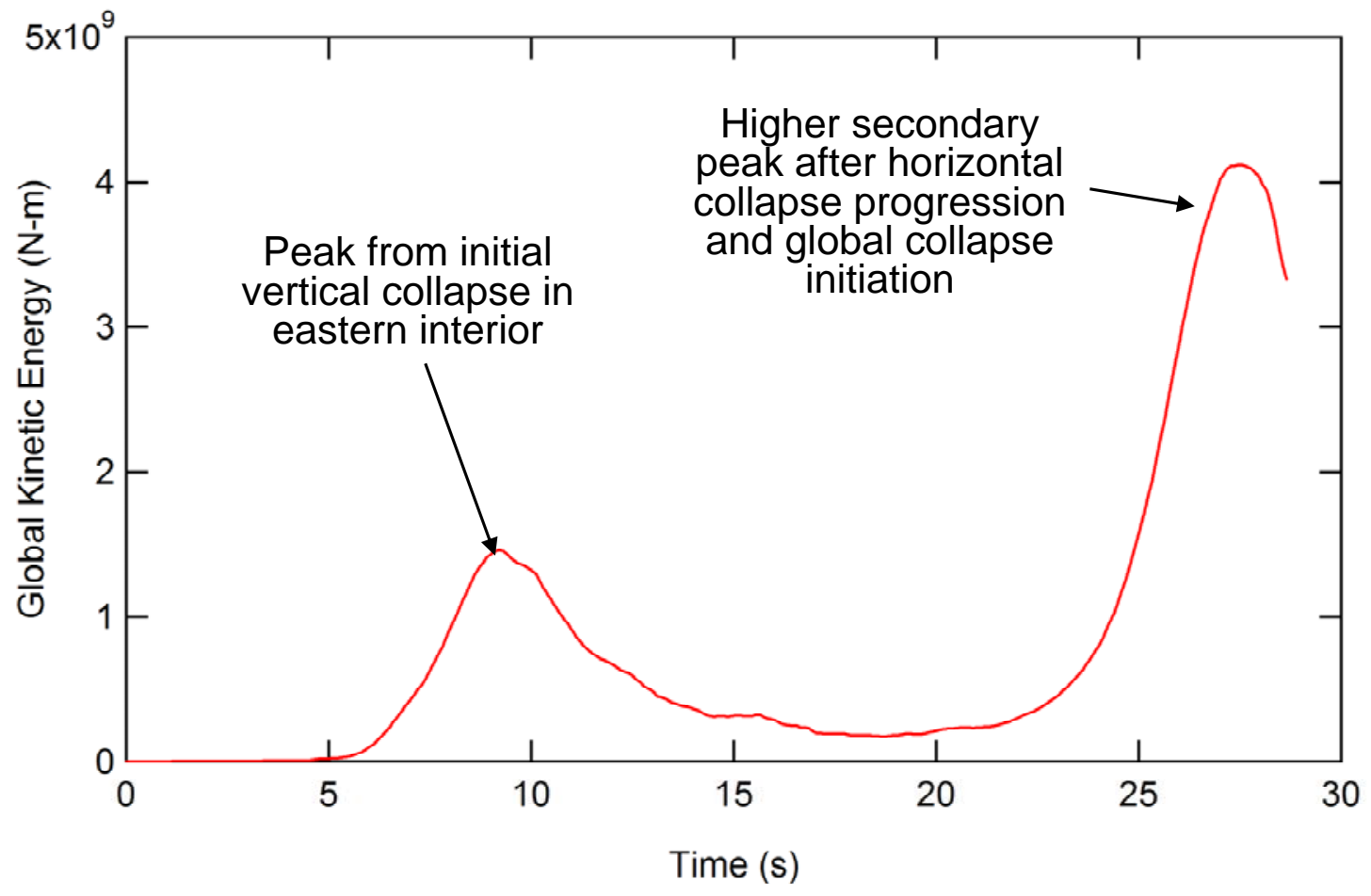

Figure 4-67. Global kinetic energy during the analysis without fire or debris impact damage. 
This page intentionally left blank. 


\section{Chapter 5 \\ SUMMARY}

\subsection{ANALYSES PERFORMED}

Analyses of a 47 story LS-DYNA debris impact damage and of WTC 7 were used to evaluate the global response of the building to initial failure events due to fire, including component and subsystem failures, to determine the events that led to the global collapse. Four global analyses were performed:

- Analysis of the building response to debris impact damage, temperature effects (Case B, $4.0 \mathrm{~h}$ temperatures), and fire induced damage based on the 16 story ANSYS analysis (Case B, $4.0 \mathrm{~h}$ damage).

- Analysis with earlier fire induced damage (Case B, 3.5 h) to determine if a lesser degree of induced damage state was sufficient to initiate a global collapse of WTC 7.

- Analysis with temperature effects (Case B, $4.0 \mathrm{~h}$ temperatures), and fire induced damage based on the 16 story ANSYS analysis (Case B, 4.0 h damage) but without the debris impact damage. The purpose of this analysis was to determine the contribution of debris impact to the global collapse sequence and whether WTC 7 would have collapsed solely due to the effects of the fires.

- Analysis for a classic progressive collapse, i.e., disproportionate structural damage from a single failure, without debris impact or fire-induced damage, to determine if a progressive collapse would occur following the removal of a section of Column 79 between Floors 11 and 13.

The key aspects of the model and the results of three global analyses are summarized.

\subsection{GLOBAL MODEL DEVELOPMENT}

The model of WTC 7 for the global collapse analyses was developed primarily with shell elements. The size of the model was approximately 3.6 million nodes and over 3 million shell elements. Beam elements were used to model the diagonal elements in the structural frame as well as the frame of the penthouse structures. Nonlinear discrete elements were used for the connection components, while brick elements were used for some rigid masses representing large equipment.

A key aspect of modeling the structural integrity of WTC 7 for global collapse is the strength characteristics of the various structural connections in the building. The structural frame for WTC 7 contained a variety of structural connection types. These connection modeling efforts were a significant part of the WTC7 model generation effort. The strengths and failure modes of the connections varied based on the connection configuration and whether the connection had welds or bolts. Similarly, the relative strength of different connections varied based on the directionality of the load (e.g., the ability of the connections to resist vertical and lateral loads). Models of the various connections were developed based on the fabrication shop drawings and incorporated into the global model. 
The global model was constructed in accordance with the structural drawings. The typical tenant floor, Floors 8 to 20 and 24 to 45, were generated once then repeated vertically through the structure. However, there were several floor constructions that were separately generated for the model. Wind bracing trusses were added to the lower core and exterior. Belt truss bracing at mid-height of the building was also included. The model accounted for the various load transfer mechanisms at the lower floors of WTC 7.

\subsection{MODEL INITIALIZATION AND LOADING SEQUENCE}

The global model was initialized as follows to minimize any dynamic effects associated with loading sequence.

- First, gravity was applied slowly to the 47 floor structure, over $4.5 \mathrm{~s}$ of elapsed simulation time to damp residual vibrations and eliminate dynamic response. The loads were applied smoothly with a sinusoidal load curve.

- Then the debris impact damage from the collapse of WTC 1 was applied to the structure instantaneously by removing damaged elements from the model that were no longer capable of bearing their loads. The structure was then allowed to damp residual vibrations for $2 \mathrm{~s}$.

- Next, the structural temperatures were applied at the same time as the damage data from the ANSYS simulation. The temperatures were applied smoothly with a sinusoidal curve and allowed to damp residual vibrations for $2 \mathrm{~s}$.

- Last, the fire-induced damage obtained from the 16-story ANSYS analysis, including damage to floor beams, girders, and connections, was applied instantaneously. The heated, damaged structure was then free to react.

Dead and live loads were distributed evenly in the concrete slabs and steel structure. This was accomplished by multiplying the modeled material densities with a common scale factor to achieve the desired total load. A 25 percent live load was used, based on estimates using the design live loads in the building at the time of collapse.

After gravity initialization, debris impact damage from the collapse of WTC 1 was applied to the global model. The damage applied was isolated to two zones on the southern side of the building. The analysis demonstrated that the remaining structure was able to redistribute the loads from the damaged zone and the building developed an equilibrium state.

Temperatures used in the global analysis were Case B temperatures at 4.0 hours (Chapter 10 of NIST NCSTAR 1-9) and were applied between $6.5 \mathrm{~s}$ and $8.5 \mathrm{~s}$. Elevated temperatures occurred between Floors 7 and 14. Temperature profiles were mapped onto the LS-DYNA model as nodal properties. The affected regions of the model were subjected to the effects of thermal expansion and thermal softening.

The final step in the initialization process was to apply fire-induced damage from the 16 story ANSYS analysis. The ANSYS model estimated the damage that occurred as the fires grew and spread on Floors 7 , 8, and 9 and Floors 11, 12, and 13. The LS-DYNA model, by comparison, considered only a temperature profile at the time when damage was transferred from the ANSYS model. The predicted damage from the 
ANSYS model was added to the LS-DYNA model as the final step before simulating the structural response to the temperatures and the damage.

\subsection{RESULTS OF GLOBAL COLLAPSE ANALYSES}

\subsubsection{Global Collapse Results with Debris Impact and Fire Induced Damage}

The 47 story model calculation showed that the combination of debris-impact damage, fire-induced damage, and thermal loads resulted in the global collapse of WTC 7. The key events that occurred in the global analysis are summarized below.

\section{Initial Failure Event and Vertical Progression of Collapse}

The initial failure event was the buckling of Column 79. This event was followed by the buckling of adjacent Columns 80 and 81.

The floor framing structure was thermally weakened at Floors 8 to 14, with the most substantial damage occurring in the east region of Floors 12, 13, and 14. During the LS-DYNA temperature application cycle, combined thermal expansion and thermally degraded material properties resulted in beam and girder connection damage throughout the heated floor structures. The connection damage and buckled beam data transferred from the 16 story ANSYS analysis were then applied. The LS-DYNA analysis calculated the dynamic response of the floor failures and resulting impact on the surrounding structure. After the fire-induced ANSYS damage was applied, floor sections surrounding Columns 79 to 81 on Floors 13 and 14 collapsed onto the floors below.

The thermally weakened floors below could not withstand the impact from the collapsing floors, and resulted in sequential floor collapses, which removed lateral support to Columns 79 to 81 . Eventually, critical conditions developed for column buckling due to a large unsupported length. Once Column 79 buckled, the column section above Floor 14 began to descend downward and pulled the floor structures downward with it, thereby creating a vertical progression of floor collapse up to roof level. The floor failures around Column 79 led to the subsequent buckling of Columns 80 and 81, which in turn resulted in a vertical progression of failure of floor systems across the east side of the building. The east penthouse, which was supported by Columns 79, 80, and 81, fell downward.

\section{Horizontal Progression of Collapse}

After the vertical progression of failure around Columns 79, 80, and 81, the failures continued to propagate from east to west across the interior columns on the lower floors due to (1) loss of lateral support from floor system failures, (2) forces exerted by falling debris impact, and (3) load redistribution from other buckled columns. The lateral support for Column 76 to 78 was lost on the east side, when the floor connections failed. In addition, as the vertical failures progressed, floor system and column debris fell from the upper floors, impacting adjacent intact columns and floors, including Truss 1 and Truss 2. The accumulation of debris and debris impacts eventually caused Truss 2 to fail. The failure of Truss 2 precipitated the buckling of Columns 77 and 78, a few moments earlier than Column 76. Column buckling progressed westward and the interior columns continued to deflect due to load redistribution and global motion of the floors above. Eventually all core columns buckled between Floors 9 to 14 . 


\section{Global Collapse}

The buckling of the interior columns in the LS-DYNA analysis was followed by the buckling of the exterior columns.

As the core columns buckled across the building, the exterior columns were impacted by falling debris and loads redistribution from the interior columns. All exterior columns buckled between approximately Floors 7 and 14. The south and west columns buckled first around 6 (22) s, followed by the north and east face columns. Once column support was lost in the lower floors, the remaining structure above began to fall vertically as a single unit.

\section{Comparison with Observables}

Comparisons were made between the observed collapse events (NIST NCSTAR 1-9, Chapter 5) and the corresponding events observed from similar angles in the LS-DYNA model. The initial downward motion in the east penthouse structures was used as a reference time $(0.0 \mathrm{~s})$. The other observables compared were as follows:

- The east penthouse structure falling below the roofline

o Observed: $2 \mathrm{~s}$

o Calculated: $2.4-2.7 \mathrm{~s}$

- Global collapse initiated, (initial downward motion of eastern section of building):

o Observed: $6.9 \mathrm{~s}$

o Calculated: 6.2-6.3 s

- East end of screening wall falling below roofline:

o Observed: $8.5 \mathrm{~s}$

o Calculated: $7.3-7.7 \mathrm{~s}$

- West penthouse falling below roofline:

o Observed: $9.3 \mathrm{~s}$

o Calculated: 6.9-7.3 s

Given the complexity of the modeled behavior, the simulation closely matched the observed behavior.

\subsubsection{Global Results with Earlier Fire Induced Damage}

The global analysis with fire-induced damage obtained from the 16 story ANSYS analysis at $3.5 \mathrm{~h}$ instead of $4.0 \mathrm{~h}$ (as before) indicated that the level of damage was not sufficient to initiate global collapse of the building. The structure remained stable due to the lack of an initiating event (i.e., buckling of an interior column). 


\subsubsection{Global Results without Debris Impact Damage}

The global analysis without debris impact damage showed that WTC 7 would have collapsed solely due to the effects of the fires. The initiation of collapse was virtually the same as for the global analysis with debris impact damage.

The initial failure event, vertical progression of failure, and early stages of the horizontal progression of failure occurred in the same order and at essentially the same times. The progression of horizontal failure in both analyses (with and without impact damage) was due to loss of lateral support as floors failed and to debris impact from adjacent failing floors and columns.

As the horizontal progression moved from east to west, some differences began to occur relative to the analysis with impact damage. Some floors failed at mid-height of the building around Columns 73 to 75 , leading to the buckling of some interior columns at this location, rather than at lower floors. The buckling at lower floor elevations in the analysis with impact damage was influenced by the damage around the west core columns when the debris impact damage was applied.

Additionally, the screenwall fell downward prior to the west penthouse, which was consistent with the observed sequence of events. In the analysis without impact damage, the horizontal progression continued to move westward after Columns 70 through 72 buckled. In the analysis with impact damage, the horizontal progression moved westward until Columns 70 to 72 buckled, after which the damaged west core columns also buckled.

For the analysis without debris impact damage, the timing of the exterior column buckling and onset of global collapse occurred at a slightly later time than was calculated for the analysis with impact damage.

\subsubsection{Global Results for a Classic Progressive Collapse Analysis}

The classic progressive collapse analysis showed that WTC 7 collapsed when a section of Column 79 between Floors 11 and 13 was removed. The global collapse occurred in the absence of debris impact damage and fire-induced damage. The collapse sequence demonstrated a vertical and horizontal progression of failure upon the removal of the Column 79 section, followed by buckling of exterior columns, which led to the collapse of the entire building. 
This page intentionally left blank. 